\title{
Empirical investigations of costs and benefits of vocational education and training
}

Citation for published version (APA):

Pfeifer, H. U. (2013). Empirical investigations of costs and benefits of vocational education and training.

[Doctoral Thesis, Maastricht University]. Maastricht University. https://doi.org/10.26481/dis.20131017hp

Document status and date:

Published: 01/01/2013

DOI:

10.26481/dis.20131017hp

Document Version:

Publisher's PDF, also known as Version of record

\section{Please check the document version of this publication:}

- A submitted manuscript is the version of the article upon submission and before peer-review. There can be important differences between the submitted version and the official published version of record.

People interested in the research are advised to contact the author for the final version of the publication, or visit the DOI to the publisher's website.

- The final author version and the galley proof are versions of the publication after peer review.

- The final published version features the final layout of the paper including the volume, issue and page numbers.

Link to publication

\footnotetext{
General rights rights.

- You may freely distribute the URL identifying the publication in the public portal. please follow below link for the End User Agreement:

www.umlib.nl/taverne-license

Take down policy

If you believe that this document breaches copyright please contact us at:

repository@maastrichtuniversity.nl

providing details and we will investigate your claim.
}

Copyright and moral rights for the publications made accessible in the public portal are retained by the authors and/or other copyright owners and it is a condition of accessing publications that users recognise and abide by the legal requirements associated with these

- Users may download and print one copy of any publication from the public portal for the purpose of private study or research.

- You may not further distribute the material or use it for any profit-making activity or commercial gain

If the publication is distributed under the terms of Article $25 \mathrm{fa}$ of the Dutch Copyright Act, indicated by the "Taverne" license above, 
Empirical Investigations of Costs and Benefits of Vocational

Education and Training 
(C) Harald Ulrich Pfeifer, Maastricht 2013

All rights reserved. No part of this publication may be reproduced, stored in a retrieval system, or transmitted in any form, or by any means, electronic, mechanical, photocopying, recording, or otherwise, without the prior permission in writing, from the author.

Published by ROA

Postbus 616

6200 MD Maastricht

ISBN: 978-90-5321-517-3

Printed in the Netherlands by Océ Business Services 


\title{
Empirical Investigations of Costs and Benefits of Vocational Education and Training
}

\author{
DISSERTATION \\ to obtain the degree of Doctor at \\ Maastricht University, \\ on the authority of the Rector Magnificus, \\ Prof.dr. L.L.G Soete in accordance with \\ the decision of the Board of Deans, \\ to be defended in public \\ on Thursday 17 October 2013, \\ at 12 hours \\ by \\ Harald Ulrich Pfeifer
}




\section{Supervisor}

Prof. Dr. H. Heijke

Prof. Dr. F. Cörvers (Tilburg University)

\section{Co-Supervisors}

Dr. B. Kriechel

\section{Assessment Committee}

Prof. Dr. A. de Grip (chair)

Prof. Dr. G. Pfann

Prof. Dr. J. de Koning (Erasmus University Rotterdam) 


\section{Acknowledgements}

I am thankful to all family members and friends who gave me the time and space to complete this $\mathrm{PhD}$ thesis. I am especially thankful for the support of my wife Sandra and my children Paula, Emma and Elliot, who were patient with me in times of unrest, which, I guess, appear in every $\mathrm{PhD}$ project at some point in time. I thank Friederike Behringer, Günter Walden and Reinhold Weiß from the Federal Institute for Vocational Education and Training (BIBB) for their support in terms of both time resources and useful comments on the chapters of this thesis. I thank the co-authors of the papers that form the core of this thesis. Especially Samuel Mühlemann and Stefan Wolter from the University of Bern were important for my achievements. Their previous and ongoing research in the field of education and the labour market was inspiring for several of the chapters in this book. Furthermore, my colleagues and co-authors at BIBB, Felix Wenzelmann and Gudrun Schönfeld, have been a great help over the entire period of writing the thesis.

I am grateful to my promoter Hans Heijke and my co-promoters Frank Cörvers and Ben Kriechel, who not only co-authored two papers that became Chapters 2 and 3 of this thesis, but who also kept me focused and motivated over the entire period of the $\mathrm{PhD}$ project. Ben Kriechel dedicated much of his time to weekly phone-calls and extra meetings. He supported me in solving many of the empirical caveats that inevitably appear when examining the relation between education and labour market outcomes with micro data sets. He greatly contributed to the success of this project.

Last but not least, I thank the Assessment Committee, Prof. Andries de Grip, Prof. Jaap de Koning and Prof. Gerard Pfann, for their willingness to evaluate the quality of this thesis. I am proud that my work was assessed by these distinguished researchers, who contributed important works to the literature in the field of education and labour market economics.

In this thesis, I treat several aspects of the costs and benefits of vocational education and training. However, too many issues of importance remain open to abandon this field of research. I am looking forward to continue to work on the topic, also in cooperation with several of the colleagues I have to thank for contributing to the success of the thesis. 



\section{Contents}

Acknowledgements i

$\begin{array}{ll}\text { 1. Introduction } & \mathbf{1}\end{array}$

1.1. Pros and cons of VET . . . . . . . . . . . . . . . . . . . . . . . . . . .

1.2. Research questions and theoretical framework . . . . . . . . . . . . 3

1.3. Outline of the study . . . . . . . . . . . . . . . . 5

2. VET and productivity - A three-country analysis 9

2.1. Introduction . . . . . . . . . . . . . . . . . . . . 9 9

2.2. Theoretical aspects and literature . . . . . . . . . . . . . . . 11

2.3. Education svstems in Germanv, Netherlands and United Kingdom . . . . . 13

2.4. Data and variable construction . . . . . . . . . . . . . . . 14

2.4.1. Data . . . . . . . . . . . . . . . . . . . . . . . . . . . . . . . . . . . .

2.4.2. Variable construction . . . . . . . . . . . . . . . 16

2.5. Descriptive analvsis . . . . . . . . . . . . . . . . . . . 17

2.6. Econometric approach and regression results . . . . . . . . . . . . . . . . . 19

2.6.1. Econometric approach . . . . . . . . . . . . . . . . . . 19

2.6.2. Regression results . . . . . . . . . . . . . . . . . . . . . . . . . . . . . . . . . 21

2.7. Summary and conclusions . . . . . . . . . . . . . . . 25

A2. Appendix . . . . . . . . . . . . . . . . . . 27

3. Life-cycle earnings patterns in VET 33

3.1. Introduction . . . . . . . . . . . . . . . . . . . . . . . . 33

3.2. Literature and theoretical aspects . . . . . . . . . . . . . . . . 35

3.3. Education svstems . . . . . . . . . . . . . . . . . . . . . . . . . . . . 39

3.3.1. Germany . . . . . . . . . . . . . . . . . . . . . 39

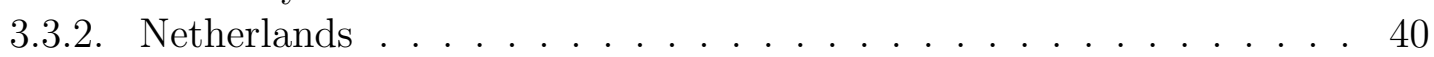

3.3.3. United Kingdom . . . . . . . . . . . . . . . . . . . . . . . . . . . 41

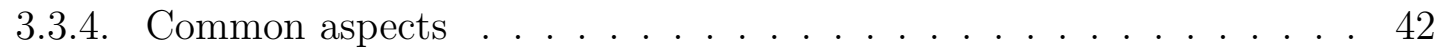

3.4. Data and variable construction ... . . . . . . . . . . . . . . . 43

3.5. Estimating wage-experience profiles . . . . . . . . . . . . . . . . . 45

3.5.1. Pooled OLS regression . . . . . . . . . . . . . . . . . . . . . . . . . . . . . . 45

3.5.2. Mixed-effects linear regression model . . . . . . . . . . . . . . . . 46

3.5.3. Robustness of results . . . . . . . . . . . . . . . . . . . . 48

3.6. Summary and conclusions . . . . . . . . . . . . . . . 50

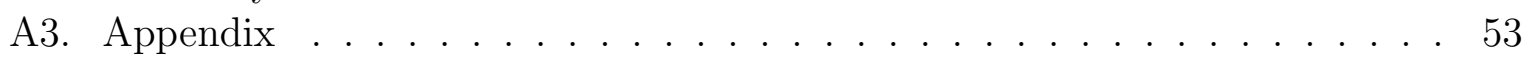

4. The firm-specific component of VET 63

4.1. Introduction . . . . . . . . . . . . . . . . 63 
4.2. Theoretical background and literature . . . . . . . . . . . . . . . . . . 65

4.3. Data source and calculation method . . . . . . . . . . . . . . . . . 67

4.3.1. BIBB Cost-Benefit Survey . . . . . . . . . . . . . . 67

4.3.2. Variable construction . . . . . . . . . . . . . . . . . . 68

4.4. Empirical strategy . . . . . . . . . . . . . . . . . . . . . . . 70

4.4.1. Precision of estimates . . . . . . . . . . . . . . . 70

4.4.2. Sample selection model . . . . . . . . . . . . . . . . . . . 71

4.5. Results . . . . . . . . . . . . . . . . . . . . . . . 72

4.6. Concluding remarks . . . . . . . . . . . . . . . . . . 76

A4. Appendix . . . . . . . . . . . . . . . . . . . 77

5. The financing of VET and labour market regulations 81

5.1. Introduction . . . . . . . . . . . . . . . . . . . . . . 81

5.2. The dual svstem and labour market regulations . . . . . . . . . . . . . 83

5.3. Relevant literature . . . . . . . . . . . . . . . . . . 85

5.4. Data and cost-benefit model . . . . . . . . . . . . . . 88

5.4.1. Data . . . . . . . . . . . . . . . . . 88

5.4.2. The cost-benefit model . . . . . . . . . . . . . . . . . 90

5.5. Econometric modelling . . . . . . . . . . . . . . . . . . . 91

5.6. Results . . . . . . . . . . . . . . . . . . . . . 94

5.6.1. The training decision of the firm . . . . . . . . . . . . . . . . 94

5.6.2. Net cost of training apprentices . . . . . . . . . . . . . . . . . . 95

5.7. Conclusions . . . . . . . . . . . . . . . . . . . . . . 99

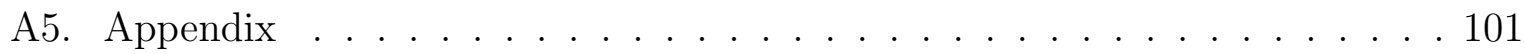

6. Works councils and firms' investment in VET 107

6.1. Introduction . . . . . . . . . . . . . . . . . . . . 107

6.2. Institutional setting and relevant literature . . . . . . . . . . . . . . 108

6.2.1. Works councils . . . . . . . . . . . . . . . . . 108

6.2.2. Linking apprenticeship training and works councils . . . . . . . . . 109

6.3. Theoretical framework . . . . . . . . . . . . . . . . . . . . 112

6.4. Data . . . . . . . . . . . . . . . . . . . . . . . 115

6.5. Estimation strategy . . . . . . . . . . . . . . . . . . . . . 116

6.6. Results . . . . . . . . . . . . . . . . . . . . 118

6.6.1. Costs and benefits during the training period . . . . . . . . . 118

6.6.2. Post-training benefits . . . . . . . . . . . . . . . . . . . . . . . . . . . . . . . . . . . . . . . . . . . .

6.6.3. Training ratio . . . . . . . . . . . . . . . . . . . . . 123

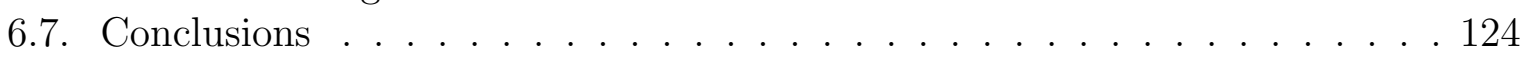

A6. Appendix . . . . . . . . . . . . . . . . . . . . 125

7. The hiring costs of vocationally trained workers 131

7.1. Introduction . . . . . . . . . . . . . . . . . . . . . . . . 131

7.2. Theoretical model and literature . . . . . . . . . . . . . . . . . 132

7.3. Labour market institutions . . . . . . . . . . . . . . . . . . . . . . . . . . . . . . . . . . . . . . . . . . . . . . .

7.4. Data and descriptive statistics . . . . . . . . . . . . . . . 135

7.4.1. Data . . . . . . . . . . . . . . . . . . 135

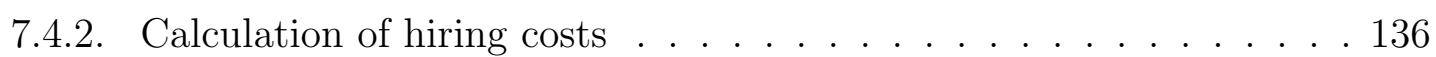

7.5. Estimation strategy and results . . . . . . . . . . . . . . . . . . 139

7.5.1. Estimation strategy . . . . . . . . . . . . . . . . . . . 139 
7.5.2. Estimation results . . . . . . . . . . . . . . . . . . . . . . 140

7.5.3. Robustness analysis . . . . . . . . . . . . . . . . . . . . 143

7.6. Conclusions . . . . . . . . . . . . . . . . . . 145

A7. Appendix . . . . . . . . . . . . . . . . . . 147

8. Conclusion and implications 155

8.1. Overview . . . . . . . . . . . . . . . . . . . . . 155

8.2. Conclusion . . . . . . . . . . . . . . . . . . 156

8.3. Implications . . . . . . . . . . . . . . . . . . . . 159

$\begin{array}{ll}\text { Samenvatting (Summary in Dutch) } & 175\end{array}$

\begin{tabular}{ll}
\hline Biography & 177
\end{tabular} 



\section{List of Figures}

2.1. Value added and VET at the intermediate level . . . . . . . . . . . 24

3.2.1. Hvpothetical experience-earnings profiles . . . . . . . . . . . . 38

3.5.1. Mixed-effects linear regression model for Germanv . . . . . . . . . . . . 48

3.5.2. Mixed-effects linear regression model for Netherlands . . . . . . . . . . . . 49

3.5.3. Mixed-effects linear regression model for United Kingdom . . . . . . . . . . 49

A3.1.OLS regression - baseline model for Germanv . . . . . . . . . . . . 57

A3.2.OLS regression - baseline model for the Netherlands . . . . . . . . . . 58

A3.3.OLS regression - baseline model for the United Kingdom . . . . . . . . . 58

A4.1.Unemployment and job vacancies in Germany (in 1000s) . . . . . . . . . 80

A6.1.Share of firms with works councils . . . . . . . . . . . . . . . . 125

A6.2. Share of firms with collective bargaining . . . . . . . . . . . 125

A7.1.Density of hiring costs. 21 to 100 employees . . . . . . . . . . . . . 147

A7.2. Marginal hiring costs $($ in $€$ ) . . . . . . . . . . . . . . . . 147 



\section{List of Tables}

2.1. Importance of VET Systems in the three reference countries 2009 . . . . . 13

2.2. Value added (VA) per hour and employment in Prais industries . . . . . . 18

2.3. Fixed-effects model: Germany (dep. var.: Real value added (log)) . . . . . 21

2.4. Fixed-effects model: Netherlands (dep. var.: Real value added $(\log )$ ) . . . . 22

2.5. Fixed-effects model: UK (dep. var.: Real value added $(\log ))$. . . . . . . . 22

A2.1. List of industries included in analysis . . . . . . . . . . . . . . . 27

A2.2. List of industries used for Prais analysis . . . . . . . . . . . . . . . . . . 29

A2.3.Summary statistics - Germany . . . . . . . . . . . . . . . . . . . . 29

A2.4.Summary statistics - Netherlands . . . . . . . . . . . . . . . 30

A2.5.Summary statistics - UK . . . . . . . . . . . . . . . . . 30

A2.6.Pooled OLS model - Germany (dep. var.: Real value added (log)

A2.7.Pooled OLS model - Netherlands (dep. var.: Real value added $(\log )$ ) . . . 31

A2.8. Pooled OLS model - UK (dep. var.: Real value added $(\log )$ ) . . . . . . . . 32

3.5.1. Mixed-effects linear regression model . . . . . . . . . . . . . . . . 47

A3.1.Descriptive statistics - Germany . . . . . . . . . . . . . . . . . . . 53

A3.2.Descriptive statistics - Netherlands . . . . . . . . . . . . . . 55

A3.3.Descriptive statistics - United Kingdom . . . . . . . . . . . . . . . . . 56

A3.4.OLS regression - baseline model . . . . . . . . . . . . . . . . 57

A3.5. Pooled OLS regressions with additional control variables . . . . . . . . . . 59

A3.6.Spline-regressions with 5 splines for experience . . . . . . . . . . . . . . . 59

A3.7. Mixed-effects linear regression model $(<20$ vears of experience $)$. . . . . . 60

A3.8. Mixed-effects linear regression model - Alternative estimates . . . . . . . . 61

A3.9. Mixed-effects linear regression model - Male workers . . . . . . . . . . . . . 61

A3.10Mixed-effects linear regression model - Female workers . . . . . . . . . . 62

4.5.1. Firms' investment in human capital and firm-specificity of training . . . . . 73

4.5.2. Maximum-likelihood selection model . . . . . . . . . . . . . . . 75

A4.1.Descriptive statistics . . . . . . . . . . . . . . . . . . . . . 77

A4.2. Firms' investment in human capital (full apprenticeship) . . . . . . . . . . 78

A4.3. Variables used for calculating the firm-specific training component . . . . . 78

A4.4.Correlation of selection variables . . . . . . . . . . . . . . 78

A4.5.OLS regression model . . . . . . . . . . . . . . . . . . . . . . 79

A4.6. Estimation of share with hypothetical wage-productivity differential . . . . 79

5.2.1.OECD indicators of emplovment protection . . . . . . . . . . . . . 84

5.3.1. Expected net training costs $N C$ and post-training benefits $B$. . . . . . 88

5.6.1. Maximum Likelihood Selection Model. German firms . . . . . . . . . . . . 96

5.6.2.Maximum Likelihood Selection Model Swiss firms . . . . . . . . . . . . . . 97 
5.6.3.Expected net costs of German and Swiss firms (in $€$ ) . . . . . . . . . . . . 98 A5.1.Detailed OECD indicators on regular emplovment . . . . . . . . . . . . . . 101

A5.2.Economic conditions in Germanv and Switzerland, 1997-2004 . . . . . . . . 102

A5.3. Descriptive statistics, cost-benefit variables . . . . . . . . . . . . . . . . 103

A5.4.Descriptive Statistics. control variables . . . . . . . . . . . . . . . 105

A5.5.OLS net cost regression. German and Swiss training firms . . . . . . . 106

6.6.1. Training costs and benefits - works council ATE . . . . . . . . . . . . 120

6.6.2. Retention rates - works council ATE . . . . . . . . . . . . . . . . 121

6.6.3. Training ratio - works council ATE . . . . . . . . . . . . . . . . . 122

A6.1.Summary statistics by works council and firm size . . . . . . . . . . 126

A6.2.Summarv statistics by works council and firm size . . . . . . . . . . . . 127

A6.3. Gross cost components - works councils ATE . . . . . . . . . . . 128

A6.4. Tasks and productivity - works councils ATE . . . . . . . . . . . . . . . 129

A6.5.Wages - works councils ATE . . . . . . . . . . . . . . . . 130

7.4.1.Summarv statistics by labour market institutions . . . . . . . . . . . . . . 138

7.5.1. Hiring costs OLS regressions . . . . . . . . . . . . . . . . . . . 141

7.5.2. Recruitment costs OLS regressions . . . . . . . . . . . . . . . 141

7.5.3. Adaptation costs OLS regressions . . . . . . . . . . . . . . . . . 142

7.5.4.Firm-level institutions and hiring, recruitment and adaptation costs . . . . 143

A7.1.Summarv statistics . . . . . . . . . . . . . . . . . . 148

A7.2.Summarv statistics of hiring costs variables . . . . . . . . . . . . . . . 149

A7.3. Hiring. recruitment and adaptation costs: 21-100 emplovees . . . . . . . . . 149

A7.4.Hiring level OLS regressions . . . . . . . . . . . . . . . . . 150

A7.5. Hiring rate OLS regressions . . . . . . . . . . . . . . . . . 151

A7.6. Hiring costs OLS regressions incl. share of skilled workers . . . . . . . . . . 152

A7.7. Costs for posting vacancv OLS regressions . . . . . . . . . . . . . . . 152

A7.8. Interview time OLS regressions . . . . . . . . . . . . . . . 153

A7.9.Adaptation cost components regressions . . . . . . . . . . . . . 153

A7.10Survey questions on hiring costs . . . . . . . . . . . . . . . . 154 


\section{Introduction}

There is little argument about the economic benefits of education for the individual, the firm and the society as a whole. For the individual, education increases one's wage prospects and reduces the risk of unemployment and poverty (Psacharopoulos and Patrinos 2004, Lauer 2005). A firm having access to a well-educated workforce can improve its competitiveness and the potential for innovation and productivity growth, in part also through spill-over effects on co-workers (Martins and Jin 2010). Finally, society benefits directly from education through higher revenues, e.g. in the form of income taxes, and indirectly as a result of lower social costs for unemployment de la Fuente and Jimeno 2009), better health (Baker et al. 2011) and lower crime rates (Machin et al. 2011).

Countries differ with respect to their institutional arrangements for organising the education system. While we observe relatively few cross-country differences in the organisation of primary education, greater heterogeneity can be found at the level of (upper-) secondary education. In several industrialised countries, initial vocational education and training (VET) is an important component of education systems 1 Other countries put a stronger emphasis on the provision of general education. Among the countries with an elaborate VET system, notable differences exist concerning the ways skills are formed. While some countries, such as the United Kingdom, focus predominantly on school-based vocational education, others feature a system in which school- and work-based vocational education and training is combined. In these, the work-based component varies and is highest in apprenticeship forms of training, as provided in the German-speaking countries and, to a somewhat lower degree, in the Netherlands.

With respect to the financing of training, the share of costs borne by the individual, the firm and the state differs. In the case of general education and vocational education that takes place preponderantly in schools, the state bears most of the education costs. In an apprenticeship system, the individual and the firm also contribute to the financing of education. For the individual, learning and working as an apprentice in a firm is compensated by a wage that is only a fraction of the wage of a skilled worker in the regular labour market. A firm training apprentices usually bears costs related to the training personnel and the training infrastructure but in turn often benefits from the

\footnotetext{
${ }^{1}$ Throughout the thesis, I use the acronym VET for initial vocational education and training. For vocational training later in the working life, I use the term continuing vocational training (CVT).
} 


\section{Introduction}

productive capacity of the apprentice. Because apprentices also spend a share of their time at vocational school, the costs to the state are not negligible but still considerably lower than in a system that is mainly based on full-time schooling.

\subsection{Pros and cons of VET}

The benefits of vocational education and training in generating the skills needed in an industrialised economy are an open topic of discussion among decision makers and researchers in the field. Critics argue that the structural change away from traditional crafts and industries towards services and, more broadly speaking, the move to a knowledgebased economy, requires more systemic and theoretical knowledge which allows for more flexibility in rapidly changing labour markets (Bowman 1993, Baethge et al. 2006). The notion is that those education systems mainly providing general skills are better equipped to meet the demand of firms operating in restructuring economies (Goldin 2001). Further, over past decades VET systems with apprenticeship programmes have often shown considerable imbalances of demand (from firms) and supply (young adults) on the training market. Responsibility for those imbalances could be attributed to an unfavourable cost-benefit ratio of training for both firms and individuals. On an overall level, OECD estimates show that in countries with VET systems, expenditures per student in vocational programmes exceed expenditures per student in general programmes. In countries with an apprenticeship system, the difference in expenditures (including firms' training costs) is even larger (OECD 2008). Implicitly, the question is posed whether vocational education and training, and especially apprenticeship programmes, are too costly and produce the wrong type of skills for economies experiencing rapid technological change. At the same time, education policy in many countries focuses on an increase in the number of academic graduates, urging young adults to enter tertiary education at universities rather than upper-secondary vocational education and training programmes. This policy increases the pressure on vocational systems if more of the better school-leavers are drawn towards the universities. An argument often used in support of such policies is that university education offers higher individual returns in the form of wage and employment prospects.

Advocates of vocational education and training argue that VET offers occupational orientation and specialisation - and not solely for disadvantaged young adults: school-leavers with high abilities also have incentives to enter vocational programmes, especially when vocational education offers career options leading to crafts master or technical university qualifications 2 A potential advantage of VET is that the combination of theoretical and practical education in an occupational field functions as a form of specialisation. Specialisation in occupational skills means a comparative advantage over workers that have

${ }^{2}$ In Germany, more than $20 \%$ of all apprentices have an upper-secondary school leaving certificate (Abitur) granting access to university (Bundesinstitut für Berufsbildung (BIBB) 2011). 
a more general set of skills. Further, it allows for a more efficient skill-adjustment process (e.g. induced by technological change) in the respective occupational field. Thus, VET may lead to higher occupation-specific productivity and, as a consequence, to higher wages for the individual choosing a VET pathway compared to a worker with a general education at the same qualification level.

In some countries, VET is highly standardised and the respective qualifications are transferable across regions. Institutional arrangements, such as cooperative systems, ensure a constant adjustment of the training contents to the skill needs of the firm. In countries with such an institutional framework, VET may lead to productivity advantages for individuals and firms compared to economic actors in countries without such a system. Firms are able to adjust the organisation of their production to the availability of occupational skills, since the standardisation of training reduces information asymmetries for firms that have little knowledge about the potential productivity of generally educated workers. Further, firms that train apprentices may use the training period of usually two to four years as a screening device to keep those apprentices as skilled workers that fit best the specific skill requirements in the firm (Stevens 1994a). Thus, by supplying apprenticeship training, firms can gain access to skilled workers.

From an individual's perspective, vocational education and training may have a number of benefits. If the content of training is transparent and standardised and firms commit themselves to providing high quality training 3 , it is highly transferable across firms employing trained workers. Recent work confirms that young adults opting for vocational education and training have better employment chances and thus a lower risk of unemployment than generally educated workers on a comparable educational level (Hanushek et al. 2011). Finally, as argued above, in countries with elaborate apprenticeship training systems, human capital is generated with relatively low costs to the state, since firms and individuals both contribute to the financing of training on a voluntary basis.

\subsection{Research questions and theoretical framework}

Summing up the pros and cons of VET, several aspects need to be considered when discussing the costs and the benefits of vocational education and training. Over the past decades, economic and sociological research in the field has improved the information base needed for an in-depth cost-benefit assessment. However, several important questions remain unanswered. How do the wages and productivity of VET workers differ to those of more generally educated workers? How do institutional frameworks influence cost and benefit structures of training for firms? How large are the benefits for firms using VET

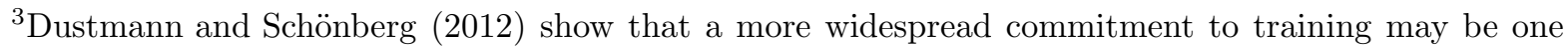
reason for the success of apprenticeship programmes in countries like Germany compared to countries like the United Kingdom, where the commitment of training is lower. 


\section{Introduction}

as a mean to meet their demand for skilled workers? In the present thesis, I intend to address these research gaps without claiming to answer all the open issues.

While estimates of the (monetary) costs of education and training have been published earlier by national and international institutions (e.g. by the OECD), the assessment of benefits faces a number of conceptual and empirical problems. On the one hand, benefits accrue not only during the training period, but also thereafter. From a firm's perspective, training may involve considerable costs over the training period. However, training costs may be seen as an investment to increase the matching quality between job requirements and the skills of future workers in and across firms 4 The training investment may then lead to higher productivity and a lower staff turnover, which are beneficial to the training firm. Also from the individual's perspective, a greater employment stability and higher wages are beneficial. However, specialisation in occupation-specific skills may be risky for the individual. Some of the skills and knowledge gained during vocational education may not be transferable to another employer, which could lead to large productivity and wage losses in case of an employer change 5

The aim of the thesis is to contribute to the assessment of costs and benefits of vocational education and training also from an international comparative perspective. It touches upon issues like potential differences in productivity and wages between vocationally and generally educated workers, and the institutional conditions under which vocational education and training systems operate. It thereby addresses topics that have received much attention since the seminal works of Schultz (1960), Becker (1964) and Mincer (1958, 1974). In addition, theoretical and empirical works focusing on the match between individuals' qualification and the job requirements (e.g. Jovanovic 1979) have given inspiration for this thesis. Finally, a strong motivation for this thesis has been the international comparative research that has been undertaken to emphasise the role of education systems in the functioning of an economy (Prais 1995, Gangl 2003).

The theoretical foundation of this thesis is a simple framework of productivity and wages and their development over an individual's lifetime 6 Before the start of the labour market career, a worker acquires a set of knowledge and skills over the course of an educational phase. Entering the labour market, the worker is productive and earns a certain wage. Over time in the labour market, the worker gains experience and increases knowledge and skills. He participates in on-the-job or off-the-job, formal or informal training during that time. The worker may also change job or even occupation in order to find work that yields a higher productivity and wage. In this setting, the initial endowment of skills determines the starting point of an individual in the labour market. Entering the labour market with a more general set of skills obtained at school, plus time and effort are required to

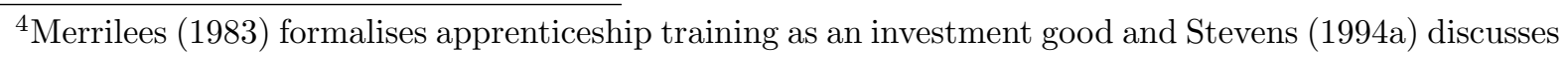
training as a screening device, which reduces recruitment costs of firms.

5 Geel et al. (2011) find that job changes within a specific skill cluster actually leads to wage gains. Job changes to skill clusters that are very different from the original cluster lead to significant wage losses. The latter changes, however, are less common than the former.

${ }^{6}$ The theoretical argumentation is further developed in Chapters 2 and 3 of the thesis. 
become productive in the first job. The time needed to adjust results initially in lower productivity compared to an experienced worker. Productivity, however, will increase over time since learning-by-doing or continuing training will extend the skills related to the specific job in the specific occupation. A bad match between skill endowment and job requirements leads to the change of job or occupation. Job search will eventually lead to an increase in productivity over the time the worker remains in the labour market 7

For workers with a (occupation-) specific initial skill endowment, i.e. for workers having undergone vocational education and training, getting acquainted with the job in the specific occupation is less costly in terms of productivity losses, since the set of skills and knowledge earned during VET fit the skill needs of firms. The match is even better if the vocational training contains a high proportion of practical elements, as in the case of apprenticeship training (Stevens 1994b). Assuming that generally educated and vocationally educated workers compete for the same type of jobs, the initial productivity and wage would be higher for VET workers compared to the generally educated workers. This initial advantage for VET workers does not have to persist over time, because workers with a more general education can catch up and, due to their broader knowledge and skill base, even become more productive after a period of adjustment.

\subsection{Outline of the study}

The theoretical relationship between initial skill endowments (due to different educational pathways) and wages and productivity is analysed in the first two chapters of this thesis. The remainder of the thesis explores the conditions under which firms are willing to finance apprenticeship training. I address the question, which institutional factors influence the training behaviour of firms. According to human capital theory, firms would not invest in training that is mainly general. The reason is that the general skills are 'marketable' and in perfect labour markets, the worker would not accept a wage below the market wage. Thus, firms that invest in training would never be able to recoup their initial investment. Acemoglu and Pischke (1998, 1999a, b) argue that in an imperfect labour market with wage compression, a firm may well have incentives to bear the costs for the training of their workers. If the productivity of the trained workers rises faster than their wage, training leads to a higher wage-productivity differential, which in turn increases the rent for the training firm. Thus, according to the authors, wage compression is a necessary precondition for the firm's training investment. Wage compression, in turn, may be caused by institutions, such as unions or minimum wages. However, other than through the wage channel, institutions may also have a direct impact on training costs. A high level of employment protection and collective bargaining or works councils at the firm level may increase labour adjustment costs and thus provide incentives for firms to finance

${ }^{7}$ The theory of job-search and matching has been advanced by Jovanovic (1979), Sattinger (1975, 1978, 1993), Thurow (1975), among others. 


\section{Introduction}

training. The firm's return on training stem from the saving of hiring and firing costs and from the lower risk of labour turnover of self-trained workers rather than from a high(er) wage-productivity differential. Thus, even without a situation of wage compression, a firm may have incentives to train in the face of strong labour market institutions.

Although the German VET system is often the focus of the thesis, several chapters apply an international comparative approach to exploit variance in the type of vocational training systems. The first chapters compare the impact of VET on productivity and wages in Germany to results for the Netherlands and the United Kingdom. While the Netherlands are similar to Germany in the importance of VET, this country provides a higher share of school-based VET. In the United Kingdom, VET is quantitatively less important compared to the other two countries, and the system is mainly school-based. For the analysis of the role of employment protection on firms' training investment, I choose a comparison with Switzerland. Switzerland is similar to Germany in many aspects, including the importance and organisation of the VET system. However, labour market regulations differ considerably between the two countries, which provides some variation in regulatory frameworks.

For a thorough analysis of the research questions, I make use of a variety of data sources and econometric parametric and non-parametric methods 8 Chapter 2 analyses the relation between vocational training and productivity. Using industry-level panel data for Germany, Netherlands and the United Kingdom the chapter assess whether productivity varies with the importance of the vocational education and training system in these countries. The hypothesis is that a well established, standardised VET system in a country leads to productivity gains for firms operating in that country. Special attention is paid to sectors that were analysed in previous case studies. Comparing the case study results to structures found in the quantitative data, I find a positive relation between the share of VET employment and the level of productivity in most of the sectors. Fixed-effects regression estimates for the entire set of sectors provide additional evidence on a positive relationship between VET and productivity. The size of the effects, however, differs between countries.

Chapter 3 compares experience-earnings profiles of workers with vocational and general education backgrounds in Germany, Netherlands and the United Kingdom. Again, the expectation is that vocationally educated and trained workers have an initial productivity advantage over generally educated workers and that this advantage is greater if the link between vocational education and the labour market is stronger. The productivity advantage is reflected in higher initial wages. Mixed-effects linear regression models show that earnings of vocationally educated workers are higher in the initial phase of their career. However, those with a general education background catch up over time in the labour market. As expected, life-cycle differences in earnings are more pronounced in

${ }^{8}$ Because Chapter 2 to Chapter 7 are based on papers that were written with co-authors, I use the pronoun we in the chapters when taking the authors' perspective. 
Germany than in the United Kingdom and the Netherlands. Keeping in mind the selectivity problems inherent to this type of analysis, these results support the view that vocational education and training offers an initial comparative advantage over more general types of education. The advantage, however, disappears and may eventually turn into a disadvantage the longer the workers stay in the labour market.

Having examined potential wage and productivity effects of vocational education and training, the subsequent chapter turns to individual benefits resulting from the transferability and transparency of VET. In many countries, training measures are specific to the skills that firms need, and there is a lack of common definitions and standards for certification of the contents of training. The German VET system is, in contrast, highly standardised and the training regulations have legal status. Thus, one would expect the skills acquired during VET to be highly transferable across firms. However, direct empirical evidence on the specificity of the German VET system is lacking.

To analyse this issue, in Chapter 4 I use firm-level data to calculate a monetary value of the firm-specific component of German apprenticeship training. The value is calculated by comparing the initial productivities and wages of externally recruited and internally trained workers in the same job, occupation and firm. The argument for this approach is that the resources needed to increase the productivity of externally recruited workers to the level of internally trained workers are an adequate measure for the firm-specificity of training. This chapter also quantifies the firm-specific component as a share of total investment in human capital during apprenticeship training. The results support the view that German apprenticeship training is mainly general, with an average firm-specific share of 12 per cent of total human capital investments. Thus, apprentices entering the VET system are fairly flexible in their choice of an employer. Even if forced to change employer, the majority of skills acquired during VET can be transferred to other employers.

The empirical evidence for the transferability of skills acquired during apprenticeship training leads to the question as to why German firms are willing to finance general training. This question is addressed in Chapters 5 and 6 . Although apprentices contribute productive work during their training, firms on average bear net costs for the training of their apprentices (Schönfeld et al. 2010). According to Acemoglu and Pischke (1998, 1999a) the institutional framework in a country plays an important role in fostering firms' investment in training. The authors argue that institutions, such as collective bargaining or minimum wages, induce wage compression, which in turn makes training investments a rational choice by firms 9

Chapter 5 investigates the influence of employment protection legislation on the costs and benefits of vocational training in firms. It compares the training behaviour of firms in Germany and Switzerland - two countries with a comparable apprenticeship system but strong differences in the regulation of their respective labour markets. It combines

[Dustmann and Schönberg (2012) argue that differences in firms' commitment to provide high quality training is an important additional condition of successful training schemes. 


\section{Introduction}

two firm-level surveys on the provision of apprenticeship training that are available for both countries to analyse differences in the firm training behaviour in the two countries. The results suggest that firms are more likely to make a substantial (short-term) net investment in apprenticeship training in the presence of strong employment protection laws.

However, it is not only the presence of employment protection legislation that influences the training behaviour of firms. In Germany, an institution at the firm level ensures compliance with both employment protection legislation and training quality standards: the works council. Under German law works councils have substantial information and co-determination rights on training-related issues. Thus, the question arises as to whether works councils may have an impact on firms' cost-benefit ratio of training. In Chapter 6, I use firm-level data to answer this question. I apply matching methods to identify the impact of works councils on training. The analysis shows that a firm with a works council makes a significantly higher net investment in training than a firm without such an institution. The fraction of former apprentices that is still employed in the firm five years after training is significantly higher in firms with works councils - which is an indication of higher post-training benefits. Thus, it seems that works councils on the one hand induce higher training costs but on the other hand safeguard these higher investments through lower labour turnover.

Having analysed different institutional frameworks that influence the decision of firms to train, Chapter 7 of the thesis addresses another form of direct training benefit to the firm: the saving of hiring costs for workers from the external labour market. By training and retaining apprentices, firms do not have to bear the costs involved in the recruitment process, such as the costs of job postings and costs of preparing, conducting and evaluating interviews with job candidates. In addition, the initial productivity of an externally recruited worker may be different to the productivity of an internally trained one, even if they underwent the same type of vocational training. Consequently, both the costs of recruitment and costs for the adaptation of external hires are important components of the benefits of training. Using detailed firm-level data, I find that the hiring costs are substantial. They average close to 5000 Euros per hire. Further, the costs per hire increase with the number of hires. The more trained workers need to be hired the higher are the costs per recruited worker. The result explains why firms may have incentives to finance apprenticeship training even if vocationally qualified workers are available on the external labour market.

The thesis closes with a short summary of the chapters and tentative conclusions on their meaning for research and policy. 


\section{VET and productivity - A three-country analysis}

\subsection{Introduction 1}

From a firm's perspective, having access to vocationally trained workers may have considerable advantages. First, employing vocationally trained workers can lead to lower adaptation costs. The skills and competencies developed through vocational training are closer to the requirements of the job market; consequently, vocationally trained workers entering the labour market need less time to be fully productive. Second, the access to vocationally trained workers may also generate benefits related to a firm's organisational and hierarchical structure. Steedman (2001) in a three-country study of Germany, France and the United Kingdom argues that a dual system of vocational training (e.g. in Germany) enables a firm to transfer many responsibilities and supervisory tasks to workers having undergone vocational training. In countries such as the United Kingdom, the firm has to bear extra investments in generating the required skills or employ more workers with tertiary education. Prais (1995) reports the results of a number of qualitative research activities comparing the productivity and quality of products in German, English, Dutch and French firms. The results indicate that the availability of vocationally trained workers for firms allows for a less hierarchical production organisation, which in turn leads to higher worker productivity and higher quality of goods and services in several sectors.

In this chapter, we revisit the hypothesis that the employment of vocationally trained workers increases labour productivity relative to the employment of workers without vocational qualifications at the same educational level. More specifically, we analyse the productivity impact of an increase in the amount of labour contributed by vocationally trained workers and compare the effect with corresponding estimates for workers that have undergone general education at the intermediate level. The underlying assumption is that vocationally trained workers better match the skill needs of firms because these workers are "specialists" in their respective occupations. Further, occupational specialisation allows a firm to organise production more efficiently by reducing hierarchical costs.

\footnotetext{
${ }^{1}$ This chapter is based on the paper Vocational education and training and its impact on productivity -
} A three-country analysis by Frank Cörvers, Hans Heijke, Ben Kriechel and Harald Pfeifer. 
We expect the impact on productivity to be stronger in countries with an institutionalised and standardised vocational education and training system. A high degree of standardisation and close links to work practice reduce information asymmetries and increase the quality of match between a worker and a job. A firm in a country with an institutionalised and standardised training system is better informed about the content and quality of training in a specific occupation; thus, the firm can organise its production process and human resources management in line with the available qualifications on the labour market.

We thus expect a significant productivity difference between generally and vocationally educated workers in all of our reference countries. We further expect the impact to be large in Germany and the Netherlands because the training systems in these countries are highly standardised, facilitating the matching of young labour market entrants (Marsden 1986; Gangl 2002). For the United Kingdom, we expect the impact to be less pronounced due to the lower degree of standardisation and transparency. Furthermore, in the United Kingdom, most vocational education occurs in schools and colleges, which limits the role of work practice and consequently leads to weaker tie between the education system and the labour market.

For our analysis, we use industry-level panel data from the EU-KLEMS Data Project and merge it with data from national person-level panel surveys 2 The analysis first focuses on the sectors that have been subject to case studies summarised by Prais (1995). We generate descriptive results of productivity and employment shares in different sectors, and compare them to the results described in the case studies. The results confirm that in a number of industries, a high share of VET workers is related to high productivity. However, several industries show a reversed pattern of high VET employment and low productivity. The analysis then extends to all sectors available in the data. We use both simple OLS regressions and fixed-effects estimators to show that an increase in the employment of vocationally trained workers is positively related to productivity in all three countries. Based on graphical simulations, we also find that the relation between the share of VET labour and productivity follows a concave structure with varying optima in all three reference countries.

The remainder of this chapter is structured as follows. The next section will discuss theoretical aspects of the relation between productivity and different types of education and briefly review literature in this field of study. Section 3 provides background information about the education and VET systems in the three reference countries. Section 4 describes the data sources and the construction of variables used in the analysis. Section 5 discusses the Prais case studies for selected industries and tests the resulting hypothesis using industry level quantitative data. In Section 6, we extend the analysis to all industries in the economy. We use panel regression techniques to estimate the impact

${ }^{2}$ The term industries refers to all economic sectors that are available in the data. According to the NACE concept, industries can include both private and public firms and workers. 
of VET on productivity and discuss the results of this econometric approach. Section 7 summarises the main results and draws some tentative conclusions.

\subsection{Theoretical aspects and literature}

The question of how different types of human capital impact on productivity has been discussed in theoretical and empirical economic literature for many years. Whereas Becker and Mincer (Becker 1962; Mincer 1958, 1974) in their seminal works focused on the relation between the amount of human capital and its impact on wages and productivity, several authors discuss the impact of different skill types on productivity. McMahon et al. (1992), among others, argue that skills obtained via vocational education and training (in the following VET) are "immediately useful at work and thus are generally associated with higher initial earnings" due to higher individual productivity (p.182). At the same time, the authors stress that general education delivers broader skills that enhance individuals' ability to learn on the job and therefore to adapt to future career changes and technical change. Bishop (1998) states that productivity derives directly from social abilities (such as good work habits and people skills) and cognitive skills that are specific to a job and occupation, not from reading, writing, and mathematical skills.

A number of international comparative studies address potential advantages of employing vocationally trained workers for firms and industries. Mason et al. (1990) find that the widespread vocational education of young workers in different continental European countries leads to a significant productivity advantage in a number of industries compared to the United Kingdom, where vocational specialisation is quantitatively less important. Mason et al. (1993) find that in the case of food processing, quality adjusted productivity in Germany is higher than in Great Britain. The authors argue that the reason for this difference is the lack of vocationally trained staff in the latter country. Steedman and Wagner (1987) find strong productivity differences between German and British furniture production plants in favour of the former country. A similar study (Steedman and Wagner 1989) analyses productivity and quality differences in the clothing industry in both countries. While German plants successfully entered the high quality/high price segment of the textile market, the authors find that British producers focused on low-quality production and thus were strongly exposed to competition from emerging markets. Prais (1995) summarises these and other case studies for several industries and countries 3

The main conclusion of the cited research was that firms operating in different countries show great discrepancies with respect to productivity, machinery used and the skill level

\footnotetext{
${ }^{3}$ The authors interviewed a small sample of firms in industries such as metal production, wood and furniture, food production and hotels. The comparability of firms in countries was further enhanced by selecting a set of specific products produced in the firms: in metal production, screws, springs, hydraulic valves and drill bits were selected; in wood furniture firms, the production of fitted kitchen cabinets was selected; and for the food industry, the product of biscuits was selected.
} 
of the workforce. In several sectors, productivity or quality (or both) were higher in countries with an elaborate VET system that is strongly linked with private sector firms, such as in Germany or the Netherlands. The reason for productivity advantages is mainly observed in the skill endowment of the workers in the respective countries. The authors argue that an institutionalised and standardised VET system in a country creates scope for productivity advantages through a number of channels. First, firms may organise their production in a more efficient way, for example through a reduced number of hierarchy levels. Fewer hierarchy levels reduce the bureaucratic frictions in a firm and consequently lead to more efficient production. Second, vocational training, with its strong practical focus, creates knowledge and skills about entire production processes rather than solely about specific steps in the production process. Such training may lead to lower control costs and less interruptions in the product line. Third, because VET is occupation specific and the skills learned inside and outside the firm are transparent for the firm, adjustment and training costs are lower for a firm having access to this type of workers. Workers with a more general (school) qualification need more time to adjust to the job, the production environment and the specific tasks to be performed.

The studies discussed are based on a relatively small set of firms and, consequently, follow a more qualitative approach to the topic. Studies using larger micro data sets to examine the relation between productivity and (firms' access to) vocational skills are rare. The purpose of this chapter therefore is to add to existing literature on the productivity impact of VET by investigating the following hypothesis:

a.) Industries in a country extensively providing vocationally trained workers rather than workers with a more general education at the same (intermediate) qualification level have higher labour productivity as measured by the (real) value added per worker. The occupational specialisation of VET workers allows firms in the industry to organise production with flat hierarchies and low control costs. Furthermore, we expect that an increase in VET labour increases productivity in the respective industry. The productivity increase occurs because VET workers acquire a mix of general and occupation-specific skills during their education and thus better match the firms' demand for intermediate qualification jobs.

b.) For industries that are located in a country with an elaborate, standardised vocational education and training system, the expected relation between vocational training and productivity is stronger. The reasoning for this hypothesis is analogous to the arguments found in the literature. Firms are well informed about the content and quality of training and may therefore 'tailor' production processes in accordance with the supply of skills available on the labour market. The match quality is further improved if firms use the training period as a screening process, after which they predominantly offer a regular working contract to those trainees that are the best match for the vacancy.

\footnotetext{
${ }^{4}$ In Germany, for example, the content of vocational education and training is highly standardised at the federal level, and employer representatives participate in the process of regulating the training content.
} 
Before turning to the empirical part, the next section briefly discusses the differences and common features of education systems in our three reference countries.

\subsection{Education systems in Germany, Netherlands and United Kingdom}

For the analysis in this chapter, we choose three countries with vocational education and training systems that vary in type and in quantitative importance: Germany is a good example of a country with a strong VET system, which mainly consists of VET programmes with a large share of firm-based, work-related training. A large share of school-leavers enter the so-called dual system (combining school education with firmbased training) of VET. The Netherlands is also a country where vocational education and training is strong; however, the system offers both a dual type of VET programme and school-based vocational education for the same occupations 5 The third country is the United Kingdom, where vocational education is mainly provided by schools and colleges. Over all, vocational qualifications are less standardised in this country, and participation in this type of education is lower compared to the other two countries. VET programmes with large firm-based training components make up a relatively small share of all VET programmes. Table 2.1 shows the respective enrolment patterns.

Table 2.1.: Importance of VET Systems in the three reference countries 2009

\begin{tabular}{|c|c|c|c|c|}
\hline & \multicolumn{4}{|c|}{$\begin{array}{c}\text { Upper secondary education } \\
\text { Distribution of enrollment by programme orientation }\end{array}$} \\
\hline & General & Vocational & $\begin{array}{l}\text { of which } \\
\text { work-based }\end{array}$ & $\begin{array}{c}\text { of which } \\
\text { school-based }\end{array}$ \\
\hline Germany & 46.8 & 53.2 & 45.3 & 7.9 \\
\hline Netherlands & 32.9 & 67.1 & 21.5 & 45.6 \\
\hline United Kingdom & 69.5 & 30.5 & $(7.2)$ & $(22.8)$ \\
\hline OECD average & 54.1 & 45.9 & 12.1 & 33.8 \\
\hline
\end{tabular}

According to OECD estimates shown in Table 2.1, more than half of all German students at the upper-secondary level are enrolled in vocational education and training programmes. In the Netherlands, an even higher share (more than two-thirds) of all students opts for this educational path. Vocational education and training also plays an important role for the United Kingdom, although to a somewhat lesser extent than in the other two reference countries. Here, approximately $30 \%$ of all students at the upper-secondary level are enrolled in vocational programmes. However, among vocational programmes, the importance of the dual (i.e. combined school and work) programmes varies between these

\footnotetext{
${ }^{5}$ Note that in Germany, school-based vocational education is common. While in Germany, the same occupation is rarely at the same time trained in schools and in the dual system, the Netherlands offers both ways of training for the same occupation.
} 
countries. These programmes are most important in Germany, where the vast majority of vocational programmes are dual programmes (apprenticeships). In the Netherlands, approximately one in five students follows a dual track. The respective share for the United Kingdom is not published by the OECD; however, the share of apprenticeship programmes is not more than one-fourth of all vocational programmes (Steedman 2010).

With respect to the education and training systems in the reference countries, these systems share a number of common aspects: students follow compulsory education until at least the age of sixteen. At this stage, students have different options to continue education. First, they can leave the formal education system and enter the labour market. This option is not unusual in the United Kingdom but is less frequent in Germany or the Netherlands. Those students continuing in the formal education system have the choice between either general education or vocational tracks with varying shares of firm-based training. In Germany, this share is large with students spending approximately two days per week in vocational schools and three days at the workplace. The same is the case for some of the vocational tracks (i.e. the so-called BBL programmes) in the Netherlands. The Dutch participants of the more school-based vocational education (i.e. the BOL program), however, spend considerably less time training within the firm. Except for apprenticeships, vocational programmes in the United Kingdom usually contain relatively low shares of firm-based training.

For students remaining in the general system, the aim is to gain an upper-secondary qualification that opens the way to tertiary education. Once achieved, however, students of the three countries again have the choice between continuing formal tertiary education or entering employment. In contrast, for the vast majority of those opting for a vocational path at the age of sixteen, it is common to enter the labour market after obtaining an upper-secondary vocational qualification 6

In this chapter, the focus is mainly on workers who have obtained upper-secondary qualifications either by following a vocational or a general educational programme and who have entered the labour market with this qualification. Workers who have obtained either a qualification below the upper-secondary level or who have continued to obtain tertiary qualifications after completing an upper-secondary education are merely included as additional labour input categories in our regression models.

\subsection{Data and variable construction}

\subsubsection{Data}

For our empirical analysis of productivity effects of differently qualified workers, we use industry-level panel data that has been generated by a research project financed by the

${ }^{6} \mathrm{~A}$ more elaborate description of the education systems and pathways is provided in Cörvers et al. (2011) and in the CEDEFOP country reports. 
European Commission: EU-KLEMS (for an overview on the methodology and construction of EU KLEMS, see O'Mahony and Timmer (2009)). The database has been created to support empirical and theoretical research in the area of economic growth, such as, on the one hand, the study of the relationship between skill formation, investment, technological progress and innovation and, on the other hand, productivity 7 As such, the KLEMS database is suited for the question analysed in this chapter. For the analysis, we use a maximum of 51 industries for a period of as much as 15 years. We obtain between 248 (Netherlands) and 750 (Germany) observations (i.e. industry*year) per country.

Because a differentiation between the labour input of VET workers and that of generally educated workers at the intermediate qualification level is not available in the KLEMS data, we aggregate a set of variables available in individual-level panel data sets at the industry level and merge these variables with the KLEMS data.

For Germany, the respective data source is the socio-economic panel (GSOEP), which started in 1984 as a longitudinal survey of private households and persons in the Federal Republic of Germany. The central aim of this panel study is to collect representative micro data on persons, households and families, covering variables in education and training, labour market and occupational dynamics. For our comparative approach, variables of educational background as well as other personal-level and firm-level information have been extracted. For the purpose of merging this information with industry-level panel data, we use the waves from 1991 to 2006.

For the analysis in the Netherlands, we use the Dutch Labour Force Survey (LFS), which is conducted by Statistics Netherlands (CBS). CBS conducts this individual-level survey every year as a cross section with a rotating element. The survey collects data about the employment situation and the behaviour of individuals on the Dutch labour market. For our analysis, we use the waves from 2001 to 2007 for reference. Because there is no information on the labour market experience of workers, we include the tenure of workers as a proxy.

Finally, for the United Kingdom, we choose the British Household Panel Survey (BHPS) as the data source for our analysis. Similar to its German counterpart, the BHPS is a representative, multi-purpose panel study. The survey started in 1991 and since then has been conducted on a yearly basis. From this panel survey, rich information on the labour market situation, earnings and education and further demographic and firm information can be obtained. Similarly to the German panel, waves from 1991 to 2006 are used to extract person-level information about education and employment characteristics.

\footnotetext{
${ }^{7}$ KLEMS has been constructed based on data from national statistical institutes. The data were then processed by the KLEMS research consortium according to agreed procedures that have been established over several years. These procedures were developed to ensure harmonisation of the basic data and to generate growth accounts in a consistent and uniform way. Importantly, this database is rooted in statistics from national accounts and follows the ESA95 framework in many respects. At the lowest level of aggregation, data were collected for 71 industries. The industries are classified according to the European NACE revision 1 classification.
} 
At this stage, it needs to be mentioned that the use of industry-level data has both advantages and disadvantages compared to individual- or firm-level data. As Dearden et al. (2006) argue in their analysis of continuing training effects on wages and productivity, the aim of estimating the relation of VET labour and productivity is mainly a concern of firms. However, authors in the endogenous growth literature (e.g. Aghion and Howitt 1998) have reasoned that human capital acquisition yields spill-over effects that may be industry specific. If these effects exist, the coefficient on the amount of VET labour estimated for the firm level does not fully reflect the productivity impact on the industry level. Further, using industry-level data could reduce some of the measurement error inherent in firm- or individual-level data and thus might lead to a reduction in the attenuation bias. In contrast, the use of aggregated data could lead to aggregation biases. As Dearden et al. (2006) indicate, it is not possible to unambiguously quantify such biases; however, a fixed-effects regression framework controls for at least some of the problems. However, because comparable data at the firm level including both labour input by education type and productivity measures are not available for all reference countries, we use the data at hand.

\subsubsection{Variable construction}

We construct our main variable of interest, i.e. labour input of differently qualified workers, by weighting the overall working hours in the KLEMS data with the respective employment shares from the national panel data sources for each of the qualification groups 8 Labour input is thus measured as working hours per type of qualification, with the main focus being the working hours conducted by VET workers. The information about capital compensation and value added stems from the KLEMS data source. For the estimation of the productivity impact of different types of labour input, we make use of a number of control variables derived from the national surveys. These variables include the age (5 groups), gender, experience of workers (in years, but in the Netherlands 4 groups) and labour turnover (represented by the share of workers changing jobs). All models estimated include year dummies to control for time-specific effects.

Descriptive information about the variables used in the models is supplied in Tables A2.3 to A2.5 The tables reveal that the volume of work performed by VET workers compared to the work volume of other qualification groups is by far the highest in Germany, considerably lower in the Netherlands and the least important in the United Kingdom 9

Because the share of workers in the respective qualification category is used to determine the labour input (in hours) for each group, the distribution of working hours is analo-

\footnotetext{
${ }^{8}$ The calculation does not reflect differences in the working time of the qualification groups. KLEMS variables of working hours by qualification level (low, intermediate, high) are only available for a reduced subset of industries.

${ }^{9}$ Note that all values given are industry-level averages. VET workers are all workers with vocational education and training at an upper-secondary (in the following: intermediate) level as the highest qualification obtained, regardless of its type (school based or work based).
} 
gous. As expected, average working hours are somewhat lower in the Netherlands than in Germany or the United Kingdom. Furthermore, the share of workers changing jobs is much higher in the United Kingdom compared to the respective value for Germany and the Netherlands, which indicates higher labour market mobility in the first country.

In Table A2.1, the industries relevant for our analysis are displayed. As described above, we also provide estimates for a subgroup of those industries that were subject to the analysis summarised in Prais (1995). Industries included in this analysis are listed in Table A2.2.

\subsection{Descriptive analysis}

For a descriptive analysis of the relation between productivity and the employment structure on the industry level, we provide a table including value added per hour worked and the shares of employment for each of the industries covered by the Prais studies (Table 2.2). We average value added and employment shares over a period from 2001 to 2006. The reason for focusing on this period is twofold. First, data for the Netherlands are not available prior to 2001. Second, we aim to analyse the respective shares for the most recent years available to avoid the influence of changes in institutional and economic conditions within countries.

Because the Prais studies focus on a comparison between similar products in different countries, in this section we specifically discuss country differences in the value added and employment shares rather than intra-country differences. Combining the entire sample of Prais sectors, as shown in the last row of Table 2.2), the average productivity in terms of value added per hour is the highest in Germany (34.63 Euro) and lower in the Netherlands (28.55 Euro) and the United Kingdom (27.39 Euro). At the same time, the share of VET workers is also largest in Germany $(66.6 \%)$.

In the Netherlands, the corresponding employment share is somewhat smaller $(38.4 \%)$, while the United Kingdom employs the smallest share of VET workers among the three countries $(20.9 \%)$. Because the average values refer to the subset of industries only, they are not representative of all industries in the economy (see Tables A2.3 to A2.5 for descriptives on the economy level).

With respect to the division of labour, a striking difference between the countries is that the United Kingdom employs a very large share of high-skilled employees (47\%) to reach a relatively low level of productivity. In Germany and the Netherlands, the share of high-skilled workers is on average much smaller (14\% for Germany and approximately $19 \%$ for the Netherlands). Furthermore, we observe that the Netherlands operates with a relatively large share of low-skilled workers $(36 \%)$ compared to the other two countries (13\% in Germany and 10\% in the United Kingdom). 
Table 2.2.: Value added (VA) per hour and employment in Prais industries

\begin{tabular}{|c|c|c|c|c|c|c|c|c|c|c|c|c|c|c|c|}
\hline \multirow[b]{3}{*}{ Industry } & \multicolumn{5}{|c|}{ Germany } & \multicolumn{5}{|c|}{ Netherlands } & \multicolumn{5}{|c|}{ United Kingdom } \\
\hline & \multirow[b]{2}{*}{$\begin{array}{c}\text { VA } \\
\text { (hour) }\end{array}$} & \multicolumn{3}{|c|}{ Share of... } & \multirow[b]{2}{*}{ high } & \multirow[b]{2}{*}{$\begin{array}{c}\text { VA } \\
\text { (hour) }\end{array}$} & \multicolumn{3}{|c|}{ Share of... } & \multirow[b]{2}{*}{ high } & \multirow[b]{2}{*}{$\begin{array}{c}\text { VA } \\
\text { (hour) }\end{array}$} & \multicolumn{4}{|c|}{ Share of... } \\
\hline & & low & $\begin{array}{l}\text { gen. } \\
\text { qua }\end{array}$ & $\begin{array}{l}\text { VET } \\
\text { ified }\end{array}$ & & & low & $\begin{array}{l}\text { gen. } \\
\text { qua }\end{array}$ & $\begin{array}{l}\text { VET } \\
\text { ified }\end{array}$ & & & low & $\begin{array}{l}\text { gen. } \\
\text { qua }\end{array}$ & $\begin{array}{l}\text { VET } \\
\text { ified }\end{array}$ & high \\
\hline \multicolumn{16}{|c|}{ Productivity advantage Germany } \\
\hline $\begin{array}{l}\text { Wearing apparel, dressing } \\
\& \text { dying of fur }\end{array}$ & 28.0 & 13.9 & 5.9 & 72.2 & 7.9 & n.a. & n.a. & n.a. & n.a. & n.a. & 20.3 & 15.8 & 40.6 & 7.3 & 36.3 \\
\hline $\begin{array}{l}\text { Wood \& products of } \\
\text { wood \& cork }\end{array}$ & 23.8 & 15.8 & 6.7 & 72.4 & 5.1 & 13.7 & 41.0 & 5.1 & 41.3 & 12.6 & 21.2 & 7.5 & 22.5 & 33.0 & 37.0 \\
\hline Fabricated metal products & 32.6 & 14.9 & 7.2 & 71.8 & 6.0 & 30.4 & 40.6 & 5.2 & 42.9 & 11.3 & 23.1 & 11.7 & 23.2 & 29.2 & 36.0 \\
\hline $\begin{array}{l}\text { Machinery, nec } \\
\text { Office, accounting }\end{array}$ & 40.2 & 3.6 & 8.3 & 58.7 & 29.5 & 38.1 & 25.5 & 4.8 & 46.7 & 23.0 & 29.0 & 5.0 & 15.7 & 25.5 & 53.8 \\
\hline \& computing machinery & 72.6 & 8.3 & 2.3 & 68.1 & 21.3 & 44.9 & 19.6 & 6.9 & 27.4 & 46.1 & 44.0 & 3.8 & 13.9 & 20.5 & 61.7 \\
\hline $\begin{array}{l}\text { Electrical machinery } \\
\text { Radio, television }\end{array}$ & 40.2 & 11.3 & 8.6 & 56.0 & 24.1 & n.a. & n.a. & n.a. & n.a. & n.a. & 24.1 & 14.1 & 38.6 & 14.9 & 32.4 \\
\hline $\begin{array}{l}\text { \& communication equipment } \\
\text { Medical, precision, }\end{array}$ & 34.8 & 3.9 & 6.7 & 59.6 & 29.7 & n.a. & n.a. & n.a. & n.a. & n.a. & 30.8 & 11.1 & 12.7 & 15.6 & 60.7 \\
\hline optical instruments & 38.5 & 13.1 & 9.4 & 58.8 & 18.8 & 28.6 & 24.7 & 7.2 & 42.2 & 26.0 & 33.2 & 6.5 & 12.3 & 20.0 & 61.2 \\
\hline Motor vehicles \& trailers & 52.9 & 10.8 & 6.5 & 62.7 & 20.0 & 47.5 & 40.1 & 4.6 & 38.6 & 16.7 & 31.1 & 7.4 & 20.9 & 25.0 & 46.8 \\
\hline Other transport equipment & 40.2 & 5.3 & 2.7 & 81.3 & 10.7 & 33.3 & 31.3 & 3.9 & 45.8 & 19.0 & 36.1 & 8.7 & 9.8 & 23.8 & 57.8 \\
\hline \multicolumn{16}{|c|}{ Productivity advantage Netherlands } \\
\hline Food products \& beverages & 23.5 & 13.8 & 4.5 & 69.9 & 11.8 & 47.9 & 40.5 & 7.1 & 37.0 & 15.4 & 33.3 & 11.2 & 18.9 & 16.9 & 53.0 \\
\hline Manufacturing nec & 25.6 & 11.1 & 5.6 & 74.1 & 9.2 & 59.2 & 52.8 & 5.0 & 30.6 & 11.7 & 17.0 & 9.3 & 32.5 & 22.6 & 35.7 \\
\hline Hotels \& Restaurants & 12.8 & 20.0 & 14.3 & 60.5 & 5.2 & 21.9 & 39.3 & 15.7 & 34.1 & 10.9 & 17.9 & 14.6 & 37.5 & 11.9 & 36.0 \\
\hline Textiles \& textile products & 25.8 & 14.2 & 3.4 & 76.6 & 5.8 & 31.0 & 46.2 & 8.0 & 34.1 & 11.7 & 19.6 & 4.1 & 32.5 & 17.1 & 46.3 \\
\hline Basic metals & 38.4 & 20.8 & 6.2 & 60.6 & 12.4 & 60.5 & 34.3 & 4.8 & 40.6 & 20.3 & 25.8 & 5.1 & 19.3 & 32.0 & 43.6 \\
\hline \multicolumn{16}{|c|}{ Productivity advantage United Kingdom } \\
\hline $\begin{array}{l}\text { Leather, leather products } \\
\& \text { footwear }\end{array}$ & 24.3 & 21.8 & 10.6 & 61.8 & 5.7 & n.a. & n.a. & n.a. & n.a. & n.a. & 26.3 & 19.3 & 16.8 & 22.0 & 41.9 \\
\hline Total & 34.6 & 12.7 & 6.8 & 66.6 & 14.0 & 28.6 & 36.3 & 6.5 & 38.4 & 18.7 & 27.4 & 9.6 & 22.8 & 20.9 & 46.7 \\
\hline
\end{tabular}

The numbers are average values for the period 2001-2006. 
A general observation is that Germany in all industries has the highest share of VET workers, followed by the Netherlands and the United Kingdom, which has the lowest share of VET workers in all industries. To facilitate the reading of Table 2.2, we rank the industries by country with the highest value added per hour in bold figures.

The table indicates that for several of the Prais sectors, productivity is highest in Germany. This result holds true for the apparel industry, the wood production industry and several metal-producing industries. Furthermore, the descriptive evidence also confirms the results presented in the Prais studies for motor vehicle production and electrical engineering: large shares of VET workers are found along with relatively high productivity.

For a number of industries, the Netherlands shows the highest productivity value. Labour in the food industry as well as in manufacturing is more productive than both in Germany and the United Kingdom. We also observe differences in favour of the Netherlands for hotels and restaurants, textiles and basic metals.

According to the quantitative descriptive data, the United Kingdom only leads the other two countries in terms of hourly value added in the leather and footwear industry.

Summarising the cross-country comparison, in most industries we find productivity advantages for countries with a relatively high share of VET workers. The observations mainly confirm prior results obtained from the Prais studies. In the next section, we extend the analysis to all available sectors in the three economies using panel regression techniques.

\subsection{Econometric approach and regression results}

\subsubsection{Econometric approach}

Although informative, the simple descriptive analysis does not consider idiosyncratic and systematic factors that determine productivity in an industry. With reference to literature addressing the impact of continuing training on wages and productivity (e.g. Dearden et al. 2006 and Schüler 2006), we estimate a panel regression model including several important control variables. 10

For the estimation of the productivity effect of VET, we start by estimating a pooled OLS regression model of the form

$$
\ln y_{i t}=\alpha+\beta_{1} k_{i t}+\beta_{2} \ln L L_{i t}+\beta_{3} \ln L V_{i t}+\beta_{4} \ln L G_{i t}+\beta_{5} \ln L H_{i t}+\beta_{6} X_{i t}+\epsilon_{i t}
$$

\footnotetext{
${ }^{10}$ Note that we essentially present an empirical application of a Cobb-Douglas production function. The mathematical derivation is not presented in this chapter because our focus is on the presentation of empirical results. However, Dearden et al. (2006) present a simple production function approach for two types of labour (trained and untrained), which is then generalised to include several types of labour.
} 
where $y$ is real value added for industry $i$ and for the year $t$. $k$ is the real capital stock in the industry. $L L, L V, L G$ and $L H$ are the number of working hours performed by workers with low, intermediate VET, intermediate general and high qualification, respectively. $X$ is a vector of additional explanatory variables. In this vector, we include controls of average labour market experience of workers, gender, share of workers changing jobs, age ( 5 groups) and the average working time in the industry. Tables A2.3 to A2.5 show descriptive information about the variables for each of the reference countries and separately for all industries and those chosen by Prais (1995). We assume the error term $\epsilon$ to be asymptotically normally distributed. Our focus is on the coefficient of variable $L V$, which represents the labour input of vocationally educated and trained workers, and its relation to $L G$ representing the labour input of workers with general education.

Due to the possibility that the observations for the same industry across time may be correlated, we make use of the panel structure of the data and estimate a fixed-effects specification in the form of

$$
\begin{aligned}
& \ln y_{i t}=\alpha+\beta_{1} k_{i t}+\beta_{2} \ln L L_{i t}+\beta_{3} \ln L V_{i t}+\beta_{4} \ln L G_{i t}+\beta_{5} \ln L H_{i t}+\beta_{6} X_{i t} \\
& +\mu_{i}+\epsilon_{i t} .
\end{aligned}
$$

Compared to equation 2.1, we add dummies for each year included in the panel to control for time-specific events. $\mu$ represents the industry-specific error component, which, in a fixed-effects framework, is time invariant and as such will be removed from the model. Such industry-specific components could be, for example, specific regulatory frameworks or international competition (as long as it does not change over time). Again, we assume the error term $\epsilon$ to be asymptotically normally distributed 11

To illustrate the relationship between the amount of VET work among the intermediately qualified workers and our productivity measure, we use the coefficients $\beta_{3}$ and $\beta_{4}$ from the extended fixed-effects specification to calculate a corresponding productivity measure for each possible division of labour between VET and general intermediate workers:

$$
\ln y=\left(\beta_{3} * \ln L G\right)+\left(\beta_{4} * \ln L V\right)
$$

with

$$
L G+L V=1
$$

${ }^{11}$ For the estimation of the impact of continuing training on productivity and wages in the United Kingdom, Dearden et al. (2006) use GMM estimation techniques to determine the respective effects on the industry level. However, for the present evaluation, the tested GMM specifications proved to be extremely sensitive to changes in the model, which most likely is a consequence of the small number of observations. Because in the literature (e.g. Roodman 2009) this estimation method is described to be useful for small $\mathrm{T}$ and large $\mathrm{N}$ data sets (which are both not true for the data used in this chapter), we refrain from a discussion of GMM results. 
Table 2.3.: Fixed-effects model: Germany (dep. var.: Real value added (log))

\begin{tabular}{lcc}
\hline Variable & Base Model & Extended Model \\
\hline Working hours low qualification $(\log )$ & $0.050^{* * *}$ & $0.048^{* * *}$ \\
Working hours VET qualification $(\log )$ & $(0.008)$ & $(0.008)$ \\
& $\left(0.0121^{* * *}\right.$ & $0.132^{* * *}$ \\
Working hours general qualification $(\log )$ & $0.033^{* * *}$ & $(0.014)$ \\
& $(0.006)$ & $\left(0.033^{* * *}\right.$ \\
Working hours high qualification $(\log )$ & $0.067^{* * *}$ & $0.070^{* * *}$ \\
& $(0.007)$ & $(0.007)$ \\
Real capital compensation $(\log )$ & $0.126^{* * *}$ & $0.126^{* * *}$ \\
& $(0.009)$ & $(0.009)$ \\
Year dummies & Yes & Yes \\
Controls for gender & No & Yes \\
Controls for average experience & No & Yes \\
Controls for average working time & No & Yes \\
Controls for labour turnover & No & Yes \\
Controls for age structure & No & Yes \\
Constant & $7.460^{* * *}$ & $7.347^{* * *}$ \\
& $(0.115)$ & $(0.161)$ \\
\hline Observations & 644 & 644 \\
\hline Standary
\end{tabular}

Standard errors in parentheses. Reference period 1991-2005.

${ }^{*} p<0.1,{ }^{* *} p<0.05,{ }^{* * *} p<0.01$.

For the simulations, we use the mean value of all time periods of the share of VET work, which is in line with the fact that the fixed-effects coefficient also describes the average productivity change regarding a change in the hours worked. The plot thus refers to the average relationship between the share of VET work and value added in the period covered.

\subsubsection{Regression results}

Fixed-effects panel regressions for the entire set of industries in the economy are presented in Tables 2.3 and 2.5. For reference, the pooled OLS regression results for the three countries are supplied in Tables A2.6 and A2.8 in the Appendix. The results for Germany confirm the hypothesis formulated above. In both the base model (excluding a vector of structural variables) and the extended model, the coefficients on the hours of vocationally educated and trained work are positive, large and significant. Thus, an increase in the volume of labour by workers having received their education and training in the VET system leads to an increase in the productivity in a sector. This also holds true for working hours performed by workers with a low, general intermediate and high qualification. However, the size of the coefficients is much lower; thus, the impact of an increase in working hours of the respective types of labour is smaller compared to an increase in VET working hours.

Estimates for the Netherlands show that in the extended model (column 2) the coefficient for VET work is also positive and significant. However, the coefficients for general 
Table 2.4.: Fixed-effects model: Netherlands (dep. var.: Real value added (log))

\begin{tabular}{lcc}
\hline Variable & Base Model & Extended Model \\
\hline Working hours low qualification $(\log )$ & 0.036 & $0.080^{*}$ \\
& $(0.043)$ & $(0.045)$ \\
Working hours VET qualification $(\log )$ & 0.095 & $0.188^{* *}$ \\
& $(0.079)$ & $(0.082)$ \\
Working hours general qualification $(\log )$ & 0.014 & -0.001 \\
& $(0.025)$ & $(0.027)$ \\
Working hours high qualification $(\log )$ & 0.009 & 0.009 \\
& $(0.053)$ & $(0.057)$ \\
Real capital compensation $(\log )$ & $0.075^{* * *}$ & $0.063^{* *}$ \\
& $(0.027)$ & $(0.029)$ \\
Year dummies & Yes & Yes \\
Controls for gender & No & Yes \\
Controls for average experience & No & Yes \\
Controls for average working time & No & Yes \\
Controls for labour turnover & No & Yes \\
Controls for age structure & No & Yes \\
Constant & $7.668^{* * *}$ & $7.093^{* * *}$ \\
& $(0.483)$ & $(0.909)$ \\
\hline Observations & 248 & 248
\end{tabular}

Standard errors in parentheses. Reference period 2001-2007.

${ }^{*} p<0.1,{ }^{* *} p<0.05,{ }^{* * *} p<0.01$.

Table 2.5.: Fixed-effects model: UK (dep. var.: Real value added $(\log )$ )

\begin{tabular}{lcc}
\hline Variable & Base Model & Extended Model \\
\hline Working hours low qualification $(\log )$ & -0.002 & -0.004 \\
& $(0.005)$ & $(0.005)$ \\
Working hours VET qualification $(\log )$ & 0.009 & $0.012^{* *}$ \\
& $(0.006)$ & $(0.006)$ \\
Working hours general qualification $(\log )$ & $0.011^{* *}$ & 0.008 \\
& $(0.006)$ & $(0.006)$ \\
Working hours high qualification $(\log )$ & $0.017^{* *}$ & $0.023^{* * *}$ \\
& $(0.007)$ & $(0.008)$ \\
Real capital compensation $(\log )$ & $0.227^{* * *}$ & $0.223^{* * *}$ \\
& $(0.013)$ & $(0.013)$ \\
Year dummies & Yes & Yes \\
Controls for gender & No & Yes \\
Controls for average experience & No & Yes \\
Controls for average working time & No & Yes \\
Controls for labour turnover & No & Yes \\
Controls for age structure & No & Yes \\
Constant & $7.270^{* * *}$ & $7.154^{* * *}$ \\
& $(0.107)$ & $(0.220)$ \\
\hline Observations & 642 & 642
\end{tabular}

Standard errors in parentheses. Reference period 1991-2005.

${ }^{*} p<0.1,{ }^{* *} p<0.05,{ }^{* * *} p<0.01$. 
intermediate- and high-qualified working hours are not significantly different from zero. A weakly significant positive effect can also be observed for the low-qualified working hours in the Netherlands.

Finally, the results for the United Kingdom show that an increase in the working hours of VET is related to an increase in the productivity of an industry. The respective coefficients for low- and general intermediate-qualified working hours are not significant. As in the case of Germany, an increase in highly qualified workers leads to a significant increase in productivity.

The respective coefficient is larger than the coefficient for VET. Summarising, for all countries, the estimates indicate that increasing the labour input of VET workers yields larger productivity gains than increasing the labour input of generally educated workers.

Further investigating the relationship between the share of VET work and productivity, we plot the shares and the corresponding productivity values using the respective coefficients for 'Working hours VET qualification' and 'Working hours general qualification'. In this analysis, we focus explicitly on the division of labour at the intermediate level and take all other factors determining productivity as given. Figure 2.1 shows the resulting structure and the average share of each type of labour over the reference period (vertical line) for the three countries. For Germany, the curve follows a concave structure with value added increasing in the share of vocationally educated and trained workers. However, the slope is decreasing and turns negative at extremely high values of the share of VET work. The average over the reference period from 1991 to 2005 is located somewhat to the right but relatively close to the optimum at approximately $80 \%$ of the labour input at the intermediate level.

The respective figure for the Netherlands indicates a similar pattern as the figure for Germany. However, because the coefficient for the generally qualified working hours is practically zero, the slope does not turn negative at extremely high values of the VET share. This result is different in the figure for the United Kingdom. Here, a rising curve reaches its optimum at approximately $65 \%$ and then decreases for higher values of VET labour input. The average value for the reference period is below $50 \%$, indicating scope for an increase in the use of vocationally educated and trained workers in relation to those with a more general qualification at the intermediate level. Interpreting the result, we need to bear in mind that the simulated changes in VET shares and the resulting productivity level are static in the sense that they do not include effects due to organisational adjustments in the countries. Thus, we could argue that a large increase in the share of VET in the United Kingdom would increase productivity by more than the increase given in Figure 
2. VET and productivity - A three-country analysis

Figure 2.1.: Value added and VET at the intermediate level

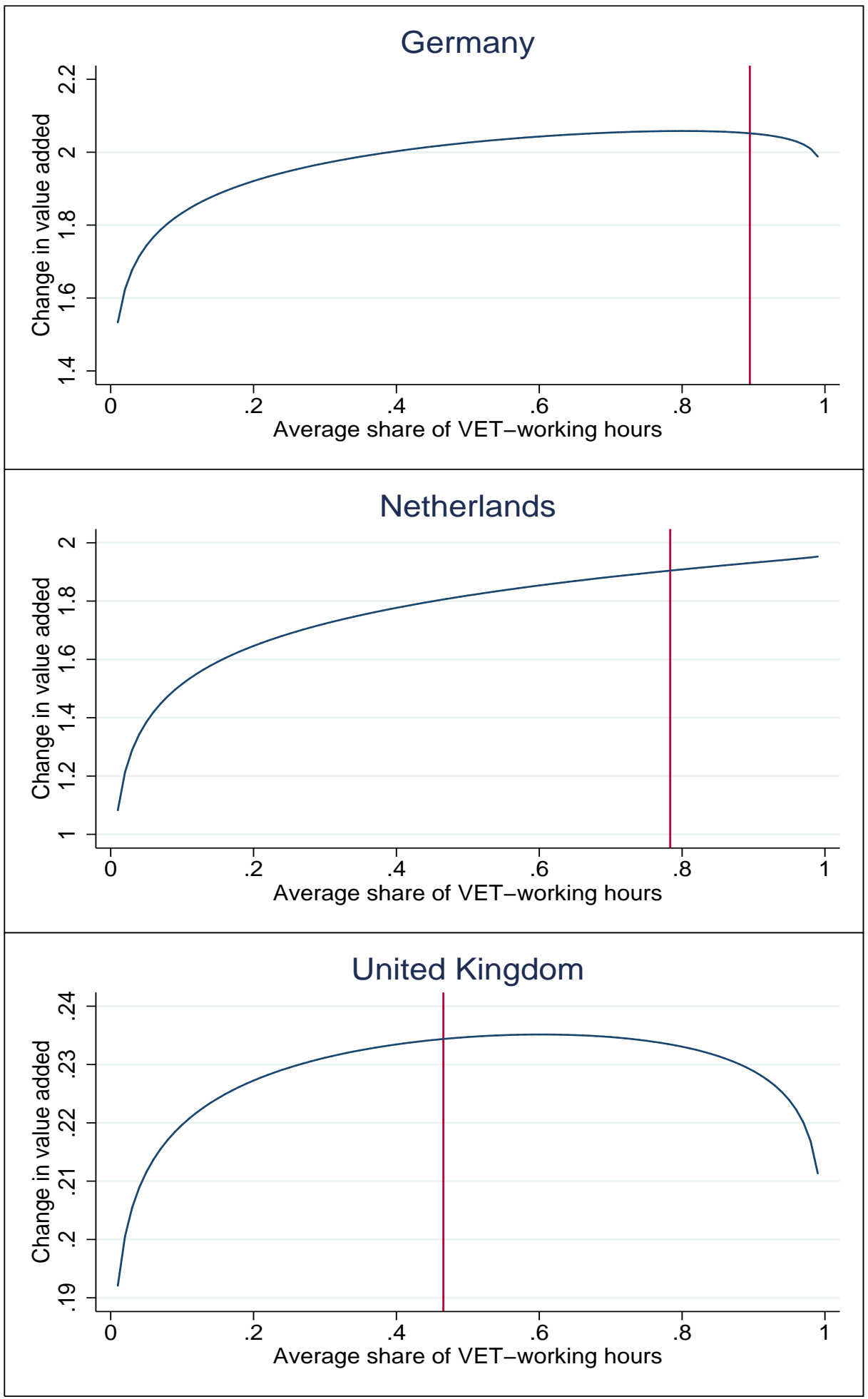




\subsection{Summary and conclusions}

In this chapter, we analyse the impact of an increase in the labour input of vocationally educated and trained workers on productivity in three countries. The countries were chosen due to their different relevance and structures of VET. Literature based on case studies lends support to the hypothesis that a well-defined, standardised and transparent VET system leads to productivity differences between firms producing the same product in different countries. The chapter adds to this literature by taking an industry-level quantitative approach. For the analyses, we first merge industry-level data stemming from the KLEMS project with aggregated data from national panel surveys. We first compare descriptive results from the merged data set with results from case study literature and then use pooled OLS and fixed-effects panel regression models to extend the analysis to the entire economy.

The descriptive analysis supports the results found in case-study literature. For most of the industries described in the Prais-studies, we find a positive relation between the share of VET workers and the value added per hour, whereas productivity in many sectors is highest in Germany. This result not only holds for the metal producing and electrical engineering industries but also for wood and motor vehicle production. For several other industries, e.g. manufacturing and textiles, the Netherlands leads the other two countries in terms of productivity. The descriptive analysis in this chapter contains another message. While the higher productivities are achieved by employing high shares of VET workers and low shares of highly qualified workers, the United Kingdom reaches only lower levels of productivity with low shares of VET workers and high shares of highly qualified workers. Thus, on the descriptive level, large shares of highly qualified workers do not necessarily induce high productivity levels in a country.

Using regression techniques for the entire set of industries, we find strong evidence that an increase in VET working hours increases productivity in all three countries. Further, the respective coefficients for VET are larger than the coefficients for hours of workers with general (intermediate) education. As expected, the impact of an increase in VET working hours is stronger in Germany and the Netherlands than in the United Kingdom. A graphical simulation of marginal changes in the composition of intermediate labour shows that the relationship between the share of VET labour and productivity follows a concave structure for all three countries. The optimal share of VET labour thereby varies for the three countries and is higher for Germany and the Netherlands than for the United Kingdom. The actual (average) share over the reference period is considerably lower than the optimum in the latter country, leaving scope for an improvement in the use of vocationally qualified work. For Germany, the labour share of VET is closer but somewhat beyond the graphical optimum.

In general terms, the simulation results suggest that the optimal level of VET labour input is higher in countries with a highly standardised, transparent and work-oriented VET system, when compared to countries where VET is more school based and more diverse in 
the "production" of vocational education qualifications. Nevertheless, the results imply ample room for productivity improvements in countries with less standardised systems of vocational education.

The results obtained from the above analysis need to be confirmed by further studies. Individual- or firm-level panel data that allow for a stronger differentiation between types of vocational education and training (e.g. school-based or work-based) would shed more light on the research question addressed in this chapter. Further, a larger set of countries would improve the explanatory power of such an analysis by considering the systematic variation between countries. 


\section{A2. Appendix}

Table A2.1.: List of industries included in analysis

\begin{tabular}{ll}
\hline Nace Ref. 1 & Industry \\
\hline 1 & Agriculture \\
2 & Forestry \\
10 & Mining of coal and lignite; extraction of peat \\
11 & Extraction of crude petroleum and natural gas and services \\
12 & Mining of uranium and thorium ores \\
13 & Mining of metal ores \\
14 & Other mining and quarrying \\
15 & Food products and beverages \\
16 & Tobacco products \\
17 & Textiles and textile products \\
18 & Wearing apparel, dressing and dying of fur \\
19 & Leather, leather products and footwear \\
20 & Wood and products of wood and cork \\
21 & Pulp, paper and paper products \\
22 & Printing, publishing and reproduction \\
23 & Coke, refined petroleum products and nuclear fuel \\
24 & Chemicals and chemical products \\
25 & Rubber and plastics products \\
26 & Other non-metallic mineral products \\
27 & Basic metals \\
28 & Fabricated metal products \\
29 & Machinery, nec \\
30 & Office, accounting and computing machinery \\
31 & Electrical machinery and apparatus, nec \\
32 & Radio, television and communication equipment \\
33 & Medical, precision and optical instruments \\
34 & Motor vehicles, trailers and semi-trailers \\
\hline &
\end{tabular}

continued on next page... 
...continued from previous page

\begin{tabular}{ll}
\hline Nace Ref. 1 & Industry \\
\hline 35 & Other transport equipment \\
36 & Manufacturing nec \\
37 & Recycling \\
40 & Electricity and gas \\
41 & Water supply \\
45 & Construction \\
50 & Sale, maintenance and repair of motor vehicles and motorcycles; \\
& retail sale of automotive fuel \\
51 & Wholesale trade and commission trade, except of motor vehicles \\
52 & and motorcycles \\
& Retail trade, except of motor vehicles and motorcycles; \\
55 & repair of household goods \\
60 & Hotels and Restaurants \\
61 & Transport and storage and communication \\
62 & Water transport \\
63 & Air transport \\
64 & Supporting and auxiliary transport activities; \\
65 & activities of travel agencies \\
66 & Post and telecommunications \\
67 & Financial intermediation, except insurance and pension funding \\
70 & Insurance and pension funding, except compulsory social security \\
71 & Activities related to financial intermediation \\
72 & Real estate activities \\
73 & Renting of machinery and equipment \\
74 & Computer and related activities \\
75 & Research and development \\
80 & Other business activities \\
85 & Public administration and defense; \\
90 & compulsory social security \\
91 & Education \\
92 & Health and social work \\
93 & Private households with employed persons \\
95 & Activities of membership organisations nec \\
& Recreational, cultural and sporting activities \\
& Sewage and refuse disposal, sanitation \\
& and similar activities \\
&
\end{tabular}


Table A2.2.: List of industries used for Prais analysis

\begin{tabular}{ll}
\hline Nace Ref. 1 & Industry \\
15 & Food products and beverages \\
17 & Textiles and textile products \\
18 & Wearing apparel, dressing and dying of fur \\
19 & Leather, leather products and footwear \\
20 & Wood and products of wood and cork \\
27 & Basic metals \\
28 & Fabricated metal products \\
29 & Machinery, nec \\
30 & Office, accounting and computing machinery \\
31 & Electrical machinery and apparatus, nec \\
32 & Radio, television and communication equipment \\
33 & Medical, precision and optical instruments \\
34 & Motor vehicles, trailers and semi-trailers \\
35 & Other transport equipment \\
36 & Manufacturing nec \\
55 & Hotels and restaurants \\
\hline
\end{tabular}

Table A2.3.: Summary statistics - Germany

\begin{tabular}{|c|c|c|c|c|}
\hline & \multicolumn{2}{|c|}{ All industries } & \multicolumn{2}{|c|}{ Prais industries } \\
\hline Variable & Mean & Std. Dev. & Mean & Std. Dev. \\
\hline Real value added (in mio Euro) & 34324 & $(42287)$ & 20898 & (18775) \\
\hline Real capital compensation (in mio Euro) & 12239 & $(28317)$ & 3972 & $(4213)$ \\
\hline Share of low qualified workers & 11.66 & $(8.92)$ & 15.52 & $(5.71)$ \\
\hline Share of VET qualified workers & 62.87 & (12.31) & 64.89 & $(5.94)$ \\
\hline Share of general qualified workers & 6.84 & $(3.31)$ & 5.69 & $(1.92)$ \\
\hline Share of high qualified workers & 18.63 & (13.89) & 13.9 & $(8.29)$ \\
\hline Average working hours per week & 39.86 & $(4.85)$ & 40.49 & $(2.22)$ \\
\hline Share of male workers & 0.62 & $(0.22)$ & 0.67 & $(0.19$ \\
\hline Share of workers having changed job & 0.15 & $(0.11)$ & 0.12 & $(0.07)$ \\
\hline Share of workers aged 16 to 24 & 0.09 & $(0.08)$ & 0.10 & $(0.06)$ \\
\hline Share of workers aged 25 to 34 & 0.26 & $(0.13)$ & 0.25 & $(0.10)$ \\
\hline Share of workers aged 35 to 44 & 0.31 & $(0.13)$ & 0.29 & $(0.10)$ \\
\hline Share of workers aged 45 to 54 & 0.23 & $(0.12)$ & 0.25 & $(0.10)$ \\
\hline Share of workers aged 55 to 68 & 0.11 & $(0.07)$ & 0.11 & $(0.06)$ \\
\hline Average working hours per week & 39.86 & $(4.85)$ & 40.49 & $(2.22)$ \\
\hline Average experience of workers (years) & 17.23 & $(3.52)$ & 17.81 & $(2.74)$ \\
\hline Observations & \multicolumn{2}{|r|}{750} & \multicolumn{2}{|r|}{219} \\
\hline
\end{tabular}


Table A2.4.: Summary statistics - Netherlands

\begin{tabular}{lcccc}
\hline & \multicolumn{2}{c}{ All industries } & \multicolumn{2}{c}{ Prais industries } \\
\hline Variable & Mean & Std. Dev. & Mean & Std. Dev. \\
\hline Real gross value added (in mio Euro) & 15638 & $(22366)$ & 10262 & $1(7960)$ \\
Real capital compensation (in mio Euro) & 3953 & $(6908)$ & 1233 & $(1556)$ \\
Share of low qualified workers & 27.68 & $(13.07)$ & 37.38 & $(8.92)$ \\
Share of VET qualified workers & 36.03 & $(7.67)$ & 38.09 & $(5.89)$ \\
Share of general qualified workers & 8.57 & $(3.63)$ & 6.47 & $(3.16)$ \\
Share of high qualified workers & 27.71 & $(15.97)$ & 18.06 & $(9.76)$ \\
Average working hours per week & 36.62 & $(2.90)$ & 37.19 & $(1.44)$ \\
Share of male workers & 0.71 & $(0.17)$ & 0.79 & $(0.14)$ \\
Share of workers having changed job & 0.06 & $(0.02)$ & 0.05 & $(0.02)$ \\
Share of workers aged 16 to 24 & 0.09 & $(0.06)$ & 0.10 & $(0.07)$ \\
Share of workers aged 25 to 34 & 0.25 & $(0.06)$ & 0.23 & $(0.04)$ \\
Share of workers aged 35 to 44 & 0.31 & $(0.05)$ & 0.32 & $(0.04)$ \\
Share of workers aged 45 to 54 & 0.24 & $(0.05)$ & 0.24 & $(0.04)$ \\
Share of workers aged 55 to 68 & 0.10 & $(0.04)$ & 0.10 & $(0.03)$ \\
Share of workers: Experience 1-4 years & 0.06 & $(0.03)$ & 0.06 & $(0.03)$ \\
Share of workers: Experience 5-9 years & 0.13 & $(0.04)$ & 0.12 & $(0.03)$ \\
Share of workers: Experience 10-19 years & 0.32 & $(0.05)$ & 0.31 & $(0.04)$ \\
Share of workers: Experience 20+ years & 0.48 & $(0.09)$ & 0.50 & $(0.08)$ \\
\hline Observations & \multicolumn{5}{c}{248} & & 77 \\
\hline
\end{tabular}

Table A2.5.: Summary statistics - UK

\begin{tabular}{|c|c|c|c|c|}
\hline \multirow[b]{2}{*}{ Variable } & \multicolumn{2}{|c|}{ All industries } & \multicolumn{2}{|c|}{ Prais industries } \\
\hline & Mean & Std. Dev. & Mean & Std. Dev. \\
\hline Real value added (in mio Euro) & 20900 & $(25252)$ & 10419 & $(9350)$ \\
\hline Real capital compensation (in mio Euro) & 5701 & (10066) & 2449 & $(2733)$ \\
\hline Share of low qualified workers & 14.79 & $(7.93)$ & 11.64 & $(6.63)$ \\
\hline Share of VET qualified workers & 21.44 & $(7.81)$ & 25.37 & $(6.35)$ \\
\hline Share of general qualified workers & 22.32 & $(9.95)$ & 21.21 & $(6.92)$ \\
\hline Share of high qualified workers & 41.45 & (12.45) & 41.78 & (10.75) \\
\hline Average working hours per week & 39.40 & $(6.76)$ & 40.44 & $(4.52)$ \\
\hline Share of male workers & 0.67 & $(0.25)$ & 0.75 & $(0.19)$ \\
\hline Share of workers having changed job & 0.20 & $(0.15)$ & 0.21 & $(0.14)$ \\
\hline Share of workers aged 16 to 24 & 0.13 & $(0.13)$ & 0.14 & $(0.15)$ \\
\hline Share of workers aged 25 to 34 & 0.24 & $(0.15)$ & 0.22 & $(0.12)$ \\
\hline Share of workers aged 35 to 44 & 0.27 & $(0.16)$ & 0.27 & $(0.13)$ \\
\hline Share of workers aged 45 to 54 & 0.23 & $(0.13)$ & 0.24 & $(0.14)$ \\
\hline Share of workers aged 55 to 68 & 0.13 & $(0.11)$ & 0.12 & $(0.11)$ \\
\hline Average working hours per week & 39.4 & $(6.76)$ & 40.44 & $(4.52)$ \\
\hline Average experience of workers (years) & 23.51 & (4.58) & 23.54 & $(4.26)$ \\
\hline Observations & & 642 & & 164 \\
\hline
\end{tabular}


Table A2.6.: Pooled OLS model - Germany (dep. var.: Real value added (log))

\begin{tabular}{lcc}
\hline Variable & Base Model & Extended Model \\
\hline Working hours low qualification $(\log )$ & 0.007 & 0.003 \\
& $(0.011)$ & $(0.012)$ \\
Working hours VET qualification $(\log )$ & $0.345^{* * *}$ & $0.354^{* * *}$ \\
& $(0.020)$ & $(0.021)$ \\
Working hours general qualification $(\log )$ & $0.061^{* * *}$ & $0.058^{* * *}$ \\
& $(0.014)$ & $(0.014)$ \\
Working hours high qualification $(\log )$ & $0.153^{* * *}$ & $0.146^{* * *}$ \\
& $(0.010)$ & $(0.012)$ \\
Real capital compensation $(\log )$ & $0.349^{* * *}$ & $0.345^{* * *}$ \\
& $(0.010)$ & $(0.010)$ \\
Controls for gender & No & Yes \\
Controls for average experience & No & Yes \\
Controls for average working time & No & Yes \\
Controls for labour turnover & No & Yes \\
Controls for age structure & No & Yes \\
Constant & $4.181^{* * *}$ & $4.642^{* * *}$ \\
& $(0.081)$ & $(0.200)$ \\
\hline Observations & 750 & 750 \\
\hline
\end{tabular}

Standard errors in parentheses. Reference period 1991-2005.

${ }^{*} p<0.1,{ }^{* *} p<0.05,{ }^{* * *} p<0.01$.

Table A2.7.: Pooled OLS model - Netherlands (dep. var.: Real value added (log))

\begin{tabular}{lcc}
\hline Variable & Base Model & Extended Model \\
\hline Working hours low qualification $(\log )$ & $0.372^{*}$ & $0.450^{* *}$ \\
& $(0.194)$ & $(0.205)$ \\
Working hours VET qualification $(\log )$ & -0.300 & -0.444 \\
& $(0.283)$ & $(0.301)$ \\
Working hours general qualification $(\log )$ & $0.254^{*}$ & 0.253 \\
& $(0.150)$ & $(0.185)$ \\
Working hours high qualification $(\log )$ & -0.040 & 0.075 \\
& $(0.154)$ & $(0.194)$ \\
Real capital compensation $(\log )$ & $0.388^{* * *}$ & $0.266^{* * *}$ \\
& $(0.080)$ & $(0.086)$ \\
Controls for gender & No & Yes \\
Controls for average experience & No & Yes \\
Controls for average working time & No & Yes \\
Controls for labour turnover & No & Yes \\
Controls for age structure & No & Yes \\
Constant & $5.290^{* * *}$ & 4.904 \\
& $(0.553)$ & $(5.332)$ \\
\hline Observations & 248 & 248
\end{tabular}

Standard errors in parentheses. Reference period 2001-2007.

${ }^{*} p<0.1,{ }^{* *} p<0.05,{ }^{* * *} p<0.01$. 
Table A2.8.: Pooled OLS model - UK (dep. var.: Real value added (log))

\begin{tabular}{lcc} 
Variable & Base Model & Extended Model \\
\hline Working hours low qualification $(\log )$ & 0.019 & 0.011 \\
& $(0.014)$ & $(0.014)$ \\
Working hours VET qualification $(\log )$ & $0.072^{* * *}$ & $0.072^{* * *}$ \\
& $(0.016)$ & $(0.016)$ \\
Working hours general qualification $(\log )$ & $0.107^{* * *}$ & $0.101^{* * *}$ \\
& $(0.015)$ & $(0.016)$ \\
Working hours high qualification $(\log )$ & $0.191^{* * *}$ & $0.202^{* * *}$ \\
& $(0.016)$ & $(0.017)$ \\
Real capital compensation $(\log )$ & $0.587^{* * *}$ & $0.586^{* * *}$ \\
& $(0.017)$ & $(0.017)$ \\
Controls for gender & No & Yes \\
Controls for average experience & No & Yes \\
Controls for average working time & No & Yes \\
Controls for labour turnover & No & Yes \\
Controls for age structure & No & Yes \\
Constant & $3.088^{* * *}$ & $3.071^{* * *}$ \\
& $(0.115)$ & $(0.607)$ \\
\hline Observations & 642 & 642
\end{tabular}

Standard errors in parentheses. Reference period 1991-2005.

${ }^{*} p<0.1,{ }^{* *} p<0.05,{ }^{* * *} p<0.01$. 


\section{Life-cycle earnings patterns in VET}

\subsection{Introduction 1}

Countries differ with respect to their education systems, which determine the supply of human capital to firms in an economy. While initial vocational education is an important component of education systems in several industrialised countries, other countries mainly emphasise the provision of general education. Among those countries with an elaborate vocational system, notable differences exist concerning the way skills are formed. While some countries focus predominantly on school-based vocational education, others feature a system of combined school- and work-based vocational education and training. The work-based component varies in those systems, and is highest for apprenticeship forms of vocational education and training (dual system), as found in Germany and, to a somewhat lesser extent, in the Netherlands. An example of a country with a mainly general education system is the United Kingdom. Although apprenticeships have a long history in that country, they play a less important role quantitatively.

The aim of the chapter is to analyse differences in earnings of individuals that have participated in different educational (i.e. a general or vocational) programmes. One motivation for doing so is that several authors call into question the appropriateness of vocational systems of education for generating the skills needed in a modern economy. Their reasoning is that the structural change away from traditional crafts and industries toward services and, more broadly, the move to a knowledge-based economy require more systemic and theoretical knowledge and skills, which allow for more flexibility in rapidly changing labour markets (Bowman 1993, Baethge et al. 2006). The authors argue that education systems providing general qualifications better meet the demand of firms operating in restructuring economies (Heidenreich 1998). Adding to that argument, figures published by the OECD (OECD 2008) show that in countries with elaborate vocational systems, expenditures for students in vocational education are much higher than for students in general education programmes. While this applies to Austria, Germany and

\footnotetext{
${ }^{1}$ This chapter is based on the paper: High and steady or low and rising - Life-cycle earnings patterns in vocational and general education by Frank Cörvers, Hans Heijke, Ben Kriechel and Harald Pfeifer. A short version of the paper is published as: Chapter 47 in Investigaciones de Economía de la Educación, 2010, vol. 5, pp. 931-948 from Asociación de Economía de la Educación (Cörvers et al. 2010). An extended version is available from the ROA-Research Memorandum Series (Cörvers et al. 2011)
} 


\section{Life-cycle earnings patterns in VET}

Switzerland, costs for general programmes exceed those of vocational programmes in the Netherlands. The question to be posed is whether vocational education generates high costs without offering corresponding benefits, especially for economies undergoing rapid technological change.

Costs of educational programmes, as published by the OECD, are relatively straightforward to measure. However, costs are only one part of the story. Before judging the efficiency and effectiveness of different educational pathways, one also needs to thoroughly consider the benefit side of such pathways. The attainment of an upper-secondary certificate by students who are more practically oriented and who would otherwise not obtain any qualification at all is one example of such benefits (see for example Gangl 2002). The close tie to firms and labour markets, especially in dual systems, offers greater chances of employment in comparison to those available to persons without an upper-secondary qualification.

The present chapter focuses on earnings after having undergone upper-secondary vocational or general education. We compare experience-earnings profiles for workers from each educational track under the hypothesis that initial earnings and the subsequent experience-earnings curves for the two groups differ. We argue that young adults opting for vocational programmes become specialists during the programme. The match between acquired and required skills already improves during the educational phase, which is not the case for young adults following a more general education path. For the generally educated, we expect that the lack of specialisation and work experience will translate into lower initial productivity and thus lower initial earnings compared to vocationally educated workers. Following this logic, the greater the share of occupation-specific training in the programme, the better the initial match and the higher the initial earnings. On the other hand, general education delivers a broad body of general knowledge that is the foundation for efficiently adapting to changing jobs over the course of their careers and for responding rapidly to technological change (Goldin 2001). Thus, over time, generally educated workers also reach their optimal productivity level by learning on the job, by participating in continuing vocational training activities, or by changing jobs and occupations. Because this broader foundation is likely to offer more opportunities to increase productivity later on in working life, one result of our analysis may well be that the wage curves of the vocationally and the generally educated intersect at some point over their working lives, and that the generally educated reach a higher earnings level than their vocationally educated fellow workers.

In our analysis, we concentrate on workers with qualifications at the upper-secondary level. Workers with either higher (i.e. tertiary) or lower level education are not included in the analysis. The reason for this focus lies in the fact that workers at this level form the largest part of the workforce in the three reference countries. This intermediate qualification level encompasses workers who are an important factor in driving production and growth in an economy. Estimates based on the European Labour Force Survey (EU- 
LFS) show that in Germany over 60 per cent of the workforce between 15 and 64 years of age has earned a qualification at upper-secondary level. In the Netherlands and the United Kingdom this share is somewhat lower (45 per cent), but still much higher than that of the respective groups at either lower-secondary or tertiary level2.

The contribution of the chapter to the literature is twofold. First, the chapter offers interesting results on the role of different types of upper-secondary level education programmes (i.e. vocational and general) for life-cycle earnings. Although a number of studies exist that estimate wage effects of vocational qualifications for Israel and the United States (Neuman and Ziderman 1991, 1999; Hotchkiss 1993; Meer 2007), evidence for European countries is rare. Second, by conducting the analysis for three different countries, we contribute to the ongoing debate on the benefits of vocational education and training systems in an international context, as put forward e.g. by Gangl (2000).

For the analysis, we use mixed-effects models that to the best of our knowledge have not been used before in estimating the impact of different educational programmes on earnings. Although we cannot rule out that selection into education programmes and the labour market might introduce a bias in our results even when narrowing down the comparison groups, we do offer a number of robustness checks and discuss the inclusion of an additional control variable to validate our results.

The results show that, in accordance with our main hypothesis, vocationally educated have initially higher earnings compared to generally educated workers. The earnings difference is strongest in Germany and somewhat weaker but still significant in the United Kingdom. In these two countries, the expected catching-up process also takes place so that earnings profiles cross after about 8 years of labour market experience. In the period thereafter, the generally educated reach a higher level of earnings. This result, however, is not significant for the Netherlands, where neither any earnings advantages for vocationally educated workers nor catching-up processes seem to exist. Part of this result might be due to the small sample size for this country.

The remainder of the chapter is structured as follows. After giving a short overview on theoretical aspects and on the literature in Section 2, in Section 3 we discuss education systems in the three countries of reference. In Section 4, we describe the data sources chosen for the analysis. The estimation of age-earnings profiles is done in Sections 5 and 6 via simple OLS earnings equations and mixed-effects linear regression models. The last section offers an overview on the main results and draws conclusions from the analysis.

\subsection{Literature and theoretical aspects}

The hypothesis of differences in life-cycle earnings patterns for vocational and general education touches upon several strands of literature. First, the relation between education and earnings is one of the most popular topics in economic literature since the seminal

\footnotetext{
${ }^{2}$ The shares refer to the year 2007. Source is the Eurostat data base New Cronos.
} 


\section{Life-cycle earnings patterns in VET}

works of Becker (1964) and Mincer (1958, 1974). An overview of methods and applications estimating returns to education based on the ideas of Mincer can be found in Grossbard (2006). Second, literature about job matching is relevant for the analysis presented in this chapter, since we argue that the shape of experience-earnings profiles reveals information about the matching of individual skills and the job requirements of firms. Concerning the latter, the importance of job characteristics for productivity and earnings has been stressed by Thurow (1975) in his job competition model. Bringing both supply and demand of skills together has been the aim of job-matching theory, which has been advanced by authors like Jovanovic (1979) and Hartog (1992).

An impressively large amount of studies deal with the estimation of the experiencetenure-earnings profile (see e.g. Altonii and Shakotko 1987, Topel 1991, Williams 1991, Altonji and Williams 2005 and Dustmann and Meghir 2005). van Eijs and Heijke (2000) develop a theoretical model in which earnings-tenure profiles are derived. Initial earnings give an indication of the quality of the match at the beginning of a job. In this framework, training "on-the-job" is used to decrease the mismatch between acquired and required skills, whereas the costs for training are mainly shifted to the worker who receives lower wages at the beginning of his career. Estimating earnings functions by occupational level and occupational field, they conclude for the Netherlands that academic graduates have a comparative advantage in complex jobs and those with a low educational level have a comparative advantage in low-level jobs. The same is concluded for workers with a medium level of education, i.e. for this group of workers, too, there is evidence of a comparative advantage over differently qualified workers in the same type of (intermediate level) jobs.

Building upon a contribution by Willis and Rosen (1979) and extending the methodological and thematic scope, Meer (2007) analyses the effect of track choice (general vs. academic vs. technical vs. business) on earnings. Meer concludes that "the evidence points to comparative advantage in track selection: those on the technical track are best off there, and those on the academic track are best off following that path" (p.572). Thus, the supply of different tracks seem to be beneficial for differently 'gifted' students. Fersterer et al. (2008) analyse the returns to apprenticeship training in Austria. The authors find wage returns of about the same size as returns to other forms of education, such as school-based education in colleges. Also Neuman and Ziderman (1991, 1999) and Hotchkiss (1993) estimate the effects of secondary vocational training on the wage received and find mixed results. While Neuman and Ziderman find a positive and significant impact on wages for Israel, Hotchkiss finds no significant effects for the US. An important point made by several authors is that individuals differ with respect to ability, social background and interest, and that these differences need to be taken into account when analysing earnings of differently qualified workers.

Yet another strand of literature analyses institutions and their role in the matching processes in the labour market. Marsden and Ryan (1986) and Marsden and Ryan (1991) 
point out the importance of education systems for labour market integration of young adults. They broadly differentiate between two institutional arrangements, one with and one without strong apprenticeship systems. The resulting labour markets are either internal labour markets (ILM) or occupational labour markets (OLM). The key difference between the two is the presence of an education and training system providing occupationspecific skills, thus transforming the stratification system from an internal labour market type into an occupational labour market system. Gangl (2000) argues that

"the structure of the education and training system is a key factor in determining the nature of the stratification system, resulting in two distinct institutional equilibria of particular types of training systems and thus in specific patterns of stratification. More specifically, it is the relative reliance of market matching processes on formal education versus experience and mobility, which is at stake here. In the context of vocationally specific and occupationally relevant initial training, the education and training system performs an effective presorting of individuals and allows for a stratification system based on certified skills. In the absence of such training systems, matching processes have to rely relatively more on experience and mobility, thus yielding a different type of stratification system" (p.3).

A recent study by Hanushek et al. (2011) on life-cycle employment patterns of vocationally and generally educated workers supports the assumed initial employment advantages of VET workers. However, especially for countries with strong apprenticeship systems, the authors find that vocationally educated workers tend to leave the labour market earlier and thus lose at least part of their initial employment advantage.

The cited literature points towards an important aspect that needs to be taken into account when analysing age-earnings profiles: education systems and labour markets are institutions that interact with each other. The way education is organised in a country influences the quantity and quality of skills offered on the labour market. Firms, in turn, adjust their organisational structure and business strategies to the amount and type of human capital "available" on the labour market. In our case, Germany and the Netherlands are examples of an occupational labour market (OLM) arrangement, while the United Kingdom can be classified as an internal labour market (ILM) arrangement. The general question that emerges is whether different systems result in different labour and product market outcomes. While works of by authors cited above and others focus mainly on the role of vocational education and training in the employment (unemployment) outcomes and further labour market careers of young adults, the task of this chapter is to analyse earnings differences between differently qualified workers over the life cycle in different educational systems. 
A central assumption is that earnings reflect upon the productivity of workers and that therefore experience-earnings profiles may be used to obtain an indication of the quality of the initial match between acquired and required skills and the development of productive capacities over the working lifetime 3 . The quality of the initial match is related to the earnings received at the beginning of a labour market career. Along the dimension of labour market experience, earnings are assumed to increase due to on-the-job learning and continuing vocational training (Gustman and Steinmeier 1982; Meyer 1982). Over time, however, the assumption is that the slope of the experience-earnings curve declines, indicating that on-the-job training and especially formal training becomes less attractive, the older and hence the closer to retirement workers are. Overall, we expect a concave experience-earnings profile for both vocationally and generally educated workers.

Figure 3.2.1.: Hypothetical experience-earnings profiles

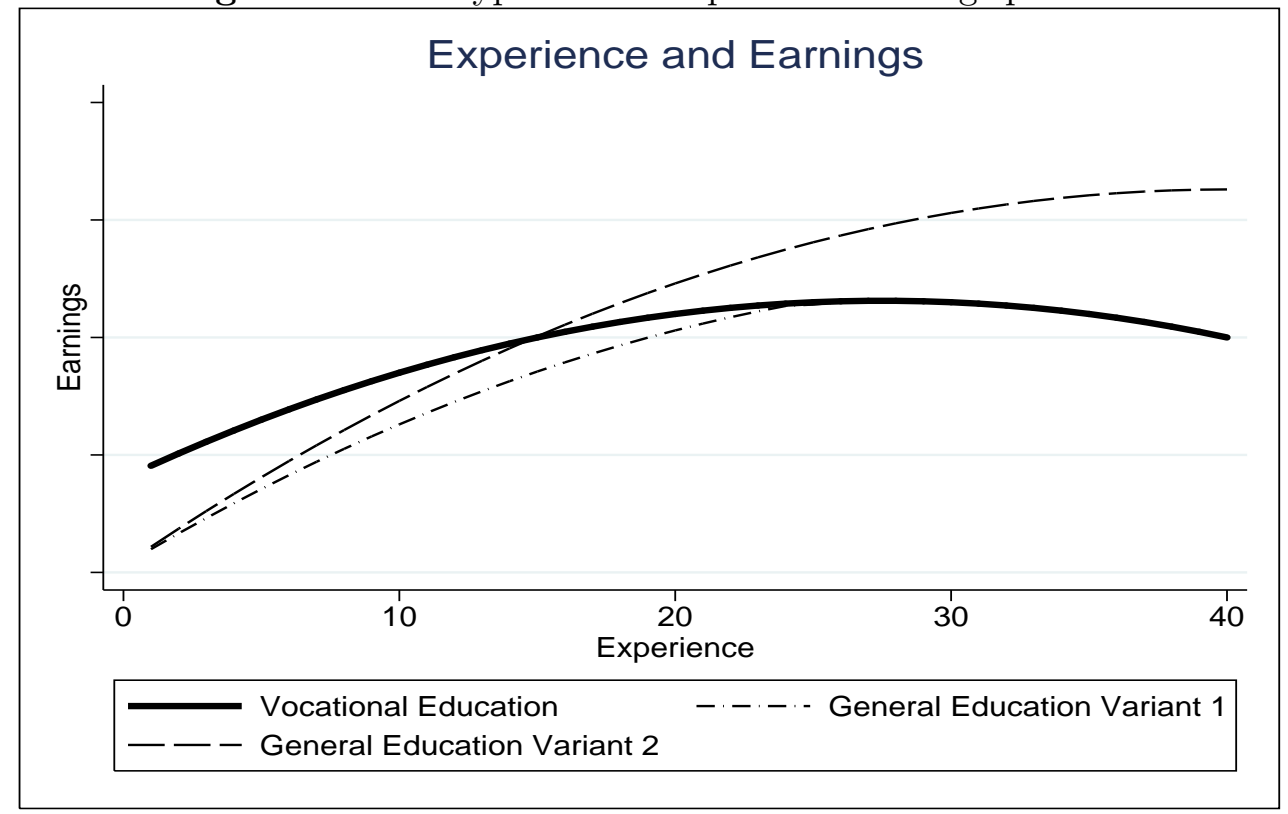

Differences in initial earnings and the shape of the experience-earnings curves can have the following explanation: although both groups of workers have obtained an education at the same (upper-secondary) educational level and consequently have invested the same amount of time in their education, the track choice differs. Whether the initial difference persists over time depends on the relationship between experience and earnings over time. The experience-earnings curve is assumed to rise more steeply, the more productive a worker becomes. The increase in productivity (and thus in earnings) stems from

${ }^{3}$ The assumption that earnings reflect the productivity of workers is not unchallenged. Several authors (Acemoglu and Pischke 1998, 1999a, Booth and Zoega 2004, Brunello 2002) claim, for example, that wage compression (i.e. the gap between productivity and earnings that increases with the amount of human capital) is an important feature of many industrialised economies and explains the investment of firms in general human capital. Dearden et al. (2006) show that productivity increases induced by training exceed the earnings gains for the training participants. However, for the analysis in this chapter it is sufficient that productivity and earnings are monotonically positive related i.e. highly productive workers earn more than less productive workers. 
the acquisition of additional human capital through on-the-job learning and continuing vocational training. According to our argument, we expect higher initial earnings for vocationally trained workers and a catching-up process for generally educated workers thereafter, as shown in Figure 3.2.1. In the first scenario shown in the graph (Variant 1), the curve of the generally educated converges to the curve of the vocationally educated. The convergence implies that the generally educated reach the productivity level of the vocationally educated after some time in the labour market, e.g. by way of on-the-job training. The optimum of productivity and earnings is similar for the two groups. In the second scenario, the curve of the generally educated rises more steeply than in Variant 1 and intersects with that of the vocationally educated at some point over the working lifetime. A catching-up process takes place and at some point the generally educated become more productive than the vocationally educated (Variant 2). Whether either group has an advantage over the other depends on the point in time at which the two curves intersect. Assuming that the initial ability of both groups is controlled for, Variant 2 contains an important message, namely that general education, ceteris paribus, leads to a higher productivity level than vocational education. The reason for higher productivity could be that the ability for learning throughout the working lifetime differs between the two groups and that on-the-job training is more effective for generally educated workers. Finding a potentially higher productivity level in generally educated workers does not, however, necessarily mean that vocational education is inferior to general education, because the initial earnings advantage may still offset the gains obtained through a higher productivity level later in the career. To understand how general and vocational education is organised in the three reference countries, the following section offers a short overview over the respective education systems.

\subsection{Education systems}

\subsubsection{Germany}

Full-time education in Germany is compulsory between the ages of six and sixteen (or fifteen, depending on Land) and part-time education is compulsory until the age of eighteen for those, who do not attend a full-time school. Already by the age of ten, most students are channeled into three secondary school types with the Hauptschule lasting another five years, the Realschule six years and the Gymnasium eight to nine years of full time education. Regardless of the school type attended, students have the option of starting vocational education (either school-based or dual) after completion of either of the school types or continuing in education at the next school type up in the system (e.g. transition from Hauptschule to Realschule or from Realschule to Gymnasium). Only those who obtain a leaving certificate from the Gymnasium gain access to university. Those 
who complete at least the twelfth year (out of usually thirteen) in the Gymnasium may enter the Fachhochschule (polytechnical university).

Concerning the organisational aspects of education, there is a clear distinction between general education, full-time vocational education in schools and the apprenticeship system. General schools and vocational schools are separate institutions under separate administration. Part-time vocational schools in apprenticeship training, on the other hand, are institutionally integrated with full-time vocational schools. Both are under the responsibility of the Länder. The contents and regulation of apprenticeship training within the firm is determined on the federal (central government) level.

More than two-thirds of a cohort (2004) of school leavers finish school after lowersecondary education (usually at the age of sixteen) with a general leaving certificate from the Hauptschule or with an advanced leaving certificate from the Realschule. The vast majority of these (around 65 per cent of a cohort) starts a vocational training programme directly after leaving school. Most of them (around 50 per cent of a cohort) start an apprenticeship in the 'dual system' that combines training in a company with education in a part-time vocational school. About fifteen per cent of the cohort enters full-time vocational schools (Berufsfachschulen). The typical age of students beginning initial vocational education and training (VET) by starting either an apprenticeship or a schoolbased vocational education programme is between sixteen and twenty years, whereas average entrance age has been increasing over the last two decades.

\subsubsection{Netherlands}

In the Netherlands, school attendance is compulsory until the age of sixteen. Between the ages of sixteen and eighteen, there is a partial compulsory education (partiële leerplicht), meaning that a student must attend some form of education for at least two days a week. Access to the senior secondary vocational education MBO (middelbaar beroepsonderwijs) is granted for those who have completed at least the first phase of (general) secondary education. Three types of secondary education exist: junior general and pre-vocational education (voorbereidend middelbaar beroepsonderwijs, VMBO) with a duration of up to four years, senior general secondary education (hoger algemeen voortgezet onderwijs, HAVO) with a duration of five years and pre-university education (voorbereidend wetenschappelijk onderwijs, VWO) with a duration of six years. All three types of secondary education begin their programme with a period of basic secondary education (basisvorming) during which all students study a similar range of subjects (although possibly at different levels), whichever their type of school. The duration of this period varies from one type of school to another, but is at least two, and usually three years. After completing VMBO at the age of sixteen, students can enter the vocational system of MBO. Students who have completed the theoretical programme within VMBO with high average grades can alternatively enter senior general secondary education (HAVO). The most common access to the MBO, however, is via VMBO. 
Two learning pathways exist within MBO. The block- (or day) release pathway BBL (beroepsbegeleidende leerweg) and the vocational schooling pathway BOL (beroepsopleidende leerweg). BBL is a learning pathway, which comprises at least 60 per cent training in a company, and the rest at a school4. Students sign a contract with the company where they receive workplace training. This learning agreement specifies that the student both works and learns within the company. The BBL is very much related to the German form of apprenticeship system. BOL, on the other hand, is a more theoretical pathway with a share of practical occupational training of between 20 and 60 per cent of the students' time. Generally, it is possible to attend any training in the qualification structure through both pathways. With respect to the relative importance of the vocational system in the Netherlands, close to 70 per cent of all students in upper-secondary education are enrolled in vocational programmes, of which close to 20 per cent follow an apprenticeship programme in the BBL (OECD 2008).

\subsubsection{United Kingdom}

Schooling in the United Kingdom is compulsory from age five to sixteen. All publicly funded schools must provide the National Curriculum. At the age of sixteen most students take public examinations, the General Certificate of Secondary Education (GCSE) (level 2) in England, Wales and Northern Ireland and the Standard Grade in Scotland. GCSEs are normally taken in a range of single subjects, and a certificate is issued listing the grade achieved in each subject. After completion of compulsory education in secondary schools, young people may choose to continue in school, move to a sixth-form college or further education (FE) college, enter an apprenticeship or enter employment.

Students remaining in education at a school or a college may choose between general (academic) and vocational subjects or take a mixture of the two. Normally, the uppersecondary phase lasts two to three years, from age sixteen to eighteen or nineteen. The dominant qualifications are the General Certificate of Education (GCE) A-levels (level 3). A-levels are elective single subject qualifications, which students choose on the basis of GCSE qualifications, interest and intended destination. Students are encouraged to study up to five subjects in the first year of post-secondary education, and upon completion they are awarded the GCE Advanced Subsidiary (AS) qualification. Those who continue in the second year study more demanding units in three of these five subjects in order to obtain the full GCE A-level on successful completion.

Vocational education may be undertaken at secondary school, or at an FE college, or with other training providers, where two forms of vocational education exist: first, schoolbased vocational education is undertaken either at school (for those aged up to eighteen) or at a FE college (for those aged sixteen and older). Successful completion could lead to direct employment or to further training, within a FE college or with another training

\footnotetext{
${ }^{4}$ In a number of BBL programmes, participants go to school only one day in a working week.
} 


\section{Life-cycle earnings patterns in VET}

provider. Second, programmes of specific training are undertaken at a FE college and allow entry to a particular trade or profession (such as hairdressing, construction trades, etc). This form of education is a blend of both initial and continuing vocational training. Within the UK, there is no unified VET structure. Historically, VET has developed in an ad hoc way rather than through central planning (CEDEFOP, 2008). Nonetheless, VET provision can be summarised according to the various contexts within which it takes place. With respect to the relative importance of vocational education and training in the United Kingdom, the OECD reports about 40 per cent of students in upper-secondary education to be enrolled in a vocational education programme. The share of those in programmes combining school and work (like apprenticeships) is considered to be rather small, especially when compared to the Netherlands and Germany.

\subsubsection{Common aspects}

To compare labour market outcomes in different countries, in this case the earnings of workers, it is useful to pin down the common features and main differences between education systems 5 The education systems of all three countries feature compulsory education at least until the age of sixteen. At this stage, students in the three countries have different options for continuing their educational career. One alternative, which is not unusual in the United Kingdom but less frequent in Germany or the Netherlands, is to leave the formal education system and enter the labour market. Those remaining in the formal education system have the choice between either more general education or vocational education with varying shares of company-based training. In Germany this share is largest with students spending about two days of their week in vocational schools and three days at the workplace. The same holds for the BBL programmes in the Netherlands. The BOL participants, however, have considerably lower shares of companybased training. In the United Kingdom, vocational programmes generally contain lower shares of company-based training (except for apprenticeships).

For students remaining in the general system, the aim is to gain an upper-secondary qualification that opens the way to tertiary education. Once achieved, however, students of the three countries (again) have the choice between continuing into formal tertiary education or entering employment. In contrast, for the vast majority of those opting for a vocational path at the age of sixteen, the usual route is to enter the labour market after obtaining an upper-secondary vocational qualification.

In this chapter, the focus is especially on workers who have obtained an upper-secondary qualification either by following a vocational or a general educational programme. Workers who have obtained either no upper-secondary education at all, or who have gone on to obtain tertiary qualifications after finishing upper-secondary education, are excluded from our analysis.

\footnotetext{
${ }^{5}$ For a detailed description of each system see previous chapter.
} 


\subsection{Data and variable construction}

The data source for Germany is the socio-economic panel (GSOEP) 6 The GSOEP started in 1984 as a longitudinal survey of private households and persons in the Federal Republic of Germany. From 1990, an additional sample was launched covering the eastern part of Germany. The central aim of this panel study is to collect representative micro data on persons, households and families, covering variables in education and training, labour market and occupational dynamics, and earnings. For our comparative approach, variables of earnings and education as well as personal-level and firm-level information have been extracted. Due to the requirement of a comparative reference period, the GSOEP data set has been restricted to the years 1991 to 2006.

For the analysis in the Netherlands, the data used has been produced by the Institute of Labour Studies (OSA). OSA conducted a survey every two years to collect data about the (potential) labour force in the Netherlands 7 The first wave of the OSA Labour Supply Panel was carried out in 1985. Subsequent surveys have taken place every two years (from 1986 to 2006). The survey asks about respondents' employment situations and their behaviour on the labour market. Further, information about education and earnings is gathered.

For the United Kingdom, the British Household Panel Survey (BHPS) is an appropriate data source for our analysis 8 Like its German and Dutch counterparts, the BHPS is a representative multi-purpose panel study. It started in 1991 and has been conducted since on a yearly basis. From this panel survey, rich information on the labour market situation, earnings and education and further personal and firm-level information can also be obtained. Similarly to the German panel, data from 1991 to 2006 is used for the estimation of earnings-profiles.

When using data from different countries, one needs to be cautious about constructing a common set of variables for comparative analysis. It must be ensured that variables mirror the same information across countries. This is especially true for variables reflecting specific national frameworks. One example is the variable used to distinguish between workers who have obtained either vocational or general qualifications. In the case of Germany and the Netherlands, the strict division of vocational and academic pathways inherent to the education systems simplifies the work. Here, a generated variable on the CASMIN classification offers an easy way to distinguish former students of each educational pathway (Brauns and Steinmann 1999). This is not so straightforward in the case of the United Kingdom. Both vocational and general qualifications may, for example, be obtained in FE colleges. The identification strategy was first to determine those workers with a highest educational attainment at the upper-secondary level, and then to use further information on the type of qualification obtained, i.e. whether it was vocational

${ }^{6}$ See Wagner et al. (2007) for a detailed description of the panel data set.

Fouarge et al. (2006) supplies detailed information about the OSA data source.

${ }^{8} \mathrm{~A}$ detailed documentation of the data source is given by Tavlor et al. (2010). 


\section{Life-cycle earnings patterns in VET}

or general.9 The earnings variable is the gross hourly real wage in Germany and the United Kingdom. For the Netherlands, hourly net wages are the only information available. For the estimation of wage profiles, we extracted several comparable variables, such as gender, age and firm size, directly from the respective panel data sources. Concerning economic branch and occupation the international classifications NACE and ISCO were used for Germany and the United Kingdom. For the Netherlands, the respective national classifications based on NACE and ISCO were used.

Tables A3.1 to A3.3 in the Appendix display the descriptive statistics for a number of relevant variables separately for generally and vocationally educated workers. It is important to note that, especially in Germany, the group size (and thus the number of observations) for workers with general education is relatively small. This reflects the fact that most of the students gaining upper-secondary qualifications either continue to university or at least follow a 'high-quality' apprenticeship (e.g. bank clerk, technician or middle manager). Further, generally educated persons entering the labour market are, on average, much younger and consequently have much lower values for experience. This is different for the United Kingdom and the Netherlands. Here, the two reference groups are more homogeneous with regard to these characteristics. However, since age is controlled for in our regressions, this asymmetry should not affect our results. For the analysis, we pooled those waves of the panel data sources that were available at the time of writing this chapter. For the GSOEP, this comprises all waves from 1991 to 2006. For the OSA panel, waves 2000 to 2006 were available. Prior waves do not directly allow for any differentiation between vocational and general qualifications. As in the case of the GSOEP, waves 1991 to 2006 were used for the BHPS.

As described above, we restrict our sample to workers who have obtained an uppersecondary qualification either through a vocational or a general type of educational programme. Our assumption is that those two groups of workers are comparable with regard to unobservable characteristics responsible for selection into different tracks and labour market outcomes. One component of our strategy to control for selection is thus to narrow down the samples to persons having similar levels of ability or a similar social background. Those workers who have either not attained upper-secondary education or who have completed tertiary education are removed from the data sets.

Further, we restricted the data to persons between 18 and 64 years of age. The lower age limit is chosen because most workers entering the labour market with an upper-secondary qualification are 18 or older 11 A higher age limit would endanger the capturing of initial wages, which is central for our reasoning. We drop those observations that have a missing

\footnotetext{
${ }^{9}$ The variable is generated by ISER and has been derived using several other education variables and mirrors whether the respondent has obtained a vocational qualification.

${ }^{10}$ Although tenure is described in the table, it is not used in the regressions due to potential endogeneity problems. However, simulations including tenure and tenure interactions showed that the inclusion of these variables in the regression would not significantly alter the results.

${ }^{11}$ In Germany and the Netherlands, education is compulsory until the age of 18 , while the corresponding age in the United Kingdom is 16.
} 
value in the wage or one of the control variables. In the pooled data sets we are left with around 70000 observations for Germany, around 2500 observations for the Netherlands and nearly 40000 observations for the United Kingdom. Whereas the sample size for Germany and the United Kingdom is relatively large, the low sample size for the Netherlands should be kept in mind when interpreting the subsequent estimation results.

\subsection{Estimating wage-experience profiles}

\subsubsection{Pooled OLS regression}

We first estimate a simple OLS model for each pooled data set of the three countries. To do so, we regress log hourly wages on a set of explanatory variables. The subscript $i$ denotes the observation of an individual $j$ in the respective year. The equation has the form

$$
\begin{aligned}
& y_{i}=\beta_{1}+\beta_{2} v_{o c}+\beta_{3} \exp _{i}+\beta_{4} \exp _{i}^{2}+\beta_{5} v_{0} * \operatorname{cxp}_{i} \\
& +\beta_{6} \operatorname{voc}_{i} * \exp _{i}^{2}+\beta_{7} X_{i}+\epsilon_{i} .
\end{aligned}
$$

where $X$ is a vector of further control variables. The estimation results of the baseline model with $X$ containing merely the individual characteristic gender and time dummies are shown in Table A3.4. For Germany, the coefficient of voc is positive and significant, indicating higher initial wage for vocationally educated. At the same time, the interaction of $v o c$ with experience is significantly negative, supporting a catching-up process for the generally educated over time. For the Netherlands, the respective coefficients tell a similar story, though at a significance level of 5 per cent. For the United Kingdom, initial wage differences between the two groups of workers are not significant. The negative and significant coefficient of the interaction term $v o c^{*} e x p$, however, indicates a faster wage growth for the generally educated.

The graphical display deducted from the regressions (shown in Figures A3.1 to A3.3 in the Appendix) is very similar to Figure 3.2.1 with Variant 2 representing the wage profile for the generally educated group. In both the hypothetical and the empirical figures an initial wage advantage of vocationally educated workers disappears after the first few years in the labour market. Afterwards, generally educated workers have higher wages than vocationally educated workers. Note that Figures A3.1 to A3.3 as well as all subsequent figures have been standardised to make a comparison of the magnitude of the differences and the progression of the curves easier.

Since the purpose of the pooled OLS models is to gain a first impression of the direction and size of the relationships, we at this stage refrain from discussing results from models containing a larger set of control variables, such as firm size, job type and industry of the 
firm. The results of such a model are, however, displayed in the separate appendix on robustness analysis (see Table A3.5 in the Appendix).

\subsubsection{Mixed-effects linear regression model}

The estimates presented above do not account for the fact that most individuals are observed for more than one time period. Consequently, the observations $i$ in the pooled data set are not necessarily independent from each other. Observations of the same individual are likely to be correlated, which could be partly due to between-person heterogeneity in the intercept (i.e. initial wage) and partly due to the slopes of covariates (Rabe-Hesketh and Skrondal 2008). Moreover, the two groups might still differ not only in their observable characteristics, but also with respect to unobservable factors, like social background, motivation, interest or ability. The unobserved heterogeneity may play a role for both the decision to follow a vocational or general educational track and the subsequent wage profile. As pointed out in the previous section, one component of our strategy to reduce potential selection problems is the narrowing down of the sample to workers that have achieved certification at the upper-secondary level. Those workers whose highest educational attainment is at the lower-secondary or primary level are removed from the sample. Further, workers who have achieved a tertiary degree are not represented in the respective data sets 12

We further develop a mixed-effects linear regression model that takes into account the differences in the intercept and slope of the wage-experience curve for vocationally and generally trained.

Building on equation 3.1, we start by describing a random intercept model with the random intercept $\theta_{1 j}$ and the residual $\epsilon_{i j}$ being the permanent and the transitory error component of the model (Rabe-Hesketh and Skrondal 2008) 13 . Since we now take advantage of the panel structure of the data, we use $i$ as the subscript of an individual observation, which is nested in the worker $j$.

$$
y_{i j}=\beta_{1}+\beta_{2} \exp _{i j}+\beta_{3} \operatorname{expx}_{i j}^{2}+\beta_{4} X_{i}+\theta_{1 j}+\epsilon_{i j}
$$

The random intercept $\theta_{1 j}$ and $\epsilon_{i j}$ are both assumed to be normally distributed with a mean of zero, independent of each other, with $\theta_{1 j}$ independent across persons and $\epsilon_{i j}$ independent across persons and observations. While the model above allows for worker-

\footnotetext{
${ }^{12}$ However, it cannot be ruled out that a share of workers with a highest educational degree at the upper-secondary level leaves the labour market to obtain a tertiary degree. Similarly, experience and wages could be simultaneously determined, i.e. there could be a problem of reverse causality. People getting higher wages (for whatever random or non-random reason) might be more motivated to stay in the labour market and accumulate over time more work experience.

${ }^{13}$ In a fixed-effects approach $\theta_{1 j}$ is eliminated entirely from the model, which removes all time invariant unobservable heterogeneity from the model. However, at the same time, the impact of observable time invariant variables on the dependent variable cannot be estimated directly either. Greene (2008) discusses advantages and problems involved when choosing mixed linear models in the context of wage regressions.
} 
specific intercepts, we can also model our assumption that wages of different workers have different slopes over time by adding a random coefficient of labour market experience $\theta_{2 j} * e x p_{i j}$. The model now has the form

$$
y_{i j}=\beta_{1}+\beta_{2} \exp _{i j}+\beta_{3} \exp _{i j}^{2}+\beta_{4} X_{i}+\theta_{1 j}+\theta_{2 j} * \exp _{i j}+\epsilon_{i j}
$$

To assess, whether there are systematic differences between vocationally and generally educated workers we add a dummy variable voc to the fixed part of the model. Further, to trace the differences between the vocationally and the generally educated over the dimension of experience, we add the cross-level interaction term voc*experience. The finally estimated model yields

$$
\begin{aligned}
& y_{i j}=\beta_{1}+\beta_{2} \exp _{i j}+\beta_{3} \exp _{i j}^{2}+\beta_{4} X+\beta_{5} v_{0 c_{i}}+\beta_{6} v_{0 c} * \exp _{i j} \\
& +\beta_{7} \operatorname{voc}_{i} * \exp _{i j}+\theta_{1 j}+\theta_{2 j} * \exp _{i j}+\epsilon_{i j} .
\end{aligned}
$$

Estimation results shown in Table 3.5.1 generally support those obtained on the basis of pooled OLS regressions. With respect to the coefficient of interest indicating the difference in initial wages (Vocational Education), it remains positive and significant in the case of Germany and the United Kingdom. For the Netherlands, however, the coefficient turns insignificant.

Table 3.5.1.: Mixed-effects linear regression model

\begin{tabular}{lrrr}
\hline Variable & Germany & Netherlands & United Kingdom \\
\hline \multirow{2}{*}{ Experience } & $0.0398^{* * *}$ & $\log ($ hourly wage) & \\
& $(0.004)$ & $0.0231^{* * *}$ & $0.0542^{* * * *}$ \\
Experience2 & $-0.0007^{* * *}$ & $(0.007)$ & $(0.002)$ \\
& $(0.000)$ & $\left(0.0003^{*}\right.$ & $-0.0009^{* * *}$ \\
Vocational Education & $0.0631^{* * *}$ & 0.0088 & $(0.000)$ \\
& $(0.020)$ & $(0.063)$ & $0.0693^{* * *}$ \\
Voc*Experience & $-0.0150^{* * *}$ & -0.0033 & $(0.019)$ \\
& $(0.004)$ & $(0.007)$ & $-0.0118^{* * *}$ \\
Voc*Experience & $0.0003^{* *}$ & 0.0000 & $(0.002)$ \\
& $(0.000)$ & $(0.000)$ & $0.0003^{* * *}$ \\
Constant & $1.9855^{* * *}$ & $1.4245^{* * *}$ & $(0.000)$ \\
& $(0.088)$ & $(0.142)$ & $1.3809^{* * *}$ \\
& 72451 & 2500 & $(0.055)$ \\
\hline Observations & \multicolumn{3}{c}{39767} \\
\hline Standard errors in parentheses. Models also include controls for female workers, \\
part-time work, cohorts and time (not shown). $p<0.10,{ }^{* *} p<0.05,{ }^{* * *} p<0.01$.
\end{tabular}

Further, the negative and significant coefficient on the interaction between Vocational Education and Experience are significantly negative in Germany and the United Kingdom, supporting the notion that the slope of the wage-experience profile is less steep for the 
vocationally educated. Again, for the Netherlands, the respective coefficient changes compared to simple pooled OLS estimate and turns insignificant.

Figure 3.5.1.: Mixed-effects linear regression model for Germany

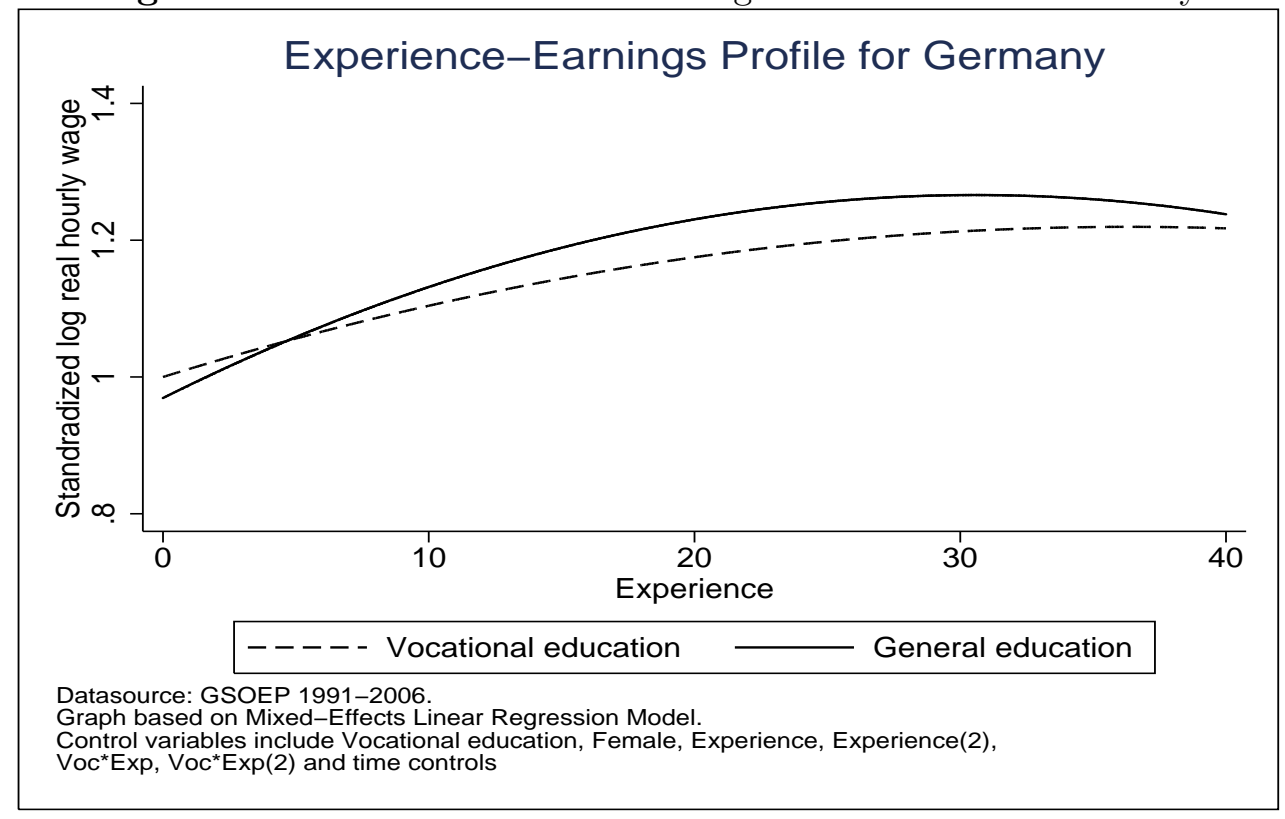

Comparing the graphical display for Germany (Figure 3.5.1) and the United Kingdom (Figure 3.5.3) suggests that both profiles (i.e. the one for vocationally educated as well as the one for generally educated) are somewhat steeper in the United Kingdom. This is in line with the notion of a comparatively strong wage differentiation or, conversely, with a more compressed wage structure in Germany. In both countries, the respective lines intersect, in Germany somewhat earlier (after 5 years) than in the United Kingdom (after 7 years). However, in the United Kingdom, the lines intersect a second time, late in the workers' labour market careers. Results for the Netherlands (Figure 3.5.3) differ from the other two countries to the extent that the differences between the two groups of workers are not statistically robust and thus not observable in the graph.

\subsubsection{Robustness of results}

A number of robustness checks are performed to examine, whether the results hold under different conditions. First, we estimate spline regressions on the pooled data (see Table A3.6). In this specification, we add a set of regressors in the form of experience splines interacted with vocational training. The effect of vocational training remains significant for Germany but are, similarly to the OLS baseline model, insignificant for the United Kingdom. Further, we estimated the mixed-effects linear regression model for the subgroup of workers with less than 20 years of experience (see Table A3.7). Again, for Germany the respective coefficients remained significant, whereas the coefficients for the United Kingdom turn out to be insignificant. The same result was obtained when including cohort 
Figure 3.5.2.: Mixed-effects linear regression model for Netherlands

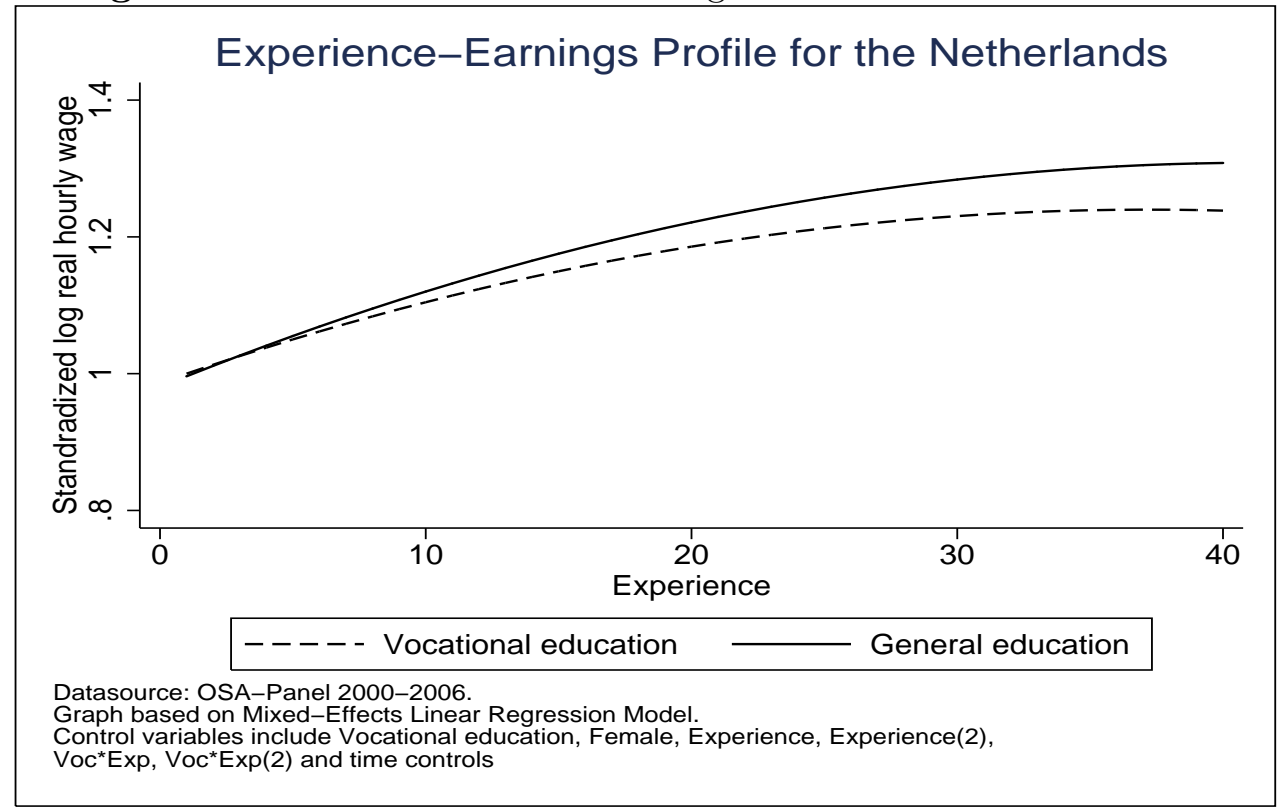

Figure 3.5.3.: Mixed-effects linear regression model for United Kingdom

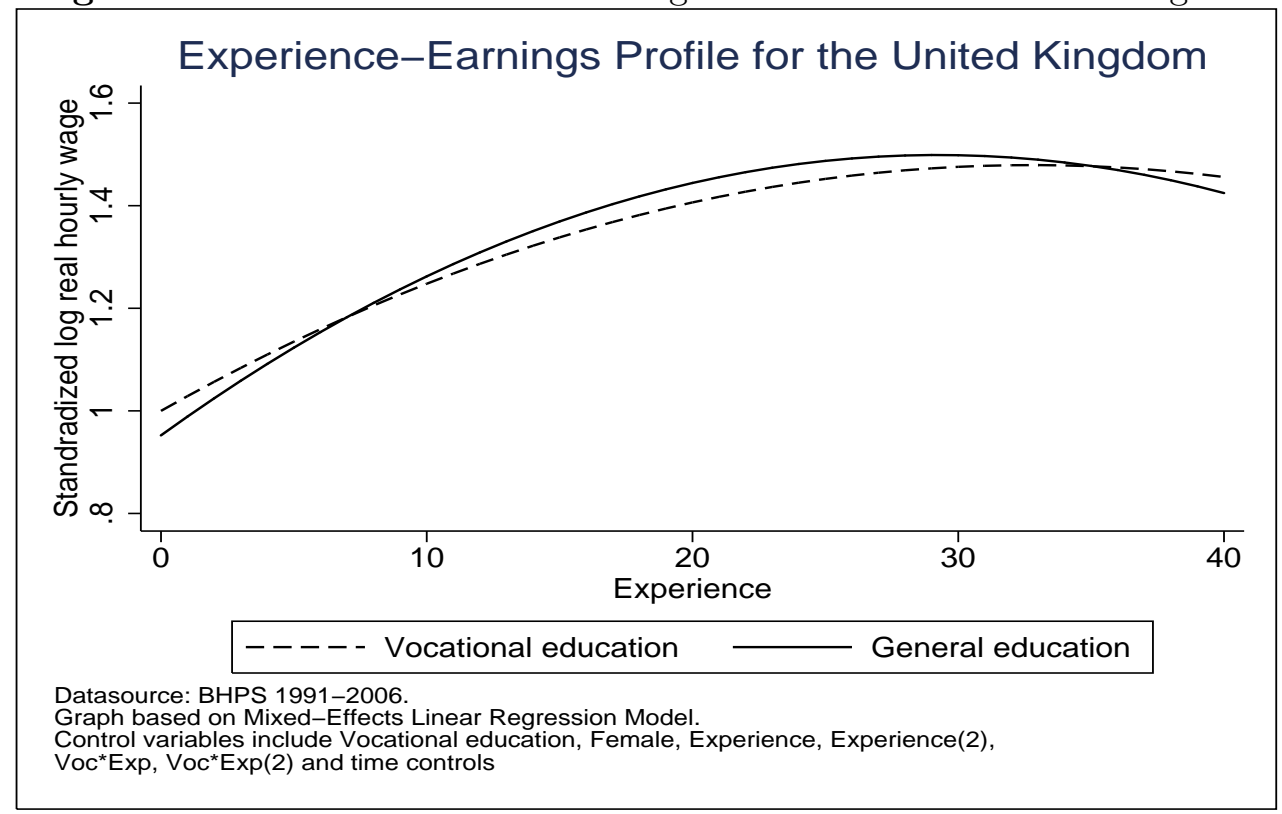


dummies (not shown). Thus, results for Germany are extremely robust while those for the United Kingdom seem sensitive to variations in the estimation method and model. On the whole, the results for the Netherlands remained insignificant for all alternative specifications and estimation methods.

To further investigate the ability problem discussed above, we followed an alternative approach, for which we construct an additional variable Cohort $*$ vocshare representing the share of vocationally educated among workers with an upper-secondary qualification in a cohort (i.e. the variable is constant for all workers belonging to the cohort). The results of the corresponding mixed-effects models and further explanations are given in in the Appendix (Table A3.8 and below). Although highly significant in Germany and the Netherlands, the inclusion of this control variable does not fundamentally change the results presented in this section.

In general, we need to point out that, despite the reduction of the sample and several robustness checks, selection into the educational programme and into the labour market is very likely to depend on unobserved characteristics. With the data at hand and the need to estimate the effect of a time-invariant variable (participation in a specific educational programme prior to labour market entry), controlling for unobserved heterogeneity is difficult. Thus, we refrain from claiming that the estimated coefficients reflect a causal relationship and rather interpret the wage differences as a description of observable labour market outcomes of the two groups of workers.

\subsection{Summary and conclusions}

In this chapter, we analyse wage-experience profiles of differently educated workers. We show that those workers who have undergone vocational education have higher wages at the beginning of their labour market career than those who have completed general education. The underlying hypothesis is that vocational specialisation paired with working practice improves the fit between job requirements and individual skills and therefore leads to a better initial match on the labour market. With increasing work experience, however, generally educated workers catch up in terms of productivity and wages due to informal and formal on-the-job training. The optimal productivity (and wage) level then may or may not differ between the two groups of workers. The countries for which the analysis is done have been chosen because of the differences in their education systems and labour market institutions. Germany and the Netherlands, on the one hand, are countries with an elaborate vocational education and training system and occupationally organised labour markets. The United Kingdom, on the other hand, is known for 'producing' mainly general skills and for featuring internal labour markets, in which experience and tenure 'sort' individuals to their labour market position.

Using panel data for all three countries, pooled OLS regressions supported the expectation of higher initial wages for vocationally educated workers in the three countries. At 
around six years of experience the wage curves intersect with those of generally educated. From there onward, the experience-earnings curve of the generally educated exceeds that of the vocationally educated. Results on the basis of a mixed-effects linear regression model show that this observation is statistically significant for Germany and the United Kingdom. For the Netherlands, however, the results reveal that initial earnings of the two groups of workers do not differ significantly. This is also the case concerning differences in the slopes of the respective experience-earnings curves. Despite narrowing down the comparison groups to workers with a highest educational attainment at the uppersecondary level and despite performing a number of robustness checks, we cannot claim to fully control for the selectivity into both education and the labour market. We thus need to take into account that the results obtained in this chapter are biased, most likely in favour of the generally educated.

Having a possible selection bias in mind, we interpret these results in the following way. Considering that in Germany the group of vocationally educated workers consists to a large extent of former apprentices with high shares of working practice, it is no surprise to find that the match between skills and job requirements is better than for generally educated workers. The earnings differential in favour of the vocationally educated is significant in this country. This result also is plausible considering the intense cooperation between unions, employer organisations and state authorities in defining the contents of vocational education and training. Employers have good knowledge about the competencies acquired by vocationally educated workers and tailor the requirements of jobs to be filled accordingly. In addition, around two-thirds of former apprentices are retained in the training firm, fostering a smooth transition from trainee to skilled worker. In the Netherlands, the share of graduates with apprenticeship training is somewhat lower and consequently the initial wage advantage of vocationally educated workers is less pronounced. Further, Dutch law requires all students enrolled in vocational programmes to be educated in a way that allows for a smooth transition to tertiary academic education. Although in practice, the number of those entering tertiary level after a vocational programme is rather small (though larger than in Germany), institutions and firms are likely to give general knowledge and skills a higher weight than in Germany. Although the respective coefficients are also large and significant for the United Kingdom, robustness checks show that the underlying relationship is not stable in this country.

Another result from the analysis is that generally educated workers overtake vocationally educated workers in their earnings after a certain period in the labour market. One reason for this result could be that general education focuses more on general problem-solving skills, which may create higher learning abilities throughout working life. However, further research is necessary to confirm this hypothesis since continuing vocational training and its effects on earnings were beyond the scope of this chapter. Finally, the chapter calls for a further differentiation by the type of vocational education and training in order to gain knowledge about the impact of the practical part of training on earnings. Our results do 
3. Life-cycle earnings patterns in VET

indeed suggest that this could be the case, since the largest earnings differences exist in a country with a strong apprenticeship system. 


\section{A3. Appendix}

\section{Descriptive statistics and pooled OLS regression results}

Table A3.1.: Descriptive statistics - Germany

\begin{tabular}{lcc} 
& General education & Vocational education \\
\hline & Mean & Mean \\
\hline Individual characteristics & 30.896 & \\
Age & 0.455 & 0.255 \\
Female & 0.545 & 0.571 \\
Male & 0.888 & 0.918 \\
National & 0.112 & 0.082 \\
Foreign & & \\
Employment characteristics & 12.980 & 13.068 \\
Hourly wage & 7.224 & 18.177 \\
Experience & 0.537 & 0.806 \\
Full-time work & 0.463 & 0.194 \\
Part-time work & & \\
Firm characteristics & 0.345 & 0.302 \\
Firm size $\leq 24$ & 0.252 & 0.281 \\
Firm size 25-200 & 0.190 & 0.213 \\
Firm size 200-1999 & 0.213 & 0.203 \\
Firm size $\geq 2000$ & & \\
Industry (NACE) & 0.007 & 0.020 \\
Agriculture & 0.001 & 0.006 \\
Mining and quarrying & 0.163 & 0.295 \\
Manufacturing & 0.006 & 0.013 \\
Electricity, gas and water supply & 0.041 & 0.097 \\
Construction & 0.148 & 0.157 \\
Wholesale and retail trade & 0.049 & 0.021 \\
Hotels and restaurants & 0.062 & 0.063 \\
Transport and communication & 0.048 & 0.039 \\
Financial intermediation & 0.135 & 0.046 \\
Real estate & & 00 \\
\hline
\end{tabular}


...continued from previous page

\begin{tabular}{lcc} 
& General education & Vocational education \\
\hline & Mean & Mean \\
\hline continuation Industry (NACE) & & \\
Public administration & 0.063 & 0.078 \\
Education & 0.090 & 0.022 \\
Health & 0.102 & 0.097 \\
Other services & 0.083 & 0.041 \\
Activities of households & 0.002 & 0.005 \\
Extra-territorial organisations & 0.002 & 0.001 \\
Job skill level (ISCO) & & \\
Senior officials and managers & 0.056 & 0.045 \\
Professionals & 0.207 & 0.028 \\
Technicians & 0.234 & 0.221 \\
Clerks & 0.155 & 0.143 \\
Service workers & 0.143 & 0.128 \\
Skilled agricultural workers & 0.001 & 0.015 \\
Craft and related trades workers & 0.059 & 0.246 \\
Plant and machine operators & 0.043 & 0.103 \\
Elementary occupations & 0.101 & 0.071 \\
\hline Observations & 2385 & 70066 \\
\hline Source GSOEP 1991-2006 & &
\end{tabular}


Table A3.2.: Descriptive statistics - Netherlands General education Vocational education

\begin{tabular}{|c|c|c|}
\hline & Mean & Mean \\
\hline \multicolumn{3}{|l|}{ Individual characteristics } \\
\hline Age & 38.751 & 39.392 \\
\hline Female & 0.560 & 0.460 \\
\hline Male & 0.440 & 0.540 \\
\hline Dutch & 0.958 & 0.971 \\
\hline Foreign & 0.042 & 0.029 \\
\hline \multicolumn{3}{|l|}{ Employment characteristics } \\
\hline Hourly wage & 10.581 & 10.272 \\
\hline Experience & 17.403 & 18.786 \\
\hline Full-time work & 0.610 & 0.690 \\
\hline Part-time work & 0.390 & 0.310 \\
\hline \multicolumn{3}{|l|}{ Firm characteristics } \\
\hline Firm size $\leq 20$ & 0.290 & 0.287 \\
\hline Firm size $\overline{2} 1-100$ & 0.253 & 0.246 \\
\hline Firm size 100-999 & 0.345 & 0.370 \\
\hline Firm size $\geq 1000$ & 0.109 & 0.094 \\
\hline \multicolumn{3}{|l|}{ Industry (SBI) } \\
\hline Agriculture & 0.016 & 0.014 \\
\hline Industry & 0.082 & 0.145 \\
\hline Building and Construction & 0.016 & 0.064 \\
\hline Wholesale and retail trade & 0.174 & 0.186 \\
\hline Transport and communication & 0.114 & 0.076 \\
\hline Material services & 0.208 & 0.121 \\
\hline Other services & 0.042 & 0.027 \\
\hline Public administration & 0.147 & 0.096 \\
\hline Education & 0.040 & 0.025 \\
\hline Health & 0.160 & 0.247 \\
\hline \multicolumn{3}{|l|}{ Job skill level (SBC92) } \\
\hline Elementary & 0.036 & 0.040 \\
\hline Low & 0.285 & 0.218 \\
\hline Middle & 0.436 & 0.562 \\
\hline High & 0.216 & 0.159 \\
\hline Scientific & 0.027 & 0.022 \\
\hline Observations & 754 & 1746 \\
\hline
\end{tabular}

Source: OSA-Panel 2000-2006 
Table A3.3.: Descriptive statistics - United Kingdom

\begin{tabular}{|c|c|c|}
\hline & General education & Vocational education \\
\hline & Mean & Mean \\
\hline \multicolumn{3}{|l|}{ Individual characteristics } \\
\hline Age & 34.177 & 37.550 \\
\hline Female & 0.509 & 0.500 \\
\hline Male & 0.491 & 0.500 \\
\hline National & 0.996 & 0.995 \\
\hline Foreign & 0.004 & 0.005 \\
\hline \multicolumn{3}{|l|}{ Employment characteristics } \\
\hline Hourly wage & 10.948 & 11.099 \\
\hline Experience & 16.177 & 19.550 \\
\hline Tenure & 3.896 & 4.578 \\
\hline Full-time work & 0.848 & 0.840 \\
\hline Part-time work & 0.152 & 0.160 \\
\hline \multicolumn{3}{|l|}{ Firm characteristics } \\
\hline Firm size $\leq 20$ & 0.345 & 0.333 \\
\hline Firm size $\overline{21}-200$ & 0.248 & 0.242 \\
\hline Firm size $200-1999$ & 0.289 & 0.304 \\
\hline Firm size $\geq 2000$ & 0.108 & 0.108 \\
\hline \multicolumn{3}{|l|}{ Industry (NACE) } \\
\hline Agriculture & 0.008 & 0.008 \\
\hline Mining and quarrying & 0.000 & 0.007 \\
\hline Manufacturing & 0.005 & 0.184 \\
\hline Electricity, gas and water supply & 0.020 & 0.023 \\
\hline Construction & 0.058 & 0.060 \\
\hline Wholesale and retail trade & 0.083 & 0.082 \\
\hline Hotels and restaurants & 0.018 & 0.014 \\
\hline Transport and communication & 0.090 & 0.075 \\
\hline Financial intermediation & 0.083 & 0.070 \\
\hline Real estate & 0.053 & 0.043 \\
\hline Public administration & 0.070 & 0.062 \\
\hline Education & 0.131 & 0.091 \\
\hline Health & 0.047 & 0.060 \\
\hline Other services & 0.117 & 0.099 \\
\hline Activities of households & 0.086 & 0.114 \\
\hline Extra-territorial organisations & 0.006 & 0.007 \\
\hline \multicolumn{3}{|l|}{ Job skill level (ISCO) } \\
\hline Senior officials and managers & 0.154 & 0.132 \\
\hline Professionals & 0.070 & 0.051 \\
\hline Technicians & 0.146 & 0.170 \\
\hline Clerks & 0.238 & 0.221 \\
\hline Service workers & 0.174 & 0.140 \\
\hline Skilled agricultural workers & 0.007 & 0.007 \\
\hline Craft and related trades workers & 0.075 & 0.160 \\
\hline Plant and machine operators & 0.080 & 0.076 \\
\hline Elementary occupations & 0.056 & 0.043 \\
\hline Observations & 19059 & 20711 \\
\hline
\end{tabular}

Source: BHPS 1991-2006 
Table A3.4.: OLS regression - baseline model

\begin{tabular}{lrrr}
\hline Variable & Germany & Netherlands & United Kingdom \\
\hline \multirow{2}{*}{ Experience } & $0.0454^{* * *}$ & Log(hourly wage) & $0.0491^{* * *}$ \\
& $(0.003)$ & $0.0472^{* * *}$ & $(0.001)$ \\
Experience2 & $-0.0007^{* * *}$ & $(0.005)$ & $-0.0009^{* * *}$ \\
& $(0.000)$ & $\left(0.0008^{* * *}\right.$ & $(0.000)$ \\
Vocational Education & $0.1285^{* * *}$ & $0.1030^{*}$ & 0.0309 \\
& $(0.016)$ & $(0.049)$ & $(0.016)$ \\
Voc*Experience & $-0.0246^{* * *}$ & $-0.0133^{*}$ & $-0.0066^{* * *}$ \\
& $(0.003)$ & $(0.006)$ & $(0.002)$ \\
Voc*Experience2 & $0.0003^{* *}$ & 0.0003 & $\left(0.0001^{* *}\right.$ \\
& $(0.000)$ & $(0.000)$ & $1.5405^{* * *}$ \\
Constant & $1.7929^{* * *}$ & $1.6910^{* * *}$ & 39767
\end{tabular}

Standard errors in parentheses. Models also include controls for female workers, part-time work, cohorts and time (not shown). ${ }^{*} p<0.10,{ }^{* *} p<0.05,{ }^{* * *} p<0.01$.

Figure A3.1.: OLS regression - baseline model for Germany

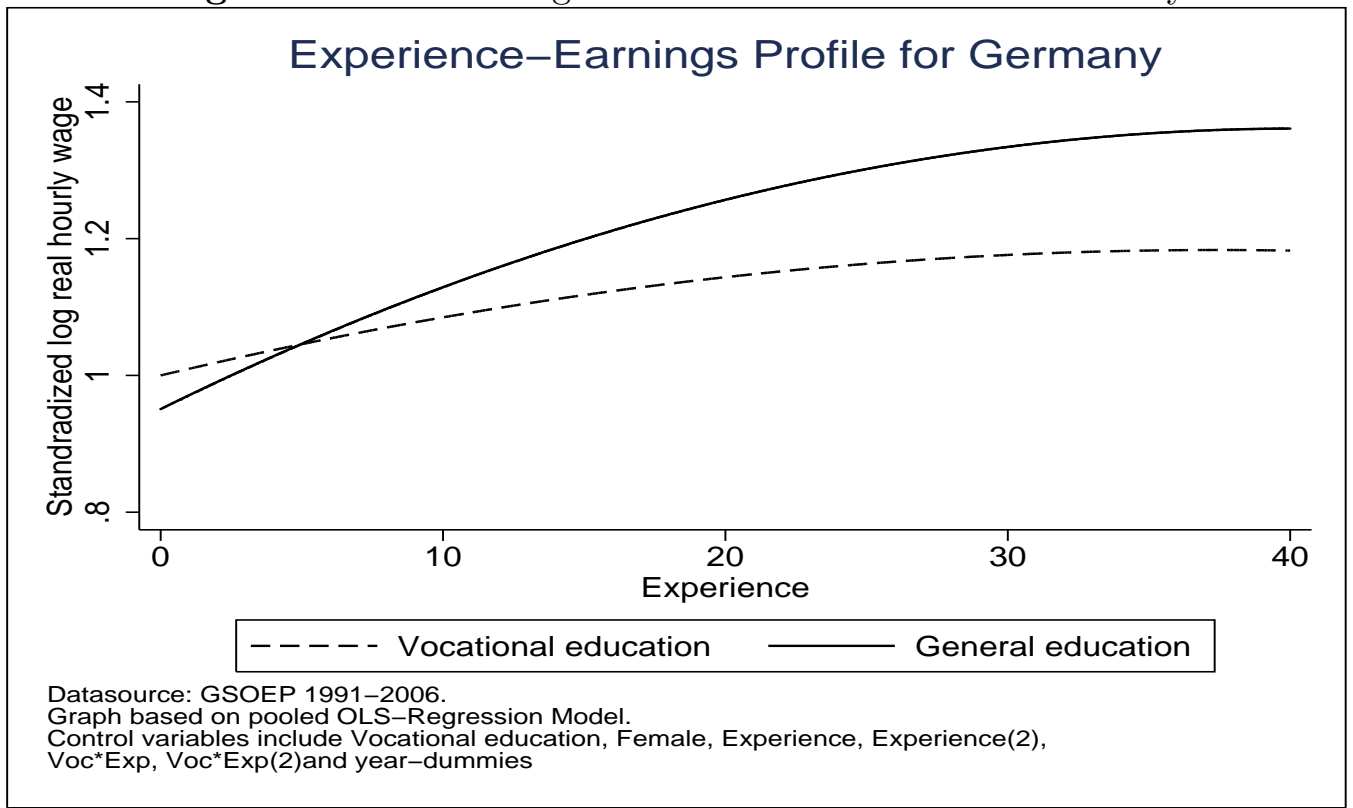


Figure A3.2.: OLS regression - baseline model for the Netherlands

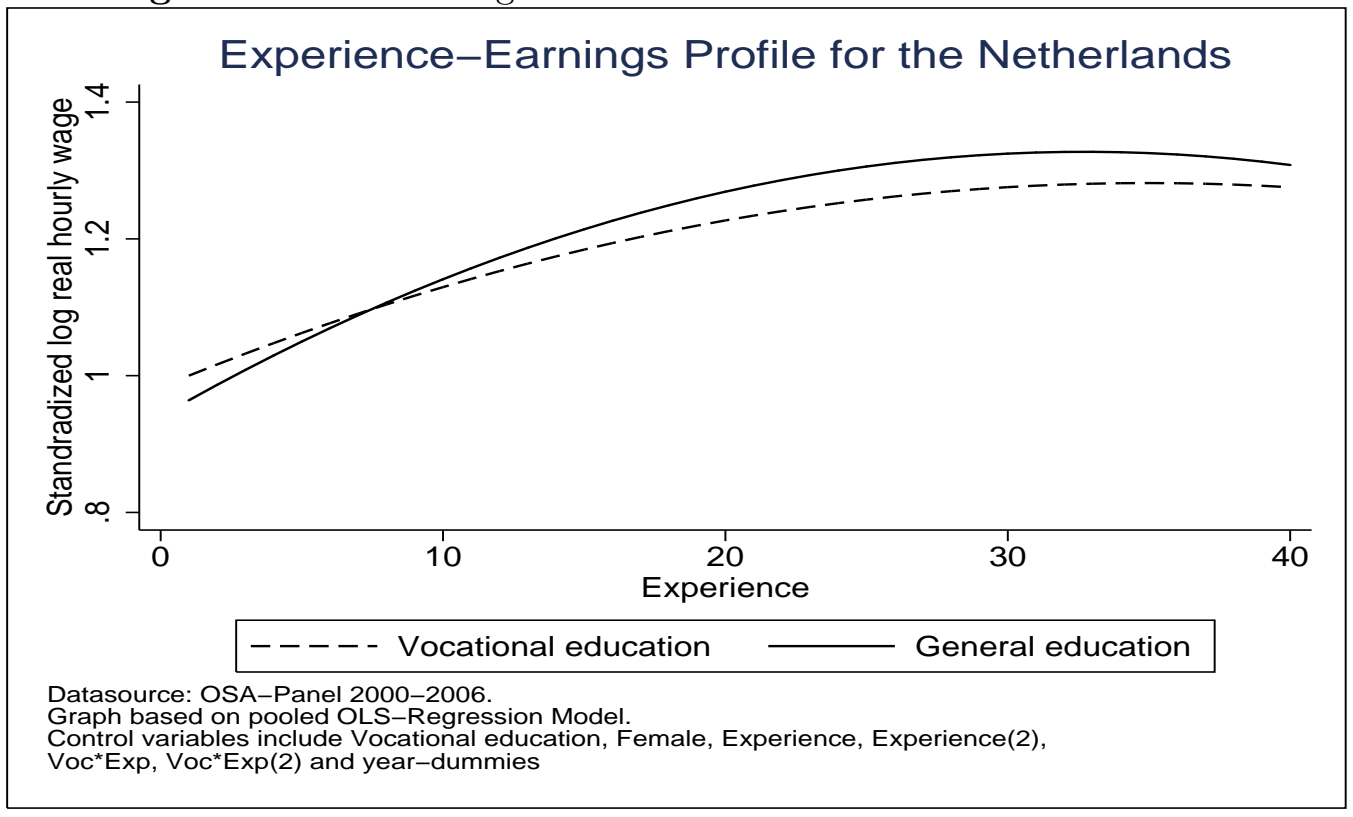

Figure A3.3.: OLS regression - baseline model for the United Kingdom

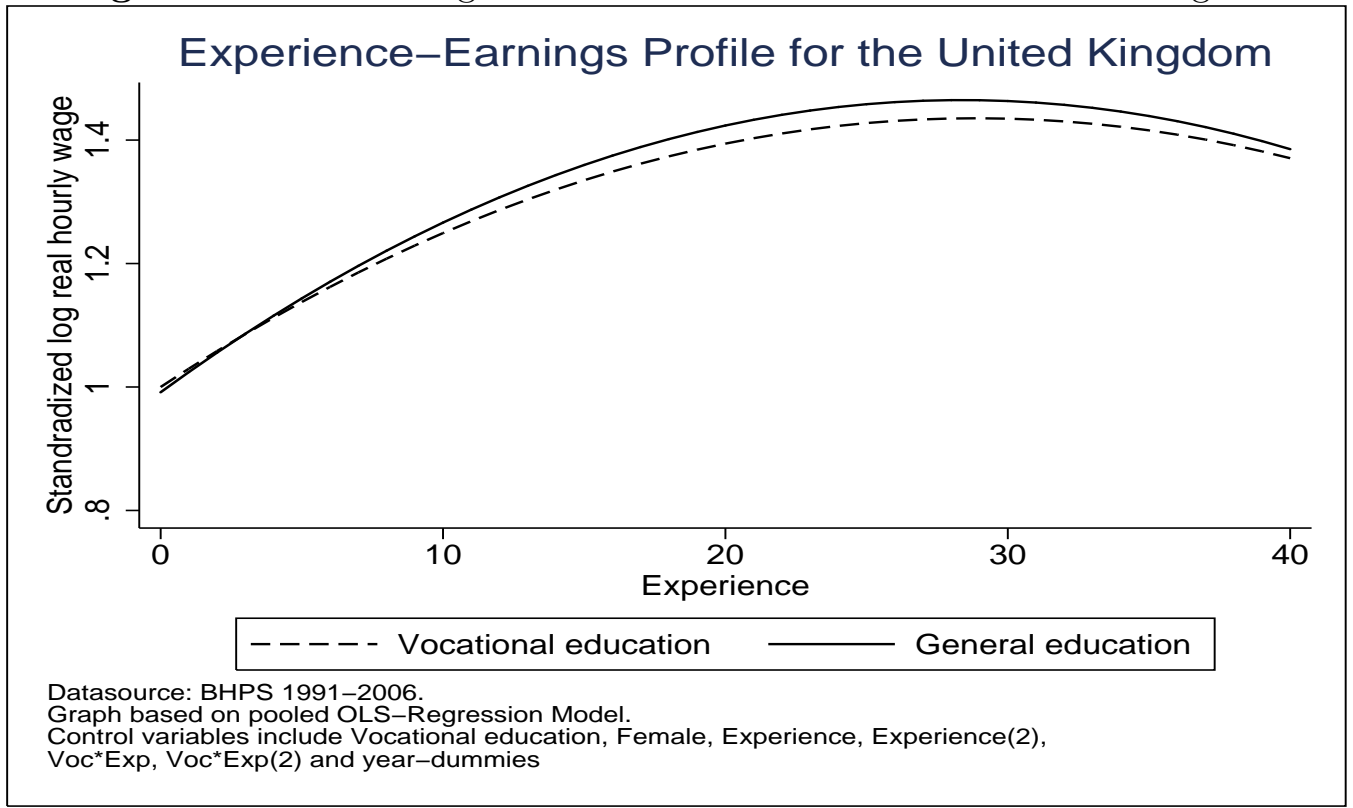




\section{Robustness analysis}

Table A3.5.: Pooled OLS regressions with additional control variables

\begin{tabular}{lrrr}
\hline Variable & Germany & Netherlands & United Kingdom \\
\hline Experience & $0.0431^{* * *}$ & Log(hourly wage) & $0.0359^{* * *}$ \\
& $(0.003)$ & $0.0410^{* * *}$ & $(0.001)$ \\
Experience2 & $-0.0008^{* * *}$ & $(0.005)$ & $-0.0007^{* * *}$ \\
& $(0.000)$ & $(0.000)$ & $(0.000)$ \\
Vocational Education & $0.1741^{* * *}$ & 0.0891 & $0.0561^{* * *}$ \\
& $(0.015)$ & $(0.048)$ & $(0.015)$ \\
Voc*${ }^{*}$ Experience & $-0.0241^{* * *}$ & -0.0101 & $-0.0061^{* * *}$ \\
& $(0.003)$ & $(0.005)$ & $(0.002)$ \\
Voc* Experience2 & $0.0004^{* * *}$ & 0.0002 & $0.0001^{*}$ \\
& $(0.000)$ & $(0.000)$ & $(0.000)$ \\
Constant & $2.2727^{* * *}$ & $1.6043^{* * *}$ & $\left(.9206^{* * *}\right.$ \\
& $(0.025)$ & $(0.067)$ & $(0.036)$ \\
\hline Observations & 72451 & 2500 & 39767 \\
\hline Standard errors in parentheses. Models also include controls for female workers, \\
nationality, part-time work, firm size, industry, occupation, cohort and year \\
dummies. ${ }^{*} p<0.10,{ }^{* *} p<0.05,{ }^{* * *} p<0.01$ &
\end{tabular}

Table A3.6.: Spline-regressions with 5 splines for experience

\begin{tabular}{lrrr}
\hline Variable & Germany & Netherlands & United Kingdom \\
\hline \multirow{2}{*}{ Experience1 } & $0.0433^{* * *}$ & Log(hourly wage) & \\
& $(0.002)$ & $0.0487^{* * *}$ & $0.0518^{* * *}$ \\
Experience2 & $0.0182^{* * *}$ & $(0.005)$ & $(0.002)$ \\
& $(0.001)$ & $0.0172^{* * *}$ & $0.0214^{* * *}$ \\
Experience3 & $0.0168^{* * *}$ & $(0.004)$ & $(0.001)$ \\
& $(0.001)$ & 0.0020 & $0.0030^{*}$ \\
Experience4 & $0.0113^{* * *}$ & $(0.003)$ & $(0.001)$ \\
& $(0.002)$ & $0.0110^{*}$ & $0.0031^{*}$ \\
Experience5 & $0.0124^{* * *}$ & $(0.004)$ & $(0.002)$ \\
& $(0.002)$ & -0.0021 & $-0.0064^{* *}$ \\
Vocational education & $0.0324^{*}$ & $(0.007)$ & $(0.002)$ \\
& $(0.013)$ & 0.0300 & -0.0147 \\
Voc* Experience & $-0.0110^{* * *}$ & $(0.030)$ & $(0.010)$ \\
& $(0.001)$ & -0.0028 & $-0.0011^{*}$ \\
Constant & $1.8953^{* * *}$ & $(0.001)$ & $(0.000)$ \\
& $(0.015)$ & $1.5612^{* * *}$ & $1.5186^{* * *}$ \\
Observations & 72451 & $(0.067)$ & $(0.038)$ \\
\hline Standard errors in parentheses. ${ }^{*} p<0.10,{ }^{* *} p<0.05,{ }^{* * *} p<0.01$.
\end{tabular}


Table A3.7.: Mixed-effects linear regression model ( $<20$ years of experience)

\begin{tabular}{lrrr}
\hline Variable & Germany & Netherlands & United Kingdom \\
\hline & & $\log ($ hourly wage) & \\
Experience & $0.0465^{* * *}$ & $0.0573^{* * *}$ & $0.0612^{* * *}$ \\
& $(0.006)$ & $(0.014)$ & $(0.004)$ \\
Experience2 & $-0.0011^{* * *}$ & $-0.0019^{* * *}$ & $-0.0017^{* * *}$ \\
& $(0.000)$ & $(0.001)$ & $(0.000)$ \\
Vocational education & $0.0416^{*}$ & 0.0976 & $0.0480^{* *}$ \\
& $(0.022)$ & $(0.093)$ & $(0.023)$ \\
Voc*Experience & $-0.0115^{*}$ & $-0.0302^{*}$ & $-0.0124^{* * *}$ \\
& $(0.006)$ & $(0.016)$ & $(0.004)$ \\
Voc*Experience2 & 0.0003 & $0.0014^{* *}$ & $0.0005^{* *}$ \\
& $(0.000)$ & $(0.001)$ & $(0.000)$ \\
Constant & $1.8507^{* * *}$ & $1.1842^{* * *}$ & $1.2116^{* * *}$ \\
& $(0.206)$ & $(0.153)$ & $(0.078)$ \\
\hline Observations & 43567 & 1516 & 23766 \\
\hline
\end{tabular}

Standard errors in parentheses. Models also include controls for female workers,

part-time work, cohorts and time (not shown). ${ }^{*} p<0.10,{ }^{* *} p<0.05,{ }^{* * *} p<0.01$.

\section{Alternative estimate including additional control variable Cohort * vocshare}

Ad Table A3.8. The variable Cohort * vocshare has been introduced as an additional variable to control for ability differences between individuals of different cohorts who do not continue to higher education but end up in vocational education or general education. The basic assumptions are: (1) the ability structure of the population is constant between cohorts; (2) the required ability for following general education and continuing in higher education is generally higher than for vocational education; (3) a higher ability level is associated with a higher wage, ceteris paribus. It is to be expected now that if the share of vocationally educated and trained in a specific cohort is higher than in another, those additionally entering VET are more able than the average student already in VET because fewer individuals of the cohort will complete general education and continue to higher education. The average ability of students in the cohort rises, which impacts positively on wages. Vice versa, a lower share of students in VET would mean that the more able students of the cohort have continued to higher education and consequently the average ability of students in VET is lower, leading to lower wages.

The result can be summarised as follows: in Germany and the Netherlands, the coefficient on Cohort * vocshare is large, positive and significant, supporting our assumptions made above. In the United Kingdom, on the other hand, the coefficient on Cohort* vocshare is positive but not significant. Compared to the regression results excluding the variable on Cohort $*$ vocshare, the main variables of interest have changed with respect to their magnitude, but not with respect to their level of significance. This is especially the case for Germany and the Netherlands. For the United Kingdom, the magnitude of the coefficients of interest changes only marginally. 
Table A3.8.: Mixed-effects linear regression model - Alternative estimates

\begin{tabular}{lrrr}
\hline Variable & Germany & Netherlands & United Kingdom \\
\hline & & Log(hourly wage) & \\
Experience & $0.0347^{* * *}$ & $0.0343^{* * *}$ & $0.0509^{* * *}$ \\
& $(0.004)$ & $(0.006)$ & $(0.002)$ \\
Experience & $-0.0007^{* * *}$ & $-0.0005^{* * *}$ & $-0.0010^{* * *}$ \\
& $(0.000)$ & $(0.000)$ & $(0.000)$ \\
Vocational Education & $0.0757^{* * *}$ & 0.0103 & $0.0421^{*}$ \\
& $(0.020)$ & $(0.064)$ & $(0.020)$ \\
Voc*Experience & $-0.0159^{* * *}$ & -0.0033 & $-0.0100^{* * *}$ \\
& $(0.004)$ & $(0.007)$ & $(0.002)$ \\
Voc*Experience2 & $0.0003^{*}$ & 0.0000 & $0.0003^{* * *}$ \\
& $(0.000)$ & $(0.000)$ & $(0.000)$ \\
Cohort $*$ vocshare & $0.5868^{* * *}$ & $0.5013^{* * *}$ & 0.0313 \\
& $(0.091)$ & $(0.146)$ & $(0.054)$ \\
Constant & $1.6354^{* * *}$ & $1.5199^{* * *}$ & $1.3920^{* * *}$ \\
& $(0.083)$ & $(0.112)$ & $(0.024)$ \\
\hline Observations & 72451 & 2500 & 39767 \\
\hline \hline
\end{tabular}

Standard errors in parentheses. Models also include controls for female workers, part-time work, cohorts and time (not shown). ${ }^{*} p<0.10,{ }^{* *} p<0.05,{ }^{* * *} p<0.01$.

Table A3.9.: Mixed-effects linear regression model - Male workers

\begin{tabular}{lrrr}
\hline Variable & Germany & Netherlands & United Kingdom \\
\hline & & Log $($ hourly wage $)$ & \\
Experience & $0.0376^{* * *}$ & $0.0490^{* * *}$ & $0.0588^{* * *}$ \\
& $(0.005)$ & $(0.008)$ & $(0.002)$ \\
Experience & $-0.0007^{* * *}$ & $-0.0008^{* * *}$ & $-0.0011^{* * *}$ \\
& $(0.000)$ & $(0.000)$ & $(0.000)$ \\
Vocational education & $0.0830^{* *}$ & 0.1465 & $0.0780^{* *}$ \\
& $(0.029)$ & $(0.084)$ & $(0.026)$ \\
Voc*Experience & $-0.0141^{* *}$ & -0.0173 & $-0.0184^{* * *}$ \\
& $(0.005)$ & $(0.009)$ & $(0.003)$ \\
Voc*Experience2 & 0.0003 & 0.0003 & $0.0004^{* * *}$ \\
& $(0.000)$ & $(0.000)$ & $(0.000)$ \\
Constant & $2.1503^{* * *}$ & $1.7452^{* * *}$ & $1.3329^{* * *}$ \\
& $(0.027)$ & $(0.070)$ & $(0.016)$ \\
\hline Observations & 41283 & 1275 & 19708 \\
\hline \hline
\end{tabular}

Standard errors in parentheses. Models also include controls for female workers, part-time work, cohorts and time (not shown). ${ }^{*} p<0.10,{ }^{* *} p<0.05,{ }^{* * *} p<0.01$ 
Table A3.10.: Mixed-effects linear regression model - Female workers

\begin{tabular}{lrrr}
\hline Variable & Germany & Netherlands & United Kingdom \\
\hline \multirow{2}{*}{ Experience } & $0.0415^{* * *}$ & $\log ($ hourly wage) & \\
& $(0.006)$ & $0.0336^{* * *}$ & $0.0401^{* * *}$ \\
Experience2 & $-0.0008^{* * *}$ & $(0.008)$ & $(0.002)$ \\
& $(0.000)$ & $-0.0006^{* *}$ & $-0.0008^{* * *}$ \\
Vocational education & $0.1106^{* * *}$ & $(0.000)$ & $(0.000)$ \\
& $(0.029)$ & -0.0082 & $0.0887^{* *}$ \\
Voc*Experience & $-0.0216^{* * *}$ & $(0.087)$ & $(0.027)$ \\
& $(0.006)$ & -0.0012 & $-0.0078^{*}$ \\
Voc*Experience2 & $0.0004^{*}$ & $(0.010)$ & $(0.003)$ \\
& $(0.000)$ & -0.0000 & $0.0002^{*}$ \\
Constant & $-1.2920^{* * *}$ & $(0.000)$ & $(0.000)$ \\
& $(0.005)$ & $-1.6647^{* * *}$ & $-0.9991^{* * *}$ \\
Observations & 31168 & $(0.039)$ & $(0.006)$ \\
\hline \hline
\end{tabular}

Standard errors in parentheses.Models also include controls for female workers, part-time work, cohorts and time (not shown). ${ }^{*} p<0.10,{ }^{* *} p<0.05,{ }^{* * *} p<0.01$. 


\section{The firm-specific component of VET}

\subsection{Introduction 1}

Classical human capital theory (Becker 1962) claims that under perfect market conditions firms do not invest in general human capital. Acemoglu and Pischke (1998, 1999a,b), in response to this claim, develop a model explaining why firms may have incentives to do so. As an empirical example, the authors refer to the case of apprenticeship training in Germany, for which several surveys have shown that, on average, firms bear substantial training costs (von Bardeleben et al. 1995; Beicht et al. 2004; Schönfeld et al. 2010). An important assumption made by Acemoglu and Pischke is that apprenticeship training generates mainly general skills because apprentices are required to follow a prescribed curriculum, take an outside examination at the end of the training period and receive a nationally recognised certificate issued by the respective industry or craft chamber. In practice, however, it is possible for firms to influence the content of apprenticeship training. In the dual system of training, apprentices spend only one or two days of the working week in a vocational school. During the remainder of the week, training takes place within the firm, giving firms substantial scope to foster skills that are specific to the firm. Consequently, it is possible that at least a fraction of the skills obtained during apprenticeship training in a firm are not directly transferable to other firms. While firms' investment in German apprenticeship training has been extensively analysed in the surveys referenced above, the degree of firm-specificity of training has not yet been estimated directly on the basis of representative firm-level data. Due to the standardisation and transparency of training, we expect firm-specificity to be rather low in the German training system. A low degree of firm-specificity might, in turn, explain part of the fact that the German apprenticeship system is still attractive for young school-leavers who also could follow an academic track.

In addition to the fact that the degree of firm-specificity of apprenticeship training is interesting from an economic perspective, the results presented in this chapter may also be important from a political point of view. For a long time, the primary goal of political leadership and social partners has been to offer young apprentices a transparent

\footnotetext{
${ }^{1}$ This chapter is based on the paper How large is the firm-specific component of German apprenticeship training? by Harald Pfeifer, Gudrun Schönfeld and Felix Wenzelmann. The paper is published in: Empirical Research in Vocational Education and Training 3(2), pp. 85-104, 2011 (Pfeifer et al. 2011).
} 


\section{The firm-specific component of VET}

and transferable education. Since the early 1990s, however, the call for more freedom in tailoring apprenticeship training to individual firms' skill needs has intensified, and this has led to the adoption of less stringent training regulations. The question arises of whether German firms have, in general, taken advantage of the freedom so provided to introduce firm-specific elements into their training to safeguard their human capital investments against the risk of poaching in increasingly competitive labour and product markets.

In this chapter, we use data from the Cost-Benefit Survey (CBS) conducted by the Federal Institute for Vocational Education and Training (BIBB) of 2007 to calculate a monetary value for the firm-specific component of German apprenticeship training. We compare the initial productivity and wages of externally recruited workers to those of internally trained workers in cases where both groups have been trained in the same occupation, perform the same type of job and are employed in the same firm. We argue that the amount of a firm's resources that is needed to raise the productivity of externally recruited workers to the level of those who were trained internally provides a good measure of the magnitude of the firm-specific training component. Because both externally recruited and internally trained workers are required to pass a standardised, external examination in their respective occupations (BMBF 2005), we make the explicit assumption that apprentices in the same occupation receive a similar amount of general and occupation-specific training and that the latter is de facto general human capital to the firm because these skills can also be transferred to other firms employing persons with the same occupation 2. Consequently, differences in productivity between internally trained and externally recruited workers in the same type of job, occupation and firm must result from differences in the endowment of non-transferable, i.e. firm-specific, skills. To estimate the monetary value of this specific component, we use firm-level information on the relative productivity, adjustment time, direct and indirect continuing training costs and wages received by the respective groups of workers. In a second step, we calculate the specific training component as a share of the firms' total investment in human capital generated by apprenticeship training. We approximate the total investment based on the costs of training personnel, training infrastructure and training organisation. Finally, we use a Heckman-type selection model to regress the share of firm-specific training on a number of explanatory variables to analyse its determinants.

The remainder of this chapter is structured as follows. In Section 4.2, we reflect upon theoretical aspects of the problem and briefly discuss the relevant literature. In Section 4.3, we describe the data source and the method used to calculate the absolute value of firm-specific training components and the gross cost of training. Our empirical strategy and selection issues are discussed in Section 4.4. The results are given in Section 4.5, and Section 4.6 concludes the chapter.

\footnotetext{
${ }^{2}$ In this chapter, occupation-specific training components are therefore categorised as a type of general human capital.
} 


\subsection{Theoretical background and literature}

Becker (1962) concluded from a theoretical analysis that firms would refrain from investment in general training. To recoup the costs related to general training, firms would need to pay trained workers wages below their marginal product. In a perfect labour market, workers would not accept this and would move to a firm willing to pay the market wage. In the case of firm-specific training, in contrast, it is rational for firms to invest in training because the additional skills acquired by workers during such training are applicable only in the training firm and do not increase the marginal product elsewhere. In this case, the firm can pay wages below the workers' marginal product and in this way recoup the cost of training 3 Acemoglu and Pischke (1998, 1999a,b), among others, have argued that firms' investment in general human capital is rational if a) labour market imperfections distort the equality of wages and productivity and b) a compressed wage structure leads to an increasing gap between wages and productivity along the training dimension. Firms are thus able to reap a benefit from general training without risking the loss of trained workers to another firm. Leuven (2005) supplies an overview of the relevant theories with respect to private sector training. Wolter and Ryan (2011) offer a comprehensive survey of theoretical and empirical issues related to apprenticeship training.

An important question discussed in the aftermath of Becker's work is whether it is possible to distinguish between general and firm-specific skills. According to Bishop (1996), all skills may be general, but each worker has a particular mix of skills. This mix may be more useful to the current employer than to alternative employers, and this encourages the employer to invest in the skill mix that she requires. Lazear (2009) formalises this argument in his 'Skill-Weights Approach'4 Similarly, Stevens (1994b) argues that, in practice, skills are neither completely general nor purely specific. This mixture of skills makes the outside market for workers non-competitive and therefore fosters firms' investment in training. Franz and Soskice (1995) and Kessler and Lülfesmann (2006) point out that from the employer's point of view, general and specific skills may be complementary. Teaching firm-specific skills may reduce the cost of also teaching general skills and vice versa. As empirical evidence for firms' investment in general training, Acemoglu and Pischke (1998, 1999a, b) refer to the German apprenticeship system 5 A series of micro-level surveys has shown that firms incur substantial net costs when training apprentices (von Bardeleben et al. 1995; Beicht et al. 2004). The most recent of these surveys for the reference year 2007, which also provides the data for the analysis conducted

\footnotetext{
$\sqrt[3]{\text { Becker }}(\underline{1962})$ and later Hashimoto (1981) argue that the investment in firm-specific human capital is shared between the worker and the firm.

${ }^{4}$ Although this chapter focuses on the firm-specific training component, we could easily transfer the analysis to this strand of thought. The absolute value of raising the productivity of an externally recruited worker and its share in total human capital investments, which is calculated in Section 4.3 , could be interpreted as the productivity loss due to differences between the skill mix needed by the firm and the mix offered by the recruited worker.

5 Autor (2001) provides empirical evidence for general training investments by temporary help agencies in the United States.
} 


\section{The firm-specific component of VET}

in this chapter, confirms these results (Schönfeld et al. 2010).6. One of the few studies that directly identifies firm-specificity is that of Schweri (2006), who uses the Swiss data set on costs and benefits of vocational training (reference year 2000) to analyse the impact of the degree of firm-specificity on training decisions and training costs. He finds that firm-specificity has no significant impact on firms' training decisions. Furthermore, he finds no clear evidence that a higher degree of firm-specificity induces firms to accept higher training costs 7

In addition to the Swiss study, a number of studies have analysed the importance of firm-specific training in German apprenticeship training. Most of these studies investigate labour market outcomes, such as wages and mobility of former apprentices, to draw conclusions about the relative importance of the firm-specific training component. Werwatz (1996) finds that apprentices who leave the training firm experience no substantial earnings loss compared to apprentices who remain in the firm. He concludes that overall, apprenticeship training does not have a strong firm-specific component. For large firms in the industry sector of the economy, however, the firm-specific component seems to be higher than in small firms in the craft sector. Clark (2001) and Clark and Fahr (2002) show that former apprentices experience no significant wage cuts after moving to another firm, at least if they stay within their broad occupational group. The authors conclude that apprenticeship training is highly transferable and thus mainly general. Korpi and Mertens (2003) also deduce from their analysis of mobility patterns in Germany and Sweden that "the proportion of truly firm-specific skills acquired during a German apprenticeship is rather low in relation to the transferable skills obtained" (p. 613). Euwals and Winkelmann (2004) confirm previously published studies in that they find no systematic wage differential between stayers and movers. On the other hand, Bougheas and Georgellis (2004) find that apprentices who leave the training firm experience an earnings loss that the authors attribute to the loss of firm-specific human capital. However, movers' earnings grow at a faster rate than those of stayers over the time spent in the labour market. A similar result is supplied by von Wachter and Bender (2006), who finds that the wage loss of movers disappears within three years at the new employer. Using Lazear's 'Skill-Weights Approach' (Lazear 2009), Geel et al. (2011) analyse the specificity of skill combinations of various occupations and the effects of such specificity on occupational mobility and wages. They further find that the more specific the skill portfolio in an occupation, the higher the net costs borne by firms for the training of apprentices.

An important drawback of a number of the cited studies is that movers can stay within a broad occupational group but perform a different type of job that requires a different set of

${ }^{6}$ Using the two latest BIBB CBS waves, Pfeifer et al. (2010) show that net training costs have dropped significantly, even when controlling for structural changes and business cycle variations.

${ }^{7}$ As a proxy for firm-specificity, Schweri uses the product of adaption time in months and the relative productivity of externally recruited workers. Although these measures are also important factors in the calculation in the present chapter, we calculate the cost for adaption using the respective wages, as formalised in Section 4.3 
skills. Thus, the loss in earnings of movers compared to stayers may be attributable to the fact that some movers cannot use the full set of general skills obtained in the training firm. In addition, firms may be forced, through collective bargaining agreements for example, to accept lower productivity during the recruited workers' adjustment period without being able to adjust wages accordingly. In addition, (lower) wages are only one part of the story. Costs for continuing training measures aimed at increasing the productivity of newly hired workers are not accounted for in the above studies. Consequently, there could be a loss of firm-specific human capital of movers that is not reflected in their initial wages.

To contribute to the existing literature in this area, the present chapter draws from rich data on the wage and productivity differences of internally trained and externally recruited workers. Further training costs for externally recruited workers are also measured in detail. Finally, we are able to observe movers and stayers not only in the same occupation and firm but also performing the same type of job. We thereby avoid some of the drawbacks of the studies cited above. The data source used and the construction of variables are described in detail in the subsequent section.

\subsection{Data source and calculation method}

\subsubsection{BIBB Cost-Benefit Survey}

The data used in our analysis stem from the 4th BIBB Cost-Benefit Survey (BIBB CBS) conducted for the reference year 2007. Representatives from a total of 2958 firms answered a detailed questionnaire during a computer-assisted personal interview (CAPI). The respondents were usually firms' employees responsible for the training of apprentices and/or were personnel managers. In the case of small firms, the interview partners were often the owners of the business. The data set contains unique information about the firms' training costs and benefits, and the firms were asked to supply information about one specific occupation trained. Altogether, 51 of the most common occupations were surveyed.

In addition to providing cost information, firms that had recruited ready-trained workers from the external labour market over the last three years answered a set of additional questions. The answers to these questions provided information on productivity and wage differences between externally recruited and internally trained workers. In addition, detailed information about the adjustment time and continuing training costs for externally recruited workers was given. In the descriptive analysis of the data, we focus on the subset of firms that recruited workers from the external labour market to fill positions in which they performed jobs similar to those of internally trained workers. This data set includes about 800 firms. Descriptive information about this sample and the entire sample of firms is given in Table A4.1. 


\subsubsection{Variable construction}

In an initial step, we calculate an indicator of total investment in human capital during apprenticeship training for the single firm $T H C_{i}$. The indicator includes three main components. The first component is the cost of training personnel involved in the training of apprentices. For this component, we use information about the average hours, $h_{i}^{t}$, that trainers spend with apprentices and multiply these by the hourly wage, $w_{i}^{t}$, of trainers. Trainers can either be full-time training staff, unskilled workers, skilled workers or members of the firm's management. For each of these subgroups of trainers, we draw on separate information for hours spent and wages paid.

The second component entails costs to the firm that are related to the infrastructure of training, $I_{i}$. Firms can have separate training centres in which apprentices can practice. Several firms make use of internal classroom teaching. The rent and costs for maintenance, equipment and furnishing of these facilities are included in the costs for infrastructure. We also include costs for tools, machines and materials used in training.

The third component consists of costs related to the organisation, coordination and administration of training, $O_{i}$. This indicator takes account of costs for external training courses and administrative costs for apprentices.

These three components can be used to calculate the total investment in human capital over the entire apprenticeship period of three (or three-and-a-half) years for firm $i$. Formalising the calculation of $T H C_{i}$ yields the following equation:

$$
T H C_{i}=h_{i}^{t} w_{i}^{t}+I_{i}+O_{i}
$$

Table A4.2 displays the respective monetary values for both samples of firms. The means for the two samples do not differ significantly from each other. It is important to note that the indicator $\mathrm{THC}_{i}$ cannot be compared to the indicator of gross costs of training used in Schönfeld et al. (2010) because the methods used to calculate the two indicators differ. The indicator of human capital investments that is presented here excludes wages paid to the apprentices because these wage costs are not directly linked to human capital formation but rather could be viewed as compensation for the productive contribution of apprentices. In addition, the indicator in this chapter has a higher value of costs for training personnel because all hours spent with the apprentice are valued with the respective wages of trainers. In the gross costs calculated in Schönfeld et al. (2010), only training hours are considered to lead to costs, which effectively reduces the productivity of trainers. We use this method of calculation because our aim is to develop an indicator approximating the monetary 'input' into human capital formation rather than to focus on a pure cost-benefit description of training from the firms' perspective.

In the second step of the calculation, our main variable of interest, the monetary indicator for firm-specificity of apprenticeship training at the firm level $S H C_{i}$, is constructed. For the calculation of $S H C_{i}$, we first calculate the adjustment costs over the time during 
which the externally recruited worker is in the firm but has a lower productivity than an internally trained worker. To do this, we use information about the relative productivity level $p_{t i}^{r}$ of the externally recruited worker in month t8; $p_{t i}^{r}$ has a value between 0 and 1 . The productivity difference between the two groups of workers is then defined as $1-p_{t i}^{r}$. Using information about the wage $w_{i}^{e x}$ of the externally recruited worker, we then calculate the adjustment costs for each month $t$ over the period of adjustment $a_{i}$, which is also available in the data set 9 In this model, we assume that the externally recruited worker's productivity improves linearly over the adjustment period. Adjustment $\operatorname{costs} c_{i}^{a}$ for the individual firm are thus determined by

$$
c_{i}^{a}=\sum_{t=1}^{a_{i}}\left(w_{i}^{e x}-w_{i}^{i n t} * p_{t i}^{r}\right) .
$$

Note that Equation 4.2 is an approximation of

$$
c_{i}^{a}=\sum_{t=1}^{a_{i}}\left(\left(\phi_{i}^{i n t}-w_{i}^{i n t}\right)-\left(\phi_{t i}^{e x}-w_{i}^{e x}\right)\right)
$$

where $\phi_{i}^{i n t}$ is the productivity of internally trained workers and $\phi_{t i}^{e x}=\phi_{i}^{i n t} * p_{t i}^{r}$ is the productivity of externally recruited workers in month $t$. Because $\phi_{i}^{\text {int }}$ is unknown and assumed to be constant over time, we approximate the productivity of internally trained workers by their wage 10 Furthermore, direct costs and indirect costs for continuing training are calculated; the direct costs, $c_{i}^{d}$, consist of fees and expenses for the firm, and the indirect wage $\operatorname{costs} c_{i}^{w}$ are the wage costs arising from the absence of the externally recruited workers during external training. Continuing training costs are then given by

$$
c_{i}^{t}=c_{i}^{d}+c_{i}^{w}
$$

The monetary indicator for the firm-specific component of training, then, is the sum of adjustment costs and further training costs:

$$
S H C_{i}=c_{i}^{a}+c_{i}^{t}
$$

\footnotetext{
${ }^{8}$ The exact wording of the question is the following: "How much lower is the productivity of the externally recruited worker compared to that of the internally trained worker in the same (or similar) occupation working in the same (or similar) type of job at the beginning of the adjustment time?" Because the question does not allow for possibility to report a higher productivity of the externally recruited worker, the measure could be biased upwards. However, an upward bias would lead to a lower degree of firm specificity and thus render our results to be an upper bound for the share of specific training.

${ }^{9}$ The exact wording of the question is the following: "How long (in months) does the adjustment period of the externally recruited worker last?"

${ }^{10}$ Because in imperfect labour markets wages could be below productivity, a different set of results could be obtained for the adjustment cost value and the estimate of the firm-specific training component. We therefore offer alternative calculations that are discussed in Section 4.5 .
} 
Finally, the monetary indicator for the firm-specific training component is divided by the total investment in human capital, yielding the share of the firm-specific component share $_{i}$.

$$
\text { share }_{i}=S H C_{i} / T H C_{i}
$$

Table A4.3 provides descriptive information on the relevant variables for the sample.

\subsection{Empirical strategy}

\subsubsection{Precision of estimates}

The strategy employed is to first calculate the share of firm-specificity and compare it across a number of structural variables. However, before discussing the results, we need to address potential problems associated with the precision of our estimates. The calculation method proposed in this chapter applies only under the assumption that, on average, apprentices who pass the outside training examination in a specific occupation possess similar stocks of general and occupation-specific human capital and that internally trained workers differ from externally recruited workers only with respect to their firm-specific skills. The method also relies on the assumption that internally trained and externally recruited workers do not differ systematically in innate ability and motivation. Because the data at hand offer no information about the employment history of externally recruited workers, these are strong assumptions; they can be challenged by arguing that the more able apprentices tend to stay in the training firm while the less able (i.e. the 'lemons') are released onto the labour market. On the other hand, the average ability of externally recruited workers could be higher than that of internally trained workers if the former group consists mainly of "poached" workers. In such a case, the firm-specific training component may in fact be larger than is estimated below. However, if the average ability of externally recruited workers is lower than that of internally trained workers, our results can be interpreted as an upper bound for the share of the firm-specific component.

Another point to be discussed at this stage is the lack of data on the productivity of internally trained employees. In section 4.3, we valued productivity differences with the wage of the internally trained employee. Models of imperfect competition predict, however, that wages paid by firms are below the workers' productivity. If this is the case, our value for the adjustment $\operatorname{costs} c_{i}^{a}$ of firm $i$ would be underestimated. Apart from the baseline calculations discussed below, we therefore recalculated the model, assuming differences between productivity and wages of $10 \%, 25 \%$ and $50 \%$. We therefore briefly discuss alternative results of this exercise in the results section. 


\subsubsection{Sample selection model}

For the second step of the empirical strategy, the analysis of the determinants of firmspecificity in a regression framework, we must take into account that restricting the analysis to a subsample of training firms that have recruited personnel over the last three years (i.e., from 2005 to 2007) may cause a selectivity problem. It is possible that the samples we have chosen to represent recruiting and non-recruiting firms differ not only in observed but also in unobserved characteristics that also relate to the firm-specific component of training. An unobserved variable could be, for example, the specialisation of firms in niche products. Recruiting personnel from the external labour market would be too costly for such firms because the production of niche products requires highly specific skills that are difficult to learn within an acceptable time period. It would be more beneficial for such firms to train apprentices and use the time the apprentices spend in the firm to invest in production-specific skills. In this case, specialising in niche products would be an omitted variable that impacts (negatively) the likelihood that the firm will recruit workers from the external labour market and at the same time impacts (positively) the share of firm-specific training. Neglecting such a relationship, if present, would lead to underestimation of the firm-specificity of training due to sample selection.

In order to obtain consistent estimates, we therefore follow a maximum-likelihood selection model frequently used in the literature (see Heckman 1979). In this model, the selection variable is the recruitment of trained workers and the main dependent variable is the share of firm-specific training. To identify the model, we need to include exclusion restriction variables in the selection equation. The choice of such variables is delicate in the sense that they should be both theoretically well founded and statistically valid, i.e. they must be correlated with the recruitment of trained workers from the external labour market but must not be correlated with the share of firm-specific training.

We choose two variables that measure a) the development of the workforce in the firm and b) whether or not the firm was able to fill all vacant apprenticeship-training slots during the past three years. The reason for choosing variable a) is that the increase in the number of workers reflects the economic success of the firm and should be highly correlated with external recruitment but not with the firm-specific component of apprenticeship training. The reason for choosing variable b) is that firms that could not fill all training slots are more likely to recruit from the external labour market. At the same time, the fact that a firm could not fill all its available training slots is not likely to be correlated with the firm-specific component of training.

However, it could be the case that, in the situation of a tight labour market, firms recruit workers that are less qualified because an insufficient number of workers with matching qualifications are available. The productivity of such employees would be lower than the productivity of those with a better qualification match. This scenario would lead to higher adjustment costs and a larger share of firm-specific human capital. A similar argument applies with respect to the variable of unfilled training slots. Firms that are not able to fill 


\section{The firm-specific component of VET}

all training slots could be firms that are less attractive to qualified workers on the labour market. These firms may be forced to recruit workers with lower ability than firms without problems filling apprenticeship vacancies. Again, the firm-specific component would be larger. In both cases, the independence of our exclusion restriction from firm-specificity would be violated.

To address this problem, we supply unemployment and open vacancy time series statistics from the Federal Employment Agency in Germany (see Figure A4.1). The reference years for our sample are the three years prior to the survey, i.e. the years 2005 to 2007. As the figure indicates, unemployment fell from 2005 onwards from an all-time peak of close to 5 million registered unemployed to under 4 million registered unemployed. At the same time, job vacancies registered at the Federal Employment Agency increased over that period from a relatively low level. In total, the figure indicates that unemployment was still substantial and that job vacancies were not extraordinarily high during the reference period; this does not lend support to the idea that labour markets were especially tight at that time. We further make use of a survey question that aims to measures the availability of skilled workers on the external labour market from the viewpoint of the single firm 11 The correlation between this variable and our measures for productivity and the share of firm-specific training is close to zero (0.008 and 0.013, respectively). Thus, the availability of skilled workers on the external labour market is statistically not related to our outcome measures. Finally, we check whether our exclusion restriction variables are correlated with productivity and firm-specificity. Table A4.4 shows that this is not the case. The correlation between the two selection variables and the outcome variables is close to zero. On the basis of this information, we conclude that our exclusion restrictions are valid instruments for identifying our model.

In addition to the exclusion restriction variables, we include a set of explanatory variables, such as firm size (four categories) and region. We also add two institutional variables. The first is a dummy indicating the existence of a works council in the firm, and the second indicates whether the firm is bound to collective wage agreements. Because the number of cases for some of the 51 occupations included in the survey is relatively low, we aggregate the occupational information according to the common classification of occupations. This classification results in 12 occupational groups; these groups are also included in the set of explanatory variables.

\subsection{Results}

Table 4.5.1 displays the results of the calculation of firms' total investment in human capital during apprenticeship training THC (column 1) and the monetary value of the

${ }^{11}$ The exact wording of the question is: "How would you judge the number of available skilled workers in the training occupation?" Response options ranged from 1 "Very good" to 5 "Very poor". 
firm-specific component $S H C$ (column 2). In column 3, the calculated firm-specific component of apprenticeship training is presented as a share of the total investment (share).

On average, the share of firm-specific training is relatively low, with a value of $12 \%$. Differentiating between firms of different sizes shows that apprenticeship training in large firms with more than 500 employees is more specific than training in small firms with up to 10 employees. While the average value for the former is $21 \%$, the firm-specific component for the latter is about $9 \%$ of total human capital investments. Notable differences also exist with respect to occupational groups. Firms that train workers in health occupations such as medical assistant or dental assistant and occupations in the fields of accommodation and food, such as cook or baker, have a low share of firm-specificity in training of about $6 \%$. For firms that train workers in occupations such as banking and insurance or chemicals, this measure is relatively high (25\% and $21 \%$, respectively). Differences in firm-specificity by region are negligible, whereas firms with a works council have relatively high firmspecific training components.

Table 4.5.1.: Firms' investment in human capital and firm-specificity of training

\begin{tabular}{|c|c|c|c|}
\hline & $\begin{array}{c}\text { Firm investment } \\
\text { in human capital } \\
\text { THC }\end{array}$ & $\begin{array}{c}\text { Monetary value } \\
\text { for firm-specific } \\
\text { training } S H C\end{array}$ & $\begin{array}{l}\text { Share of } \\
\text { firm-specific } \\
\text { training* }\end{array}$ \\
\hline \multicolumn{4}{|l|}{ Firm size } \\
\hline 1 - 9 employees & $\begin{array}{c}52884 \\
(40521)\end{array}$ & $\begin{array}{c}2971 \\
(4026)\end{array}$ & $\begin{array}{c}0.09 \\
(0.17)\end{array}$ \\
\hline 10 - 49 employees & $\begin{array}{c}41422 \\
(35887)\end{array}$ & $\begin{array}{c}3042 \\
(3288)\end{array}$ & $\begin{array}{c}0.13 \\
(0.17)\end{array}$ \\
\hline 50 - 499 employees & $\begin{array}{c}39961 \\
(31984)\end{array}$ & $\begin{array}{c}4597 \\
(4566)\end{array}$ & $\begin{array}{c}0.19 \\
(0.22)\end{array}$ \\
\hline $500+$ employees & $\begin{array}{c}45230 \\
(38235)\end{array}$ & $\begin{array}{c}4979 \\
(3649)\end{array}$ & $\begin{array}{c}0.21 \\
(0.24)\end{array}$ \\
\hline Vocational field & & & \\
\hline Metalworking & $\begin{array}{c}50398 \\
(37085)\end{array}$ & $\begin{array}{c}3575 \\
(4330)\end{array}$ & $\begin{array}{c}0.12 \\
(0.20)\end{array}$ \\
\hline Electrical engineering & $\begin{array}{c}51159 \\
(37299)\end{array}$ & $\begin{array}{c}3753 \\
(4216)\end{array}$ & $\begin{array}{c}0.12 \\
(0.19)\end{array}$ \\
\hline Information technology & $\begin{array}{c}57272 \\
(35471)\end{array}$ & $\begin{array}{c}5010 \\
(3131)\end{array}$ & $\begin{array}{c}0.13 \\
(0.13)\end{array}$ \\
\hline Chemicals & $\begin{array}{c}36716 \\
(28610)\end{array}$ & $\begin{array}{c}5400 \\
(4336)\end{array}$ & $\begin{array}{c}0.21 \\
(0.22)\end{array}$ \\
\hline Accommodation and food & $\begin{array}{c}40413 \\
(30236)\end{array}$ & $\begin{array}{c}1385 \\
(1420)\end{array}$ & $\begin{array}{c}0.06 \\
(0.08)\end{array}$ \\
\hline Construction & $\begin{array}{c}48147 \\
(50754)\end{array}$ & $\begin{array}{c}3028 \\
(3394)\end{array}$ & $\begin{array}{c}0.15 \\
(0.27)\end{array}$ \\
\hline Print and media & $\begin{array}{c}50219 \\
(38826) \\
\end{array}$ & $\begin{array}{c}2878 \\
(6592) \\
\end{array}$ & $\begin{array}{c}0.08 \\
(0.16) \\
\end{array}$ \\
\hline
\end{tabular}


4. The firm-specific component of VET

...continued from previous page

\begin{tabular}{|c|c|c|c|}
\hline & $\begin{array}{c}\text { Firm investment } \\
\text { in human capital } \\
T H C\end{array}$ & $\begin{array}{l}\text { Monetary value } \\
\text { for firm-specific } \\
\text { training } S H C\end{array}$ & $\begin{array}{c}\text { Share of } \\
\text { firm-specific } \\
\text { training* }\end{array}$ \\
\hline \multirow[t]{2}{*}{ Health } & 59019 & 2352 & 0.06 \\
\hline & $(32783)$ & $(2264)$ & $(0.06)$ \\
\hline \multirow[t]{2}{*}{ Administrative: sales and distribution } & 41319 & 4021 & 0.14 \\
\hline & $(35918)$ & $(5830)$ & $(0.22)$ \\
\hline \multirow[t]{2}{*}{ Administrative: headquarters } & 36257 & 3288 & 0.16 \\
\hline & $(36459)$ & $(2995)$ & $(0.16)$ \\
\hline \multirow[t]{2}{*}{ Administrative: banks/insurance } & 38766 & 6266 & 0.25 \\
\hline & $(29546)$ & $(3865)$ & $(0.23)$ \\
\hline \multirow[t]{2}{*}{ Other occupations } & 50181 & 1814 & 0.10 \\
\hline & $(45912)$ & $(2433)$ & $(0.20)$ \\
\hline \multicolumn{4}{|l|}{ Region } \\
\hline \multirow[t]{2}{*}{ East Germany } & 36911 & 2496 & 0.10 \\
\hline & $(27826)$ & $(3191)$ & $(0.13)$ \\
\hline \multirow[t]{2}{*}{ West Germany } & 48334 & 3479 & 0.13 \\
\hline & $(39423)$ & $(4028)$ & $(0.19)$ \\
\hline \multicolumn{4}{|l|}{ Institutional setting } \\
\hline \multirow[t]{2}{*}{ Not bound to collective bargaining } & 45249 & 3436 & 0.13 \\
\hline & $(35412)$ & $(4125)$ & $(0.19)$ \\
\hline \multirow{2}{*}{ Bound to collective bargaining } & 47157 & 3172 & 0.12 \\
\hline & $(39922)$ & $(3692)$ & $(0.18)$ \\
\hline \multirow[t]{2}{*}{ No works councils in the firm } & 45549 & 2932 & 0.11 \\
\hline & $(36145)$ & $(3477)$ & $(0.18)$ \\
\hline \multirow[t]{2}{*}{ Works councils in the firm } & 50380 & 5494 & 0.19 \\
\hline & $(46448)$ & $(5352)$ & $(0.21)$ \\
\hline \multirow[t]{2}{*}{ Total } & 46240 & 3299 & 0.12 \\
\hline & $(37812)$ & $(3906)$ & $(0.18)$ \\
\hline
\end{tabular}

Source: BIBB CBS 2007. Standard deviation in parenthesis; all numbers in $€$.

*The values in the third column are the weighted averages of the firms' shares of firm-specific training for each of the subgroups. This value differs from the ratios of the averages of SHC and $\mathrm{THC}$, which are given in the first two columns.

As described in the previous section, we recalculated the share of firm-specific training under the assumption that wages do not reflect the true productivity of workers due to factors such as labour market imperfections. The results of this sensitivity analysis are presented in Table A4.6. Even under the assumption that worker productivity is $50 \%$ higher than the wage received (i.e. $\phi_{i}^{i n t}=1.5 * w_{i}^{\text {int }}$ ), we still find only a moderate share of the firm-specific training component, of about $16 \%$.

In a final step, we estimate a maximum-likelihood selection model to assess whether the differences observed in the descriptive statistics also hold when a set of structural variables is controlled for. For this purpose, we employ the whole set of firms with the censored part of the model being those firms for which information needed for the calculation of the firm-specific training component is available. The results of the model show that both exclusion restrictions are highly significant in the selection model. Because the employment development variable is coded from -2 (strong decrease) to 2 (strong increase), the positive coefficient of the exclusion restriction indicates that employment growth in firms results in higher external recruitment. The positive coefficient of the second exclusion restriction variable (i.e. whether firms could fill all vacant apprenticeship training slots) indicates that firms that were not able to fill all vacant training slots have a higher probability of recruiting workers externally. The likelihood ratio test of 
Table 4.5.2.: Maximum-likelihood selection model

\begin{tabular}{|c|c|c|c|c|}
\hline & $\begin{array}{l}\text { Share of specific } \\
\text { component }\end{array}$ & $\begin{array}{l}\text { Std. } \\
\text { Error }\end{array}$ & $\begin{array}{l}\text { Recruitment } \\
\text { yes/no }\end{array}$ & $\begin{array}{l}\text { Std. } \\
\text { Error }\end{array}$ \\
\hline \multicolumn{5}{|l|}{ Firm size: } \\
\hline \multicolumn{5}{|l|}{ Ref. 1-9 employees } \\
\hline 10-49 employees & 0.025 & $(0.023)$ & $0.304^{* * *}$ & $(0.067)$ \\
\hline 50-499 employees & $0.075 * *$ & $(0.031)$ & $0.552^{* * *}$ & $(0.086)$ \\
\hline $500+$ employees & $0.085^{* *}$ & $(0.039)$ & $0.550^{* * *}$ & $(0.128)$ \\
\hline \multicolumn{5}{|l|}{ Vocational field: } \\
\hline \multicolumn{5}{|l|}{ Ref. Construction } \\
\hline Metalworking & -0.034 & $(0.032)$ & 0.108 & $(0.126)$ \\
\hline Electrical engineering & -0.006 & $(0.034)$ & $-0.221 *$ & $(0.126)$ \\
\hline Information technology & -0.016 & $(0.038)$ & $-0.235^{*}$ & $(0.141)$ \\
\hline Chemicals & -0.061 & $(0.042)$ & $0.284^{*}$ & $(0.172)$ \\
\hline Accommodation and food & $-0.080 * *$ & $(0.031)$ & -0.068 & $(0.120)$ \\
\hline Print and media & -0.050 & $(0.043)$ & 0.056 & $(0.170)$ \\
\hline Health & -0.059 & $(0.046)$ & -0.143 & $(0.161)$ \\
\hline Administrative: sales/distribution & -0.018 & $(0.033)$ & -0.125 & $(0.124)$ \\
\hline Administrative: headquarters & -0.002 & $(0.031)$ & -0.148 & $(0.114)$ \\
\hline Administrative: banks/insurance & 0.065 & $(0.040)$ & $0.301^{*}$ & $(0.158)$ \\
\hline Other occupations & 0.001 & $(0.044)$ & -0.075 & $(0.164)$ \\
\hline \multicolumn{5}{|l|}{ Region: } \\
\hline \multicolumn{5}{|l|}{ Ref. East Germany } \\
\hline \multirow{2}{*}{\multicolumn{5}{|c|}{ Institutional dummies }} \\
\hline & & & & \\
\hline Works council in the firm & 0.019 & $(0.021)$ & $-0.219 * * *$ & $(0.079)$ \\
\hline Bound to collective bargaining & 0.013 & $(0.015)$ & -0.028 & $(0.056)$ \\
\hline \multicolumn{5}{|l|}{ Exclusion restrictions } \\
\hline Employment development & & & $0.204^{* * *}$ & $(0.031)$ \\
\hline Unplaced apprenticeships & & & $0.311^{* * *}$ & $(0.071)$ \\
\hline Constant & 0.104 & $(0.067)$ & $-0.798^{* * *}$ & $(0.113)$ \\
\hline atrho & -0.022 & $(0.247)$ & & \\
\hline lnsigma & $-1.689^{* * *}$ & $(0.025)$ & & \\
\hline Observations & 2958 & & & \\
\hline Observations uncensored & 809 & & & \\
\hline Likelihood-Ratio test of & & & & \\
\hline independent equations $($ rho $=0)$ : & $i 2(1)=$ & & & \\
\hline
\end{tabular}

independence of equations $(\rho=0)$ indicates that selection is not likely to play a role in our case. We thus receive support in transferring the analysis of the subsample to the full sample of training firms. Table 4.5.2 shows the respective regression output of the model. For reference, in Table A4.5, we also present results of the corresponding OLS regression using only the subsample of recruiting firms.

The results of these calculations confirm the descriptive analysis in that they show that the firm-specific component of training increases with firm size. The respective coefficients of medium and large firms are significant and positive. Furthermore, regression results indicate that compared to the occupational field of construction, occupations in banking and insurance have a higher firm-specific component, with the respective coefficient being just outside the significance level of $10 \%$. On the other hand, occupations in the fields of accommodation and food have lower firm-specific components. 


\subsection{Concluding remarks}

In this chapter, we made use of the BIBB Cost-Benefit Survey of 2007 to calculate the monetary value of the firm-specific component of apprenticeship training. We argued that the resources needed to bring externally recruited workers to the productivity level of internally trained workers provide a good indicator of the magnitude of the firm-specific component of such training. Measured as a share of total human capital investments, the firm-specific training component is approximately $12 \%$. Recalculating the model under the assumption of imperfect labour markets (i.e. the inequality of productivity and wages) leads to shares of firm-specific training of not more than $16 \%$.

These results generally confirm the presumptions made by Acemoglu and Pischke and others, who took German apprenticeship training as a reference for firms' investment in general human capital. The maximum-likelihood selection model used in this chapter provides some evidence that firm-specificity increases with firm size and that some groups of occupations are trained more (or less) firm-specifically than others. Other variables, such as region, collective bargaining and works councils, seem to be of no importance in the degree of firm-specificity of training.

The results presented in this chapter are important both from an economic and from a policy perspective. Economically, the results show that changing employers after having achieved a VET qualification may lead to the loss of about one-tenth of an apprentice's human capital. The loss is relatively low but still significant. As found in recent literature, movers' wage losses are only temporary and may be offset by benefits of a better match in the long run. We thus interpret our results as evidence in favour of a mainly general VET system in Germany, which in turn explains why young school-leavers who could just as well enter academic tracks opt for VET. Although VET is occupation-specific, the large degree of flexibility within the chosen occupation may be an important benefit from an individual point of view.

Politically, the low degree of firm-specificity found in this study is surprising, considering that over the past two decades, social partners have worked towards a reduction in the degree of formalisation in training curricula and have allowed firms more freedom to introduce firm-specific training elements. Conversely, in a number of cases, different occupations with common sets of tasks and skills were merged, forming a broader occupational field and leading to more general curricula. However, the data used in this chapter do not permit an analysis of the change of firm-specificity over time. Newly available individualand firm-level survey data that provide additional information about skill formation and firms' adjustment processes should facilitate further research in this field. 


\section{A4. Appendix}

Table A4.1.: Descriptive statistics

\begin{tabular}{|c|c|c|c|c|}
\hline & \multicolumn{2}{|c|}{$\begin{array}{l}\text { Firms having } \\
\text { recruited workers }\end{array}$} & \multicolumn{2}{|c|}{$\begin{array}{l}\text { Full sample } \\
\text { of firms }\end{array}$} \\
\hline & Mean & Std. Dev. & Mean & Std. Dev. \\
\hline \multicolumn{5}{|l|}{ Firm size } \\
\hline 1 - 9 employees & 0.440 & 0.497 & 0.546 & 0.498 \\
\hline 10 - 49 employees & 0.380 & 0.486 & 0.329 & 0.470 \\
\hline 50 - 499 employees & 0.169 & 0.375 & 0.117 & 0.321 \\
\hline $500+$ employees & 0.011 & 0.106 & 0.008 & 0.091 \\
\hline \multicolumn{5}{|l|}{ Vocational field } \\
\hline Metalworking & 0.097 & 0.296 & 0.083 & 0.277 \\
\hline Electrical engineering & 0.083 & 0.276 & 0.098 & 0.297 \\
\hline Information technology & 0.080 & 0.272 & 0.068 & 0.252 \\
\hline Chemicals & 0.026 & 0.159 & 0.011 & 0.102 \\
\hline Accommodation and food & 0.120 & 0.325 & 0.128 & 0.334 \\
\hline Construction & 0.106 & 0.307 & 0.106 & 0.307 \\
\hline Print and media & 0.024 & 0.154 & 0.020 & 0.139 \\
\hline Health & 0.103 & 0.305 & 0.119 & 0.324 \\
\hline Administrative: sales and distribution & 0.132 & 0.339 & 0.138 & 0.344 \\
\hline Administrative: headquarters & 0.169 & 0.375 & 0.187 & 0.390 \\
\hline Administrative: banks/insurance & 0.023 & 0.151 & 0.016 & 0.127 \\
\hline Other occupations & 0.036 & 0.187 & 0.026 & 0.159 \\
\hline \multicolumn{5}{|l|}{ Region } \\
\hline East Germany & 0.183 & 0.387 & 0.165 & 0.371 \\
\hline West Germany & 0.817 & 0.387 & 0.835 & 0.371 \\
\hline \multicolumn{5}{|l|}{ Training organisation } \\
\hline Training centre & 0.073 & 0.260 & 0.047 & 0.212 \\
\hline Internal courses & 0.312 & 0.464 & 0.275 & 0.447 \\
\hline \multicolumn{5}{|l|}{ Institutional setting } \\
\hline Bound to collective bargaining & 0.520 & 0.500 & 0.540 & 0.499 \\
\hline Works councils in the firm & 0.143 & 0.350 & 0.130 & 0.336 \\
\hline Observations & 809 & & 2958 & \\
\hline
\end{tabular}


Table A4.2.: Firms' investment in human capital (full apprenticeship)

Firms having recruited workers

\begin{tabular}{lcccc}
\hline & Mean & Std. Dev. & Min & Max \\
\hline Wage costs for trainers in $€$ & 38161 & 35525 & 0 & 215106 \\
Costs for infrastructure in $€$ & 2606 & 3268 & 0 & 49967 \\
Organisational costs in $€$ & 5473 & 5334 & 189 & 42055 \\
\hline Firm investment in human capital in $€$ & 46240 & 37812 & 1350 & 223873 \\
\hline Observations & \multicolumn{5}{c}{809} \\
\hline
\end{tabular}

Full sample of firms

\begin{tabular}{lcccc}
\hline & Mean & Std. Dev. & Min & Max \\
\hline Wage costs for trainers in $€$ & 38125 & 35383 & 0 & 235499 \\
Costs for infrastructure in $€$ & 2649 & 3723 & 0 & 58387 \\
Organisational costs in $€$ & 5147 & 5057 & 0 & 47437 \\
\hline Firm investment in human capital in $€$ & 45921 & 37378 & 0 & 252863 \\
\hline Observations & \multicolumn{4}{c}{2958} \\
\hline
\end{tabular}

Source: BIBB CBS 2007

Table A4.3.: Variables used for calculating the firm-specific training component

\begin{tabular}{lcccc} 
& \multicolumn{3}{c}{ Firms having recruited workers } \\
\hline & Mean & Std. Dev. & Min & Max \\
\hline Monthly wage internally trained worker in $€$ & 1786 & 527 & 500 & 4000 \\
Monthly wage externally recruited workers in $€$ & 1804 & 557 & 500 & 3900 \\
Productivity difference between externally & & & & \\
recruited and internally trained workers (in \%) & 38 & 22 & 0 & 100 \\
Adjustment time in months & 4 & 4 & 0 & 36 \\
Days spent in continuing training & 21 & 44 & 0 & 243 \\
Costs for fees, etc. of continuing training in $€$ & 424 & 1034 & 0 & 9999 \\
Wage costs of continuing training in $€$ & 752 & 1562 & 0 & 4715 \\
\hline Firm-specific component of training & 3299 & 3906 & 0 & 43727 \\
\hline Observations & & 809 & &
\end{tabular}

Source: BIBB CBS 2007

Table A4.4.: Correlation of selection variables

\begin{tabular}{lcc} 
& $\begin{array}{c}\text { Employment } \\
\text { development }\end{array}$ & $\begin{array}{c}\text { Unplaced } \\
\text { apprenticeships }\end{array}$ \\
\hline Productivity difference between externally & & \\
recruited and internally trained workers (in \%) & 0.03 & -0.02 \\
Firm-specific component of training & 0.00 & 0.05 \\
\hline Observations & \multicolumn{2}{c}{809} \\
\hline Source: BIBB CBS 2007
\end{tabular}


Table A4.5.: OLS regression model

\begin{tabular}{|c|c|c|}
\hline & $\begin{array}{l}\text { Share of specific } \\
\text { component }\end{array}$ & $\begin{array}{l}\text { Std. } \\
\text { Error }\end{array}$ \\
\hline \multicolumn{3}{|l|}{ Firm size: Ref. 1-9 } \\
\hline 10-49 employees & 0.026 & $(0.019)$ \\
\hline 50-499 employees & $0.077^{* * *}$ & $(0.023)$ \\
\hline $500+$ employees & $0.086^{* *}$ & $(0.033)$ \\
\hline \multicolumn{3}{|l|}{ Vocational field: Ref. Construction } \\
\hline Metalworking & -0.034 & $(0.032)$ \\
\hline Electrical engineering & -0.007 & $(0.034)$ \\
\hline Information technology & -0.017 & $(0.038)$ \\
\hline Chemicals & -0.060 & $(0.041)$ \\
\hline Accommodation and food & $-0.080^{*}$ & $(0.031)$ \\
\hline Print and media & -0.050 & $(0.043)$ \\
\hline Health & -0.060 & $(0.046)$ \\
\hline Administrative: sales and distribution & -0.018 & $(0.033)$ \\
\hline Administrative: headquarters & -0.003 & $(0.031)$ \\
\hline Administrative: banks/insurance & 0.066 & $(0.039)$ \\
\hline Other occupations & 0.000 & $(0.044)$ \\
\hline \multicolumn{3}{|l|}{ Region: Ref. East Germany } \\
\hline West Germany & 0.018 & $(0.015)$ \\
\hline \multicolumn{3}{|l|}{ Institutional dummies } \\
\hline Works council in the firm & 0.018 & $(0.020)$ \\
\hline Bound to collective bargaining & 0.012 & $(0.015)$ \\
\hline Constant & $0.099^{* *}$ & $(0.030)$ \\
\hline Observations & 809 & \\
\hline
\end{tabular}

Table A4.6.: Estimation of share with hypothetical wage-productivity differential

Share of specific training component

\begin{tabular}{lcc}
\hline & Mean & Std.Dev \\
\hline$\phi_{i}^{\text {int }}=w_{i}^{\text {int }}$ & 0.12 & 0.17 \\
$\phi_{i}^{\text {int }}=1.1 * w_{i}^{\text {int }}$ & 0.13 & 0.19 \\
$\phi_{i}^{\text {int }}=1.25 * w_{i}^{\text {int }}$ & 0.14 & 0.20 \\
$\phi_{i}^{\text {int }}=1.5 * w_{i}^{\text {int }}$ & 0.16 & 0.22 \\
\hline \multicolumn{2}{l}{ Source: BIBB CBS 2007.}
\end{tabular}

Source: BIBB CBS 2007. 
4. The firm-specific component of VET

Figure A4.1.: Unemployment and job vacancies in Germany (in 1000s)

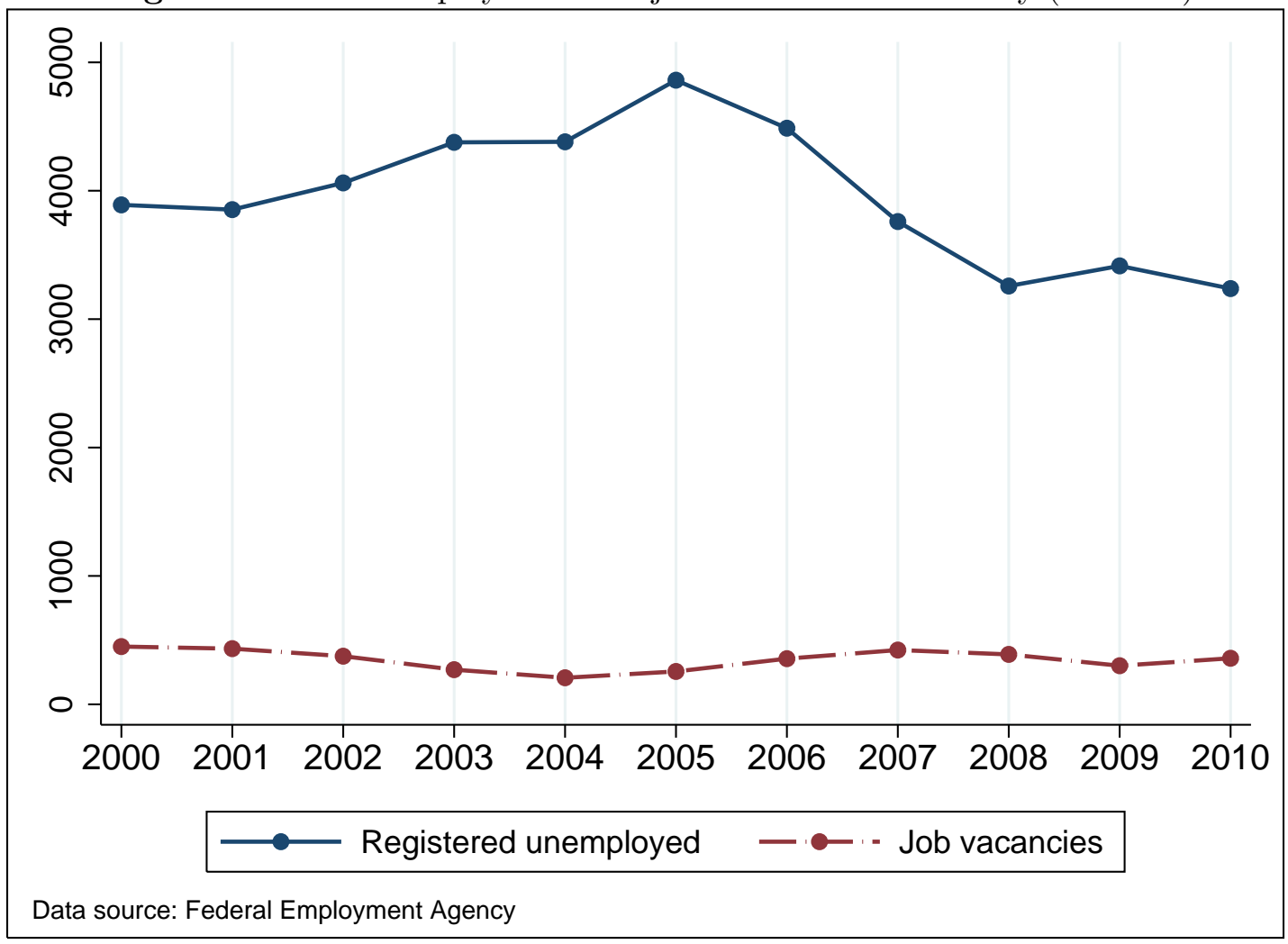




\section{The financing of VET and labour market regulations}

\subsection{Introduction 1}

In Switzerland and Germany, the dual system of apprenticeship training plays an important role in the education and qualification of young adults. In both countries, more than half of a cohort of school-leavers enter an apprenticeship training programme each year. The apprenticeship systems in both countries are highly comparable with respect to the training regulations, requirements for entering apprenticeships and the amount and type of human capital acquired during the training period. Apart from attending vocational schools, which provide general and occupation-specific education, apprentices receive formal training at the workplace. The latter is costly to the firm, as training personnel are needed to instruct apprentices. In addition, firms also make wage payments to apprentices, which are set in an apprenticeship contract before the start of training. Apprentices in turn perform productive tasks at the workplace and thereby generate benefits for the training firm. A recent empirical analysis by Dionisius et al. (2009) shows that training costs exceed training benefits in Germany, whereas the opposite is true for Switzerland. The difference in net costs between Germany and Switzerland amounts to $€ 25000$ for an average three-year apprenticeship. The main factors explaining this difference are (i) differences in relative wages of apprentices and skilled workers and (ii) the fact that apprentices contribute more to the production process in Switzerland than their colleagues in Germany.

While wages for apprentices as well as for skilled workers can be regarded as exogenous to the firm due to collective wage bargaining in Germany, the allocation of productive tasks to an apprentice appears, at first glance, to be at the discretion of the firm. However, institutional arrangements in Germany, such as work councils and unions, still play an important role for firms' personnel policy, including the organisation of apprenticeship training. Therefore, the low productive use of apprentices may well be the result of

\footnotetext{
${ }^{1}$ This chapter is based on the paper The Financing of Apprenticeship Training in the Light of Labor Market Regulations by Samuel Muehlemann, Harald Pfeifer, Günter Walden, Felix Wenzelmann and Stefan C. Wolter. The paper is published in: Labour Economics 17, pp. 799-809, 2010 (Muehlemann et al. 2010).
} 
a bargaining process, since the jobs of other workers within the training firm may be substituted by apprentices if much of their workload is shifted to the latter. However, we cannot provide direct evidence for this argument in this chapter. Instead, we take the fact that apprenticeship training in Germany results in net costs in the short-run as given, and investigate what types of post-training benefits are most important for firms to recoup training expenses after the apprenticeship period and what impact these may have on the decision to train or not to train apprentices.

There are at least two different possible ways for a firm to generate post-training benefits. (a) Through lower expected firing costs: over a period of usually three years, employers learn about the true ability of apprentices. Thus, apprenticeship training can be used as a screening device to reduce the risk of a bad match. While a firm cannot influence the absolute level of firing costs of an individual worker, it can lower the probability that such an event will occur by hiring former apprentices. Their expected tenure is longer compared to workers hired externally because the training firm has a relative information advantage and only hires those fitting the job requirements best. (b) Through lower hiring costs: by hiring former apprentices, a firm can save recruitment and adaption costs that would arise by hiring skilled workers externally. While recruitment costs include costs for jobinterviews, job-postings and head hunters, adaption costs arise because externally hired workers have no prior knowledge about firm-specific production flows and may require some on-the-job training before they can carry out their tasks, which is costly to the employer. Hence, externally hired workers initially have a lower productivity compared to internally trained apprentices that have already accumulated the corresponding human capital during their training programme.

Summing up, hiring former apprentices can reduce both hiring and firing costs, as retaining apprentices does not result in further hiring costs and the probability of dismissal is lower due to the training firm's information advantage.

Our hypothesis is that post-training benefits must be higher in Germany than in Switzerland due to institutional arrangements, e.g. stricter dismissal rules, which reduce the employer's scope of action with respect to labour adjustment and makes the latter more costly. Apprenticeship training can therefore be used as a device to lower the training firm's labour adjustment costs.

For our empirical analysis we make use of two representative firm-level surveys for German and Swiss companies, which include detailed and highly comparable measures of training costs and training benefits. We show that the firms' willingness to train apprentices depends significantly on the importance of apprenticeship training as a device to reduce labour adjustment costs. Applying econometric selection models, we find that expected net costs for Swiss non-training firms are substantial and differ significantly from those of training firms. In Germany, where employment protection is relatively strong, we find that expected net costs for non-training firms are not significantly different from training firms. Swiss non-training firms are therefore likely to refrain from training 
apprentices because of high expected net training costs, whereas non-training firms in Germany do not train because of insufficiently high post-training benefits.

The chapter is structured as follows. Section 5.2 gives a brief exposition of the apprenticeship systems and labour market regulation in Germany and Switzerland. In Section 5.3, we discuss the relevant theoretical and empirical literature. In Section 5.4, we provide information on the data sources and show descriptive statistics. In Section 5.5 , we present the econometric model and in Section 5.6 discuss the empirical results. Our conclusions are presented in the last section.

\subsection{The dual system and labour market regulations in Germany and Switzerland}

The dual apprenticeship systems in Germany and Switzerland have several common features. Both systems combine vocational education in schools with work-related training in companies, which provides apprentices with the necessary theoretical and practical knowledge. Apprenticeship training programmes have a long tradition in many industries, such as manufacturing, banking or services. In both countries, more than half of a cohort of school-leavers enrolls in the so-called "dual system". Hence, apprenticeship training is the most popular type of formal education for young people at the uppersecondary level. At the beginning of the apprenticeship, both firms and apprentices sign a legally binding contract, in which firms commit themselves to an occupation-specific curriculum.2 However, a firm can always provide more training to an apprentice than required by training regulations. During the apprenticeship period, an apprentice spends a certain amount of time in publicly financed vocational schools (typically 1-2 days per week), whereas the remaining time is spent within the training firm. The apprentices receive a wage during the training period, which differs across occupations and regions, but is usually a fraction of the market wage of skilled workers in the same occupation. At the end of the apprenticeship period, apprentices are subject to external examinations and receive a nationally recognised training certificate.

However, while there are many similarities, there are also some differences between the German and the Swiss apprenticeship system. On the one hand, Swiss apprentices spend somewhat less time in vocational schools (on average about 11 days less per year in a three-year training programme) and, as a consequence, they spend more time within the training firm. On the other hand, some training occupations differ with respect to the duration of training. While in both countries the majority of apprenticeship programmes (70\% in Germany and 60\% in Switzerland) last 3 years, there are also a number of apprenticeships that require a longer training period. These add up to about one-quarter in Germany and to one-third in Switzerland, respectively. The difference consists of

${ }^{2}$ See Dustmann and Schönberg (2012) on the importance of commitment for apprenticeship training. 
the fact that these apprenticeships are trained for 3.5 years in Germany but for 4 years in Switzerland 3 Another difference is related to the apprentices' wages. While they are mainly determined collectively in Germany, Swiss firms can set wages unilaterally 4 Despite these differences, the institutional framework of the apprenticeship system can be regarded as very similar, facilitating the comparative analysis of costs and benefits of apprenticeship training for the two countries.

In contrast, the organisation and regulation of labour markets is rather different in the two countries. According to the OECD Employment Outlook (OECD 2004), the value of the overall index of employment protection of regular employment is 2.7 for Germany and 1.2 for Switzerland (Table 5.2.1). As a comparison, the two countries with the lowest employment protection, i.e. the United States and the United Kingdom, have a value of 0.2 and 0.8 , respectively. In the late 1990's, Germany was ranked 21st out of 27 OECD countries and Switzerland was ranked 5th, where the ranking decreases with strictness of employment protection legislation.

Table 5.2.1.: OECD indicators of employment protection

\begin{tabular}{lrrrr}
\hline OECD indicators of the strictness & \multicolumn{2}{c}{ Germany } & \multicolumn{2}{c}{ Switzerland } \\
of employment protection & 1999 & 2003 & 1999 & 2003 \\
\hline Regular employment & 2.7 & 2.7 & 1.2 & 1.2 \\
Temporary employment & 2.3 & 1.8 & 1.1 & 1.1 \\
Collective dismissals & 3.5 & 3.8 & 3.9 & 3.9 \\
\hline
\end{tabular}

Source: OECD (2004)

Table A5.1 provides more details about the OECD indicator of employment protection on regular employment. The main difference between Germany and Switzerland can be found in the procedural inconveniences a firm faces when dismissing a worker. German firms are required to provide reasons for dismissal and a third party, such as works councils, must be informed about this process. The dismissal must be socially justified, which means that the firm cannot simply choose which worker is to be dismissed, but instead the selection is based on worker characteristics such as tenure, age, maintenance obligations or disability. The reasoning is that the worker who is least affected by a dismissal is to be dismissed by the employer. Further, a worker can also not be dismissed if there is a possibility of employing the worker in an other department or another position within the firm or if the worker can be retrained. In Switzerland, such dismissal rules do not exist, and a written statement is usually sufficient to terminate an employment contract.

Germany and Switzerland also differ with respect to the strength of unions. In Germany, trade union density in the year 2001 was equal to $25 \%$ of the workforce, while the respective figure in Switzerland amounted to $18 \%$ (OECD 2004). Collective bargaining coverage is

\footnotetext{
${ }^{3}$ In both countries, about $5 \%$ of all apprenticeships are trained in a period of two years.

${ }^{4}$ However, professional societies make non-binding wage recommendations. The only exception is the regulation of apprenticeship wages in the Italian part of Switzerland, which accounts for roughly $5 \%$ of all apprenticeship contracts, where wages are state-regulated.
} 
also higher in Germany, amounting to roughly $70 \%$ in the year 2000 compared to somewhat more than $40 \%$ in Switzerland (OECD 2004) 5

Recent labour market reforms in Germany led to a decrease in the OECD index of the employment protection of temporary workers from 2.3 in the late 1990 's to 1.8 in the year 2003 (Table 5.2.1). Regulations of collective dismissals, which are not the main interest of our research question, are almost equivalent for Germany and Switzerland according to the OECD index for the year 2003; Swiss regulations were even slightly stricter in the late 1990s (Table 5.2.1).

\subsection{Relevant literature}

The classical human capital theory (Becker 1962) was developed with the aim of explaining the market for on-the-job training, distinguishing general and firm-specific human capital. The former includes abilities or skills, which are of the same value in many different firms and are compensated accordingly, whereas the latter includes those abilities or skills that are only valued by the firm in which they have been acquired. Human capital theory is based on the assumption of perfect competition, which implies that workers are paid the value of their marginal product. A firm that offers a wage lower than value of the worker's marginal product would lose this worker immediately, because she would switch to another firm where a worker would be paid according to the value of her general human capital. In turn, this also implies that a firm will never pay for general training because it has no possibility to capture a return on the initial investment after training has ended. Still, a firm would be willing to pay for part of training if it is firm-specific, as neither the worker nor the firm would be willing to pay for all of the training (see Hashimoto (1981) for optimal sharing rules). However, while apprenticeship training may well have some firm-specific components, it can be regarded as mainly general human capital.

There have been a number of empirical studies that find evidence for firms being willing to pay for their workers' general human capital. The cost-benefit surveys of apprenticeship training in Germany repeatedly showed that most training firms make a substantial net investment in their apprentices' human capital (e.g. von Bardeleben et al. (1995)), serving as an important empirical motivation for many theoretical articles which have attempted to rationalise firm-sponsored general training (e.g. Acemoglu and Pischke 1998, 1999a, b) 6 Training firms can have a number of advantages over non-training firms in recruiting their skilled workforce. An apprenticeship programme usually lasts three years, during which an employer can gather relevant information about the characteristics of the trainee, such as his ability, how much effort he is willing to put into his work or how well he can learn new tasks. In addition, the training firm also knows exactly how much

\footnotetext{
${ }^{5}$ Due to the lack of data for the existence of works councils and collective agreements at the firm level, we cannot directly control for their influence on training costs. However, Chapter 6 of the thesis uses a different data set to estimate this influence.

${ }^{6}$ See Leuven (2005) for a recent survey article of the training literature.
} 
and what type of training an apprentice has received and how well he can execute certain tasks.7 This information can be very valuable to a firm, since it has a much better estimate of the worker's true productivity compared to an outside firm. As a result, the firm may be able to offer a wage below productivity, because asymmetric information about the worker's ability will prevent the former trainee from receiving a wage equal to the value of his productivity elsewhere, even if the accumulated human capital is general (see also Katz and Ziderman (1990)) 8

However, asymmetric information about worker characteristics may also have a strong impact on non-wage labour costs, in the form of hiring and firing costs. This notion has received relatively little attention in the training literature so far. Stevens (1994a) shows in a theoretical model that firms are willing to pay for general training in order to reduce recruitment costs of skilled workers. Training may also serve as a screening device by attracting the most able workers (Autor 2001, Cappelli 2004). Related to these issues, Booth and Satchell (1994), Cappelli (2004) and Euwals and Winkelmann (2002) find that the tenure of former employees can be increased by apprenticeship training. Therefore, firms may find it beneficial to invest in training in order to avoid costs associated with labour turnover.

Labour turnover costs can also be increased by specific institutions and labour market regulations. For example, employment protection legislation, as discussed in the previous chapter, can augment firing costs by making it more difficult for a firm to lay off workers that prove to be a bad match. In addition, anticipating a high level of firing costs, firms might invest more in their search and recruitment strategy, which increases non-wage labour costs even more. Apprenticeship training might therefore be a strategy for a firm to avoid such costs, since the costs to retain former apprentices as skilled workers are virtually zero.

Temporary work contracts could be thought of as an alternative to apprenticeship training, giving firms the possibility to screen future (permanent) employees. However, temporary workers may be inclined to mimic 'good' workers during the probation period, but reveal their true characteristics and work attitudes afterwards. In a study for Germany, Riphahn and Thalmaier (2001) have shown that worker absenteeism increases sharply after the probation period. Engellandt and Riphahn (2005) show that increased absenteeism after the probation period cannot be found for Swiss temporary workers, and the authors argue that the likely reason is the low level of employment protection in Switzerland. Hence, Swiss temporary employees are unable to send a signal to the employer by a

\footnotetext{
${ }^{7}$ See also Chang and Wang (1996). However, in the case of apprenticeship training, this type of asymmetric information is not likely to play a very important role, because apprenticeship training is certified and apprentices are evaluated at a state-regulated final exam. Therefore, firms have fairly accurate information about the extent and type of formal training a newly qualified apprentice had received. In line with this argument, Acemoglu and Pischke (2000) conclude that training certification increases the value of training to outside firms.

${ }^{8}$ Firms may also be willing to pay for general training if workers face substantial mobility costs (Malcomson et al. 2003).
} 
lower rate of absenteeism. However, the authors find that temporary workers have a $60 \%$ higher probability of working unpaid overtime compared to workers with a permanent position.

Several works analyse the question of whether unions also have an impact on the training behaviour of firms. Dustmann and Schönberg (2009) conclude that unionised firms are more likely to engage in apprenticeship training. They argue that unions serve as a commitment device by overcoming the infeasibility of long-term wage contracts, since trainees are guaranteed at least the union wage in the future. Booth and Chatterii (1998) show that unions can bring the level of training closer to the social optimum by setting a sufficiently high training wage, and therefore decrease turnover. Böheim and Booth (2004) and Green et al. (1999) find empirical evidence that workers with union coverage received more training in Britain, whereas Booth et al. (2003) find in addition that unionised workers received a higher return to training and a higher wage growth compared to workers without training. Green and Lemieux (2007), on the other hand, do not find any effect of union coverage on training provision in Canada. However, they provide some evidence that unions push firms to participate in the financing of training.

Summing up, while there are several reasons why firms are able to generate some kind of post-training benefit, in equilibrium one does not expect to see such benefits in the case of free-entry into the training market (e.g. Acemoglu and Pischke 1998; Dustmann and Schönberg 2009 assume a free-entry condition). With free-entry in the training market, apprentices' wages are raised up to a point where the net costs of training are equal to the expected post-training benefit in equilibrium.9 Another way of achieving zero-profits in equilibrium is to reduce the time apprentices spend in productive work, thereby reducing the benefit of training during the training period and at the same time protecting trained (union) workers from being substituted by apprentices 10 Hence, the existence of potential post-training benefits combined with a free-entry condition of firms or the existence of unions and/or works councils can be sufficient to explain the puzzle as to why German firms are willing to make a net-investment in apprenticeship training during the training period and why Swiss firms are not.

\section{Implications for apprenticeship training}

Cost-benefit surveys of apprenticeship training in Germany (Beicht et al. 2004) and Switzerland (Schweri et al. 2003) show that expected net training costs $N C$ amount to $E\left[N C_{\text {ger }}^{t}\right]>$ 0 for an average German firm and $E\left[N C_{c h}^{t}\right]<0$ for an average Swiss firm 11 Assuming that firms behave rationally, the expected post-training benefit $B$ (which cannot be observed) of a training firm must be larger than $N C$ if $N C>0$.

\footnotetext{
${ }^{9}$ This argument is in line with relatively high average apprentice wage in Germany compared to Switzerland, where post-training benefits in Switzerland are rather low.

${ }^{10}$ See Dionisius et al. (2009) for evidence for low productive use of apprentices in Germany compared to Switzerland.

${ }^{11} N C$ refers to the expected net training costs from the start until the end of the training period.
} 
Table 5.3.1.: Expected net training costs $N C$ and post-training benefits $B$

\begin{tabular}{|l|c|c|}
\hline & Germany & Switzerland \\
\hline Training firms & $E\left[B_{\text {ger }}^{t}\right]>E\left[N C_{g e r}^{t}\right]>0$ & $E\left[B_{c h}^{t}\right] \geq 0>E\left[N C_{c h}^{t}\right]$ \\
\hline Non-training firms & $E\left[N C_{g e r}^{n t}\right]>E\left[B_{g e r}^{n t}\right] \geq 0$ & $E\left[N C_{c h}^{n t}\right]>E\left[B_{c h}^{n t}\right] \geq 0$ \\
\hline
\end{tabular}

Another unknown parameter is the expected net training cost for non-training firms, i.e. $E\left[N C_{\text {ger }}^{n t}\right]$ for Germany and $E\left[N C_{c h}^{n t}\right]$ for Switzerland. Economic theory predicts that $E\left[N C^{n t}\right]>0$ and $E\left[B^{n t}\right]<E\left[N C^{n t}\right]$, otherwise non-training firms would not behave rationally and forgo an expected profit by not training apprentices. The relation between net training costs and post-training benefits for training and non-training firms in Germany and Switzerland is illustrated in Table 5.3.1.

To investigate the relation between a firm's training decision and labour market regulations, we need to obtain an estimate of net training costs for all firms, because the cost and benefit of training are obvious determinants of the firm's training decision. Our hypothesis is that $E\left[N C^{t}\right] \neq E\left[N C^{n t}\right]$, because training firms are most likely not a random sub-sample of all firms within a country. At least for Switzerland, we expect that net training costs for non-training firms will differ significantly from training firms and that they are non-negative on average. For Germany, net training costs will not necessarily differ between training and non-training firms, because the decision to train apprentices might be determined by differences in expected post-training benefits, i.e. $E\left[B^{t}\right] \neq E\left[B^{n t}\right]$.

\subsection{Data and cost-benefit model}

\subsubsection{Data}

Two cross-sectional surveys on the costs and benefits of apprenticeship training of both training and non-training firms that were conducted simultaneously in Germany (see Beicht et al. 2004) and Switzerland (Schweri et al. 2003) in 2000 provide the data source for our empirical analysis 12

The German survey contains a total of 2516 observations of training firms and 463 observations of non-training firms. The sample was randomly drawn from chamber register data and as such is representative for Germany. Information about more than 50 of the most frequently trained occupations is included in the data set. The Swiss survey includes a total of 2352 training and 2230 non-training firms in the year 2000. The survey is representative as the sample of firms has been drawn randomly from the Swiss Enterprise

\footnotetext{
${ }^{12}$ Note that the surveys focus on apprenticeship training exclusively. Concerning a possible substitution of apprenticeship training with other types of internal vocational training, Allaart et al. (2009) provide evidence that offering other internal training measures does not influence the firm's decision to train apprentices in Germany.
} 
Registry by the Swiss Federal Statistical Office 13 The survey includes all training occupations that have been available in the dual system in the year 2000. Both the German and Swiss survey include detailed information about the costs of training apprentices, such as wages of apprentices, costs for training personnel, material and infrastructure costs. Further, the data set includes measures of the productive contribution of apprentices at the workplace, i.e. the time that they spend performing productive tasks and their relative performance compared to experienced skilled workers within the firm.

From a methodological point of view, the results of the surveys are highly comparable. This is due to the fact that the survey questionnaires as well as the calculation method of costs and benefits have been harmonised before conducting the survey. The phrasing of most of the questions in the two questionnaires is identical. This highlights the uniqueness of our data, since it is difficult to obtain comparable firm-level micro data sets that have been conducted at the same time and using the same methodology in different countries. In both countries, data about our variables of interest were provided by the persons in charge of the firm's vocational training programme and the human resources department, respectively. These persons were chosen because they are typically the firm's most competent sources of information with respect to our survey questions.

We restricted our sample of training firms to include only occupations trained in a period of 3 years. Several occupations, such as mechanic, IT-technician or electronics-technician, are trained over a period longer than three years in both countries. As described above, the training period for these occupations differs between the two countries (the training period is 3.5 years in Germany and 4 years in Switzerland). Consequently, the comparison of the costs of training would be problematic, as differences in costs might simply be related to the different length of the training period. Further, we excluded firms in the public sector since these firms usually do not behave in a profit-maximising manner, which also might have consequences for their training decision and their training costs. The sample of training firms used for the calculation of costs and benefits consists of 1510 German and 1293 Swiss firms. In addition, we include 382 German and 1074 Swiss firms which were not training any apprentices at the time of the survey. Consequently, our data set consists of 1892 German and 2367 Swiss firms. All results presented in this article are weighted by sampling weights 14 The weighted training participation rate in our data is equal to $18 \%$ for Germany and $29.2 \%$ for Switzerland, which is in line with statistics based on administrative records. Descriptive statistics for training and non-training firms in each country are shown in Table A5.4.

Concerning the calculation of costs and benefits of training firms, Beicht et al. (2004) applied two different estimation methods. While the first method did not include expenses for part-time training personnel, the second one did. To maximise the comparability of the German and Swiss surveys, we re-calculated the German costs and benefits of training

\footnotetext{
${ }^{13}$ See Renfer (2002) and Potterat (2003) for more detailed information about the sample design.

${ }^{14}$ For the calculation of the weights for the Swiss survey see Renfer (2002) and Potterat (2003). For documentation on the calculation of the weights for the German survey see Schröder et al. (2001).
} 
according to the model used in the Swiss study, which is - except for some minor details - identical to the second method used in the German study.

\subsubsection{The cost-benefit model}

The costs of apprenticeship training for the training firm mainly consist of the wages of apprentices $w_{a}$ and the costs for the training personnel. The latter are given by the product of average yearly training hours $h_{t i}$ and the respective hourly wage $w_{t}$ of training personnel, which can be either management, full-time trainers, skilled workers or unskilled workers. In addition, there are expenses for material, infrastructure, external training courses, costs for hiring and administrative costs for apprentices, denoted by $X$. This yields the following costs for firm $i$ :

$$
c_{i}=w_{a i}+h_{t i} w_{t i}+X_{i}
$$

where $c_{i}$ denotes the costs for an average year of training per apprentice. The calculation of training costs suggests that they are mainly determined by wages. Thus, intra-firm differences in training costs are primarily due to variables that influence either the wage of apprentices or the wage of training personnel.

The calculation of the benefits $b$ is based on the type of work apprentices perform. An apprentice spends a fraction $\alpha$ of his productive working time $h$ performing activities that would otherwise be carried out by unskilled workers. Furthermore, the apprentice performs the remaining fraction $\beta$ of his productive working time $h$ performing skilled work 15 For the first type of work, we assume that the apprentice's performance has the same value as that of an unskilled worker, i.e. the wage of an unskilled worker $w_{u}$. However, it is assumed that the value of the apprentice's performance for an hour of skilled work is less than the hourly wage $w_{s}$ of a fully trained skilled worker. The value of the apprentice's work has to be adjusted by a relative productivity measure $\gamma$, since apprentices are not yet as efficient as a skilled worker with a vocational degree. Hence, the benefits of training to firm $i$ are given by

$$
b_{i}=\left[\alpha w_{u i}+\beta \gamma w_{s i}\right] h
$$

where $b_{i}$ denotes the benefits for an average year of training per apprentice. The net costs $N C$ of training an apprentice are the difference between the costs $c$ and the benefits $b$. As a result, the net costs of an average year of training per apprentice for firm $i$ are given by

$$
N C_{i}=c_{i}-b_{i}
$$

\footnotetext{
${ }^{15}$ Note that $1-\alpha-\beta$ is equal to the fraction of time the apprentice spends at the workplace that has
} no direct productive value to the firm. 
Table A5.3 reports the weighted averages of costs, benefits and net costs per apprentice for an average year of training in Germany and Switzerland. Further, the table provides descriptive information on the most important variables used for calculating costs and benefits. Training costs in Switzerland are somewhat higher than in Germany, which is mainly due to higher wages of training personnel, combined with the higher value for average weekly training hours. However, benefits in Switzerland exceed costs, leading to negative net costs (net benefit) of $€-1100$ for this country. On the other hand, benefits in Germany are much lower than the costs, resulting in net costs of $€ 7500$ per apprentice and year of training. The most important factor responsible for this large difference in benefits is the allocation of tasks to apprentices. Over the three-year period, Swiss apprentices spend much more time on productive tasks than German apprentices. The share of both unskilled and skilled tasks as a proportion of the overall time spent at the workplace ranges between $70 \%$ in the first to $80 \%$ in the last year of training for Swiss apprentices, whereas the corresponding values range between 40\%-70\% for German apprentices. In the light of these figures one could suspect that there might be differences in the quality of apprentices between the two countries. However, looking at the relative productivity measure $\gamma_{1}$ of the first year of training (see Table A5.3), it can be seen that the relative productivity is equal to $30.2 \%$ for German apprentices, whereas the corresponding value of their Swiss colleagues is equal to $32.4 \%$. This is an indication that German firms are, on average, not more selective compared to Swiss firms, even though German firms are willing to make a substantial net investment in the training of their apprentices. In addition, looking at the relative productivity $\gamma_{3}$ in the last year of training, we find virtually no difference in $\gamma_{3}$ between Germany and Switzerland. This indicates that the amount of human capital that apprentices accumulate during an apprenticeship programme is similar in both countries. Based on our measures of relative productivity, we find evidence that both the input and output quality of apprentices are similar in both countries.

In the following our main focus will be on estimating the expected net costs of apprenticeship training for non-training firms and to compare those to actual net costs of training firms.

\subsection{Econometric modelling}

Our aim is to estimate the expected net cost of a randomly drawn firm within each country. However, in the case of sample selection, the coefficients of the standard linear regression model (using only training firms) are biased, i.e. they are not valid for the whole population of firms. In our analysis, it is very likely that the sample of training firms differs not only in observable, but also in unobservable characteristics, such as availability of suitable work for apprentices, quality of apprentices (or applicants) or the firm's management competence and strategy. In order to obtain consistent estimates of the expected net cost of apprenticeship training in each country, we apply standard selection 
models used in the literature (see Heckman 1979) 16

We use the following parametric specification:

$$
N C_{i}=x_{1 i}^{\prime} \beta_{1}+\varepsilon_{i}
$$

and

$$
N C_{i}^{r}=x_{2 i}^{\prime} \beta_{2}+\eta_{i}
$$

where $N C_{i}$ denotes the net costs of training an apprentice and $N C_{i}^{r}$ denotes the highest expected net costs that firm $i$ is willing to bear. It should be noted that $N C_{i}^{r}$ may well be a substantial amount, if the firm expects to receive a high return on its training investment after the training period. Such a return may consist, among other factors, of rents from employing their own former apprentices as skilled workers, knowledge-transfer from the vocational school to the firm, and positive image effects.

Furthermore, $x_{1 i}$ is a vector containing variables such as firm size, industry, the share of skilled workers and regional variables. The vector $x_{2 i}$ contains the same variables, and, in addition, it must contain at least one exclusion restriction, i.e. a variable which is assumed not to have a direct influence on the net cost of training, but which has a significant effect on the firm's training decision. An obvious candidate is a variable that captures the post-training benefit to a firm but is unrelated to the net costs of training.

We use two different exclusion restrictions to identify the model. The first exclusion restriction is a measure of the tightness of the labour market. The variable we use is an indicator for whether a firm faced difficulties in finding skilled workers on the external labour market in the year 2000.17 Our hypothesis is that in times of a tight labour market, firms relying on hiring workers from the external labour market face more difficulties satisfying their labour demand than training firms, and are therefore inclined to train workers internally. Askilden and Nilsen (2005), Majumdar (2007), Wolter et al. (2006) and Muehlemann et al. (2007) previously found that firms operating in a tight labour market are more likely to train apprentices.

The second variable is a measure of the importance of internal training in reducing firing costs, which arise if a firm decides to lay off a particular worker 18 We argue that the

\footnotetext{
${ }^{16}$ We estimate two separate selection models for both Germany and Switzerland instead of a model that includes observations from both countries. The reason is that the latter model would require country dummy variable interaction terms with most independent variables, which would in turn make it very difficult to interpret the results. Table A5.5 shows the results from a net cost regression of the pooled data set including country dummy variables. It can be seen that several interaction terms with firm size as well as industry are significant at the $5 \%$-level.

${ }^{17}$ The exact phrasing of the survey question was: "Does your firm currently face the following personnel problems: Problems finding suitable skilled workers on the external labour market".

${ }^{18}$ This variable is constructed via two indicators mirroring the importance of (potential) returns to training after the training period. On the one hand, the variable measures the importance of reducing search costs in order to find skilled workers on the external labour market. On the other hand, it
} 
match quality between the worker and the firm is better if a firm hires an internally trained worker instead of a worker from the external labour market. Therefore, the probability of layoff is lower compared to external hiring. Further, firing costs must be positive for this exclusion restriction to hold, implying that there need to be frictions in the labour market.

The underlying hypothesis is that a firm is more likely to train apprentices if, in general, apprenticeship training is a more efficient way of satisfying its demand for skilled labour compared to hiring workers on the external labour market. This is the case if apprenticeship training serves as a screening device due to imperfect information about the worker's true ability and other characteristics. Information about a worker's ability might be of high value to a firm, if the costs of firing workers are high, e.g. due to a high degree of employment protection legislation. Training apprentices provides the employer with the relevant information, so that the firm can retain the most able apprentices as skilled workers after completion of training.

Net costs of training $N C_{i}$ are only observed if firm $i$ trains apprentices, which is the case if $N C_{i}<N C_{i}^{r}$, or

$$
N C_{i}-N C_{i}^{r}=x_{1}^{\prime} \beta_{1}-x_{2}^{\prime} \beta_{2}+\varepsilon_{i}-\eta_{i}=x_{i}^{\prime} \delta+\nu_{i}<0
$$

Dropping the subscript $i$, and letting $y_{1}=N C$ and $y_{2}$ denote the binary training indicator, the econometric model can be written as

$$
y_{1}=x_{1}^{\prime} \beta_{1}+\varepsilon
$$

and

$$
y_{2}=1\left[x^{\prime} \delta+\nu<0\right]
$$

where

$$
(\varepsilon, \nu) \sim N\left[0,\left(\begin{array}{cc}
\sigma_{1}^{2} & \sigma_{12} \\
\sigma_{12} & 1
\end{array}\right)\right]
$$

The standard linear regression model yields a conditional expected value of $N C$ for training firms of

$$
E\left[y_{1} \mid x_{1}, y_{2}=1\right]=x_{1}^{\prime} \beta_{1}-\sigma_{12} \frac{\phi\left(x^{\prime} \delta\right)}{\Phi\left(x^{\prime} \delta\right)}
$$

measures the importance of apprenticeship training to avoid worker-mismatch by retaining former apprentices. The variable takes on the value 1, if at least one of these two post-training benefits are considered to be important to a firm, and zero otherwise. The two indicators could have also been used as separate exclusion restrictions. However, since they measure similar post-training benefits, they are correlated. We therefore constructed a single variable in order to circumvent collinearity problems. 
and

$$
E\left[y_{1} \mid x_{1}, y_{2}=0\right]=x_{1}^{\prime} \beta_{1}+\sigma_{12} \frac{\phi\left(x^{\prime} \delta\right)}{1-\Phi\left(x^{\prime} \delta\right)}
$$

for non-training firms, where $\sigma_{12}=\rho \sigma_{1}$. If $\rho \neq 0$, then the error term has an expected value of $E\left[\varepsilon \mid x_{1}, y_{2}=1\right] \neq 0$. As a result, sample selection yields biased coefficient estimates, where the second term on the right hand side is the bias. Maximum-likelihood estimation can be carried out to consistently estimate the coefficients. The log-likelihood function is given by

$$
\begin{aligned}
l_{i}(\theta)= & \left(1-y_{2 i}\right) \log \left[1-\Phi\left(x^{\prime} \delta\right)\right]+y_{2 i} \log \Phi\left\{\left[x_{i}^{\prime} \delta+\sigma_{12} \sigma_{1}^{-2}\left(y_{1 i}-x_{1 i}^{\prime} \beta_{1}\right)\right]\right. \\
& \left.\times\left(1-\sigma_{12} \sigma_{1}^{-2}\right)^{-1 / 2}\right\}+\log \phi\left[\left(y_{1 i}-x_{1 i}^{\prime} \beta_{1}\right) / \sigma_{1}\right]-\log \left(\sigma_{1}\right) .
\end{aligned}
$$

\subsection{Results}

\subsubsection{The training decision of the firm}

The probability of providing training varies according to several observable characteristics of firm, e.g. it increases with firm size and differs amongst industries. There are no significant regional differences between the East and West Germany. In Switzerland, however, firms in the German-speaking part of the country have a higher probability of training apprentices compared to firms in the French- and Italian-speaking part. The estimation results of the maximum likelihood selection models for Germany and Switzerland are reported in Table 5.6.1 and Table 5.6.2, respectively.

The results with respect to the exclusion restrictions differ between Germany and Switzerland. The coefficient of the first exclusion restriction, i.e. difficulties in finding skilled labour, is not significant for German firms. Conversely, Swiss firms which faced difficulties to find skilled workers on the external labour market in the reference year 2000 were significantly more likely to train apprentices. These results are consistent with the economic climate in the two countries at the end of the year 2000. In Germany, the economic decline and therefore poor business outlook was already a reality and as a result there was no pronounced shortage of skilled labour 19 For Switzerland, economic conditions had been quite different, with a growth in GDP of $2 \%$ in the last quarter of 2000. Swiss firms that could not rely on retaining internally trained apprentices had significantly more difficulties in satisfying their demand for skilled workers, because the labour market was tight at the time.

For the interpretation of our findings it is necessary to note that only about one-third of the training companies in 2000 had recruited their apprentices in the year 2000; the other two-thirds of apprentices in training had been hired in the years 1998-1999. As we

${ }^{19}$ The results do not change if we exclude this variable from our model. 
have only cross-sectional data for 2000, we have no self-reported data on labour market tightness at the firm level for the earlier years. However, the training decision of twothirds of the apprentices in our sample had been made in economic conditions similar to those observed in 2000. Table A5.2 shows that unemployment in Switzerland had dropped continuously since 1997. Similarly, the percentage of firms reporting a shortage of qualified workers increased steadily until the year 2000. It can therefore be argued that all Swiss firms in our sample made the training decision in a period of continuous economic boom. As a sensitivity check, we have run a regression analysis separately for firms who decided to train apprentices in the years 1998 and 1999 and the results remained qualitatively unchanged. In addition, using more recent data for Switzerland, we have estimated the training participation of Swiss firms who decided to train apprentices in the years 2003 and 2004, a period in which unemployment was rising and the proportion of Swiss firm reporting a shortage of skilled workers had declined considerably (as illustrated in Table A5.2) 20 The results of these estimations show that our exclusion restriction does not significantly affect the firms' training decisions in this time period, indicating that the variable is indeed measuring labour market tightness, which in turn affects firms' probability of providing training 21

The results for the second exclusion restriction show a different picture. The importance of saving search and mismatch costs significantly raises the training probability in Germany, but this is not the case for Swiss firms. These results are consistent with labour market regulations in the two countries. While employment protection legislation is strong in Germany, the opposite is true for Switzerland (see Section 5.2 for a discussion). Post-training benefits obtained by retaining apprentices thus play an important role in the training decision of German firms, because the costs of laying off a worker who does not match the job requirements can be very high. This is different in Switzerland, where such costs are considerably lower.

\subsubsection{Net cost of training apprentices}

The results of the selection model for German firms (Table 5.6.1) show that training and non-training firms do not differ significantly with respect to expected net costs of training. A Wald test of independent equations $(\rho=0)$ yields a $\chi^{2}(1)$-statistic of 2.79 , which indicates that $\rho$ is not statistically different from zero at the $5 \%$ significance-level. This means that, given the observable firm characteristics, German non-training firms can expect the same net training costs as training firms if they were to engage in apprenticeship training.

Conversely, the results for Switzerland (Table 5.6.2) show that $\rho$ is positive and strongly significant with a $\chi^{2}(1)$-statistic of 14.41 , indicating sample selection. This means that

\footnotetext{
${ }^{20}$ The reason why we did not use this data for all of our estimations in this chapter is because there was no corresponding survey in Germany in the year 2004.

${ }^{21}$ The results of the sensitivity checks are available upon request.
} 
Table 5.6.1.: Maximum Likelihood Selection Model, German firms

\begin{tabular}{|c|c|c|}
\hline Dependent variable: & Net costs & $\begin{array}{l}\text { Training } \\
\text { (yes/no) }\end{array}$ \\
\hline 10-49 Employees & $\begin{array}{r}-1513.340^{* *} \\
(563.771)\end{array}$ & $\begin{array}{l}1.262^{* *} \\
(0.093)\end{array}$ \\
\hline 50-99 Employees & $\begin{array}{r}-1906.249^{*} \\
(898.233)\end{array}$ & $\begin{array}{l}1.810^{* *} \\
(0.164)\end{array}$ \\
\hline 100+ Employees & $\begin{array}{r}-1719.766 \\
(880.656)\end{array}$ & $\begin{array}{l}1.749^{* *} \\
(0.166)\end{array}$ \\
\hline Share of skilled workers (in \%) & $\begin{array}{r}-12.388 \\
(7.341)\end{array}$ & $\begin{array}{l}0.009^{* *} \\
(0.002)\end{array}$ \\
\hline Agriculture & $\begin{array}{r}-3751.807^{* *} \\
(891.028)\end{array}$ & $\begin{array}{l}2.012^{* *} \\
(0.407)\end{array}$ \\
\hline Energy, water supply & $\begin{array}{r}2937.530 \\
(2779.180)\end{array}$ & $\begin{array}{l}-0.768 \\
(0.431)\end{array}$ \\
\hline Construction & $\begin{array}{r}-932.587 \\
(644.338)\end{array}$ & $\begin{array}{l}0.310^{*} \\
(0.147)\end{array}$ \\
\hline Trade, automotive industry & $\begin{array}{r}-1379.146^{*} \\
(555.902)\end{array}$ & $\begin{array}{l}0.337^{* *} \\
(0.124)\end{array}$ \\
\hline Restaurant and hotel & $\begin{array}{r}-1982.649^{* *} \\
(585.660)\end{array}$ & $\begin{array}{r}0.249 \\
(0.191)\end{array}$ \\
\hline Transport and communication & $\begin{array}{r}41.044 \\
(1507.900)\end{array}$ & $\begin{array}{r}0.493 \\
(0.294)\end{array}$ \\
\hline Credit and insurance & $\begin{array}{r}3920.185^{* *} \\
(715.113)\end{array}$ & $\begin{array}{r}-0.068 \\
(0.218)\end{array}$ \\
\hline Real estate, IT, R\&D, Services & $\begin{array}{r}-1093.112 \\
(651.845)\end{array}$ & $\begin{array}{l}0.557^{* *} \\
(0.140)\end{array}$ \\
\hline Health and welfare & $\begin{array}{r}-507.369 \\
(1032.280)\end{array}$ & $\begin{array}{l}1.955^{* *} \\
(0.266)\end{array}$ \\
\hline Other public or personal services & $\begin{array}{r}-953.207 \\
(691.334)\end{array}$ & $\begin{array}{l}1.000^{* *} \\
(0.207)\end{array}$ \\
\hline Eastern Germany & $\begin{array}{r}-2323.462^{* *} \\
(347.023)\end{array}$ & $\begin{array}{l}-0.170 \\
(0.135)\end{array}$ \\
\hline Difficulties in finding skilled labour & & $\begin{array}{r}0.016 \\
(0.101)\end{array}$ \\
\hline Importance of search and mismatch costs & & $\begin{array}{l}0.774^{* *} \\
(0.088)\end{array}$ \\
\hline Constant & $\begin{array}{r}11271.960^{* *} \\
(1393.963)\end{array}$ & $\begin{array}{r}-2.659^{* *} \\
(0.144)\end{array}$ \\
\hline$\rho$ & 0.150 & $(0.088)$ \\
\hline & 5423.55 & $(187.679)$ \\
\hline Log-Likelihood & -4549 & \\
\hline Observations & 189 & \\
\hline
\end{tabular}

Robust standard errors in parentheses. Reference categories are: Firm size: 1-9 employees. Region: Eastern Germany. Sector: manufacturing sector. Difficulties in finding skilled labour: No. Importance of search and mismatch costs: No. ${ }^{*}$ Significant on the $5 \%$ level. ${ }^{* *}$ Significant on the $1 \%$ level. 
Table 5.6.2.: Maximum Likelihood Selection Model, Swiss firms

\begin{tabular}{|c|c|c|}
\hline Dependent variable: & Net costs & $\begin{array}{l}\text { Training } \\
\text { (yes/no) }\end{array}$ \\
\hline 10-49 Employees & $\begin{array}{r}215.380 \\
(847.140)\end{array}$ & $\begin{array}{l}0.449^{* *} \\
(0.082)\end{array}$ \\
\hline 50-99 Employees & $\begin{array}{r}-1642.435 \\
(1378.044)\end{array}$ & $\begin{array}{l}0.946^{* *} \\
(0.178)\end{array}$ \\
\hline 100+ Employees & $\begin{array}{r}-2251.820 \\
(1183.223)\end{array}$ & $\begin{array}{l}1.270^{* *} \\
(0.153)\end{array}$ \\
\hline Share of skilled workers (in \%) & $\begin{array}{r}-0.198 \\
(11.439)\end{array}$ & $\begin{array}{l}0.003^{* *} \\
(0.001)\end{array}$ \\
\hline Energy, water supply & $\begin{array}{c}-4333.540^{*} \\
(2159.719)\end{array}$ & $\begin{array}{r}0.380 \\
(0.222)\end{array}$ \\
\hline Construction & $\begin{array}{r}-603.143 \\
(1323.399)\end{array}$ & $\begin{array}{l}0.435^{* *} \\
(0.124)\end{array}$ \\
\hline Trade, automotive industry & $\begin{array}{r}-1074.726 \\
(1212.064)\end{array}$ & $\begin{array}{l}0.384^{* *} \\
(0.115)\end{array}$ \\
\hline Restaurant and hotel & $\begin{array}{r}2494.305 \\
(1660.293)\end{array}$ & $\begin{array}{r}-0.166 \\
(0.156)\end{array}$ \\
\hline Transport and communication & $\begin{array}{r}-423.810 \\
(1643.670)\end{array}$ & $\begin{array}{r}0.036 \\
(0.189)\end{array}$ \\
\hline Credit and insurance & $\begin{array}{r}-1004.174 \\
(1806.612)\end{array}$ & $\begin{array}{r}0.346 \\
(0.198)\end{array}$ \\
\hline Real estate, IT, R\&D, Services & $\begin{array}{r}1905.919 \\
(1453.231)\end{array}$ & $\begin{array}{r}0.060 \\
(0.121)\end{array}$ \\
\hline Education & $\begin{array}{r}298.266 \\
(2509.536)\end{array}$ & $\begin{array}{c}0.655^{*} \\
(0.305)\end{array}$ \\
\hline Health and welfare & $\begin{array}{r}-223.234 \\
(1291.432)\end{array}$ & $\begin{array}{l}0.619^{* *} \\
(0.127)\end{array}$ \\
\hline Other public or personal services & $\begin{array}{r}-914.986 \\
(1427.293)\end{array}$ & $\begin{array}{c}0.315^{*} \\
(0.144)\end{array}$ \\
\hline French-speaking part of Switzerland & $\begin{array}{r}-1560.011 \\
(887.394)\end{array}$ & $\begin{array}{r}-0.245^{* *} \\
(0.087)\end{array}$ \\
\hline Italian-speaking part of Switzerland & $\begin{array}{l}6318.404^{* *} \\
(2336.714)\end{array}$ & $\begin{array}{r}-0.578^{* *} \\
(0.206)\end{array}$ \\
\hline Difficulties in finding skilled labour & & $\begin{array}{c}0.458^{* *} \\
(0.069)\end{array}$ \\
\hline Importance of search and mismatch costs & & $\begin{array}{r}-0.054 \\
(0.068)\end{array}$ \\
\hline Constant & $\begin{array}{r}3870.667 \\
(2061.823)\end{array}$ & $\begin{array}{r}-1.329^{* *} \\
(0.122)\end{array}$ \\
\hline$\rho$ & 0.486 & $(0.107)$ \\
\hline & 8146.576 & $(448.516)$ \\
\hline Log-Likelihood & \multicolumn{2}{|c|}{$-8,392.85$} \\
\hline Observations & \multicolumn{2}{|c|}{2367} \\
\hline
\end{tabular}

Robust standard errors in parentheses. Reference categories are: Firm size: 1-9 employees. Region: German-speaking part of Switzerland. Sector: manufacturing sector. Difficulties in finding skilled labour: No. Importance of search and mismatch costs: No. ${ }^{*}$ Significant on the $5 \%$ level. ${ }^{* *}$ Significant on the $1 \%$ level. 
Swiss non-training firms have significantly higher expected net costs of apprenticeship training, given observable firm characteristics.

Comparing the estimates on the average expected net costs of training for non-training firms with observed net costs of training firms reveals that non-training firms in both countries would have to make a substantial net investment if they were to train apprentices (Table 5.6.3) 22 The difference in expected net training costs between German training and non-training firms is $€ 1800$ per apprentice and year, which is rather small and attributable to observed firm characteristics 23 Conditional on observable variables, i.e. firm size or economic sector, there is no significant difference in expected net costs of training between training and non-training firms in Germany. For example, the coefficients on firm size in the net cost equation (Table 5.6.1) indicate that smaller firms with less than 10 employees in Germany have significantly higher net costs compared to larger firms. Since the share of small firms among the non-training firms is equal to $88 \%$ (Table A5.3), this explains a large part of the difference in expected training costs between training and non-training firms. Furthermore, some differences in net costs arise due to differences in the allocation of training and non-training firms across economic sectors.

However, the difference between training and non-training firms is much more pronounced in Switzerland: compared to a net benefit of more than $€ 1000$ per apprentice and per year of training for the training firms, Swiss non-training firms would incur net costs of more than $€ 5500$ per year (Table 5.6.3). The reason for this difference is similar as for the German case. Large firms with 50 or more employees incur significantly lower expected net training costs compared to small firms with less than 50 employees (Table 5.6.2). In addition, the coefficient of the intercept is equal to somewhat less than $€ 4000$ and statistically different from zero.

Table 5.6.3.: Expected net costs of German and Swiss firms (in €)

\begin{tabular}{lrr}
\hline & Germany & Switzerland \\
\hline Training firms & 7493 & -1101 \\
& $(46.01)$ & $(64.52)$ \\
Non-training firms & 9280 & 5535 \\
& $(132.44)$ & $(72.33)$ \\
All firms & 8932 & 3730 \\
& $(104.51)$ & $(49.04)$ \\
\hline
\end{tabular}

Standard errors in parentheses.

Our results show that $E\left[N C_{c h}^{t}\right]<0<E\left[N C_{c h}^{n t}\right]<E\left[N C_{g e r}^{t}\right]=E\left[N C_{g e r}^{n t}\right]$

\footnotetext{
${ }^{22}$ The formulas to compute the expected net training costs for training as well as for non-training firms are given in equation (5.9) and equation (5.10), respectively.

${ }^{23}$ Note that the $95 \%$ confidence interval of the expected net costs for non-training firms is $€[9020 ; 9541]$. Hence, the mean estimate for non-training firms is statistically different from the average net costs of training firms, which are equal to $€ 7493$.
} 
Making use of economic theory, as discussed in Section 5.3, and assuming rational firm behaviour, our results have the following implication: if $E\left[N C_{g e r}^{t}\right]=E\left[N C_{\text {ger }}^{\text {nt }}\right]$ it follows that $E\left[B_{\text {ger }}^{t}\right]>E\left[B_{\text {ger }}^{n t}\right]$.

This means that if expected net costs of training are equal both for training and nontraining firms, as is the case in Germany, then it follows that non-training firms have lower expected post-training benefits.

In addition, our results reveal that Swiss non-training firms face lower expected net costs of apprenticeship training than German training firms. Therefore, it must be the case that Swiss non-training firms also face lower expected post-training benefits compared to German training firms.

Hence, we can draw some interesting comparisons of the impact of labour market regulations on training behaviour in Switzerland and Germany. In Germany, a large fraction of training firms must be able to generate a substantial post-training benefit in order to recoup the net investment during the training period. In Switzerland, however, only about a third of the training firms need to rely on benefits after the apprenticeship period in order to break even. In addition, while the expected training costs of non-training firms in Switzerland exceed those of training firms by more than $€ 6500$ per year of training on average, they are still lower compared to the realised training costs of German firms. Thus, based on observed firm behavior, we indirectly provide evidence that the German labour market is much more frictional compared to the Swiss labour market. This finding is in line with the OECD labour market indicators (see OECD 2004).

\subsection{Conclusions}

The analysis presented in this chapter is based on two identical representative firm-level surveys on the costs and benefits of apprenticeship training in Germany and Switzerland. We observe that German firms are willing to finance apprenticeship training, whereas Swiss firms on average only train if the financial investment is offset by the productive contribution of apprentices. Considering the strong similarities between Germany and Switzerland with respect to their vocational education and training systems, we argue in this chapter that an important reason for the differences in net costs of training can be found in the different labour market regulations of the two countries. A higher degree of employment protection increases the firm's labour adjustment costs. Apprenticeship training can, however, serve as a device to reduce such costs: on the one hand, firms can avoid the costs of hiring by employing former apprentices as skilled workers. On the other hand, firms can reduce labour turnover, as former apprentices tend to stay longer in a firm and the match quality between the firm and the worker is better compared to externally hired workers.

In the case where apprenticeship training constitutes a net investment for the firm, our results suggest that the firm's willingness to train depends strongly on whether appren- 
ticeship training can serve as a device to reduce labour adjustment costs. Furthermore, we find that in Switzerland, where labour markets are flexible, non-training firms face substantial expected net costs of training apprentices, which prevent them from engaging in apprenticeship training since the possibility of realising any post-training returns is very limited. German non-training firms, however, do not face significantly higher net costs than training firms. This implies for German firms that post-training benefits are the decisive factor for the training decision.

Our results are important in light of the debate about the consequences of a further deregulation of labour markets for the training system: if post-training benefits for training firms were to decrease as a result of a deregulation of the labour market, then the net costs of training would, ceteris paribus, have to decrease as well in order for firms to continue providing apprenticeship positions.

The analysis in this chapter shows that differences in employment protection legislation, which applies equally to all firms in a country, may be an important factor in explaining cross-country differences in training investments. However, in Germany, several labour market institutions, such as works councils or collective bargaining agreements, do not exist in all firms. In the following two chapters, we use the variation in the existence of firm-level institutions to analyse the impact of these institutions on the firms' training and recruitment behaviour. 


\section{A5. Appendix}

Table A5.1.: Detailed OECD indicators on regular employment

\begin{tabular}{lrrrr}
\hline OECD indicators & \multicolumn{3}{c}{ Germany } & \multicolumn{2}{c}{ Switzerland } \\
\cline { 2 - 5 } & 1999 & 2003 & 1999 & 2003 \\
\hline Regular procedural inconveniences & & & & \\
- Procedures (scale 0-3) & 2.5 & 2.5 & 0.5 & 0.5 \\
- Delay to start of notice (days) & 15 & 15 & 1 & 1 \\
\hline Difficulty of dismissal & & & & \\
Trial before eligibility arises (months) & 6 & 6 & 2 & 2 \\
Unfair dismissal compensation at & & & & \\
20 years of tenure (months) & 18 & 18 & 6 & 6 \\
Extent of reinstatement (scale 0-3) & 1.5 & 1.5 & 0 & 0 \\
\hline Notice period (in months) after... & & & & \\
9 months & 1 & 1 & 1 & 1 \\
4 years & 1 & 1 & 2 & 2 \\
20 years & 7 & 7 & 3 & 3 \\
\hline Severance pay (in months) after... & & & & \\
9 months & 0 & 0 & 0 & 0 \\
4 years & 0 & 0 & 0 & 0 \\
20 years & 0 & 0 & 2.5 & 2.5 \\
\hline Sourc: OECD (2004)
\end{tabular}

Source: OECD (2004) 
Table A5.2.: Economic conditions in Germany and Switzerland, 1997-2004

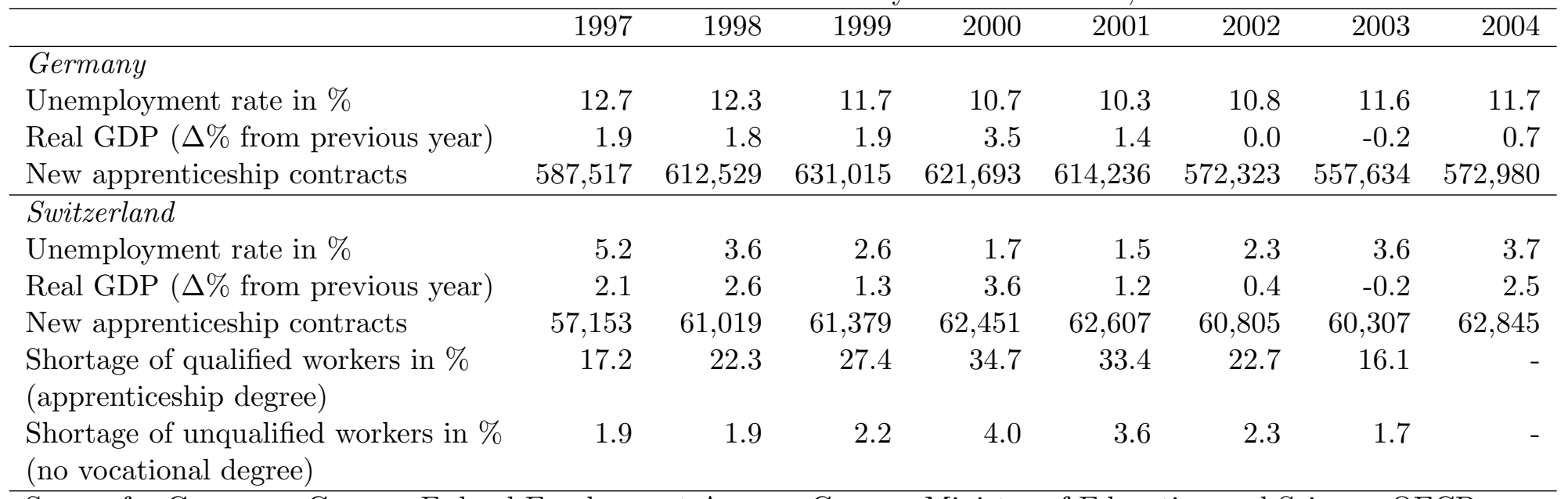

Source for Germany: German Federal Employment Agency, German Ministry of Education and Science, OECD

Source for Switzerland: Swiss Federal Statistical Office. Data on shortage of workers not available for 2004. 
Table A5.3.: Descriptive statistics, cost-benefit variables

\begin{tabular}{lrrrr}
\hline \multirow{2}{*}{ Variable } & \multicolumn{2}{c}{ Germany } & \multicolumn{2}{c}{ Switzerland } \\
Costs per average year and apprentice (in $€$ ) & 15517.94 & 5071.99 & 18046.54 & 6864.41 \\
Benefit per average year and apprentice (in $€$ ) & 8024.77 & 4009.45 & 19147.47 & 5666.32 \\
Net costs per average year and apprentice (in $€)$ & 7493.16 & 5603.28 & -1100.93 & 7629.85 \\
Monthly wage of management (in $€$ ) & 3407.28 & 1181.20 & 4907.73 & 1605.45 \\
Monthly wage of full-time training personnel (in $€)$ & 3037.70 & 198.31 & 3723.82 & 681.62 \\
Monthly wage of skilled workers (administrative, in $€$ ) & 2005.27 & 454.37 & 3188.05 & 628.62 \\
Monthly wage of skilled workers (technical/social, in $€)$ & 2279.55 & 531.21 & 3453.74 & 563.08 \\
Monthly wage of skilled workers (crafts, in $€$ ) & 1891.86 & 355.97 & 3184.98 & 634.16 \\
Monthly wage of unskilled workers (no voc. degree in $€)$ & 1477.83 & 325.50 & 2317.20 & 383.27 \\
Non-wage labour costs (in \%) & 37.30 & 10.67 & 23.14 & 9.67 \\
Yearly wage costs for apprentices $w_{a 1}($ (1st year, in $€)$ & 3727.40 & 3838.55 & 5908.26 & 2231.86 \\
Yearly wage costs for apprentices $w_{a 2}($ 2nd year in $€)$ & 4751.52 & 4339.42 & 7804.79 & 2564.17 \\
Yearly wage costs for apprentices $w_{a 3}(3 \mathrm{rd}$ year in $€)$ & 4788.89 & 4889.72 & 10164.65 & 2792.97 \\
\hline
\end{tabular}

......continued on next page 


\begin{tabular}{lrrrr}
\hline & \multicolumn{2}{c}{ Germany } & \multicolumn{2}{c}{ Switzerland } \\
Variable & Mean & Std. Dev. & Mean & Std.Dev. \\
\hline Days at the workplace $h_{t 1}$ (1st year) & 134.02 & 32.35 & 155.97 & 26.53 \\
Days at the workplace $h_{t 2}$ (2nd year) & 137.88 & 32.09 & 156.08 & 22.20 \\
Days at the workplace $h_{t 3}$ (3rd year) & 142.65 & 31.61 & 156.05 & 20.91 \\
Share of unskilled productive tasks $\alpha_{1}$ (1st year) & 29.75 & 19.18 & 48.07 & 23.16 \\
Share of unskilled productive tasks $\alpha_{2}$ (2nd year) & 31.53 & 17.96 & 36.20 & 19.83 \\
Share of unskilled productive tasks $\alpha_{3}$ (3rd year) & 27.65 & 18.38 & 26.05 & 18.78 \\
Share of skilled productive tasks $\beta_{1}$ (1st year) & 13.39 & 16.09 & 26.18 & 20.67 \\
Share of skilled productive tasks $\beta_{2}$ (2nd year) & 26.13 & 19.58 & 40.45 & 22.02 \\
Share of skilled productive tasks $\beta_{3}$ (3rd year) & 41.52 & 23.09 & 53.74 & 24.58 \\
Relative productivity $\gamma_{1}$ (1st year) & 30.24 & 14.93 & 32.42 & 22.75 \\
Relative productivity $\gamma_{2}$ (2nd year) & 46.82 & 18.24 & 49.12 & 22.67 \\
Relative productivity $\gamma_{3}$ (3rd year) & 68.58 & 22.00 & 69.24 & 25.68 \\
Training hours $h_{t}$ per apprentice/week & 5.44 & 2.86 & 6.58 & 4.71 \\
\hline
\end{tabular}

Number of observations: Germany: 1510, Switzerland: 1293. 
Table A5.4.: Descriptive Statistics, control variables

\begin{tabular}{|c|c|c|c|c|}
\hline \multirow[b]{3}{*}{ Variable } & \multicolumn{2}{|c|}{ German firms } & \multicolumn{2}{|c|}{ Swiss firms } \\
\hline & Training & Non-training & Training & Non-training \\
\hline & Mean & Mean & Mean & Mean \\
\hline \multicolumn{5}{|l|}{ Firm size: } \\
\hline 1-9 employees & 0.47 & 0.88 & 0.55 & 0.76 \\
\hline 10-49 employees & 0.40 & 0.11 & 0.34 & 0.22 \\
\hline 50-99 employees & 0.06 & 0.01 & 0.06 & 0.02 \\
\hline $100+$ employees & 0.07 & 0.01 & 0.05 & 0.01 \\
\hline \multicolumn{5}{|l|}{ Share of skilled workers } \\
\hline in training occupation (in \%) & $\begin{array}{c}70.35 \\
(29.39)\end{array}$ & $\begin{array}{c}59.34 \\
(32.32)\end{array}$ & $\begin{array}{c}57.58 \\
(29.44)\end{array}$ & $\begin{array}{c}53.07 \\
(33.90)\end{array}$ \\
\hline \multicolumn{5}{|l|}{ Industry: } \\
\hline Agriculture & 0.04 & 0.01 & & \\
\hline Manufacturing & 0.18 & 0.32 & 0.07 & 0.09 \\
\hline Energy, water supply & 0.001 & 0.004 & 0.005 & 0.003 \\
\hline Construction & 0.1083 & 0.09 & 0.19 & 0.13 \\
\hline Trade, automotive industry & 0.19 & 0.21 & 0.27 & 0.23 \\
\hline Restaurant and hotel & 0.05 & 0.10 & 0.08 & 0.15 \\
\hline Transport and communication & 0.02 & 0.02 & 0.04 & 0.05 \\
\hline Credit and insurance & 0.02 & 0.03 & 0.05 & 0.03 \\
\hline Real estate, IT, R\&D, Services & 0.12 & 0.15 & 0.08 & 0.14 \\
\hline Education & & & 0.02 & 0.01 \\
\hline Health and welfare & 0.12 & 0.02 & 0.12 & 0.08 \\
\hline Other public or personal services & 0.16 & 0.05 & 0.08 & 0.08 \\
\hline \multicolumn{5}{|l|}{ Region: } \\
\hline Western Germany & 0.19 & 0.25 & & \\
\hline Eastern Germany & 0.81 & 0.75 & & \\
\hline German-speaking part of Switzerland & & & 0.81 & 0.74 \\
\hline French-speaking part of Switzerland & & & 0.18 & 0.22 \\
\hline $\begin{array}{l}\text { Italian-speaking part of Switzerland } \\
\text { Training motives: }\end{array}$ & & & 0.01 & 0.04 \\
\hline Difficulties in finding skilled labour & 0.68 & 0.35 & 0.39 & 0.41 \\
\hline $\begin{array}{l}\text { Importance of search } \\
\text { and mismatch costs }\end{array}$ & 0.41 & 0.28 & 0.55 & 0.36 \\
\hline Observations & 1510 & 382 & 1293 & 1074 \\
\hline
\end{tabular}

Standard errors in parenthesis. 
Table A5.5.: OLS net cost regression, German and Swiss training firms

\begin{tabular}{|c|c|c|}
\hline Dependent variable: Net cost of training & Coeff. & Std.err. \\
\hline 10-49 employees & $1593.98^{*}$ & 770.23 \\
\hline 50-99 employees & 1172.74 & 1232.64 \\
\hline 100+ employees & 1344.54 & 690.51 \\
\hline Share of skilled workers (in \%) & 6.35 & 10.94 \\
\hline Energy, water supply & -3802.11 & 2081.73 \\
\hline Construction & 382.264 & 1283.06 \\
\hline Trade, automotive industry & -194.04 & 1161.49 \\
\hline Restaurant and hotel & 2148.11 & 1622.81 \\
\hline Transport and communication & -695.75 & 1593.62 \\
\hline Credit and insurance & -552.54 & 1638.32 \\
\hline Real estate, IT, R\&D & 1409.32 & 1425.50 \\
\hline Education & 1417.73 & 2346.62 \\
\hline Health and welfare & 1258.81 & 1195.04 \\
\hline Other public or personal services & -312.04 & 1346.43 \\
\hline German firm & $11334.16^{* *}$ & 1376.73 \\
\hline German firm $\times$ 10-49 Employees & $-2493.10^{* *}$ & 854.46 \\
\hline German firm $\times$ 50-99 Employees & -2152.88 & 1409.49 \\
\hline German firm $\times 100+$ Employees & $-2232.92^{*}$ & 929.82 \\
\hline German firm $\times$ Share of skilled workers (in $\%$ ) & -12.14 & 12.76 \\
\hline German firm $\times$ Agriculture & $-2904.35^{* *}$ & 661.61 \\
\hline German firm $\times$ Energy, water supply & 6028.11 & 3569.50 \\
\hline German firm $\times$ Construction & -1424.26 & 1430.45 \\
\hline German firm $\times$ Trade, automotive industry & -1027.47 & 1286.15 \\
\hline German firm $\times$ Restaurant and hotel & $-4183.43^{*}$ & 1722.42 \\
\hline German firm $\times$ Transport and communication & 1340.90 & 2201.83 \\
\hline German firm $\times$ Credit and insurance & $4628.90^{*}$ & 1785.42 \\
\hline German firm $\times$ Real estate, IT, $\mathrm{R}$ & -2274.70 & 1555.56 \\
\hline German firm $\times$ Health and welfare & -605.14 & 1444.55 \\
\hline German firm $\times$ Other public or personal services & -23.36 & 1465.39 \\
\hline Constant & $-2440.43^{*}$ & 1174.75 \\
\hline $\mathrm{R}^{2}$ & \multicolumn{2}{|l|}{0.28} \\
\hline Observations & \multicolumn{2}{|c|}{2803} \\
\hline
\end{tabular}

Robust standard errors. Reference category: Country: Swiss firm. Firm size: 1-9 employees. Sector: manufacturing. ${ }^{*}$ Significant on the $5 \%$ level. ${ }^{* *}$ Significant on the $1 \%$ level. 


\section{Works councils and firms' investment in VET}

\subsection{Introduction 1}

Recent literature has discussed the impact of works councils on worker productivity, wages, employment and capital investments. Works councils also have substantial rights and duties with respect to apprenticeship training. However, although apprenticeship training is the dominant educational track at the upper-secondary level in Germany, no studies thus far have analysed the effect of works council on the magnitude of firms' apprenticeship training investments.

Works councils are in charge of implementing and enforcing quality standards for apprenticeship training. Our main hypothesis, therefore, is that works councils increase a firm's costs for such training. In addition, a works council has to protect the regular workforce in the firm and consequently aims to avoid a substitution of regular workers through productive activities by apprentices. We thus expect the amount of productive work done by apprentices and therefore the firm's benefits of training to be lower in works council firms. Both mechanisms yield a higher net investment in training.

On the other side of the scale, works councils may also increase the benefits of training, because one of their main tasks is to improve job security and working conditions. As trainees spends the majority of their time during an apprenticeship programme at the work-place, they become an integral part of the workforce. Works councils have a formal obligation to represent the interests of the apprentice, thereby increasing the likelihood that the firm will offer a regular employment contract after training. We thus expect the retention rate for former apprentices to be higher in these firms. Once a former apprentice is part of the regular work force, expected tenure is longer due to works council rights in the firing procedures of the firm. Thus, works councils may justify higher human capital investments, because higher retention rates and longer tenure of former apprentices enable the firm to recoup training investments over a longer period.

\footnotetext{
${ }^{1}$ This chapter is based on the paper Works Councils, Collective Bargaining and Apprenticeship Training by Ben Kriechel, Samuel Mühlemann, Harald Pfeifer and Miriam Schütte. The paper is forthcoming in: Industrial Relations (Kriechel et al. 2014).
} 
For our empirical analysis, we make use of detailed and representative firm-level data on the costs and benefits of apprenticeship training in Germany for the year 2007. We present a model that takes into account both the firm's costs and benefits during the training period as well as potential benefits after training. We then empirically test whether a firm with a works council differs in certain parameters of the model compared to a firm without a works council. We differentiate between firms that are subject to collective bargaining and those that are not. We further offer a separate analysis for a subsample of medium-sized firms with 20 to 100 employees, thereby excluding small (large) firms with a very low (high) probability of having works councils.

Our main results do indeed suggest that a firm with a works council makes a significantly higher net investment in training compared to a firm without one, but only if it is also covered by collective bargaining agreements. We further find that a firm with a works council retains a higher percentage of apprentices than a firm without this institution. This enables a works council firm to generate higher post-training benefits and thus explains part of the firm's incentives to bear the higher costs for training. Finally, we find some evidence for a lower training ratio (i.e. the share of apprentices among all employees in the firm) in a works council firm compared to a non-works council firm. This result implies a more restrictive hiring policy in a firm, where firm-level institutions increase training investments and the retention probability of former apprentices.

The remainder of the chapter is structured as follows. In the next section, we provide information on the institutional setting in Germany and review the relevant literature. In Section 3, we present a simple theoretical model of the costs and benefits of apprenticeship training and formulate hypotheses about the impact of works councils and collective bargaining on the important determinants of costs and benefits. We describe our data in Section 4, and present the empirical estimation strategy in Section 5. We then discuss the results in Section 6, while Section 7 concludes the chapter.

\subsection{Institutional setting and relevant literature}

\subsubsection{Works councils}

Works councils play an important role within the German system of industrial relations. The Works Constitution Act (Betriebsverfassungsgesetz, 1972) implemented in the early 1970s outlines the formation conditions and all rights and duties of works councils. According to this act, the staff in every firm with 5 or more employees has the right to elect a works council. Elected members of the works council are to be exempted from their regular work without pay-cuts during their council activities. In larger firms, works council members are exempted full-time.2 The rights and duties of a works council are

\footnotetext{
${ }^{2}$ The number of works council members that have to be exempted full-time increases with the total number of employees in the firm. A firm with 200 employees has to exempt 1 works council member, while a firm with up to 8000 employees has to exempt 10 members.
} 
manifold. It may formally object to hiring and firing decisions taken by the management in the event that social criteria are not respected. It further monitors safety standards and is responsible for the implementation and monitoring of collective bargaining agreements at the plant level. Despite the legal right to establish a works council, only $10 \%$ of firms with more than 5 employees in the private sector feature a works council. However, since the probability of having a works council increases with firm size, well over $40 \%$ of all employees are working in a firm with a works council. While the percentage of firms with a works council has been relatively stable over the last two decades, the share of employees represented by works councils has dropped by around 10 percentage points since 1996 (Ellguth and Kohaut 2010).

According to the exit-voice hypothesis (Hirschman 1970), workers have two options when they are dissatisfied with their employment situation. They can either leave the firm or express their dissatisfaction towards the management. Works councils are an example of a collective voice for workers at the firm level. In Germany, the voice function of works councils sometimes co-exists with collective bargaining agreements that already define wages, working time and safety issues on a sectoral level. Thus, works councils in firms covered by collective agreements do not need to bargain for them. However, also in this case, a works council has extensive information, consultation and co-determination rights regarding employment issues. The impact of works councils on the mobility of workers has been discussed by Freeman (1976, 1980). Several empirical studies confirm that the presence of works councils leads to a lower separation rate (Hirsch et al. 2010) both in terms of voluntary quits (Pfeifer 2010) and in terms of lay-offs (Frick 1996). Boockmann and Steffes (2010) find a positive works council effect on tenure, which is greatest for blue-collar workers. Concerning levels of employment, Addison and Teixeira (2006) find a negative effect of works councils on employment growth, while Jirjahn (2010) reports positive employment effects, when taking potential endogeneity of works councils into account.

A number of early studies further found significant effects of works councils on productivity, profitability and wages (Addison, 2001; Hubler and Jiriahn, 2003) 3 More recent studies, however, point to a neutral impact of works councils on investments (Addison et al., 2007) and productivity (Wagner, 2008). The positive effects on wages remain robust even when more sophisticated estimation methods and richer data sets are applied (Addison et al., 2010).

\subsubsection{Linking apprenticeship training and works councils}

Before turning to the link between works councils and apprenticeship training, it is useful to pin down the main features of this 'dual' system of training in Germany. About twothirds of all young adults enter the apprenticeship training system. Thus, the 'dual' system

$\sqrt[3]{\text { Addison et al. (2004) and Frege (2002) }}$ provide assessments of theory and the early literature on the economic consequences of works councils. 
is the most important educational pathway at secondary level in Germany. The apprentice signs a formal contract with the firm and receives a predetermined wage over the entire training period. An apprentice's wage is usually a fraction of the wage paid to fully trained workers in the same occupation.4 Depending on the occupation of training, the duration of an apprenticeship varies between 2 and 3.5 years, during which the apprentice spends on average 2 days of a working week in a vocational school and the rest of the week in the firm. During the time in the firm, apprentices learn in different ways how to become a skilled worker. Some firms, especially larger ones, use separate in-house training centres and organise additional internal schooling. Other firms train more 'on the job', which effectively increases the benefits for the training firm due to the productive activities of the apprentices. Thus, the way apprentices are trained in the firm strongly impacts on the cost-benefit relation of training. At the end of the training, apprentices take an external standardised exam. The certificate obtained is acknowledged by employers throughout the country.

The Works Constitution Act explicitly gives a works council the right to participate in the planning, implementation, and monitoring of vocational training activities in the firm (Oetker 1986; Hammer 1990). With regard to apprenticeship training, the role of a works council is to ensure that the content and the process of training meets the formal training regulations (Ausbildungsordnungen) 5 A works council has the right to call for a replacement of training personnel neglecting its duties (§98). Thus, the training quality in a firm with a works council may be positively affected by this institution, as it is more likely that negligence of such duties will go undetected in a firm that does not have a works council. A higher level of training quality may go hand in hand with higher training costs, as workers in charge of training spend more on training-related issues.

Despite this direct institutional link between works councils and training activities of firms, only few studies deal with the relation of works councils and the firm's organisation of apprenticeship training. Freeman and Lazear (1995) argue that a works council leads to a longer-run perspective of workers, and that a firm with a works council consequently invests more in the firm-specific human capital of workers, which in turn also increases the firm's willingness to invest in general human capital (Kessler and Lülfesmann 2006). In line with Freeman and Lazear (1995), a recent contribution by Hirsch et al. (2010) shows that a German firm with a works council has a lower separation rate of employees than a firm without a works council. Thus, the former may be more inclined to invest in the training of apprentices compared to the latter if expected tenure - and therefore the pay-off period for training investments - is longer.

\footnotetext{
${ }^{4}$ An apprentice's wage usually increases annually over the training period.

${ }^{5}$ Since training regulations have the status of a legal regulation, a violation on part of the firm may have severe consequences for the firm. The training regulation outlines the main contents of training to be undertaken by the firm. However, the firm has considerable freedom in how to achieve the respective training aims.
} 
While the latter studies focus on the investment in training once the worker is in the firm, Backes-Gellner et al. (1997), in one of the few empirical works on this issue, analyse the role of works councils for the quantity of apprentices hired. They find that a firm with a works council employs a significantly lower proportion of apprentices per employee than a firm without this institution. Yet, they do not find any significant effects of a works council on the retention rate of apprentices. This is explained by an early selection at the apprenticeship level, while the goal of a works council is to limit the number of participants in the rent-sharing process. Furthermore, Niederalt (2004) finds a negative effect of works councils and a positive effect of collective bargaining agreements on a firm's willingness to offer apprenticeship training. He further shows that works councils impact negatively on a firm's training intensity, while the impact of collective bargaining agreements on training intensity is not significant.

The second pillar of industrial relations in Germany is the collective bargaining of social partners. Although the coverage of collective bargaining has declined in recent years (Fitzenberger et al. 2011) this type of institution remains important and may have considerable effects on the firm's training behaviour. Dustmann and Schönberg (2009) find that unionisation increases participation in training and that a non-unionised firm is less likely to finance training. Furthermore, Dustmann et al. (2009) find that de-unionisation goes hand-in-hand with an increased skilled-unskilled worker wage differential.

In practice, unions support the implementation of a works council. Conversely, as many works council members are also members of unions, the two institutions are interwoven at the firm level. The interrelation of the two types of institutions has consequences for our analysis. We argue in this chapter that collective agreements bargained by unions amplify the effectiveness of a works council's voice function through at least three channels. First, a works council can draw on informational and logistic resources provided by the respective union responsible for the collective agreement (Müller-Jentsch 1995). Second, collective bargaining agreements reduce potential conflicts between the works council and the management of a firm, because several sensitive issues, e.g. wages, working time and safety issues, are already resolved externally. This may lead to a more constructive cooperation between the works council and the management (Freeman and Lazear 1995). Third, collective agreements reduce the burden for a works council to deal with several issues simultaneously. More resources are available for employment and training matters, which leads to a more effective voice function for workers in the firm (Berger 2012). For our analysis, we consequently expect the works council's influence to be stronger in a firm that is also covered by collective agreements 6

\footnotetext{
${ }^{6}$ Collective bargaining agreements exist on multiple levels, such as the regional, sector and firm level. Firm-level agreements, however, are relatively rare. About $3 \%$ of all covered firms have arrangement and these firms are usually large. The data source used in this chapter does not distinguish between different levels of agreements.
} 


\subsection{Theoretical framework}

The cost and benefits of apprenticeship training within the firm can be summarised in the following framework 7 . The firm aims to maximise the total benefits of training, consisting of benefits during training $\left(B_{t}\right)$, and expected benefits after training $\left(E\left[B_{t+1}\right]\right)$. Since training also involves costs $\left(C_{f}\right)$ during the training period, the principal maximisation problem can be formulated as 8

$$
\max B_{t}-C_{t}+E\left[B_{t+1}\right]
$$

First, benefits during the training period $\left(B_{t}\right)$ arise from the apprentice performing unskilled work to which he devotes $h_{u}$ hours of his working time. Apprentices also perform $h_{s}$ hours of skilled work with a relative productivity of $\gamma<1$, since apprentices are not yet as productive as skilled workers in the training occupation. The total time an apprentice spends on productive work is consequently given by

$$
h_{w}=h_{u}+h_{s}
$$

The apprentice's involvement in skilled and unskilled tasks is valued at the within-firm wage rate of skilled $\left(w_{s}\right)$ and unskilled workers $\left(w_{u}\right)$. The benefit of an apprentice during the training period, is therefore given by

$$
B_{t}=h_{u} \cdot w_{u}+h_{s} \cdot \gamma \cdot w_{s}
$$

The costs to the training firm $\left(C_{t}\right)$ consist of the wage of the apprentice $w_{a}$, the wage of training personnel $w_{t}$ for the number of hours $h_{t}$ during which training personnel was not able to pursue other productive tasks. Other expenses for an apprentice, such as material, infrastructure, external training courses, recruitment and administrative costs, are denoted by $X$ :

$$
C_{t}=w_{a}+h_{t} \cdot w_{t}+X
$$

Finally, there is a possibility that a firm generates returns in the period following the training programme. Such post-training benefits $\left(B_{t+1}\right)$ crucially depend on whether apprentices are retained, and if so, for how long these workers remain with the training firm. The retention rate of apprentices is denoted by $\kappa$. The sources for post-training benefits are given by (i) reduced hiring costs $H(\kappa)$ and (ii) reduced firing costs $F(\kappa)$. Retaining former apprentices reduces both the firm's need to hire skilled workers, and, through employer-learning, the likelihood of having to fire an internally trained worker, which is

\footnotetext{
${ }^{7}$ The basis for a cost-benefit model of apprenticeship training has been laid by the "Expert-Commission on the costs and financing of vocational education and training" (Sachverständigenkommission Kosten und Finanzierung der beruflichen Bildung, 1974)

${ }^{8}$ Firms maximise over the number of apprentices.
} 
due to the employer's information advantages regarding the worker's ability and motivation. A further channel for post-training benefits is (iii) a compressed wage structure. In this case, the firm is able to extract a rent $\Delta(\tau)$ from paying a wage below productivity, and the size of that rent must be positively affected by employing former apprentices as skilled workers. One could think of the superior ability of retained apprentices compared to those on the external labour market ('lemons'). Due to information asymmetries, even the most talented apprentices are willing to stay with the training firm despite the wage being below productivity 9

Post-training benefits $B_{t+1}$ can thus be summarised as

$$
B_{t+1}=H(\kappa)+F(\kappa)+\Delta(\tau)
$$

Total training benefits consist of net benefits (costs) during the training period $t$ as well as a potential post-training benefit in period $t+1$. The maximisation problem in equation 1 thus extends to

$$
\max B_{t}\left[w_{u}, w_{s}, \gamma, h_{u}, h_{s}\right]-C_{t}\left[w_{a}, h_{t}, w_{t}, X\right]+I\left[B_{t+1}(H(\kappa), F(\kappa), \Delta(\tau)] .\right.
$$

Instead of focusing on the analytical solution of the maximisation problem above, our aim is to analyse whether a firm with a works council (in the following: WoCo) differs from a firm without a works council (in the following: NWoCo) with respect to the relevant factors of the maximisation problem.

First, it has been observed that wages $\left(w_{u}, w_{s}\right)$ in WoCo are generally higher than in NWoCo (Addison et al. 2010). This, in our framework, means that the value of productive work performed by an apprentice is higher in WoCo than in NWoCo. However, it is not clear if the relative productivity of an apprentice $\gamma$ differs between WoCo and NWoCo, as we might not expect the productivity of an apprentice in a firm to be systematically different from the productivity of a skilled worker.

The hours that an apprentice spends performing productive activities $\left(h_{u}+h_{s}\right)$, however, are likely to be lower in WoCo than NWoCo, because a works council may have the goal to protect work volume for the existing work-force, therefore opposing substitution of productive activities by the apprentice. Thus, even if the value of productive work is higher in WoCo than NWoCo, the overall effect on the training benefit is ambiguous, as WoCo are likely to reduce the volume of productive work $\left(h_{w}\right)$ allocated to an apprentice.

The gross costs of apprenticeship training might be affected through apprentice pay $\left(w_{a}\right)$ being higher in WoCo than NWoCo due to a more selective recruitment strategy of WoCo, which has been argued by Backes-Gellner et al. (1997). WoCo may offer higher apprentice pay in order to attract the more able school-leavers. WoCo may also be inclined to offer more training hours $\left(h_{t}\right)$ to their apprentices. Instruction time in WoCo might therefore

${ }^{9}$ The post-training benefits can be seen as an option that the firm holds in the hiring of their own apprentices. 
be more expensive, as training personnel - typically skilled workers in the same training occupation - receive higher wages $\left(w_{t}\right)$ than in NWoCo. Thus, we expect gross training costs to be higher in WoCo than in NWoCo.

Summing up, the total effect of works councils on net costs is ambiguous based on the theoretical predictions above, and therefore needs to be determined empirically.

With respect to post-training benefits $\left(B_{t+1}\right)$, we expect those to be higher in WoCo than in NWoCo, if (i) hiring costs $(H)$ in WoCo are higher, e.g. because WoCo has higher requirements with regards to the qualification of employees, (ii) firing costs $(F)$ are higher, because it is more difficult and therefore more costly to lay off an individual worker in the presence of a works council, or (iii) the wage structure with respect to the skill level $(\Delta \tau)$ is more compressed in WoCo than NWoCo, e.g. because workers in WoCo have a higher productivity than in NWoCo 10

The realisation of post-training benefits crucially depends on the retention rate of former apprentices $(\kappa)$. Assuming a more selective recruitment strategy, it would be expected that WoCo retain a higher share of apprentices than NWoCo. In addition, we expect that an apprentice would accept a job with a higher probability in WoCo than in NWoCo, because a works council typically signals better working conditions, higher wages and increased job security compared to NWoCo (Backes-Gellner and Tuor 2010). Thus, based on theoretical arguments, we expect that WoCo has higher expected post-training benefits than NWoCo - and thus, WoCo would be willing to accept higher net training costs than NWoCo.

As argued in Section 2, we further expect that the effects of a works council may be reinforced by collective bargaining agreements in the firm. Freeman and Lazear (1995) argue that distributional conflicts are 'externalised' in firms covered by collective bargaining, which leads to a more efficient cooperation between works councils and management. This would, on the one hand, dampen the wage effects of a works council, as wages are predominantly determined on the regional or sectoral level. By contrast, a works council could fully concentrate on worker representation, which could lead to increased tenure of skilled workers 11 Thus, we expect the effect of a works council on wages to be lower in a firm that is also subject to a collective bargaining agreement, but we would, in turn, expect a stronger effect of a works council on tenure.

In the remainder of the chapter, we will now focus on testing differences in the relevant factors of the firm's maximisation problem above empirically and discuss implications for the training behaviour of WoCo and NWoCo.

\footnotetext{
${ }^{10} \mathrm{~A}$ general advantage of all training firms (both WoCo and NWoCo) is that they can learn about the workers true ability in a work related context (Schönberg 2007; Pinkston 2008; Lange 2007). Lange (2007) shows that employers learn quickly, after three years the initial expectation error is halved for all employers. However, there is no reason why a WoCo would learn about an apprentice's ability more quickly than a NWoCo.

${ }^{11}$ Pfeifer (2010) shows that the effect of a works council on voluntary quits is larger if the firm is also covered by collective bargaining agreements. Frick and Möller (2003) provide evidence that the effect on separations is largest when works councils as well as collective agreements are present in the firm.
} 


\subsection{Data}

For the analysis in this chapter, we make use of unique firm-level data containing detailed information on the costs and benefits of apprenticeship training. The survey was carried out by the Federal Institute for Vocational Education and Training (BIBB) for the reference year 2007 (Schönfeld et al. 2010). It is the fourth wave of a series of costbenefit studies. Prior surveys were conducted for the years 1980 (Noll et al. 1983), 1990 (von Bardeleben et al. 1995) and 2000 (Beicht et al. 2004). About 3000 German training firms were interviewed in a computer-assisted personal interview (CAPI) 12 . The sample was randomly drawn from social security register data and, as such, is representative for Germany. Interview partners in the firms were the persons responsible for the training organisation and, if necessary, the human resource manager of the firm. In small firms, the interview partner was often the owner or the general manager of the firm.

To calculate the costs of training, we require information on direct costs, such as apprentices' wages, material and costs for administration as well as indirect costs, such as the productivity loss of part-time trainers. For the calculation of the benefits during the training period, firms were asked to provide information about apprentices' productive work both on the unskilled and skilled level. Further, firms reported a relative productivity measure for the hours spent on skilled work and information on wages of unskilled and skilled workers in the training occupation.

Apart from questions about benefits for the period during training, firms supplied information about the recruitment, retention and tenure of former apprentices. In addition, the data set includes information about the process and organisation of apprenticeship training in the respective firm.

For the analysis in this chapter, we exclude firms operating in the public sector as well as firms with less than 5 employees. The reason to exclude the former is that firms in the public sector usually do not follow a profit-maximising strategy, as can be assumed for private sector firms. The reason for excluding small firms with fewer than 5 employees is that the legal right to establish a works council applies only to employees in firms with a staff of 5 or more employees. Eliminating these firms from the sample leaves us with 2362 training firms. Since the share of firms with a works council becomes very small among firms with less than 20 employees and very large among firms with more than 100 employees (Figure A6.1), we supply a separate analysis for the group of firms with a size between 20 and 100 employees, as suggested by Addison et al. (2010) - which reduces our sample to 700 firms.

Descriptive information about the samples is provided separately for NWoCo and WoCo in Tables A6.1 and A6.2.

\footnotetext{
${ }^{12}$ The field work was managed by the Institute for Applied Social Sciences (infas). For documentation on the survey methodology as well as the calculation of weights used in the subsequent analysis see Schröder and Schiel (2008).
} 


\subsection{Estimation strategy}

Our primary aim is to estimate whether and how WoCo differs from NWoCo with respect to the costs and benefits of apprenticeship training. In a first step, we estimate this effect on gross costs, benefits and net training costs. Second, we investigate this effect in more detail by analysing relevant subcomponents of the cost-benefit model, as discussed in Section 6.3. Third, we are also interested in whether WoCo and NWoCo differ in respect to post-training benefits. We use a variable measuring the percentage of apprentices that remain in the training firm 1, 3 and 5 years after completion of training. Finally, we investigate the training intensity in terms of the quantity of apprentices. We analyse both the ratio of apprentices to all employees within a firm as well as the ratio of apprentices to skilled workers in the training profession. As we only focus on training firms, the variables of training ratio are continuously distributed, with only very few firms reporting a training ratio $>1$.

For our estimation we apply nearest neighbour matching models 13 Our goal is to estimate average treatment effects of a work council.

Let the observed outcome be denoted by $Y_{i}$ :

$$
Y_{i}=Y_{i}\left(W o C o_{i}\right)=\left\{\begin{array}{lll}
Y_{i}(0) & \text { if } W o C o_{i}=0 \\
Y_{i}(1) & \text { if } W o C o_{i}=1
\end{array}\right.
$$

where $W_{o} C_{i}$, for $W_{o} C_{i} \in 0,1$ is the treatment indicator. We are interested in estimating the average treatment effect (ATE), which can be interpreted as the overall effect of a works council on the entire sample of training firms:

$$
A T E_{i}=E\left[Y_{i}(1)-Y_{i}(0) \mid W o C o_{i}=1\right]
$$

To ensure that the matching estimators are a consistent estimate of the treatment effects of interest, we need to assume that the assignment to treatment (i.e. implementing a works council) is independent of the outcomes, conditional on the covariates included in the matching process. Further, the probability of implementing a works council is restricted between zero and one (Abadie et al. 2004). While in our case, the treatment cannot be interpreted as random, the unconfoundedness assumption (see Rosenbaum and Rubin 1983) holds when there are no unobserved factors that affect both the employees' decision to implement works councils and the costs and benefits of apprenticeship training. Thus, we need to assume that the treatment $W_{o} \mathrm{Co}_{i}$ is independent of the outcome variables $(Y(0), Y(1))$, i.e. the cost and benefit variables. To ensure independence of the outcome variables we would need an experimental setting where some firms are randomly assigned

\footnotetext{
${ }^{13}$ For seminal work on matching methods see among others Rubin (1974) and Rosenbaum and Rubin
} (1983). 
to implement workers councils, while other firms would not be allowed to install works councils. Even though apprenticeship training is typically not the core business of a firm, and employees may base their decision to implement a works council solely on unobserved factors that do not affect the costs and benefits of apprenticeship training, our findings cannot be interpreted as strictly causal as is the case in any non-experimental analysis. A potential violation of the unconfoundedness assumption can be found in wages, since those are an integrated part of training costs (and benefits). Unobserved firm heterogeneity, such as the average worker quality in the firm, may be correlated both with the probability that a firm instates works councils as well as with average labour productivity - and therefore average wages. To account for such heterogeneity, we have included qualitative measures describing the economic situation, productivity, and the legal form of the company.

A further issue is that the probability of instating works council increases strongly by firm size. While firms with 5 to 20 employees almost never instate works councils, it can be observed that the majority of firms with more than 100 employees have works councils (see Figure A6.1 in the Appendix) 14 To reduce potential biases due to unobserved firm characteristics correlated with firm size, we also carry out our estimations in a reduced sample containing firms with 21 to 100 employees.

We apply a simple matching estimator proposed by Abadie et al. (2004) to estimate the counterfactual outcomes, i.e. the value that is not observed for firm $i$. While the observed outcome is its own estimate, the unobserved outcome is estimated by averaging the outcomes of the most similar firms in the other group of firms, so that

$$
\hat{Y}_{i}(0)=\left\{\begin{array}{cl}
Y_{i} & \text { if } W o C o_{i}=0 \\
\frac{1}{\# \mathcal{J}_{M}(i)} \sum_{l \in \mathcal{J}_{M(i)}} Y_{l} & \text { if } W o C o_{i}=1
\end{array}\right.
$$

and

$$
\hat{Y}_{i}(1)=\left\{\begin{array}{cl}
\frac{1}{\# \mathcal{J}_{M}(i)} \sum_{l \in \mathcal{J}_{M(i)}} Y_{l} & \text { if } W o C o_{i}=0 \\
i & \text { if } W o C o_{i}=1
\end{array}\right.
$$

where $\mathcal{J}_{M}(i)$ denotes the set of indices for the matches for a firm $i$ (for more details see Abadie et al. 2004).

For the matching of WoCo with NWoCo firms, we use a set of structural variables from the survey. Several of these covariates are required to exactly match the respective other firm. The precondition for a valid match thus is an identical value in these variables, which include binary variables on whether the firm is covered by collective wage agreement,

\footnotetext{
${ }^{14}$ With respect to collective bargaining, Figure $\overline{A 6.2}$ implies that a firm's probability to be covered is less correlated to firm size.
} 
region (East- and West Germany) and on whether the firm uses a separate in-house training centre in the process of training. We further require the matched firm to be in the same economic sector ( 5 categories) and train in the same occupation (12 categories). Further variables that we include in the matching process but do not necessarily have an exact counterfactual value are the number of employees, and the number of apprentices. We choose these variables considering both the literature on the determinants of costs and benefits of training (as surveyed in Wolter and Ryan 2011) and the literature on works councils discussed above.

\subsection{Results}

\subsubsection{Costs and benefits during the training period}

Our results show that a WoCo incurs higher gross training costs per apprentice than a NWoCo (Table 6.6.1). However, the effects are only significant in the full sample of firms with more than 5 employees. If we restrict the sample to firms with 21 to 100 employees, the effect of a works council is no longer significant. Thus, by excluding firms that either have a very high probability (large firms) or a very low probability (small firms) of having a works council, the effect on the gross costs of training disappears.

Analysing apprentice pay (which is an important determinant of gross training costs), we find works council effects of about $€ 2100$ per year in the full sample, and $€ 800$ per year in the sample for medium-sized firms (Table A6.3). Thus, apprentice pay is about $8 \%$ to $25 \%$ higher in a WoCo than in a NWoCo. Other costs, such as administrative costs, or recruitment costs, are significantly higher in a WoCo than in a NWoCo in the full sample - but only in combination with collective bargaining agreements 15

Further, training benefits are, on average, somewhat lower for a WoCo than for a NWoCo, but the average treatment effect is not significant in any of the models. In full sample, we find that a WoCo allocates a significantly higher share of non-productive tasks to its apprentices, however, this is not the case for the small sample (table A6.4). We also find that the relative productivity of an apprentice in performing qualified tasks does not differ significantly between a WoCo and a NWoCo. 16

A further important factor for both costs and benefits of training is the wage of skilled and unskilled workers, as well as ancillary wage costs. While our estimates suggest positive and significant wage effects of a works council in the full sample, we find no significant

\footnotetext{
${ }^{15}$ We have further tested for any differences in recruitment costs of hiring an apprentice - however, we do not find any significant differences for a firm with works council and/or collective bargaining. Thus, besides offering higher apprentice pay (which might attract better apprentices), we do not find any evidence for more selective recruitment strategies in WoCo than NWoCo.

${ }^{16}$ This result is in line with Muehlemann et al. (2010), who find in a cross-country analysis for Germany and Switzerland for the year 2000, that apprentices do not differ in their relative productivity. This indicates that the learning process for the apprentice does not seem to differ much whether he is working actively in the firm's production process or learning by practising. However, productive tasks performed by an apprentice positively influence the firm's cost-benefit ratio.
} 
effects on both the skilled and unskilled wage for medium-sized firms (Table A6.5). This result suggests that restricting the sample to medium-sized firms is important, as wage determination in small and large firms may depend on other (unobservable) factors correlated with the existence of a works council and thus lead to biased estimates. Furthermore, we also do not find any significant works council effects with respect to ancillary wage costs in medium-sized firms.

The resulting net training costs (i.e. the difference between gross costs and benefits of training) turn out to be substantially and significantly higher in a WoCo than in a NWoCo - however, only if a firm has both a works council and a collective bargaining agreement (table 6.6.1). The average treatment effect in the full sample is almost $€ 6300$, whereas the effect for firms with $21-100$ employees is $€ 3500$ (significant at the $10 \%$-level). This result is in line with our expectation that a works council is more effective in its voice function when the firm is also covered by collective bargaining agreements.

\subsubsection{Post-training benefits}

While we find that a WoCo is making a higher net investment in apprenticeship training than a NWoCo, we expect profit-maximising firms to have higher post-training benefits to recoup the higher training investment, as discussed in section 2 .

We find significantly higher retention rates in a WoCo compared to a NWoCo one, three and five years after training, in the full sample (Table 6.6.2). In the restricted sample, however, retention rates in a WoCo are only significantly different from a NWoCo after three and five years and in combination with collective bargaining agreements, which is in line with Freeman and Lazear (1995). Thus, immediate retention does not differ much due to a works council, however, a WoCo is able to keep former apprentices for a longer period compared to a NWoCo, which is what we expect if a works council in fact lobbies for job stability. Our results for firms with 21-100 employees show that the average treatment effects increase from $5.74 \%$-points (not significant) after one year to $13.2 \%$ points (significant at $5 \%$ level) after five years. This effect is economically substantial, as the average 5 -year retention rate in the restricted sample is $48.3 \%$ (compared to $35.8 \%$ in the full sample).

A further possibility for post-training benefits arises in the presence of compressed wage structures, as discussed in Section 6.3. Unfortunately, we cannot directly observe worker productivity in our data. Assuming that the productivity of workers in a WoCo and a NWoCo do not differ significantly, as suggested by the literature, wage compression is likely to have an effect on the skilled/unskilled wage differential Acemoglu and Pischke, 1999b). However, our results do not show any significant differences (Table A6.5). This suggests that wage compression is not the main source of differences in post-training benefits, and therefore does not justify significantly higher net training investments of a WoCo. 
Table 6.6.1.: Training costs and benefits - works council ATE

\begin{tabular}{lcccccc}
\hline \hline & \multicolumn{2}{c}{ all firms } & \multicolumn{2}{c}{ collective bargaining } & \multicolumn{2}{c}{ no collective bargaining } \\
& $5+$ empl. & $21-100 \mathrm{empl}$. & $5+$ empl. & $21-100 \mathrm{empl}$ & $5+$ empl. & 21-100 empl. \\
\hline Gross training costs & $3746^{* * *}$ & 491 & $6154^{* * *}$ & 2505 & 236 & -1290 \\
& $(1086)$ & $(1044)$ & $(1608)$ & $(1523)$ & $(1292)$ & $(1302)$ \\
Benefits of training & -192 & -804 & -114 & -954 & -195 & -684 \\
& $(641.153)$ & $(798)$ & $(805)$ & $(958)$ & $(1048)$ & $(1243)$ \\
Net training costs & $3938^{* * *}$ & 1294 & $6268^{* * *}$ & $3459^{*}$ & 431 & -606 \\
& $(1252)$ & $(1297)$ & $(1729)$ & $(1786)$ & $(1716)$ & $(1724)$ \\
\hline Observations & 2362 & 700 & 674 & 183 & 1688 & 517 \\
\hline \hline
\end{tabular}

${ }^{*} p<0.10,{ }^{* *} p<0.05,{ }^{* * *} p<0.01$. Robust standard errors in parentheses.

The table shows the average treatment effect (ATE) of a works council versus a non-works council firm.

Costs and benefits are given in Euros per apprentice and training year. Reference year is 2007. 
Table 6.6.2.: Retention rates - works council ATE

\begin{tabular}{lcccccc}
\hline \hline & \multicolumn{2}{c}{ all firms } & \multicolumn{2}{c}{ collective bargaining } & \multicolumn{2}{c}{ no collective bargaining } \\
& $5+$ empl. & $21-100 \mathrm{empl}$. & $5+$ empl. & $21-100 \mathrm{empl}$. & $5+$ empl. & $21-100$ empl. \\
\hline 1-yr retention rate & $17.13^{* * *}$ & 3.48 & $16.45^{* * *}$ & 5.75 & $18.36^{* * *}$ & 2.46 \\
& $(4.61)$ & $(5.10)$ & $(6.26)$ & $(6.64)$ & $(6.70)$ & $(7.44)$ \\
3-yr retention rate & $22.85^{* * *}$ & $10.70^{* *}$ & $19.19^{* * *}$ & $11.78^{*}$ & $25.79^{* * *}$ & 10.36 \\
& $(4.37)$ & $(5.18)$ & $(5.80)$ & $(6.76)$ & $(6.58)$ & $(7.54)$ \\
5 -yr retention rate & $24.70^{* * *}$ & $10.87^{* *}$ & $21.98^{* * *}$ & $13.16^{* *}$ & $26.90^{* * *}$ & 8.26 \\
& $(4.23)$ & $(5.05)$ & $(5.50)$ & $(6.66)$ & $(6.55)$ & $(7.43)$ \\
\hline Observations & 2362 & 700 & 674 & 183 & 1688 & 517 \\
\hline \hline
\end{tabular}

${ }^{*} p<0.10,{ }^{* *} p<0.05,{ }^{* * *} p<0.01$. Robust standard errors in parentheses.

The table shows the average treatment effect (ATE) of a works council on the percentage retention rate

of apprentices one, three, and five years after finishing their apprenticeship in the firm. Reference year is 2007. 
Table 6.6.3.: Training ratio - works council ATE

\begin{tabular}{|c|c|c|c|c|c|c|}
\hline & \multicolumn{2}{|c|}{ all firms } & \multicolumn{2}{|c|}{ collective bargaining } & \multicolumn{2}{|c|}{ no collective bargaining } \\
\hline & $5+$ empl. & 21-100 empl. & $5+$ empl. & 21-100 empl. & $5+$ empl. & 21-100 empl. \\
\hline Apprentice/employees & $\begin{array}{c}-0.079^{* * *} \\
(0.013)\end{array}$ & $\begin{array}{l}-0.011 \\
(0.015)\end{array}$ & $\begin{array}{c}-0.064^{* * *} \\
(0.017)\end{array}$ & $\begin{array}{l}-0.016 \\
(0.017)\end{array}$ & $\begin{array}{c}-0.095^{* * *} \\
(0.021)\end{array}$ & $\begin{array}{l}-0.007 \\
(0.024)\end{array}$ \\
\hline $\begin{array}{l}\text { Apprentices/skilled workers } \\
\text { (in training occupation) }\end{array}$ & $\begin{array}{c}-0.201^{* * *} \\
(0.045)\end{array}$ & $\begin{array}{l}-0.037 \\
(0.048)\end{array}$ & $\begin{array}{c}-0.201^{* * *} \\
(0.062)\end{array}$ & $\begin{array}{l}-0.109^{*} \\
(0.063)\end{array}$ & $\begin{array}{c}-0.184^{* * *} \\
(0.069)\end{array}$ & $\begin{array}{c}0.013 \\
(0.068)\end{array}$ \\
\hline Observations & 2362 & 700 & 674 & 183 & 1688 & 517 \\
\hline
\end{tabular}

$p<0.01$. Robust standard errors in parentheses. Reference year is 2007

The table shows the average treatment effect (ATE) of a works council on two indicators of apprenticeship training ratio.

The first is the ratio of apprentices to all workers in the firm and the second is the ratio of apprentices to skilled workers. 


\subsubsection{Training ratio}

As net training costs and retention rates are higher in a WoCo than in a NWoCo, it may be expected that a WoCo trains at a lower intensity, i.e. that the number of apprentices in relation to the workforce is lower than in a NWoCo. The reason for the expected relationship is that firm-level institutions may influence training investments and the retention of apprentices. Nevertheless, they have no legal right to participate in the decision on whether to train apprentices, and if so, how many. A firm expecting pressure for higher training investments and a higher retention rate may be more selective in the provision of training posts.

While Backes-Gellner et al. (1997) provide some evidence for this hypothesis, no study has so far been able to investigate this question using representative establishment-level data that allows researchers to control for firm size, industry, training occupation and most importantly - collective bargaining agreements.

We use two measures of a training ratio for our empirical investigation. First, we define the training ratio as the number of apprentices divided by total employment in the firm. The results for the full sample show that a WoCo does indeed have a significantly lower apprentice training ratio compared to a NWoCo. On average, a WoCo trains at a $7.4 \%$ points lower ratio than a NWoCo (Table6.6.3). For medium-sized firms, however, average treatment effects are practically zero. Thus, we suspect that our findings in the full sample may be driven (at least partly) by unobserved firm heterogeneity.

Second, we define the training ratio as the number of apprentices divided by the number of skilled workers in the same occupation, which may be a more meaningful measure of a firm's training intensity, as the comparison is restricted to the training occupation in question. Using this indicator shows that a WoCo has a 18.5\%-points lower apprentice training ratio compared to a NWoCo in the full sample (Table 6.6.3). As in the case of our first indicator, the coefficient on works council is insignificant when concentrating on the restricted sample with only medium-sized firms. However, the treatment effect is equal to $11.3 \%$ (and marginally significant) in a firm with a collective bargaining agreement, which is economically significant, as average training ratio is $19.7 \%$ (Table A6.2). The lower training ratio could be driven by two different effects. First, the management in a WoCo decides to train fewer apprentices, anticipating that the works council will strive to retain a large share of apprentices after the training. This effect could be described as an indirect effect of a works council, since the effect occurs without direct participation of the works council. Second, the works council may actively propose a strategy to train (relatively) fewer apprentices, since bringing in too many new potential future workers may increase the pressure for the already existing workforce in the firm. The data at hand does not allow for a differentiation between the two (potential) effects.

Summing up the main results from the analysis above, we find that, among the firms that are covered by a collective wage agreement, a WoCo is associated with higher net 
investment in apprenticeship training, a higher retention rate of apprentices, and a lower training ratio compared to a NWoCo.

\subsection{Conclusions}

In this chapter, we use German firm-level data to analyse whether a firm with a works council differs from a firm without such an institution concerning its training costs, retention strategy and training intensity. We use detailed firm-level data to show that a firm with a works council incurs about $€ 6300$ higher net costs per apprentice and year of training, compared to a firm without works council. As very small firms hardly ever implement a works council, and a large firm almost always does, we also investigate a sample of medium-sized firms with 21 to 100 employees, for which an analysis of works council effects is more appropriate. The results for medium-sized firms show that firms with a works council have $€ 3500$ higher net training costs, but only in combination with a collective bargaining agreement. The main sources for higher net costs are increased wages for apprentices, and - to a smaller extent - a lesser involvement of apprentices in productive activities.

Our results suggest that firms face a trade-off: worker representation - both at the firm and the industry level - puts an upward pressure on a firm's net investment in apprenticeship training, but at the same time enables a firm to generate higher posttraining benefits to recoup the additional training expenditures. The high-investmenthigh-retention strategy, however, partly comes at the cost of a lower training ratio. It appears that these findings are robust mainly for firms with both types of firm-level institutions: works council and collective bargaining agreement.

Our empirical results further indicate that higher net training costs go hand in hand with a longer tenure of former apprentices. In a firm with works council, the fraction of workers that is still employed in the training firm five years later is 25 percentage points higher (full sample). For a medium-sized firm, the works council effect is equal to 13 percentage points - but, again, only in combination with a collective bargaining agreement. This result suggests that collective bargaining plays an important role in amplifying the voice function of works councils. One reason could be that a collective agreement reduces the potential for conflicts within the firm, since wage and safety issues are resolved externally. This may lead to a more efficient cooperation between the works council and the management. Another reason could be that a collective agreement disburdens works councils, so that consequently they can concentrate more effectively on employment and training issues, eventually leading to a higher training investment and longer worker tenure in firms with both institutions. 


\section{A6. Appendix}

Figure A6.1.: Share of firms with works councils

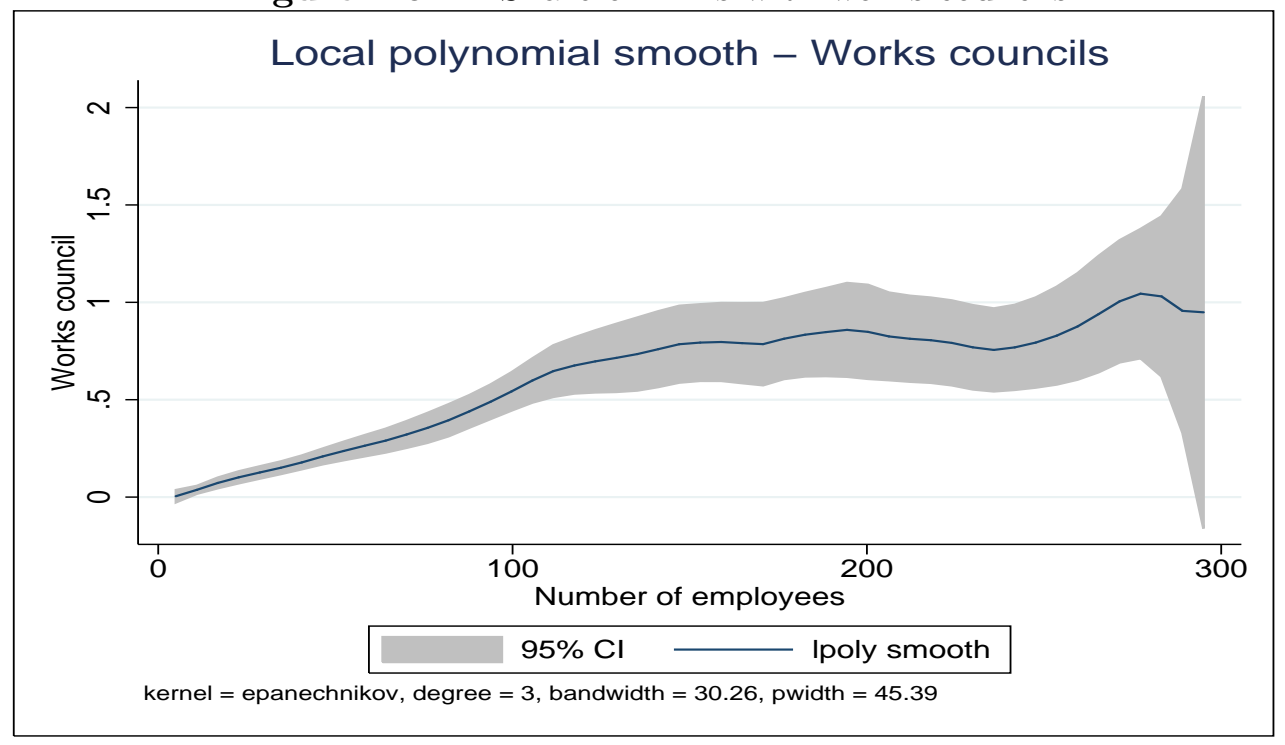

Figure A6.2.: Share of firms with collective bargaining

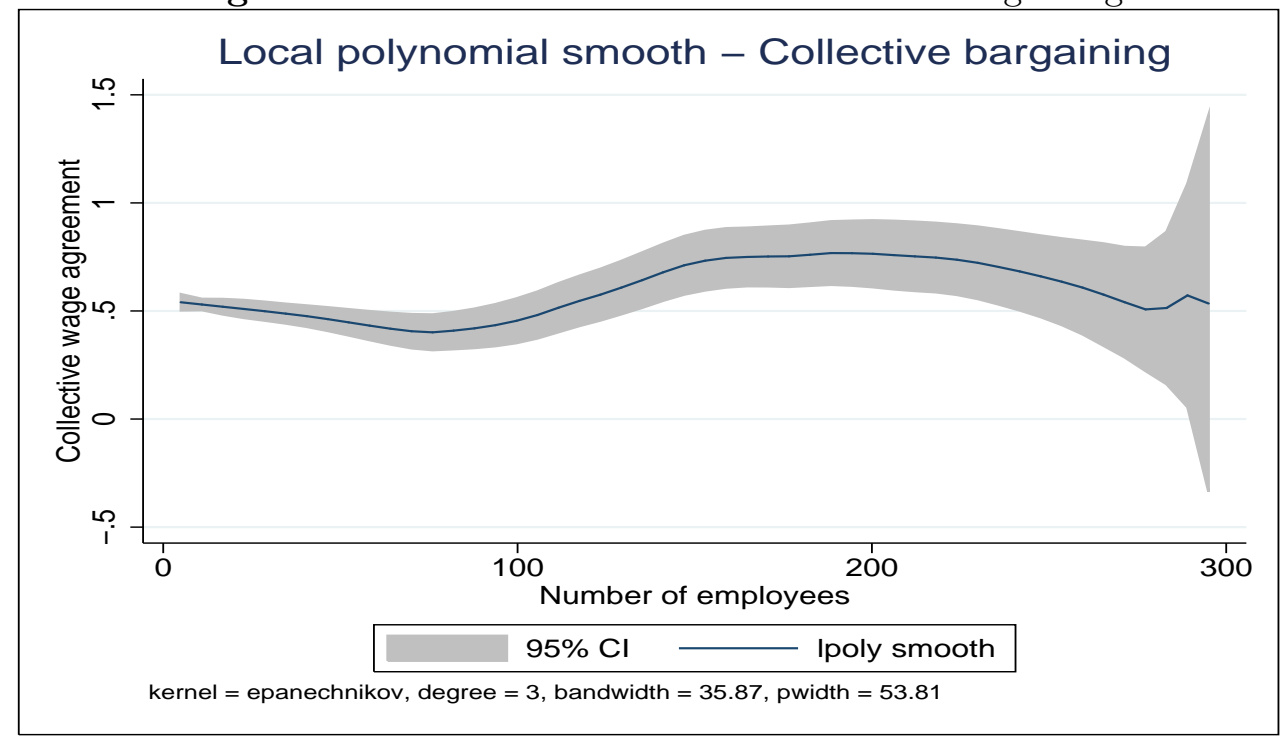


Table A6.1.: Summary statistics by works council and firm size

\begin{tabular}{|c|c|c|c|c|c|}
\hline & Works & councils & No works & councils & Total \\
\hline Number of employees & $5+$ & $21-100$ & $5+$ & $21-100$ & \\
\hline \multicolumn{6}{|l|}{ Institutions } \\
\hline Firm bound by collective wage agreement & 0.76 & 0.60 & 0.52 & 0.45 & 0.53 \\
\hline Firm located in Eastern Germany & 0.14 & 0.22 & 0.15 & 0.20 & 0.16 \\
\hline \multicolumn{6}{|l|}{ Occupation trained in the firm } \\
\hline Metalworking & 0.13 & 0.10 & 0.084 & 0.12 & 0.10 \\
\hline Electrical engineering & 0.13 & 0.12 & 0.09 & 0.12 & 0.10 \\
\hline Information technology & 0.09 & 0.05 & 0.06 & 0.08 & 0.07 \\
\hline Chemistry & 0.07 & 0.04 & 0.003 & 0.02 & 0.01 \\
\hline Gastronomy & 0.06 & 0.08 & 0.14 & 0.12 & 0.13 \\
\hline Construction & 0.03 & 0.05 & 0.12 & 0.10 & 0.10 \\
\hline Print, media & 0.04 & 0.08 & 0.02 & 0.03 & 0.02 \\
\hline Health & 0.003 & 0.00 & 0.14 & 0.04 & 0.10 \\
\hline Administrative: sales and distribution & 0.13 & 0.17 & 0.15 & 0.15 & 0.15 \\
\hline Administrative: headquarters & 0.23 & 0.25 & 0.16 & 0.19 & 0.18 \\
\hline Administrative: banks/insurance & 0.06 & 0.05 & 0.01 & 0.01 & 0.02 \\
\hline Other occupations & 0.01 & 0.01 & 0.03 & 0.02 & 0.03 \\
\hline \multicolumn{6}{|l|}{ Economic sector of firm } \\
\hline Crafts & 0.39 & 0.39 & 0.33 & 0.36 & 0.34 \\
\hline Trade & 0.20 & 0.29 & 0.25 & 0.29 & 0.25 \\
\hline Services I & 0.12 & 0.09 & 0.14 & 0.12 & 0.13 \\
\hline Services II & 0.15 & 0.14 & 0.15 & 0.16 & 0.15 \\
\hline Public services, education, health & 0.14 & 0.10 & 0.14 & 0.08 & 0.12 \\
\hline \multicolumn{6}{|l|}{ Training organisation } \\
\hline In-house training center & 0.06 & 0.01 & 0.01 & 0.02 & 0.02 \\
\hline
\end{tabular}

Note: Mean of each variable with standard deviation in parentheses. 
Table A6.2.: Summary statistics by works council and firm size

\begin{tabular}{|c|c|c|c|c|c|}
\hline & Works & councils & No works & councils & Total \\
\hline Number of employees & $5+$ & $21-100$ & $5+$ & $21-100$ & \\
\hline Monthly pay management & $\begin{array}{c}4187 \\
(1574)\end{array}$ & $\begin{array}{c}3926 \\
(1355)\end{array}$ & $\begin{array}{c}3515 \\
(1622)\end{array}$ & $\begin{array}{c}3844 \\
(1606)\end{array}$ & $\begin{array}{c}3648 \\
(1618)\end{array}$ \\
\hline $\begin{array}{l}\text { Monthly pay skilled worker } \\
\text { (administration) }\end{array}$ & $\begin{array}{l}2633 \\
(649)\end{array}$ & $\begin{array}{l}2447 \\
(672)\end{array}$ & $\begin{array}{l}2120 \\
(705)\end{array}$ & $\begin{array}{l}2450 \\
(880)\end{array}$ & $\begin{array}{l}2236 \\
(755)\end{array}$ \\
\hline $\begin{array}{l}\text { Monthly pay skilled worker } \\
\text { (crafts) }\end{array}$ & $\begin{array}{l}2452 \\
(599)\end{array}$ & $\begin{array}{l}2297 \\
(467)\end{array}$ & $\begin{array}{l}2055 \\
(637)\end{array}$ & $\begin{array}{l}2234 \\
(651)\end{array}$ & $\begin{array}{l}2132 \\
(642)\end{array}$ \\
\hline $\begin{array}{l}\text { Monthly pay skilled worker } \\
\text { (technical) }\end{array}$ & $\begin{array}{l}2839 \\
(734)\end{array}$ & $\begin{array}{l}2748 \\
(767)\end{array}$ & $\begin{array}{l}2406 \\
(749)\end{array}$ & $\begin{array}{l}2640 \\
(712)\end{array}$ & $\begin{array}{l}2500 \\
(757)\end{array}$ \\
\hline Monthly pay unskilled worker & $\begin{array}{l}1769 \\
(612)\end{array}$ & $\begin{array}{l}1628 \\
(562)\end{array}$ & $\begin{array}{l}1324 \\
(522)\end{array}$ & $\begin{array}{l}1557 \\
(582)\end{array}$ & $\begin{array}{l}1417 \\
(563)\end{array}$ \\
\hline Ancillary wage costs & $\begin{array}{l}848 \\
(382)\end{array}$ & $\begin{array}{c}771 \\
(309)\end{array}$ & $\begin{array}{c}647 \\
(327)\end{array}$ & $\begin{array}{c}726 \\
(366)\end{array}$ & $\begin{array}{c}684 \\
(344)\end{array}$ \\
\hline $\begin{array}{l}\text { Weekly hours of instruction time } \\
\text { (per apprentices) }\end{array}$ & $\begin{array}{c}5.13 \\
(6.08)\end{array}$ & $\begin{array}{c}5.71 \\
(6.98)\end{array}$ & $\begin{array}{c}5.91 \\
(6.91)\end{array}$ & $\begin{array}{c}5.74 \\
(6.74)\end{array}$ & $\begin{array}{c}5.81 \\
(6.82)\end{array}$ \\
\hline Number of apprentices & $\begin{array}{c}7.5 \\
(35.2)\end{array}$ & $\begin{array}{l}3.5 \\
(4.5)\end{array}$ & $\begin{array}{l}1.8 \\
(1.7)\end{array}$ & $\begin{array}{c}3.1 \\
(2.6)\end{array}$ & $\begin{array}{c}2.6 \\
(10.6)\end{array}$ \\
\hline $\begin{array}{l}\text { Training intensity } \\
\text { (apprentices/all employees) }\end{array}$ & $\begin{array}{c}0.09 \\
(0.09)\end{array}$ & $\begin{array}{c}0.11 \\
(0.12)\end{array}$ & $\begin{array}{c}0.22 \\
(0.12)\end{array}$ & $\begin{array}{c}0.13 \\
(0.10)\end{array}$ & $\begin{array}{c}0.19 \\
(0.13)\end{array}$ \\
\hline $\begin{array}{l}\text { Training intensity } \\
\text { (apprentices/skilled workers) }\end{array}$ & $\begin{array}{c}0.17 \\
(0.30)\end{array}$ & $\begin{array}{l}0.20 \\
(0.29)\end{array}$ & $\begin{array}{c}0.46 \\
(0.47)\end{array}$ & $\begin{array}{c}0.25 \\
(0.36)\end{array}$ & $\begin{array}{c}0.39 \\
(0.45)\end{array}$ \\
\hline Share of non-productive tasks & $\begin{array}{c}28.44 \\
(19.01)\end{array}$ & $\begin{array}{c}26.35 \\
(16.93)\end{array}$ & $\begin{array}{c}21.55 \\
(14.92)\end{array}$ & $\begin{array}{c}25.38 \\
(17.94)\end{array}$ & $\begin{array}{c}23.02 \\
(16.12)\end{array}$ \\
\hline Relative productivity of apprentice & $\begin{array}{c}61.10 \\
(17.17)\end{array}$ & $\begin{array}{c}58.40 \\
(15.71)\end{array}$ & $\begin{array}{c}57.38 \\
(17.00)\end{array}$ & $\begin{array}{c}58.30 \\
(17.53)\end{array}$ & $\begin{array}{c}57.90 \\
(17.08)\end{array}$ \\
\hline Apprentice pay (p.a.) & $\begin{array}{l}12127 \\
(3315)\end{array}$ & $\begin{array}{l}10718 \\
(2567)\end{array}$ & $\begin{array}{c}8610 \\
(2047)\end{array}$ & $\begin{array}{c}9663 \\
(2469)\end{array}$ & $\begin{array}{c}9189 \\
(2514)\end{array}$ \\
\hline Costs for infrastructure (p.a.) & $\begin{array}{c}1013 \\
(1849)\end{array}$ & $\begin{array}{c}554 \\
(1487)\end{array}$ & $\begin{array}{c}394 \\
(749)\end{array}$ & $\begin{array}{c}493 \\
(1293)\end{array}$ & $\begin{array}{c}471 \\
(1049)\end{array}$ \\
\hline Other training costs (p.a.) & $\begin{array}{c}2824 \\
(2479)\end{array}$ & $\begin{array}{c}2307 \\
(1848)\end{array}$ & $\begin{array}{c}1799 \\
(1439)\end{array}$ & $\begin{array}{c}2086 \\
(1825)\end{array}$ & $\begin{array}{c}1960 \\
(1669)\end{array}$ \\
\hline Gross training costs (p.a.) & $\begin{array}{c}20841 \\
(10980)\end{array}$ & $\begin{array}{l}17965 \\
(7407)\end{array}$ & $\begin{array}{l}15340 \\
(6694)\end{array}$ & $\begin{array}{l}16834 \\
(7673)\end{array}$ & $\begin{array}{l}16189 \\
(7528)\end{array}$ \\
\hline Benefits of training (p.a.) & $\begin{array}{l}11789 \\
(5590)\end{array}$ & $\begin{array}{l}12131 \\
(5510)\end{array}$ & $\begin{array}{r}11795 \\
(5176)\end{array}$ & $\begin{array}{l}12350 \\
(6103)\end{array}$ & $\begin{array}{c}11907 \\
(5402)\end{array}$ \\
\hline Net costs of training (p.a.) & $\begin{array}{c}9052 \\
(13131)\end{array}$ & $\begin{array}{c}5834 \\
(9681)\end{array}$ & $\begin{array}{c}3545 \\
(7852)\end{array}$ & $\begin{array}{c}4485 \\
(9108)\end{array}$ & $\begin{array}{c}4282 \\
(8866)\end{array}$ \\
\hline
\end{tabular}

Note: Mean of each variable with standard deviation in parentheses. 


\begin{tabular}{|c|c|c|c|c|c|c|}
\hline & \multicolumn{2}{|c|}{ all firms } & \multicolumn{2}{|c|}{ collective bargaining } & \multicolumn{2}{|c|}{ no collective bargaining } \\
\hline & $5+$ empl. & 21-100 empl. & $5+$ empl. & 21-100 empl. & $5+$ empl. & $21-100 \mathrm{empl}$. \\
\hline \multirow[t]{2}{*}{ Apprentice pay } & $2128^{* * *}$ & $802^{* *}$ & $2341^{* * *}$ & $816^{*}$ & $1918^{* * *}$ & $761^{*}$ \\
\hline & $(354)$ & $(312)$ & $(560)$ & $(441)$ & $(359)$ & $(412)$ \\
\hline \multirow{2}{*}{ Costs for training personnel } & 870 & -154 & $2338^{* *}$ & 1442 & -1269 & -1558 \\
\hline & $(761)$ & $(854)$ & $(1098)$ & $(1318)$ & $(1018)$ & $(1026)$ \\
\hline \multirow[t]{2}{*}{ Costs for training infrastructure } & $224^{*}$ & 42 & $413^{* *}$ & 51 & -87 & -45 \\
\hline & $(136)$ & $(175)$ & $(206)$ & $(262)$ & $(161)$ & $(186)$ \\
\hline \multirow[t]{2}{*}{ Other costs } & $923^{* * *}$ & 225 & $1489^{* * *}$ & 555 & 113 & -21 \\
\hline & $(250)$ & $(266)$ & $(355)$ & $(354)$ & $(313)$ & $(362)$ \\
\hline Observations & 2362 & 700 & 674 & 183 & 1688 & 517 \\
\hline
\end{tabular}

${ }^{*} p<0.10,{ }^{* *} p<0.05,{ }^{* * *} p<0.01$. Robust standard errors in parentheses.

The table shows the average treatment effect (ATE) of a works council on gross training cost components.

ATE is given in Euros per apprentice and year of training. Reference year is 2007. 
Table A6.4.: Tasks and productivity - works councils ATE

\begin{tabular}{lcccccc}
\hline \hline & \multicolumn{2}{c}{ all firms } & \multicolumn{2}{c}{ collective bargaining } & \multicolumn{2}{c}{ no collective bargaining } \\
& $5+$ empl. & $21-100$ empl. & $5+$ empl. & $21-100$ empl. & 5+ empl. & 21-100 empl. \\
\hline Share of non-productive tasks & $3.61^{* *}$ & 2.57 & $4.47^{*}$ & 3.71 & 4.03 & 2.15 \\
& $(1.76)$ & $(2.51)$ & $(2.41)$ & $(3.30)$ & $(2.74)$ & $(3.70)$ \\
Relative productivity & -0.57 & 0.14 & -0.11 & 2.58 & -1.62 & -1.54 \\
& $(2.03)$ & $(2.38)$ & $(2.74)$ & $(3.13)$ & $(3.26)$ & $(3.47)$ \\
\hline Observations & 2362 & 700 & 674 & 183 & 1688 & 517 \\
\hline \hline
\end{tabular}

${ }^{*} p<0.10,{ }^{* *} p<0.05,{ }^{* * *} p<0.01$. Robust standard errors in parentheses.

The table shows the average treatment effect (ATE) of a works council on the share of non-productive

tasks and relative productivity of apprentices. ATE is given in percentage points. Reference year is 2007. 
Table A6.5.: Wages - works councils ATE

\begin{tabular}{|c|c|c|c|c|c|c|}
\hline & \multicolumn{2}{|c|}{ all firms } & \multicolumn{2}{|c|}{ collective bargaining } & \multicolumn{2}{|c|}{ no collective bargaining } \\
\hline & $5+$ empl. & 21-100 empl. & $5+$ empl. & 21-100 empl. & $5+$ empl. & 21-100 empl. \\
\hline Log unskilled worker wage & $\begin{array}{c}0.162^{* * *} \\
(0.049)\end{array}$ & $\begin{array}{c}0.057 \\
(0.054)\end{array}$ & $\begin{array}{c}0.168^{* * *} \\
(0.059)\end{array}$ & $\begin{array}{l}-0.006 \\
(0.061)\end{array}$ & $\begin{array}{c}0.219^{* * *} \\
(0.079)\end{array}$ & $\begin{array}{c}0.097 \\
(0.087)\end{array}$ \\
\hline Log skilled worker wage & $\begin{array}{c}0.133^{* * *} \\
(0.031)\end{array}$ & $\begin{array}{c}0.028 \\
(0.040)\end{array}$ & $\begin{array}{c}0.079^{* *} \\
(0.040)\end{array}$ & $\begin{array}{l}-0.005 \\
(0.049)\end{array}$ & $\begin{array}{c}0.173^{* * *} \\
(0.049)\end{array}$ & $\begin{array}{c}0.056 \\
(0.059)\end{array}$ \\
\hline Skilled/unskilled worker wage diff. & $\begin{array}{c}0.010 \\
(0.039)\end{array}$ & $\begin{array}{c}0.004 \\
(0.045)\end{array}$ & $\begin{array}{c}0.040 \\
(0.049)\end{array}$ & $\begin{array}{l}-0.018 \\
(0.056)\end{array}$ & $\begin{array}{c}0.031 \\
(0.065)\end{array}$ & $\begin{array}{c}0.012 \\
(0.067)\end{array}$ \\
\hline Ancillary wage costs & $\begin{array}{c}115.417^{* * *} \\
(39.876)\end{array}$ & $\begin{array}{c}31.995 \\
(48.400) \\
\end{array}$ & $\begin{array}{c}76.407 \\
(51.845) \\
\end{array}$ & $\begin{array}{c}71.115 \\
(64.237) \\
\end{array}$ & $\begin{array}{c}120.223^{*} \\
(62.159) \\
\end{array}$ & $\begin{array}{c}-3.732 \\
(68.579) \\
\end{array}$ \\
\hline Observations & 2362 & 700 & 674 & 183 & 1688 & 517 \\
\hline
\end{tabular}

${ }^{*} p<0.10,{ }^{* *} p<0.05,{ }^{* * *} p<0.01$. Robust standard errors in parentheses.

The table shows the average treatment effect (ATE) of a works council on wages, wage differential and ancillary wage costs in Euro. Reference year is 2007. 


\section{The hiring costs of vocationally trained workers}

\subsection{Introduction 1}

Vocational education and training may have a number of benefits with respect to productivity and wages (see Chapters 2 and 3). In the case of apprenticeship training, a firm has the option to retain the former apprentice as a skilled worker in the firm after the training. The firm may use training to screen the apprentice over the entire training period of 2 to 4 years. Screening and retaining apprentices may save costs that occur when hiring skilled workers from the external labour market (Stevens 1994a). Such costs include costs for the posting of vacancies or for the use of external placement agencies. In addition, a firm needs to screen applications and to invite a number of suitable job candidates for an interview. After signing a contract, new workers may need time to adapt to the specific environment of the firm. Thus, a firm also incurs adaptation costs resulting from a temporarily lower productivity of the new worker. Taken together, the costs of hiring skilled workers may be considerable for a firm adjusting its labour force.

This chapter analyses the hiring costs of skilled workers in Germany, thereby adding to the literature in two ways: first, we quantitatively determine the size and structure of hiring costs. Both size and structure are important for understanding the firm's training behaviour, because training apprentices may be a measure of avoiding hiring costs. Formulated differently, the saving of hiring costs may be an important benefit from training that may explain why many German firms bear costs for the training of apprentices. The higher the hiring costs of skilled workers, the higher the benefit of retaining a worker trained in the firm. Further, increasing hiring costs in the number of workers to be hired may, ceteris paribus, induce incentives to cover larger shares of the labour demand for skilled workers via apprenticeship training. Second, we analyse the role of labour market institutions on hiring costs in Germany. We distinguish between the institution of worker representation at the firm level (i.e. works councils or other forms of representation) and the firm's coverage of collective bargaining agreements. We argue that institutions may

\footnotetext{
${ }^{1}$ This chapter is based on the working paper The structure of hiring costs in Germany by Samuel Muehlemann and Harald Pfeifer (Muehlemann and Pfeifer 2012).
} 
influence hiring costs and therefore (part of) the benefits of training. While the previous chapter has analysed the role of institutions for training investments of firms, we analyse their role for post-training benefits.

Our results show that the average hiring costs per new worker are substantial, averaging around $€ 4700$, and that they increase strongly by firm size. Furthermore, the structure of hiring costs is convex in the number of hired workers. We find an elasticity of hiring costs with respect to the number of hires equal to 1.33 (i.e. a $10 \%$ increase in hires increases average hiring costs by about $13.3 \%$ ). Convex hiring costs underline the importance of training and retaining workers, because the more hiring depends on the external labour market, the more expensive hiring processes become.

We further find that worker representation in the firm is associated with a $33 \%$ increase in average hiring costs but with no effect on the degree of convexity of hiring costs. This result complements the finding in the previous chapter that worker representation induces higher training costs but also higher training benefits (i.e. saved hiring costs). We find no statistically significant effect on hiring costs for collective bargaining agreements.

The remainder of the chapter is structured as follows. Section 2 provides an illustrative model of hiring costs and discusses the relevant literature. Section 3 outlines the different labour market institutions in Germany. Section 4 describes our data sources and discusses the calculation of hiring costs. Section 5 presents the estimation strategy, the main empirical results and a robustness analysis. Section 6 draws conclusions and offers some policy implications.

\subsection{Theoretical model and literature}

Manning (2011) highlights the importance of understanding the structure of hiring costs in modelling labour market frictions in matching models, as extensively discussed in Mortensen and Pissarides (1994) and Pissarides (2009). Convex hiring costs can explain why firms do not immediately adjust their workforce after experiencing a (positive or negative) productivity shock. However, the shape of hiring costs is still the focus of current debates in the literature. While many studies use indirect inference from hiring costs based on worker flows (e.g. Caballero et al. 1997; Caballero and Engel 2004; Cooper and Willis 2004; Davis et al. 2006; Cooper and Willis 2009), direct empirical evidence is relatively scarce. Moreover, comparing the results of the empirical studies is difficult because the data are from different countries at different times, and estimated hiring costs are not based on the same methodology. Some studies find concave hiring costs with a fixed component (Abowd and Kramarz 2003 for France) or linear hiring costs (Kramarz and Michaud 2010 for France). Conversely, Dube et al. (2010) for the United States, Manning (2006) for the United Kingdom and Blatter et al. (2012) for Switzerland report evidence of a convex structure of hiring costs. 
The shape of the hiring costs function depends potentially on both variable and fixed costs. While a large fixed cost component typically results in economies of scales in hiring, diseconomies of scale arise if marginal hiring costs increase 2

Yashiv (2000) defines the hiring decision as an investment under uncertainty:

Firms maximise

$$
\max _{N_{t}} \Pi=E_{t}\left\{\sum_{k=0}^{\infty} \theta^{k}\left[F\left(N_{t+k}\right)-w_{t+k} N_{t+k}-f\left(H_{t+k}, N_{t+k}, w_{t+1}, I_{t+k}\right)\right]\right\}
$$

subject to $N_{t+1}=\left(1-s_{t}\right) N_{t}+H_{t}$. The firm's production function $F(N)$ depends on the number of employees $N$. We denote the wage $w$ and the separation rate $s$, which is the percentage of employees leaving the firm every period. Future profits are discounted by the factor $\theta$. The hiring costs function is $f\left(H_{t+i}, N_{t+i}, w_{t+1}, I_{t+i}\right)$, depending on the number of hires $H$, on the number of employees $N$, the wage $w$ and on labour market institutions $I$ (which include collective bargaining agreements and worker representation at the firm level).

Following Manning (2011), we assume that total hiring costs $C$ take the form

$$
f\left(H_{t+k}, N_{t+k}, w_{t+1}, I_{t+k}\right)=C=H^{\alpha} N^{\beta} w^{\gamma} I^{\delta}
$$

thereby accounting for the interdependence of hiring costs with the number of hires and the number of workers employed (i.e. the size of the firm). Hiring costs further depend on wages, because high-wage firms may be more attractive to job applicants (reducing hiring costs) and because interview costs and adaptation costs strongly depend on wages (increasing hiring costs). Finally, hiring costs depend on institutional arrangements in the firm, such as collective bargaining coverage or the presence of works councils.

While we are interested in the magnitude of the average hiring costs for filling a vacancy, another objective is to determine whether average hiring costs in Germany increase or decrease with the number of hires.

Marginal hiring costs are given by

$$
\frac{\partial C}{\partial H}=\alpha H^{\alpha-1} N^{\beta} w^{\gamma} I^{\delta}
$$

As noted in Manning (2011), marginal hiring costs can be written in terms of average hiring costs.

From equation 7.2 we can derive average hiring costs to be

$$
\frac{C}{H}=H^{\alpha-1} N^{\beta} w^{\gamma} I^{\delta}
$$

Thus, the relation between marginal and average hiring costs boils down to

${ }^{2}$ See Hamermesh and Pfann (1996) for a more detailed discussion of the literature. 


$$
\frac{\partial C}{\partial H}=\alpha \frac{C}{H}
$$

In the following, we define average hiring costs $H C \equiv \frac{C}{H}$.

In equation 7.5, $\alpha$ determines whether average hiring costs increase or decrease with the number of skilled workers hired: an $\alpha$ larger than 1 implies that average costs for hiring increase while an $\alpha$ smaller than 1 implies decreasing average hiring costs in the number of hires. Empirically, we use data on average hiring costs to determine $\alpha$. Before turning to the description of this data and the empirical analysis, we describe the relevant labour market institutions in Germany.

\subsection{Labour market institutions}

Unlike other countries, Germany has a specific framework for labour market institutions. Worker representation and collective bargaining agreements are embedded in an extensive legal framework, outlining the rights and duties of the particular institution. While the social partners in collective agreements usually focus on issues such as wages and working conditions, work councils handle both employment issues and individual grievances, and monitor the implementation of and compliance with collective bargaining agreements for the individual firm. Collective agreements are usually binding for firms that are members of employers' associations 3 In contrast, worker representation in the form of a works council is initiated by the employees 4 Only firms with five or more employees have the legal right to form a works council 5

A works council is a firm-specific entity of employees whose function is to represent - to the management - the interests of all employees in the firm. Works councils may affect hiring costs because employers must seek the approval of works councils in each hiring case. Works councils may review all job applications and may object if (a) the hiring procedure is not in accordance with legal or collective bargaining agreements, (b) the hiring may lead to a layoff of current firm employees, or (c) the person to be hired may be harmful to the firm's business climate. When the works council raises an objection, the employer must appeal to a court to formally approve the hiring decision 6

\footnotetext{
${ }^{3}$ Collective bargaining agreements are also binding for employees who are union members. However, in most cases, all employees are covered in a firm that is also subject to collective bargaining agreements. In a number of cases, collective bargaining agreements are binding for all firms in a certain industry, regardless of their membership in an employer's association.

${ }^{4}$ The establishment of works councils is often supported by members of unions inside or outside the firm.

${ }^{5}$ The Works Constitution Act (Betriebsverfassungsgesetz, 1972) formulates the conditions and procedures for the implementation of a works council.

${ }^{6}$ These rules, however, apply only to firms with more than 20 employees. We therefore also present the results of our analysis for a subsample of firms with between 21 and 100 employees.
} 
A number of previous studies have analysed the impact of worker representation and collective bargaining agreements on employment related indicators.7 Addison and Teixeira (2006) find a negative effect of works councils on employment growth, while Jirjahn (2010) reports positive employment effects when taking the endogeneity of works councils into account.

In this chapter, we analyse the relationship between firm-level institutions (i.e. worker representation and collective bargaining coverage) and the cost of hiring skilled workers. We expect that the presence of worker representation in the firm increases hiring costs because works councils have the right to participate in the hiring process and can object to the hiring of workers from the external labour market. Thus, worker representation could directly or indirectly prolong the process of hiring, making it more costly for the firm. In addition, firms with works councils have a lower separation rate of employees than firms without such institutions (Hirsch et al. 2010). The lower turnover increases the training incentives and therefore the training costs for new hires, as the payoff period is longer than in firms without a works council.

We further expect that firms bound by collective bargaining agreements may have lower hiring costs due to a lower recruitment effort because wages are determined collectively, thereby making pay and safety negotiations redundant. Conversely, one could expect these firms to have higher hiring costs due to higher adaptation costs, as workers in these firms tend to have longer tenure. As in the case of works councils, employers may have stronger incentives to invest in formal and on-the-job training for new hires (Gerlach and Stephan, 2008). As both recruitment and adaptation costs are components of the overall hiring costs, determining which of the two opposing effects of collective bargaining agreements is stronger remains an empirical question.

In the following section we first describe the data sources for our analysis and then provide some descriptive statistics on hiring costs.

\subsection{Data and descriptive statistics}

\subsubsection{Data}

The data used in this study stems from the Federal Institute of Vocational Education and Training (BIBB) in Bonn, Germany. Since the 1970s, BIBB has interviewed firms engaged in apprenticeship training in several cross-sectional surveys. The main purpose of these surveys is to assess the costs and benefits of apprenticeship training. A particularly important benefit of training is that a firm may offer the former trainee a position as a skilled worker after the training. Because the former trainee is already familiar with the firm environment, the costs of retaining the trainee are negligible. To obtain a precise

Addison et al. (2004) and Frege (2002) provide assessments of theory and the early literature on the general economic consequences of works councils. 
measure of the size of this benefit, we asked firms to provide information about the costs incurred when they hire skilled workers from the external labour market. The firms report the number of workers recruited in the three years prior to the survey.

The survey contains questions on the recruitment and adaptation component of the hiring process. Recruitment costs include costs associated with advertising vacancies, as well as preparing, conducting, and evaluating interviews with job applicants. Adaptation costs arise because newly hired workers typically are less productive than the more experienced workers in the firm. Moreover, the survey measures training costs for newly hired workers, accounting for both direct and indirect (time away from workplace) training costs 8

This chapter uses, as in the Chapters 4 to 6, the BIBB Cost-Benefit Survey data (BIBB CBS) for 2007, which includes detailed information on the hiring costs for skilled workers. The field work of the BIBB CBS was conducted by infas Institute for Applied Social Sciences in Bonn, Germany in the period of April to August 2008.9

The sample of the BIBB CBS was drawn from the administrative register for all German firms subject to social benefit contributions for at least one employee. As such, the data are representative of German firms with at least one employee. Self-employed workers and sole proprietorships are not part of the register and are consequently excluded. However, for our analysis, we exclude firms that have fewer than five workers because we are interested in analysing the potential effects of labour market institutions on the structure of hiring costs 10 Because employees in firms with fewer than five employees have no legal right to establish a works council, we do not include observations of these firms 11 Thus, our final sample consists of 1001 firms that recruited skilled workers over the past three years. As discussed in Chapter 4, we have to consider that the year 2007 as well as the three years of the reference period before the survey may have been specific in their labour market conditions and thus possibly influencing the hiring costs of firms. However, the analysis in Sections 4.4 and 4.5 suggests that the sample of firms recruiting workers does not significantly differ from non-recruiting firms. Further, Table A4.1 displays unemployment and vacancy statistics for this period. The descriptive statistics for the sample is provided in Table A7.1,

\subsubsection{Calculation of hiring costs}

The hiring costs of a skilled worker for firm $i$ are given by the sum of recruitment and adaptation costs, which are measured in the survey as an average over all skilled workers

\footnotetext{
${ }^{8}$ For the exact phrasing of the questions, see table A7.10.

${ }^{9}$ For more information about methods of data collection, see Schröder and Schiel (2008).

${ }^{10}$ Even if we use the full sample, our main results remain qualitatively similar. Results are available upon request.

${ }^{11}$ In principle, the possibility exists that small firms might choose less than 5 employees in order to avoid the creation of a works council, which might result in a biased sample. However, as shown in Figure A6.1, the share of firms having a works council increases only slowly from zero per cent upwards instead of jumping to a higher level at the size of 5 employees.
} 
hired in the period of the last three years. First, average recruitment costs $R C_{i}$ are given by

$$
R C_{i}=v_{i}+j_{i}+e_{i}
$$

where $v_{i}$ are the average costs for job postings and $j_{i}$ are average costs to prepare, conduct, and evaluate interviews with job candidates. Finally, we denote the costs for external advisors or placement agencies by $e_{i}$.

Second, we consider average adaptation costs $A C_{i}$ that arise because a new hire is not initially fully productive. $A C_{i}$ is given by

$$
A C_{i}=\sum_{m=1}^{M_{i}} w_{i}\left(1-p_{m i}\right)+\left(D C_{i}+I C_{i}\right)
$$

where the first term on the right-hand side corresponds with the value of production loss during the adaptation period. The survey contains information about the relative productivity $p_{i}\left(0 \leq p_{i} \leq 1\right)$ of a new hire compared to an average skilled worker in the firm (and in the same occupation) and the duration of the productivity gap $\left(M_{i}\right) .12$ Thus, the difference in relative productivity is $1-p_{i}$. To calculate adaptation costs for each month $m_{i}$ during the adaption period $M_{i}$, we then use information about the wage of the externally recruited worker $w_{i} .13$ Again, all of the above variables on the adaptation period and productivity are firm-level averages.

The second term captures direct and indirect training costs. Direct costs $D C_{i}$ consist of course fees and other direct expenses borne by the firm. Indirect training costs $I C_{i}$ are the opportunity costs (productivity loss) for the time that new hires are away from their workplace to attend training. Average hiring costs to fill a vacancy in firm $i$ are then given by the sum of average recruitment and average adaptation costs:

$$
H C_{i}=R C_{i}+A C_{i}
$$

Finally, the survey supplies information about labour market institutions. In particular, we observe worker representation at the firm level, such as works councils and other forms of employee representation (e.g. round tables or employee-speakers) 14

\footnotetext{
${ }^{12}$ For the exact phrasing of the questions, see table $\mathrm{A7.10}$.

${ }^{13}$ We assume that the productivity of new hires increases linearly during the adaptation period. Thus, $p_{m i}=p_{1 i}+\left(m_{1}-1\right) \cdot\left(1-p_{1 i}\right) / M$, whereas $p_{1}, i$ is the starting value as given in the survey and $1-p_{1 i}$ is the adjustment over the period $M$.

${ }^{14}$ The variable is coded 1 if a works council or other form of representation is present. The exact phrasing of the question is given in table $\mathrm{A7.10}$.
} 
Table 7.4.1.: Summary statistics by labour market institutions

\begin{tabular}{lccccc}
\hline & \multicolumn{2}{l}{ Worker representation } & \multicolumn{2}{c}{ No worker representation } & Total \\
& CBA & No CBA & CBA & No CBA & \\
\hline Average hiring costs per hired worker $(€)$ & 6718 & 5985 & 3291 & 4435 & 4733 \\
& $(4690)$ & $(5049)$ & $(3219.5)$ & $(4402)$ & $(4461)$ \\
Average recruitment costs per hired worker $(€)$ & 1828 & 2284 & 931 & 1713 & 1638 \\
& $(2170)$ & $(2813)$ & $(1583)$ & $(2191)$ & $(2231)$ \\
Average adaptation costs per hired worker $(€)$ & 4890 & 3701 & 2360 & 2723 & 3095 \\
& $(3665)$ & $(3528)$ & $(2421)$ & $(3428)$ & $(3360)$ \\
Number of skilled workers in firm & 76 & 27 & 14 & 13 & 24 \\
Number of other workers in firm & $(164)$ & $(68)$ & $(20)$ & $(27)$ & $(72)$ \\
& 37 & 13 & 6 & 5 & 11 \\
Average skilled worker wage in firm $(€)$ & $(232)$ & $(45)$ & $(10)$ & $(13)$ & $(87)$ \\
& 2523 & 2450 & 2350 & 2292 & 2365 \\
Observations & $(684)$ & $(623)$ & $(1054)$ & $(734)$ & $(805)$ \\
\hline
\end{tabular}

Note: Displayed are means of firm-level averages with standard deviation in parentheses.

$\mathrm{CBA}=$ Collective bargaining agreement. 
We also have information on whether a firm is bound by a collective bargaining agreement 15 Table 7.4 .1 summarises the average hiring costs per newly hired skilled worker both by type of labour market institution and in total. Average hiring costs amount to $€ 4700$ to fill a single vacancy, of which about one-third corresponds to recruitment costs and the remaining two-thirds can be attributed to adaptation costs.

Average hiring costs are higher for firms with worker representation than for firms that solely have a collective bargaining agreement or firms that have neither of the two institutional arrangements. While firms with worker representation are typically larger than firms without worker representation, Figure A7.1 shows that the difference in the level of hiring costs persists when we restrict the sample to firms with 21 to 100 employees (where the proportion of firms with and without worker representation is similar). Average hiring costs are lowest for firms only having a collective bargaining agreement and highest for firms having both institutions. Thus, the cost-reducing effect of bargaining agreements is more than offset by the additional presence of worker representation. As discussed in the previous chapter, a reason for this result could be that worker representation is more effective when collective bargaining agreements already solve many bargaining issues and therefore more resources can be dedicated to the hiring process of workers. Descriptive statistics of all other variables appear in Table A7.2 in the Appendix.

\subsection{Estimation strategy and results}

\subsubsection{Estimation strategy}

As discussed in the previous section, our data provides information about average hiring costs to fill a vacancy, which takes the form

$$
H C=H^{\alpha-1} N^{\beta} w^{\gamma} I^{\delta}
$$

where we denote the number of hired skilled workers by $H$, the number of employees by $N$, and the wage by $w$. I represents institutions at the firm level, in our case worker representation and collective bargaining agreements.

Taking natural logs on both sides of the equation, we regress $\ln H C$ on $\ln H, \ln N, \ln w$ and $\ln I$, whereas the term $\ln I$ is replaced a dummy variable $I$ that takes on the value of 1 in case the respective institution is present in the firm and 0 in case it is not. In addition, we include control variables in a vector $x$ to take account of the local unemployment rate, region, occupation, and industry.

Thus, we estimate the following model by ordinary least squares:

$$
\ln H C_{i}=(\alpha-1) \ln H_{i}+\beta \ln N_{i}+\gamma \ln w_{i}+\delta I_{i}+\zeta x_{i}+\eta_{i} .
$$

${ }^{15}$ The exact phrasing of the question is given in table A7.10. 
In the subsequent empirical analysis, we thus estimate the coefficient $(\alpha-1)$. As discussed in Section 7.2, average hiring costs increase with the number of hires if $\alpha>1$ and decrease if $\alpha<1$.

\subsubsection{Estimation results}

Table 7.5.1 supplies the results of the regression analysis for four different models. In column 1, the natural logarithm of average hiring costs is regressed on the natural logarithm of the number of hires and occupational and industry controls, only. The model displayed in column 2 additionally controls for firm size (natural logarithm), while model 3 also contains skilled worker wage (natural logarithm), the local unemployment rate and the region of the firm. Finally, the model presented in column 4, contains the firm-level labour market institutions, i.e. collective bargaining and worker representation. The coefficients on hires, number of employees, and the monthly skilled worker wage can be interpreted as elasticities.

With respect to the number of hires, we find a significantly positive effect on average hiring costs. Because the estimated coefficient for the number of hires is $(\alpha-1)$ (see equation 7.10), $\alpha$ equals 1.33 . Consequently, a $10 \%$ increase in the number of hires increases hiring costs by $13.3 \%$, which is an economically substantial effect. The result implies a convex cost structure on hiring costs, meaning that it becomes increasingly expensive to hire additional workers in a given period 16 Running non-parametric local polynomial regressions, Figure A7.2 in the Appendix illustrates graphically that also marginal hiring costs increase with the number of hires 17 The figure further shows that marginal hiring costs reach up to $€ 7000$ and stay almost constant from about 20 hires onwards.

Table 7.5.1 suggests that the effect of the number of employees in a firm is not significantly different from zero once we control for skilled worker wage. Considering that the models in columns 3 and 4 include wages on both sides of the equation (i.e. in the calculation of hiring costs on the left hand side and as an explanatory variable on the right hand side), we need to address this potential problem. We therefore present a number of robustness checks treating this issue in the subsequent section.

To gain further insight into the relation between the number of hires and the two components of hiring costs we run separate regressions with the average recruitment costs $R C_{i}$ and the average adaptation costs $A C$, as dependent variables (Tables 7.5.2 and 7.5.3).

Concerning recruitment costs, the elasticity with respect to the number of hires is somewhat larger than for hiring costs. Again, plugging in the respective coefficient into equa-

\footnotetext{
${ }^{16}$ Our results are very similar to those obtained by Blatter et al. (2012), who use comparable survey data for Switzerland.

${ }^{17}$ We first calculate marginal hiring costs on the basis of the OLS regression coefficients (model 4). Then, we perform a (kernel-) weighted local polynomial regression on the data with $y_{i}$ being the marginal hiring costs and $x_{i}$ being the number of hires in the firm. The advantage of such regression is that the functional form is not pre-specified (i.e. it is a non-parametric procedure).
} 
Table 7.5.1.: Hiring costs OLS regressions

\begin{tabular}{|c|c|c|c|c|}
\hline Dependent variable: ln Average hiring costs & $(1)$ & $(2)$ & $(3)$ & $(4)$ \\
\hline ln Number of hires & $\begin{array}{c}0.41^{* * *} \\
(0.12)\end{array}$ & $\begin{array}{c}0.32^{* * *} \\
(0.12)\end{array}$ & $\begin{array}{c}0.33^{* * *} \\
(0.10)\end{array}$ & $\begin{array}{c}0.33^{* * *} \\
(0.10)\end{array}$ \\
\hline ln Number of employees & & $\begin{array}{c}0.15^{* *} \\
(0.07)\end{array}$ & $\begin{array}{c}0.03 \\
(0.06)\end{array}$ & $\begin{array}{c}-0.02 \\
(0.06)\end{array}$ \\
\hline ln Monthly wage of skilled workers & & & $\begin{array}{c}1.11^{* * *} \\
(0.23)\end{array}$ & $\begin{array}{c}1.08 * * * \\
(0.23)\end{array}$ \\
\hline Local unemployment rate & & & $\begin{array}{l}-2.91 \\
(2.75)\end{array}$ & $\begin{array}{l}-3.53 \\
(2.75)\end{array}$ \\
\hline Firm located in western Germany & & & $\begin{array}{l}-0.19 \\
(0.22)\end{array}$ & $\begin{array}{l}-0.14 \\
(0.22)\end{array}$ \\
\hline Works council/other representation form & & & & $\begin{array}{c}0.33^{* *} \\
(0.14)\end{array}$ \\
\hline Collective bargaining agreement & & & & $\begin{array}{l}-0.00 \\
(0.15)\end{array}$ \\
\hline Occupational controls & Yes & Yes & Yes & Yes \\
\hline Industry controls & Yes & Yes & Yes & Yes \\
\hline Constant & $\begin{array}{c}7.57^{* * *} \\
(0.14)\end{array}$ & $\begin{array}{c}7.23^{* * *} \\
(0.26)\end{array}$ & $\begin{array}{l}-0.63 \\
(1.83)\end{array}$ & $\begin{array}{l}-0.36 \\
(1.87)\end{array}$ \\
\hline$R^{2}$ & 0.05 & 0.06 & 0.32 & 0.33 \\
\hline Observations & 1001 & 1001 & 1001 & 1001 \\
\hline
\end{tabular}

Table 7.5.2.: Recruitment costs OLS regressions

\begin{tabular}{|c|c|c|c|c|}
\hline Dependent variable: ln Average recruitment costs & (1) & $(2)$ & $(3)$ & $(4)$ \\
\hline ln Number of hires & $\begin{array}{c}0.48^{* * *} \\
(0.12)\end{array}$ & $\begin{array}{c}0.37^{* * *} \\
(0.11)\end{array}$ & $\begin{array}{c}0.38^{* * *} \\
(0.08)\end{array}$ & $\begin{array}{c}0.34^{* * *} \\
(0.08)\end{array}$ \\
\hline ln Number of employees & & $\begin{array}{c}0.16^{* *} \\
(0.08)\end{array}$ & $\begin{array}{l}0.11^{*} \\
(0.06)\end{array}$ & $\begin{array}{c}0.12^{* *} \\
(0.06)\end{array}$ \\
\hline ln Monthly wage of skilled workers & & & $\begin{array}{c}0.80 * * * \\
(0.21)\end{array}$ & $\begin{array}{c}0.71^{* * *} \\
(0.22)\end{array}$ \\
\hline Local unemployment rate & & & $\begin{array}{l}-3.93 \\
(2.55)\end{array}$ & $\begin{array}{l}-4.70^{*} \\
(2.48)\end{array}$ \\
\hline Firm located in western Germany & & & $\begin{array}{l}-0.08 \\
(0.26)\end{array}$ & $\begin{array}{l}-0.10 \\
(0.24)\end{array}$ \\
\hline Works council/other representation form & & & & $\begin{array}{l}0.28^{*} \\
(0.15)\end{array}$ \\
\hline Collective bargaining agreement & & & & $\begin{array}{c}-0.51^{* * *} \\
(0.13)\end{array}$ \\
\hline Occupational controls & Yes & Yes & Yes & Yes \\
\hline Industry controls & Yes & Yes & Yes & Yes \\
\hline Constant & $\begin{array}{c}6.31^{* * *} \\
(0.12)\end{array}$ & $\begin{array}{c}5.94^{* * *} \\
(0.26)\end{array}$ & $\begin{array}{c}0.07 \\
(1.69)\end{array}$ & $\begin{array}{c}0.92 \\
(1.75)\end{array}$ \\
\hline$R^{2}$ & 0.06 & 0.07 & 0.30 & 0.33 \\
\hline Observations & 1001 & 1001 & 1001 & 1001 \\
\hline
\end{tabular}


Table 7.5.3.: Adaptation costs OLS regressions

\begin{tabular}{|c|c|c|c|c|}
\hline Dependent variable: ln Average adaptation costs & $(1)$ & $(2)$ & $(3)$ & $(4)$ \\
\hline ln Number of hires & $\begin{array}{c}0.46 \\
(0.38)\end{array}$ & $\begin{array}{c}0.23 \\
(0.38)\end{array}$ & $\begin{array}{c}0.32 \\
(0.36)\end{array}$ & $\begin{array}{c}0.40 \\
(0.36)\end{array}$ \\
\hline ln Number of employees & & $\begin{array}{c}0.38 \\
(0.24)\end{array}$ & $\begin{array}{c}0.09 \\
(0.20)\end{array}$ & $\begin{array}{c}-0.14 \\
(0.22)\end{array}$ \\
\hline ln Monthly wage of skilled workers & & & $\begin{array}{c}1.87^{* *} \\
(0.78)\end{array}$ & $\begin{array}{c}2.00^{* *} \\
(0.78)\end{array}$ \\
\hline Local unemployment rate & & & $\begin{array}{l}-0.22 \\
(9.54)\end{array}$ & $\begin{array}{l}-0.46 \\
(8.79)\end{array}$ \\
\hline Firm located in western Germany & & & $\begin{array}{l}-0.81 \\
(0.80)\end{array}$ & $\begin{array}{l}-0.53 \\
(0.80)\end{array}$ \\
\hline Works council/other representation form & & & & $\begin{array}{c}0.52 \\
(0.56)\end{array}$ \\
\hline Collective bargaining agreement & & & & $\begin{array}{c}1.60^{* * *} \\
(0.45)\end{array}$ \\
\hline Occupational controls & Yes & Yes & Yes & Yes \\
\hline Industry controls & Yes & Yes & Yes & Yes \\
\hline Constant & $\begin{array}{c}5.48^{* * *} \\
(0.47)\end{array}$ & $\begin{array}{c}4.63^{* * * *} \\
(0.87)\end{array}$ & $\begin{array}{l}-8.27 \\
(6.52)\end{array}$ & $\begin{array}{l}-9.75 \\
(6.53)\end{array}$ \\
\hline$R^{2}$ & 0.01 & 0.02 & 0.16 & 0.20 \\
\hline Observations & 1001 & 1001 & 1001 & 1001 \\
\hline
\end{tabular}

tion 7.10 yields an $\alpha$ of 1.34 . Consequently, a $10 \%$ increase in the number of hires leads to a $13.4 \%$ increase in the total recruitment costs (Table 7.5.2).

The local unemployment rate, which is a proxy for the tightness of the local labour market, has a negative effect on average recruitment costs, implying that recruiting new workers is more expensive if the local availability of skilled workers is limited. A 1\%-point increase in the local unemployment rate is associated with a $4.7 \%$ decrease in average recruitment costs. Firm size has a significantly positive effect, while high-wage firms are associated with higher recruitment costs than low-wage firms.

Turning to the relation between hires and average adaptation costs, Table 7.5.3 suggests that average adaptation costs are not significantly affected by the number of hired workers. The coefficient is not statistically different from zero, implying a linear structure of adaptation costs. Adaptation costs are mainly driven by the skilled worker wage, and they vary by occupation and industry.

With respect to labour market institutions, Table 7.5.4 sums up the main results from Tables 7.5.1 to 7.5.3. We find that worker representation at the firm level is associated with a $33 \%$ increase in the average hiring costs of skilled labour. This result is due to both higher recruitment and adaptation costs, although the latter is not statistically significant.

Collective bargaining coverage has no significant effect on overall hiring costs. However, firms with collective bargaining agreements have lower recruitment costs but higher adaptation costs. As previously argued, the former result may arise because individual wage bargaining does not take place in such firms (the wage is already set prior to signing 
Table 7.5.4.: Firm-level institutions and hiring, recruitment and adaptation costs

\begin{tabular}{llll}
\hline Dependent Variable (in logs): & $\begin{array}{c}\text { Average } \\
\text { hiring costs }\end{array}$ & $\begin{array}{c}\text { Average } \\
\text { recruitment costs }\end{array}$ & $\begin{array}{c}\text { Average } \\
\text { adaptation costs }\end{array}$ \\
\hline $\begin{array}{l}\text { Works council or other } \\
\text { form of representation }\end{array}$ & $+^{* * *}$ & $+^{*}$ & + \\
$\begin{array}{l}\text { Collective bargaining } \\
\text { agreement }\end{array}$ & 0 & $-* * *$ & $+{ }^{* * *}$ \\
\hline
\end{tabular}

Table summarizes results from tables 7.5 .1 to 7.5 .3 .

${ }^{*} p<0.10,{ }^{* *} p<0.05,{ }^{* * *} p<0.01$.

the contract). Higher adaptation costs may be due to higher expected tenure in firms with collective bargaining agreements. Investments in informal and formal training have a longer expected pay-off period, providing an incentive to invest more in a new hire during the adaptation period.

\subsubsection{Robustness analysis}

The effects of institutions on hiring costs have no strictly causal interpretation, as firms can choose whether to agree to worker representation or participate in collective bargaining agreements. As very small firms almost never have works councils and very large firms almost always do, we provide results for a reduced sample of firms employing 21 to 100 workers. We do so because in this firm-size category we find similar shares of firms with and without works councils (see previous chapter for more details). Table A7.3 shows that the impact of worker representation on hiring costs also remains strong and positive for this subsample. The respective coefficient, however, is significant only at the $10 \%$ level. The individual coefficients on recruitment and adaptation costs remain strongly positive in size, but they are not significantly different from zero (possibly due to the smaller sample size).

As in any non-experimental study, our results may be driven by unobserved heterogeneity. While observing hiring costs across time would enable us to account for time-invariant factors at the firm level, we have to rely on cross-sectional information. However, to validate our findings, we carry out a number of further robustness checks along similar lines as Blatter et al. (2012).

First, we regress hiring costs on the number of hires (Table A7.4), rather than estimating an iso-elastic cost function. The results confirm the convex structure of hiring costs. Larger firms find it cheaper to hire a given number of new workers per period, as the interaction term of firms size and the number of hires $(H \times N)$ has a statistically significant and negative coefficient. However, hiring costs increase for firms hiring a high number of new workers, since the coefficient on the interaction term $\left(H^{2} \times N\right)$ is positive and statistically significant. To explicitly test for a fixed component, we also estimate a 
version including a term $1 / H$. However, as the coefficient is not statistically significant from zero (and even negative), we find no evidence for fixed costs 18

Second, to account more directly for large firms hiring more new workers in a given period, we regress hiring costs on hiring rates $(H / N)$ (Table A7.5). We find that an increase in the hiring rate is associated with a significant increase in average hiring costs. Consequently, firms hiring more workers relative to their level of employment incur higher average hiring costs, which confirms a convex structure of hiring costs. The effects are economically substantial, as a one-standard-deviation increase in the hiring rate is associated with a 0.34 standard-deviation increase in marginal hiring costs.

Third, due to the possibility that differences in the composition of the work force have an influence on the level and structure of hiring cost in a firm, we added the share of skilled workers as an additional control variable to model 4 in Table 7.5.1. The corresponding estimates are presented in Table A7.6 in the Appendix. Compared to the results from our reference model, the coefficient of the number of hires on average hiring costs is slightly smaller (0.30 instead of 0.33). The coefficient on the share of skilled workers itself is positive but not significantly different from 0 .

Finally, we consider that hiring costs are to a large degree determined by wages (e.g. for personnel participating in the interviews or when calculating productivity loss in the adaptation period). Thus, regressing hiring costs on wages may lead to biased results. We thus estimate alternatives of equation 7.10 , both leaving out the wage component on the right hand side of the equation and substituting it by the deviation from the average wage in the occupational field. Neither alternative estimate changes the main results significantly 19

We further provide a set of regressions on the non-wage components of both recruitment and adaptation costs (as discussed in Section 7.4.2.) to show that wage correlations are not the driving force behind the relation between hiring costs and the number of hires. Table A7.7 displays the results when regressing the average costs of posting vacancies on the number of hires, both in natural logarithms. For both the total sample ( 5 and more employees) and the subset of firms (21 to 100 employees), average job-posting costs increase with the number of hires. Regressing the average interview time on the number of hires likewise suggests a positive relation to hiring costs; however, the respective coefficients are not significant in neither of the two samples (Table A7.8). With respect to components of adaptation costs, column 1 of Table A7.9 suggests a positive impact of the number of hires on the productivity difference between newly hired and established skilled workers in the firm. Likewise, the coefficient on training time is positive and significant at the 10\%-level (column 3). Column 2 of Table A7.9 suggests that the number of hires has no significant impact on the adaptation period.

\footnotetext{
${ }^{18}$ Results on the fixed component are available upon request.

${ }^{19}$ Results are not shown but are available upon request.
} 
Concerning the relation between collective bargaining and the non-wage components of hiring costs, we find support for the hypothesis that collective bargaining reduces the costs associated with the recruitment process. Collective bargaining agreements already define important aspects of the working contract (such as wages and safety issues) and thereby lead to a lower amount of time to be spent on interviews. In contrast, Table A7.9 gives no clear indication of a positive effect on adaptation costs. For works council firms in the full sample, the number of hires relates positively to job posting costs. However, the respective coefficient turns insignificant using the reduced sample. Column 3 in Table A7.9 supports the hypothesis that firms invest more into the training of new hires if a works council is present.

Summing up the results of robustness exercises, in general we find support for the main result of the previous subsection that hiring costs increase with the number of hires and differ according to the specific institutional arrangements at the firm level.

\subsection{Conclusions}

Saving hiring costs may be an important benefit for a firm that offers apprenticeship training. The firm may save both recruitment and adaptation costs when retaining a former apprentice. The chapter provides evidence that the costs of filling a vacancy in Germany are substantial, ranging on average from $€ 4000$ to $€ 6000$. Moreover, our results show that the structure of hiring costs is convex, implying that hiring additional workers in a given period becomes increasingly expensive. We find that an increase in the number of hires by $10 \%$ increases total hiring costs by about $13.3 \%$ and leading to marginal hiring costs of up to $€ 7000$. The result are important for explaining why firms may have incentives to bear the costs for apprenticeship training even if vocationally qualified workers are available on the external labour market. The substantial hiring costs increase a firm's incentive to finance the training of apprentices. Further, the convex structure implies that it may be beneficial for a firm to cover large shares of their demand for skilled workers through the training and retention of apprentices.

Labour market institutions also affect hiring costs. While hiring costs in firms with collective bargaining coverage do not significantly differ from other firms, we find that worker representation at the firm level increases hiring costs by more than $33 \%$. Thus, with respect to the results obtained from the previous chapter, worker representation not only increases a firm's training investment, but also its post-training benefits in the form of saved hiring costs.

With respect to results from the literature, the structure of hiring costs in Germany is similar to that obtained from a comparable study by Blatter et al. (2012) for Switzerland, a country with a relatively low degree of employment protection legislation (like the United States). Thus, our findings suggest the existence of a general structure of hiring costs across countries with varying degrees of labour market regulations. 
Our results are also relevant for recent policies aimed at reducing unemployment. In Germany, short-time work (Kurzarbeit) is a widely used policy instrument for preventing firms from laying off workers, enabling a firm to employ workers at reduced working hours. Under this programme, the government covers part of the wage bill, thereby providing financial incentives for a firm not to lay off employees. Our findings imply that rational firms already have incentives to retain workers when the business outlook is bad, because re-hiring skilled workers in the future is costly, particularly when a firm needs to hire a number of workers at once. Thus, while our findings help to explain why a firm hoards labour, our results also help to quantify possible benefits of short-time work policies (i.e. saved resources on future hiring costs). Nonetheless, such policies may also generate substantial windfall gains for firms that had no intention of laying off workers in the first place. 


\section{A7. Appendix}

Figure A7.1.: Density of hiring costs, 21 to 100 employees

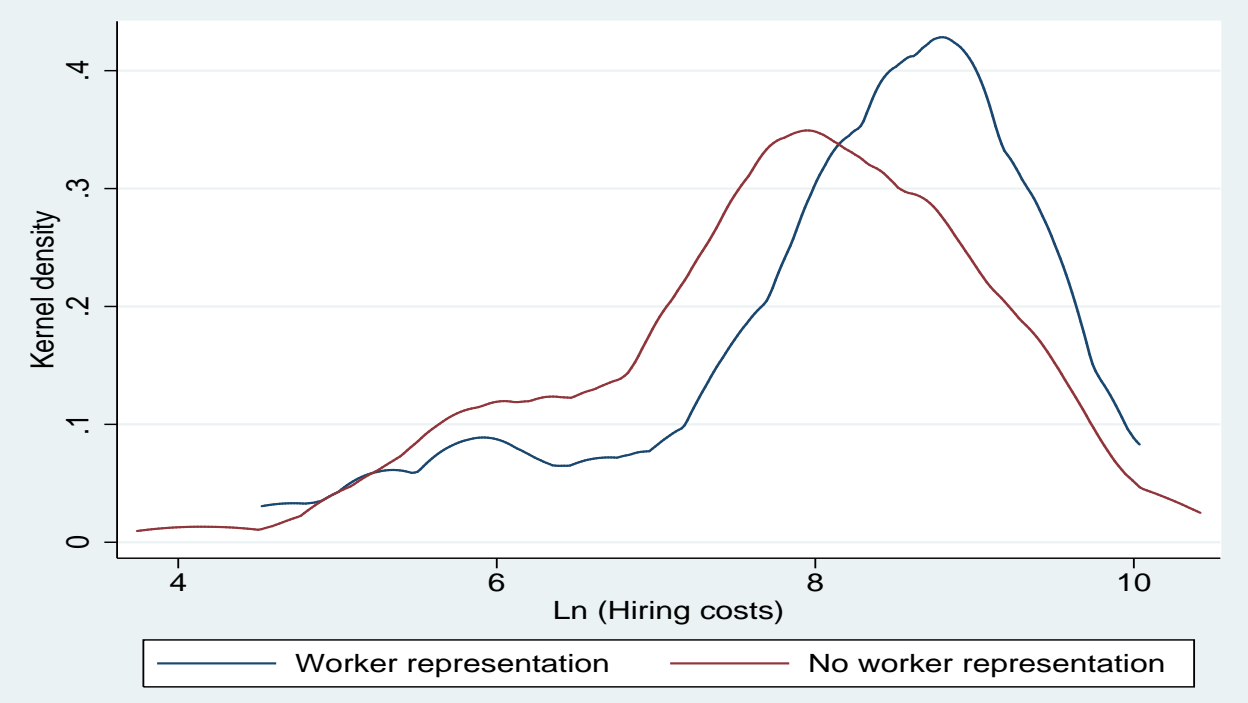

Figure A7.2.: Marginal hiring costs (in $€$ )

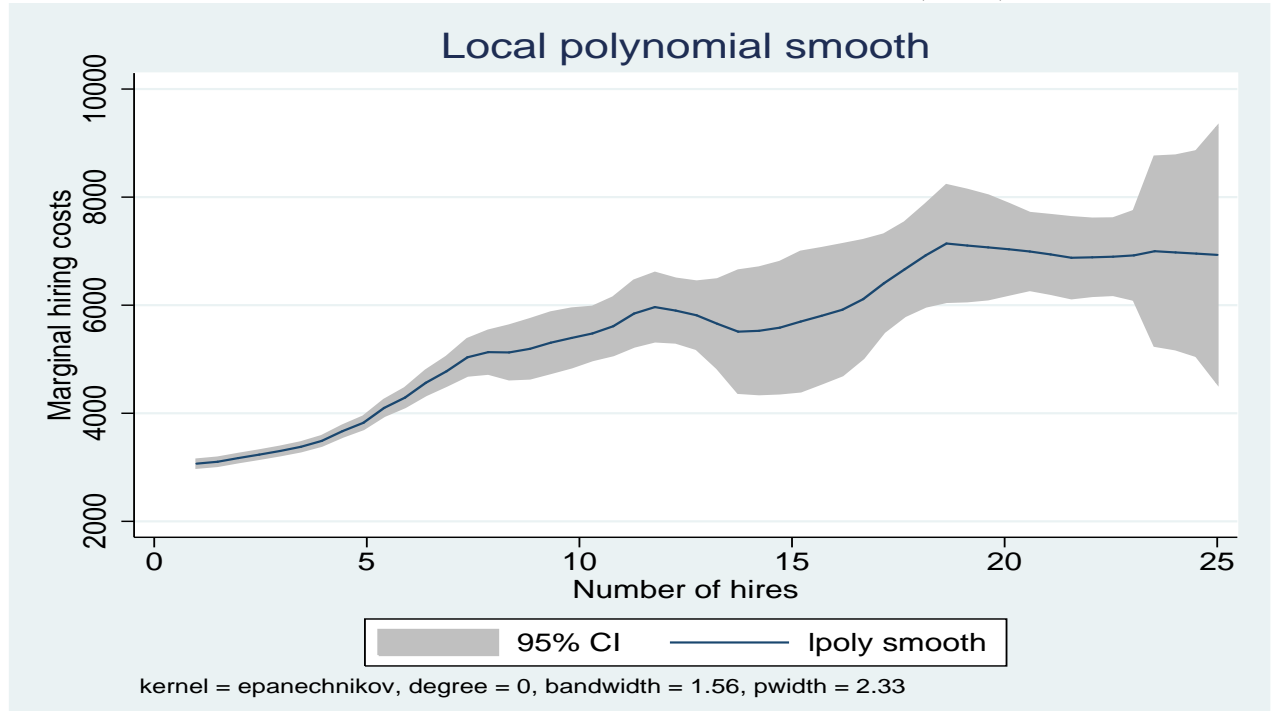


Table A7.1.: Summary statistics

\begin{tabular}{lc}
\hline \multicolumn{1}{c}{ Variable } & Mean \\
\hline Economic Sector & \\
Crafts & 0.32 \\
Trade & 0.17 \\
Services I & 0.19 \\
Services II & 0.17 \\
Public services, education, health & 0.16 \\
\hline Occupational Field & \\
Metalworking & 0.08 \\
Electrical engineering & 0.07 \\
Information technology & 0.04 \\
Chemicals & 0.01 \\
Accommodation and food & 0.09 \\
Construction & 0.1 \\
Print and media & 0.04 \\
Health & 0.12 \\
Administrative: sales and distribution & 0.14 \\
Administrative: headquarters & 0.25 \\
Administrative: banks/insurance & 0.01 \\
Other occupations & 0.06 \\
\hline Region & \\
Firm located in West Germany & 0.8 \\
Firm located in East Germany & 0.2 \\
\hline Institutional factors & \\
Works council or other form of representation & 0.31 \\
No worker representation & 0.69 \\
Collective bargaining agreement & 0.38 \\
No collective bargaining agreement & 0.62 \\
\hline Other variables & 2.85 \\
Number of hires & $(2.75)$ \\
Standard deviation (Number of hires) & 1001 \\
\hline Observations & \\
\hline &
\end{tabular}


Table A7.2.: Summary statistics of hiring costs variables

\begin{tabular}{lcc}
\hline \multicolumn{1}{c}{ Variable } & Mean & Std. Dev. \\
\hline Average costs for posting vacancy & 563 & $(828)$ \\
Average costs for job interview process & 626 & $(700)$ \\
Average costs for external consultants & 449 & $(1620)$ \\
\hline Average recruitment costs & 1638 & $(2231)$ \\
\hline Average skilled worker wage in firm & 2365 & $(805)$ \\
Adaptation period (in months) & 3.8 & $(2.8)$ \\
Productivity difference newly hired vs established worker $(\%)$ & 42.2 & $(21.2)$ \\
Continuing training: wage costs & 514 & $(949)$ \\
Continuing training: fees and traveling expenses & 606 & $(1177)$ \\
Average costs of productivity difference & 1975 & $(2197)$ \\
\hline Average adaptation costs & 3095 & $(3360)$ \\
\hline Average hiring costs per hire & $\mathbf{4 7 3 3}$ & $(\mathbf{4 4 6 1 )}$ \\
\hline Observations & & 1001 \\
\hline
\end{tabular}

Table A7.3.: Hiring, recruitment and adaptation costs: 21-100 employees

\begin{tabular}{lccc}
\hline Dependent Variable: & $\begin{array}{c}\text { ln Average } \\
\text { hiring costs }\end{array}$ & $\begin{array}{c}\text { ln Average } \\
\text { recruitment costs }\end{array}$ & $\begin{array}{c}\text { ln Average } \\
\text { adaptation costs }\end{array}$ \\
\hline ln Number of hires & $0.23^{*}$ & $0.35^{* * *}$ & 0.31 \\
& $(0.14)$ & $(0.12)$ & $(0.43)$ \\
ln Number of employees & -0.01 & -0.22 & 0.60 \\
& $(0.27)$ & $(0.22)$ & $(0.87)$ \\
ln Monthly wage of skilled workers & 0.55 & $0.51^{* *}$ & 0.19 \\
& $(0.36)$ & $(0.26)$ & $(1.03)$ \\
Firm located in western Germany & 0.28 & 0.00 & 0.24 \\
& $(0.29)$ & $(0.26)$ & $(0.95)$ \\
Local unemployment rate & -5.02 & $-4.90^{*}$ & -7.21 \\
& $(3.07)$ & $(2.85)$ & $(10.64)$ \\
Works council/other representation form & $0.49^{*}$ & 0.31 & 1.20 \\
& $(0.27)$ & $(0.24)$ & $(0.81)$ \\
Collective bargaining agreement & -0.12 & $-0.71^{* * *}$ & $1.57^{* *}$ \\
& $(0.26)$ & $(0.21)$ & $(0.71)$ \\
Occupational controls & Yes & Yes & Yes \\
Industry controls & Yes & Yes & Yes \\
Constant & 3.00 & 2.67 & 1.54 \\
& $(2.93)$ & $(2.09)$ & $(7.77)$ \\
\hline Observations & 356 & 356 & 356 \\
\hline Standard deviation in parenthesis. ${ }^{*} p<0.10, * *<0.05,{ }^{* * *} p<0.01$. &
\end{tabular}


7. The hiring costs of vocationally trained workers

Table A7.4.: Hiring level OLS regressions

\begin{tabular}{lccc}
\hline Dependent Variable: & Average & Average & Average \\
& hiring costs & recruitment costs & adaptation costs \\
\hline New hires $H$ & $817.05^{* * *}$ & $386.22^{* * *}$ & $430.81^{* *}$ \\
& $(201.25)$ & $(141.39)$ & $(170.53)$ \\
$H^{2}$ & $-26.60^{* * *}$ & $-13.57^{* *}$ & -13.03 \\
Number of employees $N$ & $(9.01)$ & $(6.42)$ & $(8.50)$ \\
& $7.77^{* * *}$ & $4.05^{* *}$ & $3.72^{*}$ \\
$H \times N$ & $(2.89)$ & $(1.72)$ & $(1.99)$ \\
& $-1.95^{* * *}$ & -0.74 & $-1.21^{* *}$ \\
$H^{2} \times N$ & $(0.72)$ & $(0.47)$ & $(0.54)$ \\
& $0.08^{* * *}$ & 0.03 & $0.05^{* *}$ \\
Firm located in West Germany & $(0.03)$ & $(0.02)$ & $(0.02)$ \\
& 253.83 & 239.66 & 14.27 \\
Monthly wage of skilled worker & $(638.00)$ & $(372.22)$ & $(504.12)$ \\
& $1.62^{* * *}$ & $0.80^{* * *}$ & $0.82^{* *}$ \\
Local unemployment rate & $(0.30)$ & $(0.19)$ & $(0.34)$ \\
& -12368.49 & -3457.47 & -8911.24 \\
Works council/other representation form & $(7829.76)$ & $(4553.51)$ & $(5745.35)$ \\
& $985.73^{* *}$ & 236.58 & $749.12^{*}$ \\
Collective bargaining agreement & $(493.25)$ & $(272.57)$ & $(430.66)$ \\
& -410.47 & $-510.91^{* *}$ & 100.23 \\
Occupational controls & $(486.00)$ & $(220.26)$ & $(410.06)$ \\
Industry controls & Yes & Yes & Yes \\
Constant & Yes & Yes & Yes \\
& $2281.61^{*}$ & 151.72 & 2130.29 \\
Observations & $(1348.07)$ & $(567.35)$ & $(1156.22)$ \\
\hline Stans & 1001 & 1001 & 1001 \\
\hline
\end{tabular}

Standard deviation in parenthesis. ${ }^{*} p<0.10,{ }^{* *} p<0.05,{ }^{* * *} p<0.01$. 
Table A7.5.: Hiring rate OLS regressions

\begin{tabular}{lccc}
\hline Dependent Variable: & Average & Average & Average \\
& hiring costs & recruitment costs & adaptation costs \\
\hline Hiring rate (hires/skilled workers) & $8984.21^{* * *}$ & $3416.14^{* * *}$ & $5568.22^{*}$ \\
& $(3258.73)$ & $(1167.73)$ & $(3313.79)$ \\
Monthly skilled worker wage $W$ & $1.74^{* * *}$ & $0.79^{* * *}$ & $0.95^{* * *}$ \\
& $(0.36)$ & $(0.19)$ & $(0.35)$ \\
10-49 employees & $1009.49^{*}$ & $852.14^{* * *}$ & 157.35 \\
& $(544.81)$ & $(285.98)$ & $(452.16)$ \\
$50-99$ employees & 1739.64 & $842.98^{*}$ & 896.72 \\
& $(1241.82)$ & $(460.76)$ & $(1008.44)$ \\
100-249 employees & $3067.64^{* * *}$ & $2240.70^{* * *}$ & 826.92 \\
& $(1153.53)$ & $(595.96)$ & $(842.62)$ \\
250-499 employees & $2947.37^{* * *}$ & $1987.53^{* * *}$ & 959.78 \\
& $(948.56)$ & $(588.43)$ & $(706.58)$ \\
500-999 employees & $1999.84^{* *}$ & $2144.35^{* * *}$ & -144.62 \\
& $(842.52)$ & $(459.83)$ & $(707.82)$ \\
1000+ employees & $4234.87^{* * *}$ & $2616.25^{* * *}$ & 1618.52 \\
& $(1440.38)$ & $(754.58)$ & $(1183.02)$ \\
Local unemployment rate & $-12682.87^{*}$ & -3088.51 & $-9594.59^{*}$ \\
& $(7462.55)$ & $(4178.02)$ & $(5606.05)$ \\
Works council/other representation form & $1147.33^{* *}$ & 178.60 & $968.71^{* *}$ \\
Collective bargaining agreement & $(541.08)$ & $(293.32)$ & $(452.39)$ \\
& -459.35 & $-598.15^{* * *}$ & 138.59 \\
Occupational controls & $(444.36)$ & $(203.72)$ & $(387.88)$ \\
Industry controls & Yes & Yes & Yes \\
Constant & Yes & Yes & Yes \\
& $6323.41^{* * *}$ & 1696.17 & $4627.44^{* * *}$ \\
\hline Observations & $(1344.66)$ & $(615.30)$ & $(1130.39)$ \\
\hline
\end{tabular}

Standard deviation in parenthesis. ${ }^{*} p<0.10,{ }^{* *} p<0.05,{ }^{* * *} p<0.01$. 
Table A7.6.: Hiring costs OLS regressions incl. share of skilled workers

\begin{tabular}{|c|c|c|c|c|}
\hline Dependent variable: ln Average hiring costs & (1) & $(2)$ & (3) & $(4)$ \\
\hline ln Number of hires & $\begin{array}{c}0.41^{* * *} \\
(0.12)\end{array}$ & $\begin{array}{c}0.26^{* *} \\
(0.12)\end{array}$ & $\begin{array}{c}0.30^{* * *} \\
(0.11)\end{array}$ & $\begin{array}{c}0.30^{* * *} \\
(0.11)\end{array}$ \\
\hline ln Number of employees & & $\begin{array}{c}0.19^{* * *} \\
(0.07)\end{array}$ & $\begin{array}{c}0.05 \\
(0.06)\end{array}$ & $\begin{array}{c}0.01 \\
(0.06)\end{array}$ \\
\hline Share of skilled workers in firm & & $\begin{array}{c}0.93^{* *} \\
(0.36)\end{array}$ & $\begin{array}{c}0.43 \\
(0.32)\end{array}$ & $\begin{array}{c}0.43 \\
(0.31)\end{array}$ \\
\hline ln Monthly wage of skilled workers & & & $\begin{array}{c}1.11^{* * *} \\
(0.23)\end{array}$ & $\begin{array}{c}1.07^{* * *} \\
(0.23)\end{array}$ \\
\hline Local unemployment rate & & & $\begin{array}{l}-2.70 \\
(2.81)\end{array}$ & $\begin{array}{l}-3.32 \\
(2.81)\end{array}$ \\
\hline Firm located in western Germany & & & $\begin{array}{l}-0.20 \\
(0.22)\end{array}$ & $\begin{array}{l}-0.15 \\
(0.22)\end{array}$ \\
\hline Works council/other representation form & & & & $\begin{array}{c}0.33^{* *} \\
(0.14)\end{array}$ \\
\hline Collective bargaining agreement & & & & $\begin{array}{l}-0.01 \\
(0.15)\end{array}$ \\
\hline Occupational controls & Yes & Yes & Yes & Yes \\
\hline Industry controls & Yes & Yes & Yes & Yes \\
\hline Constant & $\begin{array}{c}7.57^{* * *} \\
(0.14) \\
\end{array}$ & $\begin{array}{c}6.49^{* * *} \\
(0.33) \\
\end{array}$ & $\begin{array}{c}-0.94 \\
(1.85) \\
\end{array}$ & $\begin{array}{r}-0.66 \\
(1.88) \\
\end{array}$ \\
\hline$R^{2}$ & 0.03 & 0.05 & 0.32 & 0.33 \\
\hline Observations & 1001 & 1001 & 1001 & 1001 \\
\hline
\end{tabular}

Table A7.7.: Costs for posting vacancy OLS regressions

\begin{tabular}{|c|c|c|c|c|}
\hline Dependent variable: ln Average job posting costs & \multicolumn{2}{|c|}{$5+$ employees } & \multicolumn{2}{|c|}{ 21-100 employees } \\
\hline ln Number of hires & $\begin{array}{c}0.75^{* * *} \\
(0.23)\end{array}$ & $\begin{array}{c}0.76^{* * *} \\
(0.23)\end{array}$ & $\begin{array}{c}0.72^{* * *} \\
(0.23)\end{array}$ & $\begin{array}{c}0.68^{* * *} \\
(0.23)\end{array}$ \\
\hline ln Number of employees & $\begin{array}{c}0.00 \\
(0.15)\end{array}$ & $\begin{array}{l}-0.10 \\
(0.15)\end{array}$ & $\begin{array}{l}-0.21 \\
(0.48)\end{array}$ & $\begin{array}{l}-0.11 \\
(0.49)\end{array}$ \\
\hline ln Monthly wage of skilled workers & $\begin{array}{l}1.07^{*} \\
(0.58)\end{array}$ & $\begin{array}{l}1.07^{*} \\
(0.57)\end{array}$ & $\begin{array}{l}0.66 \\
(0.73)\end{array}$ & $\begin{array}{c}0.65 \\
(0.75)\end{array}$ \\
\hline Firm located in western Germany & $\begin{array}{l}-0.37 \\
(0.53)\end{array}$ & $\begin{array}{l}-0.45 \\
(0.51)\end{array}$ & $\begin{array}{l}-0.76 \\
(0.52)\end{array}$ & $\begin{array}{l}-0.81 \\
(0.52)\end{array}$ \\
\hline Works council/other representation form & & $\begin{array}{c}0.90^{* * *} \\
(0.33)\end{array}$ & & $\begin{array}{c}0.01 \\
(0.57)\end{array}$ \\
\hline Collective bargaining agreement & & $\begin{array}{l}-0.71^{*} \\
(0.37)\end{array}$ & & $\begin{array}{l}-0.71 \\
(0.59)\end{array}$ \\
\hline Occupational controls & Yes & Yes & Yes & Yes \\
\hline Industry controls & Yes & Yes & Yes & Yes \\
\hline Constant & $\begin{array}{l}-4.95 \\
(4.89)\end{array}$ & $\begin{array}{l}-4.43 \\
(4.81)\end{array}$ & $\begin{array}{l}-0.37 \\
(6.34)\end{array}$ & $\begin{array}{l}-0.08 \\
(6.46)\end{array}$ \\
\hline$R^{2}$ & 0.17 & 0.20 & 0.16 & 0.16 \\
\hline Observations & 1001 & 1001 & 356 & 356 \\
\hline
\end{tabular}


Table A7.8.: Interview time OLS regressions

\begin{tabular}{|c|c|c|c|c|}
\hline \multicolumn{5}{|l|}{ Dependent variable: ln Average interview time (hours) } \\
\hline ln Number of hires & $\begin{array}{c}0.04 \\
(0.09)\end{array}$ & $\begin{array}{c}0.02 \\
(0.08)\end{array}$ & $\begin{array}{c}0.18 \\
(0.11)\end{array}$ & $\begin{array}{c}0.17 \\
(0.11)\end{array}$ \\
\hline ln Number of employees & $\begin{array}{c}0.09 \\
(0.06)\end{array}$ & $\begin{array}{c}0.13^{* *} \\
(0.06)\end{array}$ & $\begin{array}{c}-0.15 \\
(0.18)\end{array}$ & $\begin{array}{l}-0.09 \\
(0.18)\end{array}$ \\
\hline ln Monthly wage of skilled workers & $\begin{array}{c}0.43^{* *} \\
(0.20)\end{array}$ & $\begin{array}{c}0.40^{* *} \\
(0.20)\end{array}$ & $\begin{array}{c}-0.05 \\
(0.26)\end{array}$ & $\begin{array}{l}-0.12 \\
(0.27)\end{array}$ \\
\hline Firm located in western Germany & $\begin{array}{c}0.01 \\
(0.16)\end{array}$ & $\begin{array}{l}-0.05 \\
(0.15)\end{array}$ & $\begin{array}{c}-0.07 \\
(0.23)\end{array}$ & $\begin{array}{l}-0.06 \\
(0.22)\end{array}$ \\
\hline Works council/other representation form & & $\begin{array}{l}-0.08 \\
(0.17)\end{array}$ & & $\begin{array}{c}0.02 \\
(0.19)\end{array}$ \\
\hline Collective bargaining agreement & & $\begin{array}{c}-0.32^{* *} \\
(0.13)\end{array}$ & & $\begin{array}{c}-0.43^{* *} \\
(0.18)\end{array}$ \\
\hline Constant & $\begin{array}{l}-1.16 \\
(1.59)\end{array}$ & $\begin{array}{c}-0.85 \\
(1.54)\end{array}$ & $\begin{array}{c}3.37 \\
(2.14)\end{array}$ & $\begin{array}{l}3.69^{*} \\
(2.22)\end{array}$ \\
\hline$R^{2}$ & 0.11 & 0.13 & 0.11 & 0.14 \\
\hline Observations & 1001 & 1001 & 356 & 356 \\
\hline
\end{tabular}

Table A7.9.: Adaptation cost components regressions

\begin{tabular}{lccc}
\hline Dependent Variable: & $\begin{array}{c}\text { Productivity } \\
\text { difference (percent) }\end{array}$ & $\begin{array}{c}\text { Adaptation } \\
\text { period (months) }\end{array}$ & $\begin{array}{c}\text { Training } \\
\text { time (days) }\end{array}$ \\
\hline Number of hires & $0.83^{* *}$ & 0.03 & $0.45^{*}$ \\
Number of employees & $(0.36)$ & $(0.04)$ & $(0.27)$ \\
& 0.00 & 0.00 & $-.004^{*}$ \\
Monthly wage of skilled workers & $(0.00)$ & $(0.00)$ & $(0.00)$ \\
Local unemployment rate & -0.00 & 0.00 & 0.00 \\
& $(0.00)$ & $(0.00)$ & $(0.00)$ \\
Firm located in western Germany & 28.55 & -1.98 & -18.72 \\
& $(45.21)$ & $(4.76)$ & $(18.56)$ \\
Works council/other representation form & 0.83 & 0.31 & 0.06 \\
& $(4.38)$ & $(0.44)$ & $(2.24)$ \\
Collective bargaining agreement & 0.06 & 0.25 & $3.79^{* *}$ \\
& $(2.66)$ & $(0.39)$ & $(1.49)$ \\
Constant & 1.37 & -0.26 & -1.77 \\
& $(2.44)$ & $(0.32)$ & $(1.39)$ \\
\hline$R^{2}$ & $33.82^{* * *}$ & $2.96^{* * *}$ & -4.69 \\
Observations & $(7.25)$ & $(0.87)$ & $(7.04)$ \\
\hline
\end{tabular}

Standard deviation in parenthesis. ${ }^{*} p<0.10,{ }^{* *} p<0.05,{ }^{* * *} p<0.01$.

Model 1 and model 3 are tobit regression models with lower limit $=0$

and upper limit $=100($ only model 1$)$ 
Table A7.10.: Survey questions on hiring costs

\begin{tabular}{l}
\hline Recruitment costs \\
\hline Did your firm hire skilled workers in [occupation] in the last \\
3 years from the labour market? \\
If yes, how many workers in [occupation] did your firm hire? \\
How high are the average costs for posting a vacancy in newspapers, at \\
the employment agency or in internal postings in your firm? \\
How many hours did your employees [unskilled employees, skilled \\
employees, management] spend on the hiring process? \\
- Please consider the entire hiring process, including time for scanning \\
job applications, preparing for and conducting the job interviews. \\
Do you also make use of external consultants in the hiring of \\
skilled workers? \\
If yes, how high are the costs for external consultants?
\end{tabular}

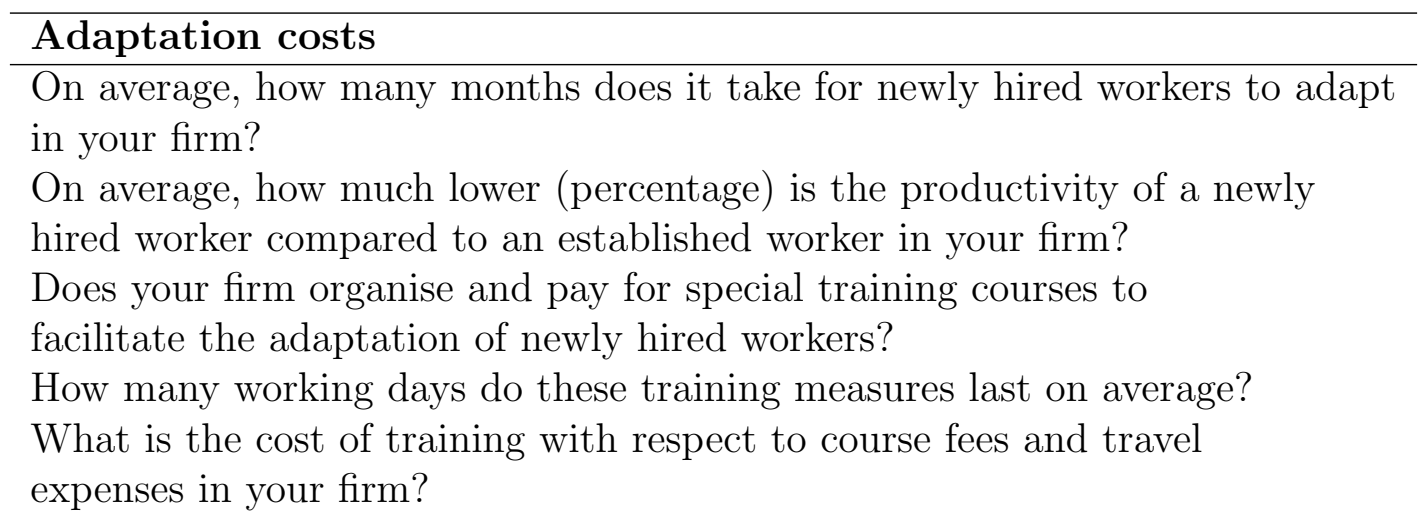

\begin{tabular}{l} 
Wage information \\
How high is the average monthly wage of a worker in [occupation]? \\
What is the average difference in wage (percentage) between \\
a newly hired worker and an established worker? \\
\hline Institutions \\
Are the wages in your firm bound to collective bargaining agreements? \\
Does your firm have a works council elected on the basis of the \\
Betriebsverfassungsgesetz (Works Constitution Act)? \\
Does your firm have any other firm-specific form of employee representation, \\
such as an employee speaker, round table or the like?
\end{tabular}




\section{Conclusion and implications}

\subsection{Overview}

In the first part of this thesis, the empirical assessment centred around wage and productivity differences between vocationally and generally educated workers. The argument was that workers having acquired vocational qualifications are equipped with skills that are immediately usable in the firm. The combination of theoretical and practical education in a particular occupational field allows firms to organise their production more efficiently with flat hierarchies and low control costs. Chapter 2 analysed whether firms benefit from having access to VET workers in terms of productivity.

In Chapter 3, I argued that a labour market entrant with occupation-specific vocational education and training may earn higher wages than an entrant having gained a more general qualification. However, whether the initial wage advantage persists over time was not clear a priori. The hypothesis was that a generally educated worker catches up over time and eventually earns a higher wage resulting from his broader general knowledge and problem solving skills.

Chapter 4 studied another potential benefit of vocational training from the individual's perspective: mobility after training. The chapter examined if a VET system with a high degree of transparency and standardisation allows the worker to transfer his skills to other employers. The hypothesis was that a former apprentice moving firms but working in the initial occupation and job would lose only moderate shares of the acquired human capital.

The remaining parts of the thesis dealt with the impact of institutions on firms' investment in apprenticeship training. I analysed the question whether employment protection legislation in general, and labour market institutions at the firm level in specific, foster a firm's training investment, as suggested in recent theoretical training literature. The expectation was that institutions impact positively on both the cost and the post-training benefits of training and thus explain the training behaviour of firms facing these institutions.

This concluding chapter summarises the main results of the empirical analysis and discusses implications for policy and future research. 


\section{Conclusion and implications}

\subsection{Conclusion}

Following the introductory chapter, I first analysed the impact of an increase in the share of vocationally educated and trained workers on productivity in Germany, the Netherlands and the United Kingdom. Previous literature using case studies in several countries suggested that access to a standardised and transparent VET system leads to productivity and quality differences between firms producing the same product in different countries. The chapter aimed to add to this literature using merged individual and industry-level panel data stemming from the KLEMS project and national multi-purpose panel surveys.

Comparing descriptive results from the industry-level data with those given in the literature, I found a positive relation between VET and productivity in most of the industries. Results of panel regression analysis confirmed that an increase in VET working hours impacts positively on labour productivity in all three countries. Compared to the coefficient on generally qualified labour, the coefficient for VET labour is larger in each of the countries. As expected, the impact of an increase in VET labour has a stronger impact in Germany and the Netherlands than in the United Kingdom. Graphical simulations showed that the relationship between the share of intermediate-level VET labour (compared to intermediate-level 'general' labour) and productivity is concave for all three countries. The optimal share of VET labour varies and is higher in Germany and the Netherlands than in the United Kingdom. Comparing the average share of VET over the past years with the estimated optimum in each of the countries implied that Germany and the Netherlands are closer to the optimal level of VET work than the United Kingdom. For the latter country, the graphical analysis suggests potential for productivity gains through an increase in the quantity and quality of VET labour, even when considering the lower level of transparency and standardisation of the VET system in that country.

Chapter 3 answers the question whether workers who have undergone vocational education earn higher wages at the beginning of their labour market career than workers who have received general education at the same qualification level. Similar to the reasoning in the previous chapter, the underlying hypothesis was that vocational education improves the fit between job requirements and individual skills and therefore leads to a better initial match on the labour market. On the basis of individual-level panel data sets and a mixed-effects linear regression framework, the chapter provided support for this hypothesis for Germany and the United Kingdom. However, the wage advantage for VET workers is only temporary as the generally educated catch up over time and, after a period of about 6 years in the labour market, reach higher wage-levels than vocationally trained workers.

To determine the transferability of VET, in Chapter 4 I used the BIBB Cost-Benefit Survey of 2007 to calculate a monetary value for the firm-specific component of German apprenticeship training. I argued that the resources needed to bring externally recruited workers up to the productivity level of internally trained workers provide a good indicator of the magnitude of the firm-specific component of such training. Results show that 
apprenticeship training is predominantly general and thus transferable across firms. If workers are employed in the same job and occupation, they can transfer, on average, $90 \%$ of their skills acquired during the training programme to the new firm.

Summarising the main results of Chapters 2 to 4, I find empirical support for the hypothesis that VET may have considerable benefits for individuals and firms. While wage advantages for individuals seem to be relevant only at the beginning of the labour market career, the productivity gains at the industry level suggest a more persisting advantage for firms operating in markets characterised by strongly institutionalised VET systems. Thus, individual benefits appear to be temporary while firm benefits persist over time. The seemingly inconsistent result may well be plausible when assuming that the wedge between the productivity of VET workers and their wages increases over time (Acemoglu and Pischke 1998, 1999a, b).

At least three issues have to be discussed when interpreting these chapter results. First, the graphical analysis in Chapter 2 suggested the existence of an optimal level of VET qualifications, which can, and in the presented analysis indeed does, vary across countries. Hence, the positive impact of VET labour on productivity may be specific to our chosen set of countries and thus may not hold for other countries. Second, the analysis in Chapter 3 shows that wage effects of VET at the individual level are temporary and can be offset by wage gains later in the working lifetime. Since the focus of the study has been the early labour market outcomes of VET, we cannot draw inferences about the net wage effects of VET compared to general education over the worker's entire labour market career. However, recent comparative research cited in the chapter finds support for the result that initial employment advantages of VET may well be offset by an early exit from the labour market. Third, although apprenticeship training in Germany is transferable across firms, we analyse the specific case where the worker keeps working in the initially trained occupation and performs a similar type of job in his new firm. Workers having to change jobs or even occupations may experience a loss of occupation- and job-specific human capital, as several of the studies cited in the chapter show 1 The three issues named here have to be borne in mind when interpreting these chapters' main results.

Chapters 5 and 6 focused on the influence of labour market institutions on private sector VET investment. Chapter 5 analysed the role of employment protection in raising incentives for firms to invest in the training of apprentices. For the analysis, I chose two countries with strong similarities in the apprenticeship training system but strong differences in labour market regulations. Germany (still) has a relatively strict employment protection legislation. At the same time, firms are willing to bear considerable net costs in the provision of training. In Switzerland, employment protection and the average investment in the training of apprentices is low. This chapter shows that one important reason for the differences in training investment is the difference in labour market regula-

\footnotetext{
${ }^{1}$ However, generally educated workers also lose job-specific skills when changing jobs. Only an analysis of the difference in earnings-loss would give an indication of the relative mobility disadvantage of VET workers.
} 


\section{Conclusion and implications}

tions in the two countries: a higher degree of employment protection increases the firm's labour adjustment costs. Apprenticeship training serves as a device for the firm to reduce such costs through two mechanisms. First, the firm can avoid hiring costs by employing its former apprentices as skilled workers. Second, the firm can reduce labour turnover, because former apprentices tend to stay longer and the match quality between the job and the worker is better compared to externally hired workers.

Chapter 6 analysed whether a firm with a works council differs from a firm without a works council in its training costs, retention strategy and training intensity. Nearestneighbor matching of firm-level data shows that a firm with a works council incurs about $€ 6300$ higher net costs per apprentice and year of training compared to a firm without such an institution. As very small firms hardly ever implement a works council, and large firms almost always do, I also investigated a sample of medium-sized firms with 21 to 100 employees, for which an analysis of works council effects is more appropriate. The results for medium-sized firms show that a works council leads to $€ 3500$ higher net training costs, but only in combination with collective agreements. The main sources for higher net costs are increased wages for apprentices, and - to a smaller extent - a lesser involvement of apprentices in productive activities.

The results of Chapters 5 and 6 are important in light of the debate about the consequences of a further deregulation of labour markets for the training system. Chapter 5 implies that a deregulation of the labour market would have consequences for the VET system in Germany because a lower degree of employment protection would reduce posttraining benefits for training firms. Firms would, ceteris paribus, need to reduce their investment in training in order to continue providing apprenticeship positions. The analysis in Chapter 6 supported the view that institutions are important for firms' human capital investments. In addition to employment protection, also institutions such as works councils and collective bargaining agreements influence firms' training behaviour.

The results suggest that firms face a trade-off: worker representation at the firm level (works councils) and the industry level (collective agreements) increases a firm's net investment in apprenticeship training, but at the same time enables firms to generate higher post-training benefits to recoup the additional training expenditures. Summing up, as in the case of employment protection, a continuing decentralisation of wage bargaining combined with a weakening of works council influence may have considerable negative consequences for the German VET system.

Finally, Chapter 7 investigated an important benefit of apprenticeship training: the costs that occur if a firm needs to hire skilled workers from the external labour market instead of training and retaining its own apprentices. Hiring costs of skilled workers in Germany are substantial, ranging on average from 7 to 14 weeks of wage payments ( $€$ 4000 to $€ 6000)$. The results further show that the structure of hiring costs is convex, implying that the more workers a firm hires in a given period the more expensive the 
average hire becomes. We find that an increase in the number of hires by $1 \%$ increases hiring costs by $1.3 \%$, leading to marginal hiring costs of up to $€ 7000$.

Labour market institutions also affect hiring costs. While hiring costs in firms with collective bargaining coverage do not significantly differ from other firms, we find that worker representation at the firm level increases hiring costs by more than $30 \%$. The structure of hiring costs in Germany, however, is similar to that obtained from a comparable study in Switzerland, a country with a relatively low degree of employment protection legislation (like the United States). Thus the findings suggest the existence of a general structure of hiring costs across countries, with varying degrees of labour market regulations.

The results of this chapter show first that training apprentices may generate substantial benefits if former apprentices stay in the firm as skilled workers. The hiring costs that can be saved this way are substantial. Second, institutions increase hiring costs and therefore post-training benefits. As shown in Chapter 6, firms that have works councils invest more in training. The analysis in this chapter indicates that these firms also have higher benefits of training in terms of saved recruitment costs. Thus, institutionalised firms with a higher net investment in training behave rationally when considering high post-training benefits.

\subsection{Implications}

The results of this thesis may also be important from a policy perspective. Vocational education and training remains an essential ingredient for the functioning of the economy in many European countries. It offers wage and productivity opportunities for individuals and firms, and, hence, are at least competitive with other forms of education at the same educational level, such as general school education. In Germany, apprentices in the dual system receive an education that is transferable across firms, if they stay with their initial occupational choice. From a firm's perspective, investments in apprenticeship training is rational considering the benefits resulting from retention and tenure of former apprentices. Results presented in this thesis suggest that the institutional framework, under which firms operate in an economy, may be crucial for the realisation of such benefits. Employment protection, collective bargaining and works councils foster the willingness of firms to invest in training. Policy-induced institutional change, therefore, should carefully consider possible consequences for the VET system that is currently financed in large part by firms on a voluntary basis.

Finally, the thesis opens up new research areas, which could be addressed in the future. While it has analysed important aspects of costs and benefits of vocational education and training for individuals and firms, some of the analysis performed in the thesis is limited by data restrictions and related methodological problems. For example, more detailed information about the personal characteristics and social background of labour market participants would improve the econometric options to control for selectivity is- 


\section{Conclusion and implications}

sues. Employer-employee data on training investments and the labour market outcomes after VET would open up new opportunities for analysing potential effects. Another important topic is the relation between initial and continuing vocational training. While the shape of age-earnings profiles estimated in Chapter 3 suggests that the wages of VET workers remain relatively stable over time in comparison to those of generally educated workers, we know little about the role of on-the-job training or formal continuing training during the time these individuals stay in the labour market. 


\section{Bibliography}

Abadie, Alberto, David Drukker, Jane Leber Herr, and Guido W. Imbens (2004). Implementing Matching Estimators for Average Treatment Effects in Stata. Stata Journal 4 (3), 290-311.

Abowd, John M. and Francis Kramarz (2003). The costs of hiring and separations. Labour Economics 10(5), 499-530.

Acemoglu, Daron and Joern-Steffen Pischke (1998). Why Do Firms Train? Theory and Evidence. Quarterly Journal of Economics 113(1), 79-119.

Acemoglu, Daron and Joern-Steffen Pischke (1999a). Beyond Becker: Training in Imperfect Labour Markets. Economic Journal 109, 112-142.

Acemoglu, Daron and Joern-Steffen Pischke (1999b). The Structure of Wages and Investment in General Training. Journal of Political Economy 107(3), 539-72.

Acemoglu, Daron and Joern-Steffen Pischke (2000). Certification of Training and Training Outcomes. European Economic Review 44(4-6), 917-27.

Addison, John T. (2001). Works Councils in Germany: Their Effects on Establishment Performance. Oxford Economic Papers 53(4), 659-694.

Addison, John T., Thorsten Schank, Claus Schnabel, and Joachim Wagner (2007). Do Works Councils Inhibit Investment? Industrial and Labor Relations Review 60(2), $187-203$.

Addison, John T., Claus Schnabel, and Joachim Wagner (2004). The Course of Research into the Economic Consequences of German Works Councils. British Journal of Industrial Relations 42(2), 255-281.

Addison, John T. and Paulino Teixeira (2006). The Effect of Works Councils on Employment Change. Industrial Relations 45(1), 1-25.

Addison, John T., Paulino Teixeira, and Thomas Zwick (2010). German Works Councils and the Anatomy of Wages. Industrial and Labor Relations Review 63(2), 247-270. 
Aghion, Phillipe and Peter W. Howitt (1998). Endogenous Growth Theory. MIT Press. Cambridge, Massachusetts.

Allaart, Piet, Lutz Bellmann, and Ute Leber (2009). Company-provided Further Training in Germany and the Netherlands. Empirical Research in Vocational Education and Training 1, 103-122.

Altonji, Joseph G. and Robert A.. Shakotko (1987). Do Wages Rise with Job Seniority? Review of Economic Studies 54(3), 437-459.

Altonji, Joseph G. and Nicolas Williams (2005). Do Wages Rise with Job Seniority? A Reassessment. Industrial and Labor Relations Review 58(3), 370-397.

Askilden, Jan Erik and Oivind Anti Nilsen (2005). Apprentices And Young Workers: A Study Of The Norwegian Youth Labour Market. Scottish Journal of Political Economy 52(1), 1-17.

Autor, David H. (2001). Why Do Temporary Help Firms Provide Free General Skills Training? Quarterly Journal of Economics 116(4), 1409-48.

Backes-Gellner, Uschi, Bernd Frick, and Dieter Sadowski (1997). Codetermination and Personnel Policies of German Firms: The Influence of Works Councils on Turnover and Further Training. International Journal of Human Resource Management 8(3), $328-347$.

Backes-Gellner, Uschi and Simone N. Tuor (2010). Avoiding Labor Shortages by Employer Signaling - On the Importance of Good Work Climate and Labor Relations. Industrial and Labor Relations Review 63(2), 271-286.

Baethge, Martin, Heike Solga, and Martin Wieck (2006). Berufsbildung im Umbruch. Signale eines überfälligen Aufbruchs. Gutachten zur beruflichen Bildung in Deutschland. Technical report, Friederich-Ebert-Stiftung, Bonn.

Baker, David P., Juan Leon, Emily G. Smith Greenaway, John Collins, and Marcela Movit (2011). The Education Effect on Population Health: A Reassessment. Population \& Development Review 37(2), 307-332.

Becker, Gary S. (1962). Investment in Human Capital: A Theoretical Analysis. The Journal of Political Economy 70(5), 9-49.

Becker, Gary S. (1964). Human Capital: A Theoretical and Empirical Analysis with Special Reference to Education. Columbia University Press, New York, London.

Beicht, Ursula, Günter Walden, and Hermann Herget (2004). Kosten und Nutzen der betrieblichen Berufsausbildung in Deutschland. Bundesinstitut für Berufsbildung. Berichte zur beruflichen Bildung, Heft 264. Bertelsmann, Bielefeld. 
Berger, Klaus (2012). Betriebsräte und betriebliche Weiterbildung. WSI-Mitteilungen 5, 358-364.

Böheim, René and Alison L. Booth (2004). Trade Union Presence and Employer-Provided Training in Great Britain. Industrial Relations 43(3), 520-545.

Bishop, John (1996). What We Know About Employer-Provided Training: A Review of Literature. CAHRS Working Paper 96-09.

Bishop, John (1998). Occupation-Specific Versus General Education and Training. The annals of the American Academy of Political and Social Science 559, 24-38.

Blatter, Marc, Samuel Muehlemann, and Samuel Schenker (2012). The Costs of Hiring Skilled Workers. European Economic Review 56(1), 20-35.

BMBF (2005). Berufsbildungsgesetz (BBiG).

Boockmann, Bernhard and Susanne Steffes (2010). Workers, Firms or Institutions: What Determines Job Duration for Male Employees in Germany? Industrial and Labor Relations Review 64(1), 109-127.

Booth, Alison L. and Monojit Chatterji (1998). Unions and Efficient Training. Economic Journal 108(447), 328-43.

Booth, Alison L., Marco Francesconi, and Gylfi Zoega (2003). Unions, Work-related Training, and Wages: Evidence for British Men. Industrial and Labor Relations Review 57(1), 68-91.

Booth, Alison L. and Stephen E. Satchell (1994). Apprenticeships and Job Tenure. Oxford Economic Papers 46(4), 676-95.

Booth, Alison L. and Gylfi Zoega (2004). Is Wage Compression a Necessary Condition for Firm-Financed General Training? Oxford Economic Papers 56(1), 88-97.

Bougheas, Spiros and Yannis Georgellis (2004). Early Career Mobility and Earnings Profiles of German Apprentices: Theory and Empirical Evidence. LABOUR 18(2), 233-63.

Bowman, Mary Jean (1993). The Economics of Education in a World of Change. In E.P.Hoffman (Ed.), Essays on the Economics of Education, pp. 163-175. Upjohn Institute for Employment Research, Michigan.

Brauns, Hildegard and Susanne Steinmann (1999). Educational Reform in France, WestGermany and the United Kingdom: Updating the CASMIN Educational Classification. ZUMA-Nachrichten 44, 7-44. 
Brunello, Giorgio (2002). Is Training more Frequent when Wage Compression is Higher? Evidence from 11 European Countries. CESifo Working Paper No. 637.

Bundesinstitut für Berufsbildung (BIBB) (2011). VET Data Report Germany 2011.

Caballero, Ricardo J. and Eduardo M. R. A. Engel (2004). A Comment on the Economics of Labor Adjustment: Mind the Gap: Reply. American Economic Review 94(4), 12381244 .

Caballero, Ricardo J., Eduardo M. R. A. Engel, and John Haltiwanger (1997). Aggregate Employment Dynamics: Building from Microeconomic Evidence. American Economic Review 87(1), 115-37.

Cappelli, Peter (2004). Why Do Employers Pay for College? Journal of Econometrics 121(1-2), 213-41.

CEDEFOP (2008). Country Report - Thematic Overview: United Kingdom. Technical report, CEDEFOP.

Chang, Chun and Yijiang Wang (1996). Human Capital Investment under Asymmetric Information: The Pigovian Conjecture Revisited. Journal of Labor Economics 14(3), $505-19$.

Clark, Damon (2001). How Transferable is German Apprenticeship Training? Centre for Economic Performance (CEP). London School of Economics, London.

Clark, Damon and Rene Fahr (2002). Transferability, Mobility and Youth Training in Germany and Britain: A Simple Theoretical Analysis. Konjunkturpolitik 48(3-4), 23555 .

Cooper, Russell W. and Jonathan L. Willis (2004). A Comment on the Economics of Labor Adjustment: Mind the Gap. American Economic Review 94(4), 1223-1237.

Cooper, Russell W. and Jonathan L. Willis (2009). The Cost of Labor Adjustment: Inferences from the Gap. Review of Economic Dynamics 12(4), 632-647.

Cörvers, Frank, Hans Heijke, Ben Kriechel, and Harald Pfeifer (2010). High and Steady or Low and Rising? Vocational Versus General Education in Life-Cycle Earnings. In Mancebón-Torrubia, de Embún, Gómez-Sancho, and Esteban (Eds.), Investigaciones de Economía de la Educación 5 (1 ed.), Volume 5, Chapter 47, pp. 931-948. Asociación de Economía de la Educación.

Cörvers, Frank, Hans Heijke, Ben Kriechel, and Harald Pfeifer (2011). High and Steady or Low and Rising - Life-cycle Earnings Patterns in Vocational and General Education. ROA Research Memorandum 2011/7, Maastricht. 
Davis, Steven J., R. Jason Faberman, and John Haltiwanger (2006). The Flow Approach to Labor Markets: New Data Sources and Micro-Macro Links. Journal of Economic Perspectives 20(3), 3-26.

de la Fuente, Angel and Juan Francisco Jimeno (2009). The Private and Fiscal Returns to Schooling in the European Union. Journal of the European Economic Association 7(6), 1319-1360.

Dearden, Lorraine, Howard Reed, and John Van Reenen (2006). The Impact of Training on Productivity and Wages: Evidence from British Panel Data. Oxford Bulletin of Economics and Statistics 68(4), 397-421.

Dionisius, Regina, Samuel Muehlemann, Harald Pfeifer, Günter Walden, Felix Wenzelmann, and Stefan Wolter (2009). Cost and Benefit of Apprenticeship Training. A Comparison of Germany and Switzerland. Applied Economics Quarterly 55(1), 7-38.

Dube, Arindrajit, Eric Freeman, and Michael Reich (2010). Employee Replacement Costs. Institute for Research on Labor and Employment, Working Paper Series 1193228, Institute of Industrial Relations, UC Berkeley.

Dustmann, Christian, Johannes Ludsteck, and Uta Schönberg (2009). Revisiting the German Wage Structure. Quarterly Journal of Economics 124(2), 843-881.

Dustmann, Christian and Costas Meghir (2005). Wages, Experience and Seniority. Review of Economic Studies 72(1), 77-108.

Dustmann, Christian and Uta Schönberg (2009). Training and Union Wages. Review of Economics and Statistics 91(2), 363-376.

Dustmann, Christian and Uta Schönberg (2012). What Makes Firm-based Vocational Training Schemes Successful? The Role of Commitment. American Economic Journal: Applied Economics 4(2), 36-61.

Ellguth, Peter and Susanne Kohaut (2010). Tarifbindung und betriebliche Interessenvertretung: Aktuelle Ergebnisse aus dem IAB-Betriebspanel 2009. WSI Mitteilungen 4, 204-209.

Engellandt, Axel and Regina T. Riphahn (2005). Temporary Contracts and Employee Effort. Labour Economics 12(3), 281-299.

Euwals, Rob and Rainer Winkelmann (2002). Mobility after Apprenticeship-Evidence from Register Data. Applied Economics Quarterly 48(3-4), 256-78.

Euwals, Rob and Rainer Winkelmann (2004). Training Intensity and First Labor Market Outcomes of Apprenticeship Graduates. International Journal of Manpower 25(5), 447-62. 
Fersterer, Josef, Jörn-Steffen Pischke, and Rudolf Winter-Ebmer (2008). Returns to Apprenticeship Training in Austria: Evidence from Failed Firms. Scandinavian Journal of Economics 110(4), 733-753.

Fitzenberger, Bernd, Karsten Kohn, and Qingwei Wang (2011). The Erosion of Union Membership in Germany: Determinants, Densities, Decompositions. Journal of Population Economics 24(1), 141-165.

Fouarge, Didier, Anne Gielen, Rob Grim, Marcel Kerkhofs, Amelia Román, Joop Schippers, and Ton Wilthagen (2006). Trendrapport aanbod van arbeid 2005. Technical report, Organisatie voor Strategisch Arbeidsmarktonderzoek, Tilburg.

Franz, Wolfgang and David Soskice (1995). The German Apprenticeship System. In Buttler, Franz, Schettkat, and Soskice (Eds.), Institutional Frameworks and Labour Market Performance. Comparative Views on the U.S. and German Economies., pp. 208-34. Routledge, London, New York.

Freeman, Richard B (1976). Individual Mobility and Union Voice in the Labor Market. American Economic Review 66(2), 361-68.

Freeman, Richard B. (1980). The Exit-Voice Tradeoff in the Labor Market: Unionism, Job Tenure, Quits. NBER Working Papers 0242, National Bureau of Economic Research.

Freeman, Richard B. and Edward P. Lazear (1995). An Economic Analysis of Works Councils. In Rogers and Streeck (Eds.), Works Councils: Consultation, Representation, and Cooperation in Industrial Relations. University of Chicago Press, Chicago.

Frege, Carola M. (2002). A Critical Assessment of the Theoretical and Empirical Research on German Works Councils. British Journal of Industrial Relations 40(2), 221-248.

Frick, Bernd (1996). Co-determination and Personnel Turnover: The German Experience. LABOUR 10(2), 407-430.

Frick, Bernd and Iris Möller (2003). Mandated works councils and firm performance: Labor productivity and personnel turnover in German establishments. Schmollers Jahrbuch (Journal of Applied Social Science Studies) 123(3), 423-454.

Gangl, Markus (2000). European Perspectives on Labour Market Entry: A Matter of Institutional Linkages between Training Systems and Labour Markets? MZES Arbeitspapiere No 24.

Gangl, Markus (2002). Changing Labour Markets and Early Career Outcomes : Labour Market Entry in Europe over the Past Decade. Work Employment Society 16(26), $67-90$. 
Gangl, Markus (2003). The Structure of Labour Market Entry in Europe: A Typological Analysis. In Müller and Gangl (Eds.), Transitions from education to work in Europe the integration of youth into EU labour markets, pp. 107-128. Oxford University Press, Oxford.

Geel, Regula, Johannes Mure, and Uschi Backes-Gellner (2011). Specificity of Occupational Training and Occupational Mobility: An Empirical Study Based on Lazear's Skill-Weights Approach. Education Economics 19(5), 519-535.

Gerlach, Knut and Gesine Stephan (2008). A Note on Job Tenure and Collective Contracts. LABOUR 22(1), 167-183.

Goldin, Claudia (2001). The Human Capital Century and American Leadership: Virtues of the Past. NBER-Working Papers No. 8239. National Bureau of Economic Research.

Green, David and Thomas Lemieux (2007). The Impact of Unionization on the Incidence of and Sources of Payment for Training in Canada. Empirical Economics 32(2), 465489.

Green, Francis, Stephen Machin, and David Wilkinson (1999). Trade Unions and Training Practices in British Workplaces. Industrial and Labor Relations Review 52(2), 179-195.

Greene, William H. (2008). Econometric Analysis (5 ed.). Prentice Hall, N.J.

Grossbard, Shoshana, ed. (2006). Jacob Mincer: A Pioneer of Modern Labor Economics. Springer, New York.

Gustman, Alan and Thomas Steinmeier (1982). Labor Markets and Evaluations of Vocational Training Programs in the Public High Schools: Toward a Framework for Analysis. Southern Economic Journal 49(1), 185-200.

Hamermesh, Daniel S. and Gerard A. Pfann (1996). Adjustment Costs in Factor Demand. Journal of Economic Literature 34(3), 1264-1292.

Hammer, Ulrich (1990). Berufsbildung und Betriebsverfassung: Begriff und Grenzen der Beteiligungsrechte des Betriebsrats bei betrieblichen Berufsbildungsmaßnahmen. Nomos.

Hanushek, Eric A., Ludger Woessmann, and Lei Zhang (2011). General Education, Vocational Education, and Labor-Market Outcomes over the Life-Cycle. NBER Working Paper No. 17504.

Hartog, Joop (1992). Capabilities, Allocation and Earnings. Kluwer Academic Publishers, Alphen aan den Rijn.

Hashimoto, Masanori (1981). Firm-Specific Human Capital as a Shared Investment. American Economic Review 71 (3), 475-82. 
Heckman, James J. (1979). Sample Selection Bias as a Specification Error. Econometrica 47(1), 153-61.

Heidenreich, Martin (1998). Die duale Berufsausbildung zwischen industrieller Prägung und wissensgesellschaftlicher Herausforderung. Zeitschrift für Soziologie 27/5, 321-341.

Hirsch, Boris, Thorsten Schnabel, and Claus Schnabel (2010). Works Councils and Separations: Voice, Monopoly, and Insurance Effects. Industrial Relations 49(4), 566-592.

Hirschman, Albert O. (1970). Exit, Voice and Loyalty. Responses to Decline in Firms, Organizations and States. Harvard University Press, Cambridge MA.

Hotchkiss, Lawrence (1993). Effects of Training, Occupation, and Training-Occupation Match on Wage. Journal of Human Resources 28(3), 482-496.

Hubler, Olaf and Uwe Jirjahn (2003). Works Councils and Collective Bargaining in Germany: The Impact on Productivity and Wages. Scottish Journal of Political Economy $50(4), 471-491$.

Jirjahn, Uwe (2010). Works Councils and Employment Growth in German Establishments. Cambridge Journal of Economics 34(3), 475-500.

Jovanovic, Boyan (1979). Job Matching and the Theory of Turnover. Journal of Political Economy 87(5), 972-990.

Katz, Eliakim and Adrian Ziderman (1990). Investment in General Training: The Role of Information and Labour Mobility. Economic Journal 100(403), 1147-58.

Kessler, Anke S. and Christoph Lülfesmann (2006). The Theory of Human Capital Revisited: on the Interaction of General and Specific Investments. Economic Journal 116(514), 903-923.

Korpi, Tomas and Antje Mertens (2003). Training Systems and Labor Mobility: A Comparison between Germany and Sweden. Scandinavian Journal of Economics 105(4), 597-617.

Kramarz, Francis and Marie-Laure Michaud (2010). The Shape of Hiring and Separation Costs in France. Labour Economics 17(1), 27-37.

Kriechel, Ben, Samuel Muehlemann, Harald Pfeifer, and Miriam Schuette (2014). Works Councils, Collective Bargaining and Apprenticeship Training. Industrial Relations. forthcoming.

Lange, Fabian (2007). The Speed of Employer Learning. Journal of Labor Economics $25(1), 1-36$. 
Lauer, Charlotte (2005). Education and Labour Markets Outcomes: A French-German Comparison. ZEW Economic Studies, vol. 30. Physica, Heidelberg and New York.

Lazear, Edward P. (2009). Firm-Specific Human Capital: A Skill-Weights Approach. Journal of Political Economy 117(5), 914-940.

Leuven, Edwin (2005). The Economics of Private Sector Training: A Survey of the Literature. Journal of Economic Surveys 19(1), 91-111.

Machin, Stephen, Olivier Marie, and Suncica Vujic (2011). The Crime Reducing Effect of Education. Economic Journal 121, 463-484.

Majumdar, Sumon (2007). Market conditions and worker training: How does it affect and whom? Labour Economics 14, 1-23.

Malcomson, James M., James W. Maw, and Barry McCormick (2003). General Training by Firms, Apprentice Contracts, and Public Policy. European Economic Review 47(2), $197-227$.

Manning, Alan (2006). A Generalised Model of Monopsony. Economic Journal 116(508), $84-100$.

Manning, Alan (2011). Imperfect Competition in the Labor Market. In O.Ashenfelter and D.Card (Eds.), Handbook of Labor Economics, Volume 4, Chapter 11, pp. 973-1041. Elsevier, North-Holland.

Marsden, David (1986). The End of Economic Man? Custom and Competition in Labour Markets. Wheatsheaf, Brighton.

Marsden, David and Paul Ryan (1986). Where Do Young Workers Work? Youth Employment by Industry in Various European Economies. British Journal of Industrial Relations 24(1), 83-102.

Marsden, David and Paul Ryan (1991). The Structuring of Youth Pay and Employment in Six Industrial Economies. In P.Ryan, P.Garonna, and R.C.Edwards (Eds.), The Problem of Youth: The Regulation of Youth Employment and Training in Advanced Economies. Palgrave Macmillan, London.

Martins, Pedro S. and Jim Y. Jin (2010). Firm-Level Social Returns to Education. Journal of Population Economics 10, 539-558.

Mason, Geoff, S. J. Prais, and Bart van Ark (1990). Vocational Education and Productivity in the Netherlands and Britain. National Institute of Economic and Social Research, London. 
Mason, Geoff, Bart van Ark, and Karin Wagner (1993). Productivity, Product Quality and Workforce Skills: Food Processing in Four European Countries. Discussion Paper 34, National Institute of Economic and Social Research, London.

McMahon, Walter W., Jin Hwa Jung, and Boediono (1992). Vocational and Technical Education in Development: Theoretical Analysis of Strategic Effects on Rates of Return. Economics of Education Review 11(3), 181-194.

Meer, Jonathan (2007). Evidence on the Returns to Secondary Vocational Education. Economics of Education Review 26, 559-573.

Merrilees, William J. (1983). Alternative Models of Apprentice Recruitment: With Special Reference to the British Engineering Industry. Applied Economics 15(1), 1-21.

Meyer, Robert H. (1982). Job Training in the Schools. In Taylor, Rosen, and Pratzner (Eds.), Job Training for Youth, pp. 307-44. The National Center for Research in Vocational Education, Ohio State University.

Mincer, Jacob A. (1974). Schooling, Experience, and Earnings. NBER Books. National Bureau of Economic Research, Cambridge.

Mincer, Jakob (1958). Investment in Human Capital and Personal Income Distribution. Journal of Political Economy 66(4), 281-302.

Müller-Jentsch, Walther (1995). Germany: From collective voice to co-management. In J.Rogers and W.Streeck (Eds.), Works Councils: Consultation, Representation, and Cooperation in Industrial Relations, pp. 53-78. University of Chicago Press, Chicago.

Mortensen, Dale T. and Christopher A. Pissarides (1994). Job Creation and Job Destruction in the Theory of Unemployment. Review of Economic Studies 61(3), 397-415.

Muehlemann, Samuel and Harald Pfeifer (2012). The structure of hiring costs in Germany. Economics of Education Working Paper Series 0077, University of Zurich, Institute for Strategy and Business Economics (ISU).

Muehlemann, Samuel, Harald Pfeifer, Günter Walden, Felix Wenzelmann, and Stefan C. Wolter (2010). The Financing of Apprenticeship Training in the Light of Labor Market Regulations. Labour Economics 17(5), 799-809.

Muehlemann, Samuel, Juerg Schweri, Rainer Winkelmann, and Stefan C. Wolter (2007). An Empirical Analysis of the Decision to Train Apprentices. LABOUR 21 (3), 419-441.

Neuman, Shoshana and Adrian Ziderman (1991). Vocational Schooling, Occupational Matching and Labor Market Earnings in Israel. The Journal of Human Resources 26 (2), 256-281. 
Neuman, Shoshana and Adrian Ziderman (1999). Vocational Education in Israel: Wage Effects of the VocEd-Occupation Match. The Journal of Human Resources $34(2)$, 407-420.

Niederalt, Michael (2004). Zur ökonomischen Analyse betrieblicher Lehrstellenangebote in der Bundesrepublik Deutschland. Europäische Hochschulschriften. Reihe 5, Volks- und Betriebswirtschaft, 3082). Lang, Frankfurt am Main u.a.

Noll, Ingeborg, Ursula Beicht, Georg Boll, Wilfried Malcher, and Susanne WiederholdFritz (1983). Nettokosten der betrieblichen Berufsausbildung. Schriften zur Berufsbildungsforschung, Band 23. Bundesinstitut für Berufsbildung, Berlin.

OECD (2004). Employment Outlook. OECD, Paris.

OECD (2008). Education at a Glance. OECD, Paris.

Oetker, Hartmut (1986). Die Mitbestimmung der Betriebs- und Personalräte bei der Durchführung von Berufsbildungsmaßnahmen. Luchterhand.

O'Mahony, Mary and Marcel P. Timmer (2009). Output, Input and Productivity Measures at the Industry Level: The EU KLEMS Database. The Economic Journal 119(538), F374-F403.

Pfeifer, Christian (2010). Works Councils, Union Bargaining and Quits in German Firms. Economic and Industrial Democracy 32(2), 243-260.

Pfeifer, Harald, Gudrun Schönfeld, and Felix Wenzelamnn (2011). How Large is the Firm-specific Component of German Apprenticeship Training? Empirical Research in Vocational Education and Training 3(2), 85-104.

Pfeifer, Harald, Gudrun Schönfeld, and Felix Wenzelmann (2010). Ausbildungskosten und das Übernahmeverhalten von Betrieben - Ein Vergleich der BIBB-Kosten- und Nutzenerhebungen der Jahre 2000 und 2007. German Review of Social Policy 59(6-7), $174-182$.

Pinkston, Joshua C. (2008). A Model of Asymmetric Employer Learning with Testable Implications. Review of Economic Studies 76(1), 367-394.

Pissarides, Christopher A. (2009). The Unemployment Volatility Puzzle: Is Wage Stickiness the Answer? Econometrica rr7(5), 1339-1369.

Potterat, Jann (2003). Kosten und Nutzen der Berufsbildung im Jahr 2001 aus der Sicht der Betriebe. Schätzverfahren. Technical report, Bundesamt für Statistik, Neuenburg.

Prais, S. J. (1995). Productivity, Education and Training. Cambridge University Press, Cambridge. 
Psacharopoulos, George and Harry Anthony Patrinos (2004). Human capital and rates of return, Chapter 1, pp. 1-57. Edward Elgar Publishing, Cheltenham.

Rabe-Hesketh, Sophia and Anders Skrondal (2008). Multilevel and Longitudinal Modeling Using Stata (2nd ed.). Stata Press, College Station.

Renfer, Jean-Pierre (2002). Enquête 2001 sur les coûts et l'utilité de la formation des apprentis du point de vue des établissements. Technical report, Office fédéral de la statistique, Neuchâtel.

Riphahn, Regina T. and Anja Thalmaier (2001). Behavioral Effects of Probation Periods: An Analysis of Worker Absenteeism. Jahrbücher für Nationalökonomie und Statistik 221(2), 179-201.

Roodman, David (2009). How to do xtabond2: An Introduction to Difference and System GMM in Stata. The Stata Journal 9(1), 86-136.

Rosenbaum, Paul R. and Donald B. Rubin (1983). The Central Role of the Propensity Score in Observational Studies for Causal Effects. Biometrika $70(1)$, 41-55.

Rubin, Donald B. (1974). Estimating Causal Effects of Treatments in Randomized and Nonrandomized Studies. Journal of Eucational Psychology 66, 668-701.

Sachverständigenkommission Kosten und Finanzierung der beruflichen Bildung (1974). Kosten und Finanzierung der ausserschulischen beruflichen Bildung - Abschlussbericht. Bertelsmann, Bielefeld.

Sattinger, Michael (1975). Comparative Advantage and the Distributions of Earnings and Abilities. Econometrica 43(3), 455-468.

Sattinger, Michael (1978). Comparative Advantage in Individuals. Review of Economics \& Statistics 60(2), 259-268.

Sattinger, Michael (1993). Assignment Models of the Distribution of Earnings. Journal of Economic Literature 31(2), 831-880.

Schüler, Anja (2006). Wage and Productivity Effect of Continuing Training in Germany: A Sectoral Analysis. ZEW Discussion Paper 06-025.

Schönberg, Uta (2007). Testing for Asymmetric Employer Learning. Journal of Labor Economics 25(4), 651-691.

Schönfeld, Gudrun, Felix Wenzelmann, Regina Dionisius, Harald Pfeifer, and Günter Walden (2010). Kosten und Nutzen der dualen Ausbildung aus Sicht der Betriebe. Bundesinstitut für Berufsbildung (BIBB), Bonn. 
Schröder, Helmut and Stefan Schiel (2008). Betriebsbefragung zu den Kosten und dem Nutzen der betrieblichen Berufsausbildung - Methodenbericht. Institute for Applied Social Sciences (infas), Bonn.

Schröder, Helmut, Stefan Schiel, Reiner Gilberg, and Karen Marwinski (2001). Nutzen und Nettokosten der Berufsausbildung: Methodenbericht zu einer repräsentativen Betriebsbefragung. Institute for Applied Social Sciences (infas), Bonn.

Schultz, Theodore W. (1960). Capital Formation by Education. Journal of Political Economy 68(6), 571-583.

Schweri, Juerg (2006). Das Ausbildungsverhalten Schweizer Firmen: Welche Rolle spielen asymmetrische Information und firmenspezifisches Training? dissertation.de.

Schweri, Juerg, Samuel Muehlemann, Yasmina Pescio, Belinda Walter, Stefan C. Wolter, and Lukas Zuercher (2003). Kosten und Nutzen der Lehrlingsausbildung aus der Sicht Schweizer Betriebe, Volume 2 of Beiträge zur Bildungsökonomie. Ruegger Verlag, Chur, Zuerich.

Steedman, Hilary and Karin Wagner (1989). Productivity, Machinery and Skills: Clothing Manufacture in Britain and Germany. National Institute Economic Review 128(1), 4057.

Steedman, Hillary (2001). Benchmarking Apprenticeship: UK and Continental Europe Compared. Working Paper 513, Centre for Economic Performance, London.

Steedman, Hillary (2010). The State of Apprenticeship in 2010: International Comparisons. Report, Centre for Economic Performance, London.

Steedman, Hillary and Karin Wagner (1987). A Second Look at Productivity, Machinery and Skills in Britain and Germany. National Institute Economic Review 122(1), 84-95.

Stevens, Margaret (1994a). An Investment Model for the Supply of Training by Employers. Economic Journal 104(424), 556-70.

Stevens, Margaret (1994b). A Theoretical Model of On-the-Job Training with Imperfect Competition. Oxford Economic Papers 46(4), 537-62.

Taylor, Marcia Freed, John Brice, Nick Buck, and Elaine Prentice-Lane (2010). British Household Panel Survey User Manual Volume A: Introduction, Technical Report and Appendices. Technical report, University of Essex, Colchester.

Thurow, Lester C. (1975). Generating Inequality. Basic Books, New York.

Topel, Robert H. (1991). Specific Capital, Mobility, and Wages: Wages Rise with Job Seniority. Journal of Political Economy 99(1), 145-176. 
van Eijs, Patrick and Hans Heijke (2000). Mismatch between Occupation and Education and the Costs and Benefits of Job-related Training. In Heijke and Muysken (Eds.), Education and Training in a Knowledge-Based Economy, pp. 159-189. Macmillan Press, London.

von Bardeleben, Richard, Ursula Beicht, and Kalman Fehér (1995). Betriebliche Kosten und Nutzen der Ausbildung: repräsentative Ergebnisse aus Industrie, Handel und Handwerk. Bertelsmann, Bielefeld.

von Wachter, Till and Stefan Bender (2006). In the Right Place at the Wrong Time: The Role of Firms and Luck in Young Workers' Careers. American Economic Review 96(5), 1679-1705.

Wagner, Gerhard G., Joachim R. Frick, and Jürgen Schupp (2007). The German SocioEconomic Panel Study (SOEP) - Scope, Evolution and Enhancements. Schmollers Jahrbuch 127(1), 139-169.

Wagner, Joachim (2008). German Works Councils and Productivity: First Evidence from a Nonparametric Test. Applied Economics Letters 15(9), 727-730.

Werwatz, Axel (1996). How Firm-specific is German Apprenticeship Training? Working papers, Sonderforschungsbereich 373, Humboldt University, Berlin.

Williams, Nicolas (1991). Reexamining the Wage, Tenure and Experience. Review of Economics and Statistics 73(3), 512-517.

Willis, Robert J. and Sherwin Rosen (1979). Education and Self-Selection. Journal of Political Economy 87(5), 7-36.

Wolter, Stefan C., Samuel Muehlemann, and Juerg Schweri (2006). Why Some Firms Train Apprentices and Many Others Do Not. German Economic Review 7(3), 249264.

Wolter, Stefan C. and Paul Ryan (2011). Apprenticeship. In Hanushek, Machin, and Woessmann (Eds.), Handbook of the Economics of Education, Volume 3, pp. 521-576. Elsevier Science, North-Holland.

Yashiv, Eran (2000). Hiring as Investment Behavior. Review of Economic Dynamics 3(3), 486-522. 


\section{Samenvatting (Summary in Dutch)}

Is het beroepsonderwijs rendabel voor bedrijven en individuen? Hebben landen met een uitgebreid beroepsonderwijssysteem competitieve voordelen ten opzichte van andere landen? Dit proefschrift onderzoekt enkele vraagstukken op het gebied van de kosten en baten van het beroepsonderwijs (VET).

In het eerste gedeelte van het proefschrift richt het empirisch onderzoek zich op de verschillen in lonen en productiviteit tussen de werknemers met algemeen onderwijs versus beroepsgericht onderwijs. De hypothese is dat de werknemers die beroepsgericht onderwijs gevolgd hebben dit direct productief in het bedrijfsleven kunnen gebruiken. De combinatie van theoretische en praktische onderwijselementen uit het beroepsgerichte onderwijs laat toe dat bedrijven het productieproces efficiënt organiseren. Zij hebben minder hiërarchische niveaus nodig en daardoor lagere aansturingskosten. Vanuit de theorie leidt dit tot hogere productiviteit. Dit maakt ook hogere lonen mogelijk voor de werknemers met een opleiding uit het beroepsonderwijs ten opzichte van de werknemers met een algemene opleiding. In comparatief onderzoek tussen landen, zouden de landen waar bedrijven makkelijk toegang hebben tot werknemers met beroep specifieke opleidingen hier in het voordeel moeten zijn.

In de eerste hoofdstukken vind ik empirische ondersteuning voor de hypothese dat beroepsopleidingen (VET) duidelijke baten voor individuen en bedrijven met zich meebrengen. Voor de werknemers zijn de loonvoordelen vooral in het begin van hun carrière te vinden. Voor de bedrijven blijken er structurele productiviteitsvoordelen te zijn in landen met sterk beroepsgerichte opleidingssystemen.

Deze uitkomst lijkt op het eerste gezicht inconstistent, maar blijkt aannemelijker als men looncompressie aanneemt. Hierdoor is een verschil mogelijk tussen de productiviteit en de lonen van werknemers met een beroepsopleiding. Dit verschil tussen productiviteit en lonen verhoogt de winsten ("rents") van bedrijven op beroepsgericht opgeleid personeel.

De verdere hoofdstukken van het proefschrift onderzoeken de invloed van de instituties op de investering die bedrijven in beroepsgerichte opleidingssystemen doen. Aansluitend op de recente theoretische literatuur wordt onderzocht of de bescherming van werknemers op de arbeidsmarkt, in het algemeen, en de instituties binnen bedrijven in het bijzonder, de bedrijfsinvesteringen in trainingen laten toenemen. De verwachting is dat de instituties die ontslagbescherming bieden, een positieve invloed hebben op zowel de kosten als de 
van het leerlingwezen (beroepsbegeleidend leren, BBL); de instituties beïnvloeden zo het gedrag van bedrijven.

De empirische resultaten geven aan dat de bedrijfsspecifieke verschillen in opleidingsinvesteringen voor een belangrijk deel te verklaren zijn door verschillen in arbeidsmarktregulering en -instituties; meer ontslagbescherming verhoogt de aanpassingskosten van bedrijven. Verder wordt aangetoond dat Duitse bedrijven met een werknemersvertegenwoordiging ("Betriebsräte") meer in de opleiding van hun BBL'ers investeren dan bedrijven die geen werknemersvertegenwoordiging hebben.

Het laatste hoofdstuk geeft een empirische analyse van de structuur van de wervingskosten en de kosten van het beroepsbegleidend opleidingssysteem in Duitsland weer. Het opleiden van leerlingen kan substantiële baten met zich meebrengen als deze na hun opleiding in het bedrijf blijven. De op deze manier bespaarde wervingskosten zijn substantieel. Wederom kunnen de instituties van werknemerrepresentatie en ontslagbescherming deze resultaten beïnvloeden. Bedrijven die met zulke instituties geconfronteerd worden, kunnen met hogere baten van hun eigen opleidingsinspanningen rekenen.

De uitkomsten van dit proefschrift zijn belangrijk voor het beleid. Beroepsonderwijs en beroepsbegeleidend leren blijven essentiële ingrediënten van een goed functionerende economie in veel Europese landen. Zij brengen productiviteits- en loonvoordelen voor bedrijven en werknemers. Deze opleidingsvormen zijn dus op zijn minst concurrerend met algemenere opleidingen van vergelijkbaar niveau. In Duitsland krijgen leerlingen een kwalificatie die zij in verschillende bedrijven kunnen gebruiken, mits zij binnen het beroepsdomein van de opleiding blijven. Voor bedrijven zijn de initiële investeringen in de leerlingen rationeel gezien winstgevend. Dit blijkt uit het onderzoek naar het percentage leerlingen dat in vaste dienst wordt genomen bij hun leerbedrijf en de duur van deze dienstverbanden. De empirische resultaten voor Duitsland suggereren ook dat de institutionele context van werknemerrepresentatie en -bescherming cruciaal kunnen zijn voor de realisatie van zulke baten. Ontslagbescherming, centrale loononderhandeling en werknemerrepresentatie bevorderen de bereidheid van bedrijven om te investeren in het leerlingwezen en het beroepsonderwijs. De politiek moet daarom voorzichtig zijn met het veranderen van instituties en de mogelijke consequenties voor het door bedrijven gefinancierde beroepsonderwijs in acht nemen. 


\section{Biography}

Harald Ulrich Pfeifer studied economics at the University of Bonn before acquiring his Master in International Economic Studies at Maastricht University in 2001. During his studies, he specialised in labour economics and industrial relations. After working for the International Labour Organisation (ILO) in Geneva and the Federal Statistical Office (Destatis) in Wiesbaden, he, in 2004, joined the Federal Institute for Vocational Education and Training (BIBB) in Bonn. Harald is affiliated with the Research Centre for Education and the Labour Market (ROA) at Maastricht University. 